\title{
Integration von Connexonen in Lipidmembranen auf porösen Oberflächen
}

\author{
Dissertation
}

zur Erlangung des

mathematisch-naturwissenschaftlichen Doktorgrades

„Doctor rerum naturalium“

der Georg-August-Universität Göttingen

\author{
vorgelegt von \\ Helmut Albin Oliver Gaßmann \\ aus Sondershausen
}

Göttingen 2010 
Referentin: Prof. Dr. Claudia Steinem

Korreferent: Prof. Dr. Christian Griesinger

Tag der mündlichen Prüfung: 
Meiner Frau Maike

„Wichtig ist, dass man nicht aufhört zu fragen.“ Albert Einstein 

Abstract. Connexin26 (Cx26) is a member of the connexin family, the building blocks for gap junction intercellular channels. These dodecameric assemblies are involved in gap junction-mediated cell-cell communication allowing the passage of ions and small molecules between two neighboring cells. As central nervous system diseases like Alzheimer, Parkinson or depressions are today one of the most important medical challenges and are accompanied by significant economical impact in our society we want to use this biological elementary communication pathway in a joint research project. The goal is to develop a biochip to assay target receptors or ion channels of neurons expressed in a cellular system. These cells are supposed to be investigated without the need to apply a technically elaborate electrical contact of the cellular interior via patch clamp electrodes. This cellular access shall be achieved via the electrical coupling of the cells on a connexon-doped pore suspending membrane and the formation of gap junctions between the cells and the artificial membrane system. This setup would lead to a high throughput detection system, which is essential in the quest to find new pharmacological active substances. Towards achieving this goal, the integration of connexons in lipid bilayers on porous substrates is a basic milestone to be achieved and therefor aim of this $\mathrm{PhD}$ thesis.

Using a cytochrome $c$ based vesicle assay we first prove, that the hexameric connexon hemichannels of Cx26 can be reconstituted in a simple artificial membrane system. We also demonstrate that its activity can be inhibited using Cx specific blockers like carbenoxolone, calcium ions and $\alpha$-cyclodextrin. In a next step, two different substrates and reconstitution methods are used to prove the functional integration of $\mathrm{Cx} 26$ connexons in artificial pore suspending membranes. One the one hand, we are able to show that Cx26 wild-type forms active hemichannels when reconstituted with a detergent based method in nano-BLMs. Besides the wild-type, this technique was used to characterize the Cx26 mutants M34A and V84L on a single channel level, revealing a similar behavior of M34A and different properties of V84L compared to the wild-type. On the other hand, Cx26 is reconstituted in micro-BLMs via spreading of connexon-doped giant unilamellar vesicles on a microporous substrate. Using a fluorescently labeled antibody we provide evidence that Cx26 is immobile on the functionalized substrate, whereas fluorescently labeled lipids stay laterally mobile. With a giant unilamellar vesicle based dye transfer assay we finally succeed in obtaining the first evidence of a functional gap junction formation.

Together with the work of our cooperation partners, the goal to provide a biochip based application for pharmacological high throughput screening will be within reach in the near future. 



\section{Inhaltsverzeichnis}

$1 \quad$ Einleitung

$1.1 \quad$ Connexine ………............................................................................................... 1

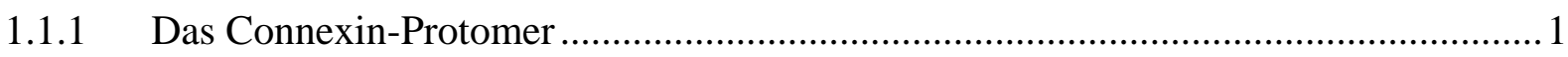

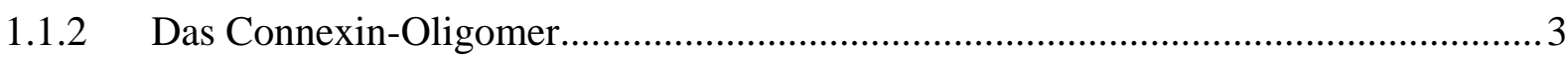

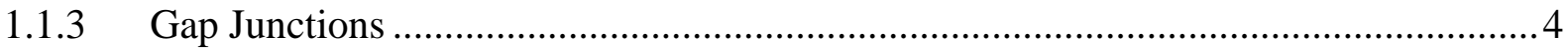

1.1.4 Regulation von Gap Junctions und Connexonen ...................................................6

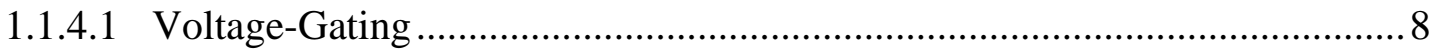

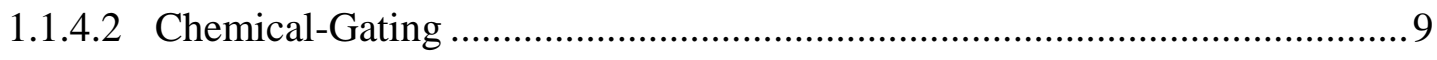

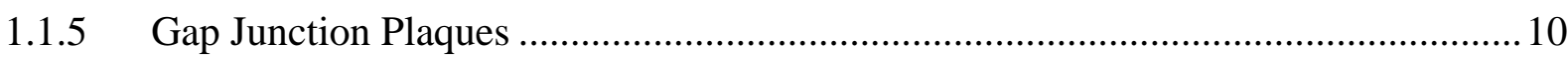

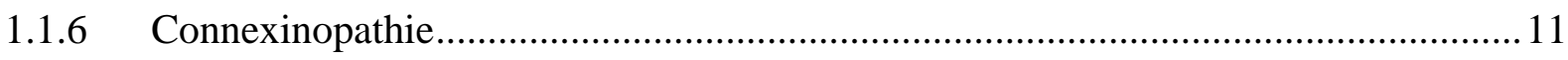

1.1.6.1 Angeborene Taubheit ............................................................................ 11

1.1.6.2 Mögliche strukturbiologische Ursachen der Taubheit ................................... 13

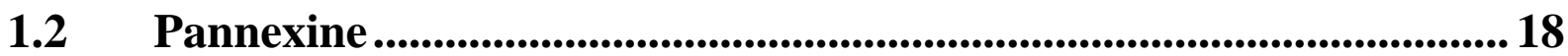

1.3 Artifizielle Membransysteme .............................................................................. 20

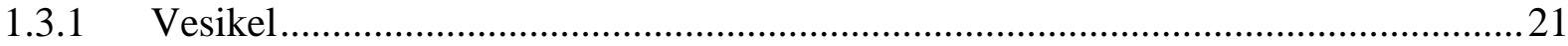

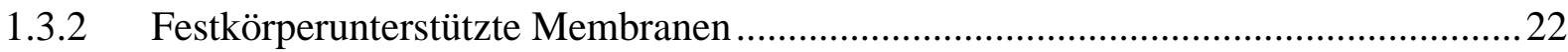

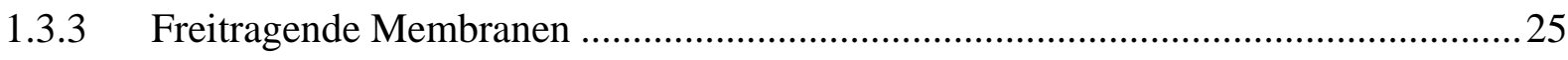

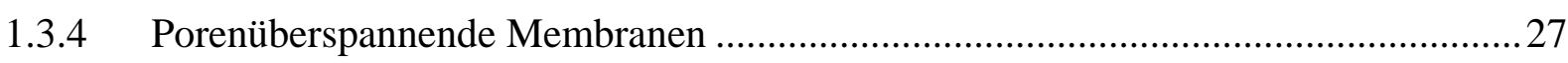

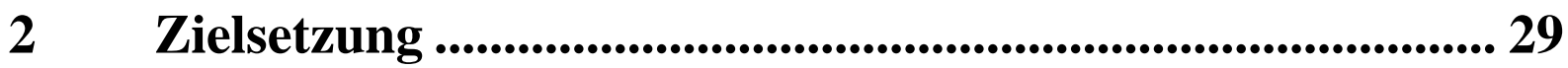

$3 \quad$ Material und Methoden ....................................................... 31

3.1 Impedanzspektroskopie.................................................................................... 31

3.1.1 Physikalische Grundlagen .................................................................................... 31

3.1.2 Impedanzspektroskopie an Membransystemen........................................................32

3.1.3 Darstellung und Auswertung von Impedanzspektren ................................................33

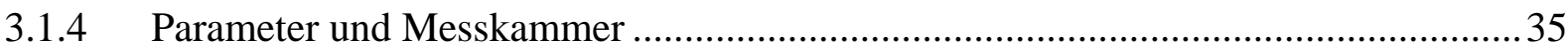




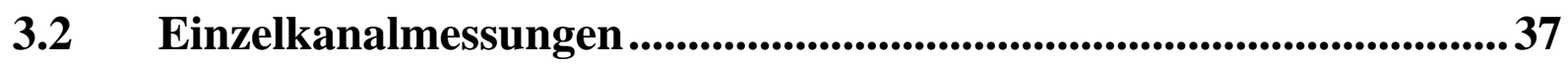

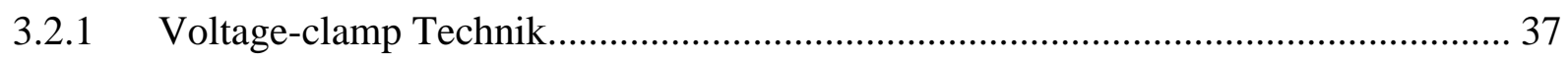

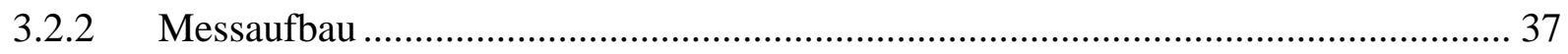

3.2.3 Messbedingungen ................................................................................... 38

3.2.4 Auswertung von Einzelkanaldaten ...................................................................... 39

3.3 UV/VIS-Spektroskopie ...............................................................................43

3.4 Konfokale Laserrastermikroskopie.............................................................46

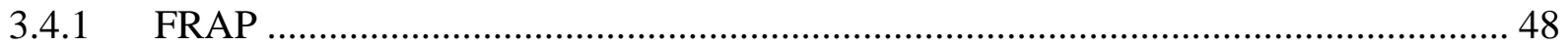

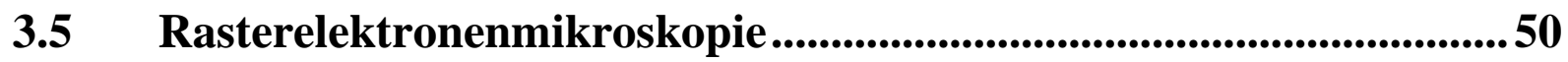

3.6 Präparative Methoden .....................................................................552

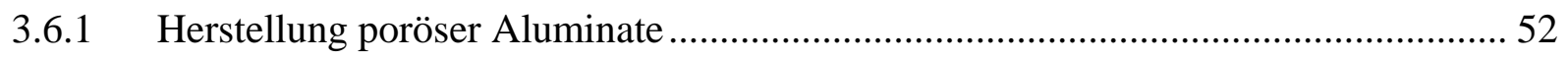

3.6.1.1 Grundlagen der Oxidbildung ................................................................ 52

3.6.1.2 Herstellung hochgeordneter poröser Aluminate ........................................... 55

3.6.2 Herstellung von nano-BLMs und Rekonstitution von Connexonen.......................... 58

3.6.3 Präparation von platinierten Platinelektroden.......................................................... 59

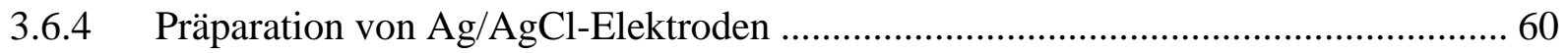

3.6.5 Herstellung von unilamellaren Liposomen und Proteoliposomen.............................. 60

3.6.6 Herstellung Cytochrom $c$-haltiger Proteoliposomen ............................................... 61

3.6.7 Herstellung von riesigen unilamellaren Vesikeln ................................................... 62

3.6.8 Spreiten von riesigen unilamellaren Vesikeln auf mikroporösen Substraten ............. 64

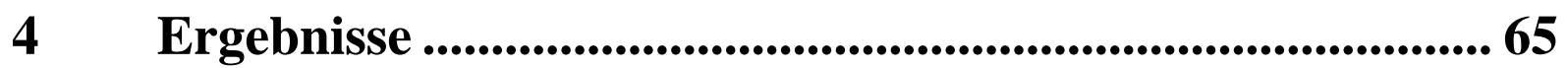

4.1 Cytochrom $c$ basierter Vesikelassay ..............................................65

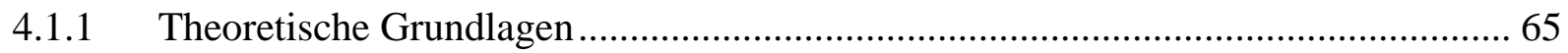

4.1.2 Prinzip des Vesikelassays ............................................................................... 66

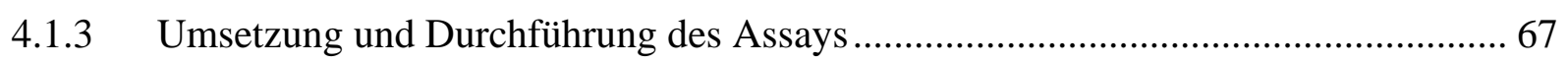

4.1.3.1 Herstellung von Cytochrom $c$-haltigen Proteoliposomen.............................. 67

4.1.3.2 Überprüfung des Assay-Grundprinzips .......................................................... 68

4.1.3.3 Experimentelle Umsetzung des Assays ...................................................... 70

4.1.3.4 Modulation der Kanalaktivität mittels chemischer Blocker ......................... 71 


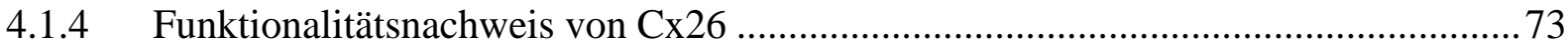

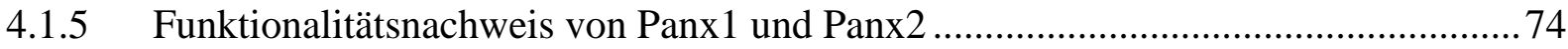

\subsection{Integration von Connexonen in Lipidmembranen auf nanoporösen}

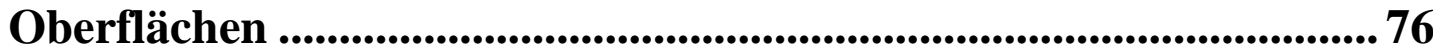

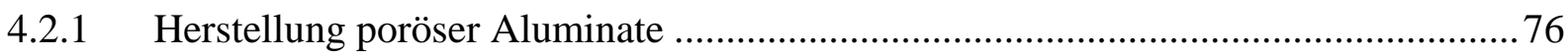

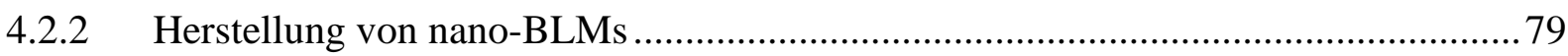

4.2.3 Elektrophysiologische Charakterisierung von Cx26 sowie seiner Mutanten M34A

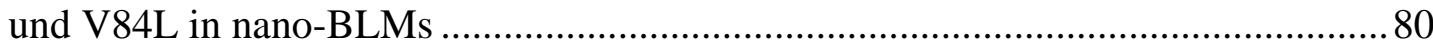

4.2.3.1 Histogrammanalyse zur Bestimmung der Leitfähigkeit ............................ 82

4.2.3.2 Analyse der Strom-Spannungs-Abhängigkeit......................................... 84

4.2.3.3 Bestimmung der mittleren Öffnungsdauer.............................................. 88

4.2.3.4 Darstellung der Öffnungsdauern nach Sigworth \& Sine............................. 91

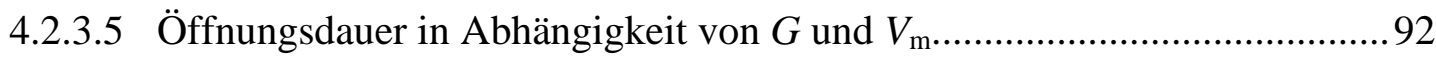

4.2.3.6 Bestimmung der Öffnungswahrscheinlichkeit ......................................... 96

4.2.3.7 Modulation der Leitfähigkeit mit Calciumionen.......................................99

4.2.4 Ergebnisse der Nanion Technologie GmbH........................................................ 100

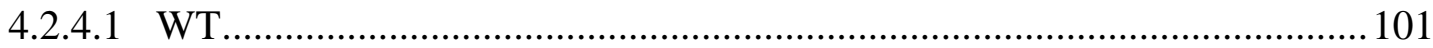

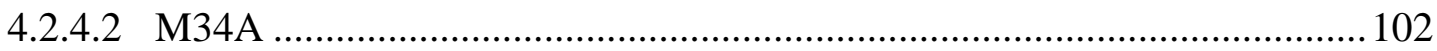

4.2.4.3 Chemische Modulation der Leitfähigkeit................................................ 102

\subsection{Integration von Connexonen in Lipidmembranen auf mikroporösen} Oberflächen ........................................................................................................................ 105

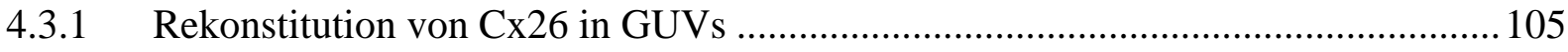

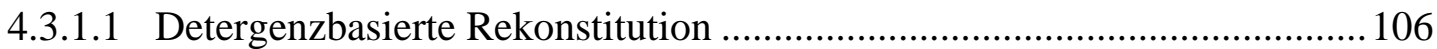

4.3.1.2 Rekonstitution mittels partieller Dehydratisierung .................................. 106

4.3.1.3 Rekonstitution durch Fusion von Proteoliposomen .................................. 107

4.3.2 Herstellung porenüberspannender Cx26 dotierter Lipidmembranen ...................... 110

4.3.2.1 Direkter Nachweis der Rekonstitution von Cx26 in porenüberspannenden Membranen durch FITC markierten Antikörper...................................... 111

4.3.2.2 Laterale Mobilität der Lipid-gekoppelten Fluoreszenz............................ 113

\subsection{Nachweis der Proteinaktivität mittels GUV basierter Assays........ 117}

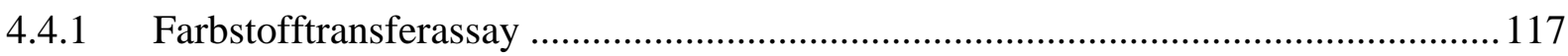

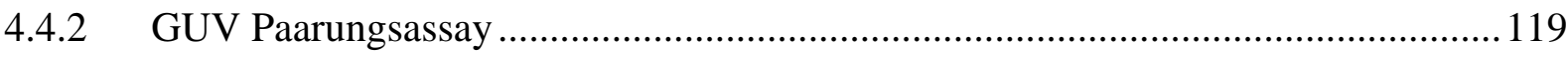


5.1 Aktivitätsnachweis von Cx26 in Proteoliposomen 127

5.1.1 Chemische Modulation der Kanalaktivität von Cx26.......................................... 128

5.1.1.1 Modulation der Kanalaktivität mit $\alpha-\mathrm{CD}$............................................. 128

5.1.1.2 Modulation der Kanalaktivität mit Calciumionen und CBX 130

5.2 Nachweis der Kanalaktivität von Pannexin2

5.3 Integration von Connexonen in Lipidmembranen auf nanoporösen Oberflächen................................................................................................ 134

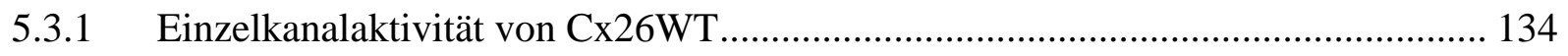

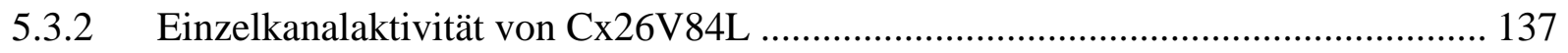

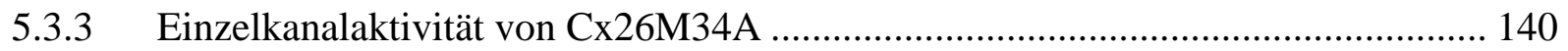

5.3.4 Modulation der Leitfähigkeit mit Calciumionen .................................................. 143

5.3.5 Vergleich der verwendeten artifiziellen Membransysteme ................................... 144

5.4 Integration von Connexonen in Lipidmembranen auf mikroporösen

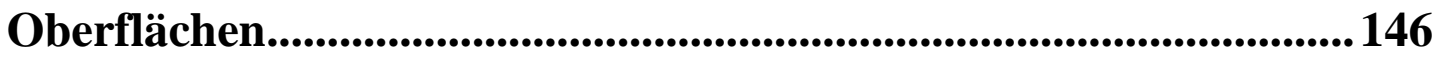

5.4.1 Herstellung von mikro-BLMs mit hoher Connexon-Oberflächenkonzentration..... 146

5.4.1.1 Rekonstitution von Cx26 in GUVs....................................................... 146

5.4.1.2 Spreiten von GUVs auf funktionalisierten mikroporösen Substraten ....... 148

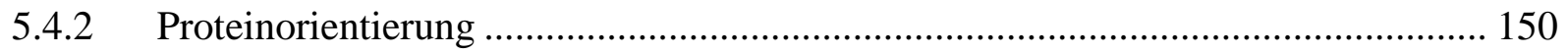

5.4.3 Blockade falsch orientierter und ungepaarter Connexone ..................................... 153

5.4.4 Auswahl des Substrates und Herstellung der mikro-BLM .................................... 154

5.5 Ausbildung von Gap Junctions..................................................................... 157

5.6 Permeabilität von Gap Junctions und Connexonen ..........................159

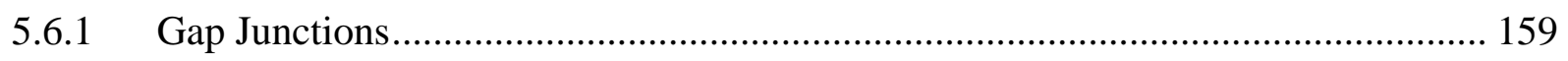

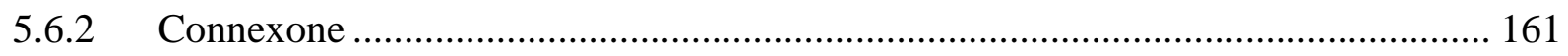

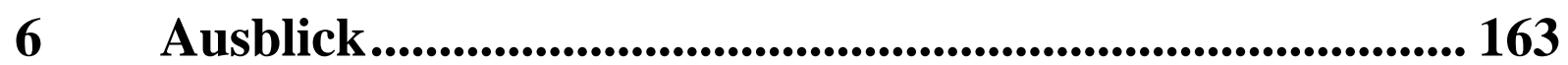


$7 \quad$ Zusammenfassung.................................................................... 166

$8 \quad$ Literaturverzeichnis..................................................................... 169

$9 \quad$ Anhang ........................................................................................... 193 



\section{$1 \quad$ Einleitung}

\subsection{Connexine}

Im Gegensatz zu einzelligen Organismen wie Bakterien sind höherer Organismen wie Tiere und Pflanzen aus einer Vielzahl von Zellen aufgebaut, welche in funktionellen Einheiten zu Geweben oder Organen organisiert sind. Für die Aufrechterhaltung ihrer Funktion bedarf es der interzellulären Kommunikation sowie der elektrischen und metabolischen Kopplung der Zellen. In nahezu allen Wirbel- und Gewebetieren wird diese Aufgabe von einer spezifischen Proteinklasse übernommen, den Connexinen. Als ubiquitäre Transmembranproteine ermöglichen sie die passive Diffusion zellulärer Bestandteile bis zu einem Molekulargewicht von etwa $1 \mathrm{kDa}$ zwischen benachbarten Zellen. Dies beinhaltet den direkten Austausch von Ionen, Metaboliten, sekundäre Botenstoffen und Wasser. Connexine sind essentieller Bestandteil der Biogenese und beteiligt an einer breiten Vielfalt biologischer Prozesse wie der metabolischen Homeostase, dem Zellwachstum sowie der Weiterleitung von Aktionspotentialen in Nervensystem und Herz [Harris 2001].

Im Folgenden soll zunächst der biochemische Aufbau dieser strukturell anspruchsvollen Proteinklasse und die strukturelle Organisation zum interzellulären Kanal näher erläutert werden, um anschließend auf die Regulation sowie genetisch bedingte Fehlfunktionen einzugehen.

\subsubsection{Das Connexin-Protomer}

Bis heute können der Connexin Gen-Familie 21 Gene im Menschen und 20 Gene in der Maus zugeordnet werden. Davon sind 19 ortholog, weisen also ähnliche Funktionen auf bzw. stammen von einem gemeinsamen Vorläufer ab. Innerhalb einer Spezies können die verschiedenen Isoformen spezifischen Gewebetypen zugeordnet werden, wobei die meisten Zellen mehr als eine Isoform exprimieren [Söhl \& Willecke 2004]. Die Tertiärstruktur aller Isoformen ist hierbei identisch (Abb. 1-1). 

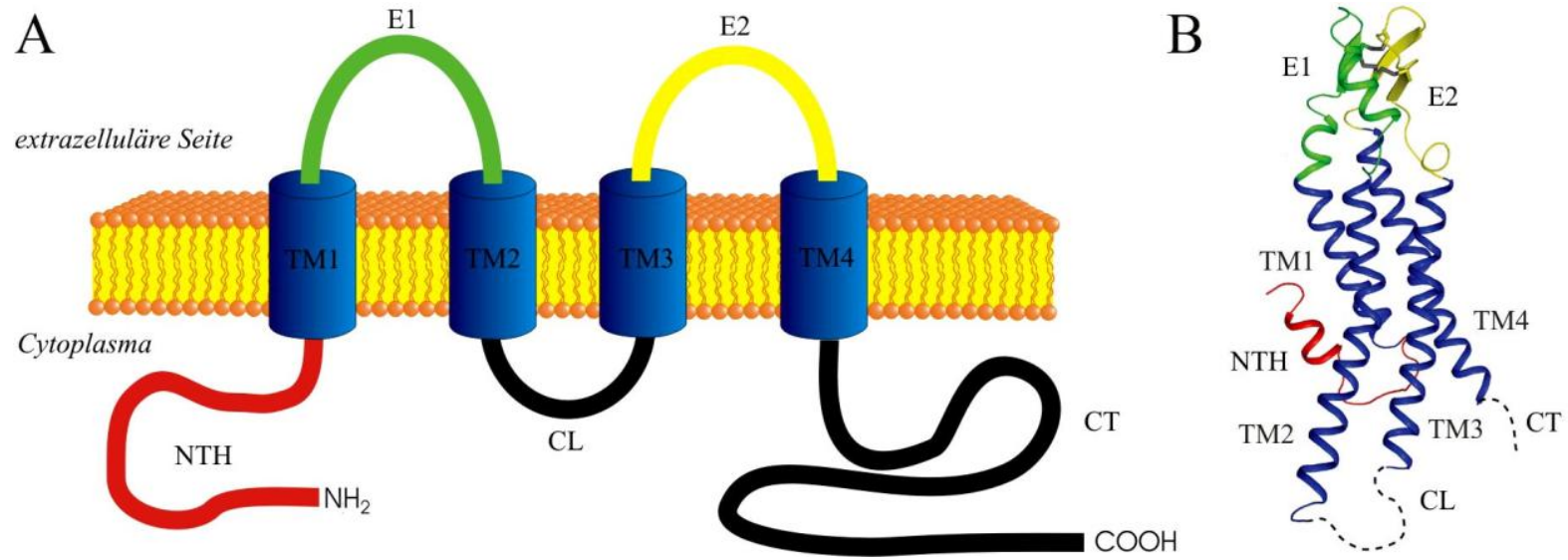

Abb. 1-1: (A) Schematische Darstellung der Membrantopologie eines Connexin-Protomers. (B) Strukturelle Orientierung der Untereinheiten des Cx26 Protomers im Bänder-Modell nach [Maeda et al. 2009]. Die Strukturelemente sind in (A) und (B) farblich gekennzeichnet: NTH (匹), CL und CT (匹), TM1-TM4 (घ), E1 (घ) und E2 ( $)$.

Jedes Connexin besitzt vier überwiegend hydrophobe $\alpha$-helikale Transmembranregionen (TM1-TM4). Die N-terminale Domäne (NTH), der cytoplasmatische Loop (CL) und die Cterminale Domäne (CT) liegen auf der cytoplasmatischen Seite der Zellmembran, wohingegen die extrazellulären Domänen E1 und E2 von extrazellulärer Seite zugänglich sind und sowohl $\beta$-Faltblatt als auch $\alpha$-Helix Strukturelemente aufweisen. Die Sequenzhomologie zwischen den verschiedenen Isoformen liegt bei etwa $40 \%$. Die extrazellulären Domänen sowie die Transmembranregionen sind hierbei hochkonserviert. Der cytoplasmatische Loop und die Cterminale Domäne haben die größten Abweichungen in der Sekundärstruktur, wobei die Länge der C-terminalen Domäne maßgeblich für den Unterschied im Molekulargewicht der Connexin-Isoformen verantwortlich ist. Diese beiden Domänen können zudem Phosphorylierungsstellen und Bindungsstellen für andere zelluläre Proteine besitzen und sind damit entscheidend für die Regulation dieses Proteintyps [Harris 2001].

Die geläufigste Nomenklatur benennt die Spezies aus welcher das Connexin (Cx) stammt und bringt dies in Verbindung mit dem theoretischen Molekulargewicht in kDa. So kommt etwa das größte bekannte Connexin, das hCx62, nur im Menschen vor, wohingegen das kleinste bekannte Connexin, das Cx23 sowohl im Menschen als auch in der Maus zu finden ist, also zwischen mCx23 und hCx23 unterschieden werden kann [Söhl \& Willecke 2004]. Eine andere Nomenklatur teilt die Connexine entsprechend ihrer Sequenzhomologie und der Länge des cytoplasmatischen Loops in $\alpha, \beta$ und $\gamma$ Untergruppen ein [Eiberger et al. 2001].

Die für die interzelluläre Kommunikation multizellulärer Organismen so entscheidende Kanalaktivität wird hierbei durch den Zusammenschluss von Connexin-Untereinheiten zu einem Connexon so genannten Halbkanälen gewährleistet. 


\subsubsection{Das Connexin-Oligomer}

Sechs Connexin-Moleküle bilden zusammen den porenbildenden Komplex eines Connexons (Abb. 1-2). Mit einer Auflösung von $3.5 \AA$ konnte die Struktur des hCx26 im Jahr 2009 mittels Röntgenkristallographie mit Ausnahme des cytoplasmatischen Loops und der Cterminalen Domäne nahezu vollständig aufgeklärt werden [Maeda et al. 2009]. Die transmembranen Domänen TM1-TM4 der Connexin-Untereinheiten bilden ein Bündel antiparalleler $\alpha$-Helices, wobei die Domänen TM3 und TM4 mit der hydrophoben Membranumgebung interagieren und TM1 sowie TM2 dem Poreninneren zugewandt sind. Die hydrophile Pore des Kanals wird hierbei hauptsächlich von TM1 ausgekleidet. Durch die transmembrane Neigung dieses $\alpha$-helikalen Strukturelements verengt sich der Porendurchmesser von $35 \AA$ auf der cytoplasmatischen Seite der Membran hin zu $14 \AA$ auf der extrazellulären Membranoberfläche. Hier werden die beiden extrazellulären Domänen E1 und E2 durch intramolekulare Disulfidbrücken miteinander verknüpft. Dipol-Dipol Wechselwirkungen des antiparallelen vier-Helix-Bündels und zahlreiche hydrophobe Wechselwirkungen zwischen diesen transmembranen Domänen, sowie mit der extrazellulären Domäne E1, führen zur weiteren intramolekularen Stabilisierung der ConnexinUntereinheiten.

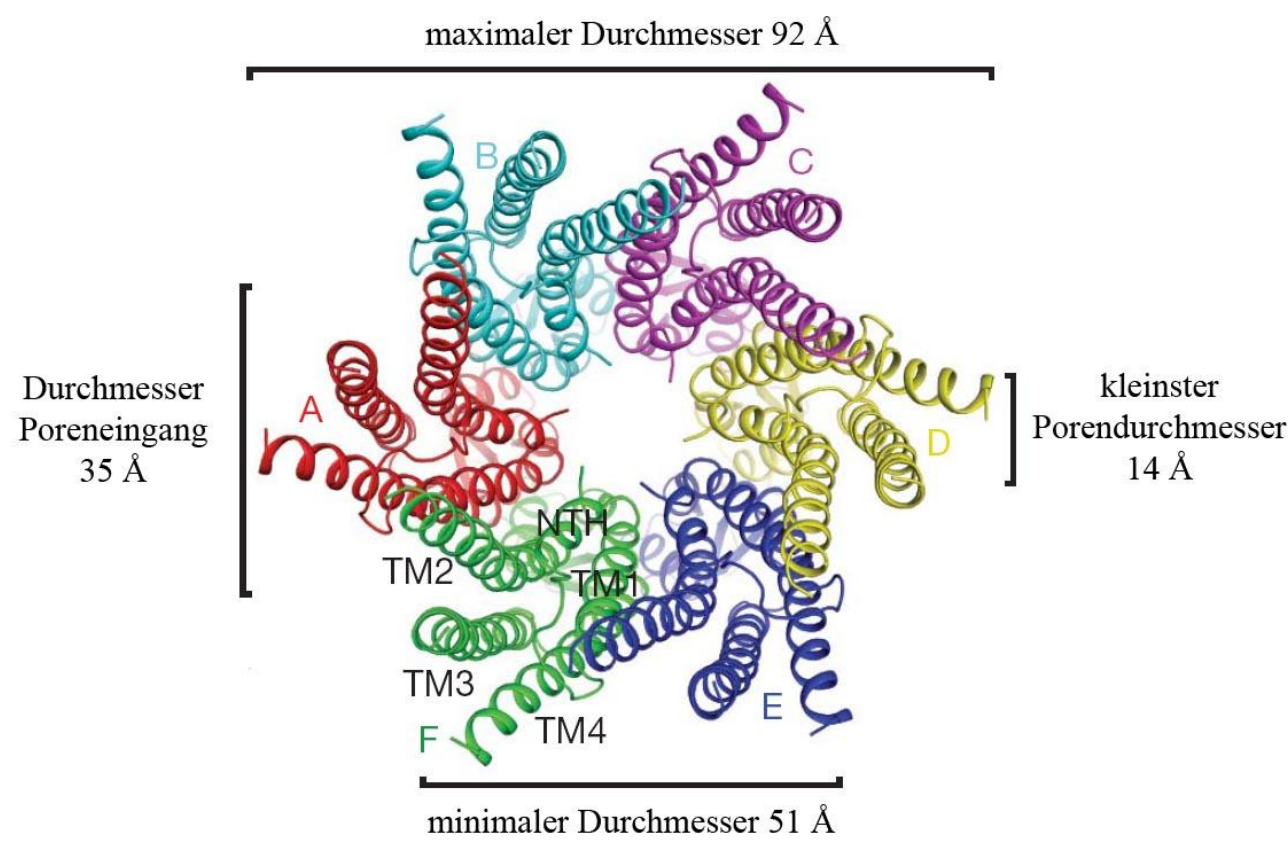

Abb. 1-2: Aufriss eines hexameren Cx26-Oligomers (Connexon) im Bändermodell von cytoplasmatischer Seite [Maeda et al. 2009]. Die sechs Connexin-Protomere (A-F) sind farblich gegeneinander abgegrenzt. Eine Ebene darunter (ausgeblichene Darstellung) sind die Connexin-Protomere eines gegenüberliegenden Connexons bei der Ausbildung von Gap Junctions dargestellt. 
Die hexamere Gesamtstruktur des Connexons wird durch intermolekulare Wechselwirkungen stabilisiert. Hierzu zählen hydrophobe Wechselwirkungen gegenüberliegender aromatischer Aminosäuren in den transmembranen Helices benachbarter Untereinheiten, sowie zahlreiche Wasserstoffbrückenbindungen und Salzbrücken der extrazellulär lokalisierten Abschnitte von M2 und M4 sowie E1 [Maeda et al. 2009].

\subsubsection{Gap Junctions}

Für den direkten interzellulären Austausch zwischen dem Cytoplasma zweier benachbarter Zellen werden zwei gegenüberliegende Halbkanäle durch zahlreiche Wasserstoffbrückenbindungen und Salzbrücken gegenüberliegender extrazellulärer Domänen E1 und E2 zu einem verdichteten doppelschichtigen Kanal mit einem Durchmesser von etwa $25 \AA$ verbunden. Da diese Strukturelemente unter nahezu allen Connexin-Isoformen hochkonserviert vorliegen, kann die extrazelluläre Kluft (engl. gap) von etwa $40 \AA$ zwischen benachbarten Zellen auch durch Paarung unterschiedlicher Connexone erfolgen [Maeda et al. 2009]. Die Gesamtstruktur des hCx26 Gap Junction Kanals (Abb. 1-3 A entspricht damit den bereits 1999 postulierten Dimensionen des verkürzten rekombinanten Cx43 Kanals [Unger et al. 1999] (Abb. 1-3 B). Ist die Strukturaufklärung von Membranproteinen auch heute noch sehr schwierig, so verdeutlicht Abb. 1-3 dennoch die enormen Fortschritte im Bereich der Strukturanalyse dieser biologischen Makromoleküle. 

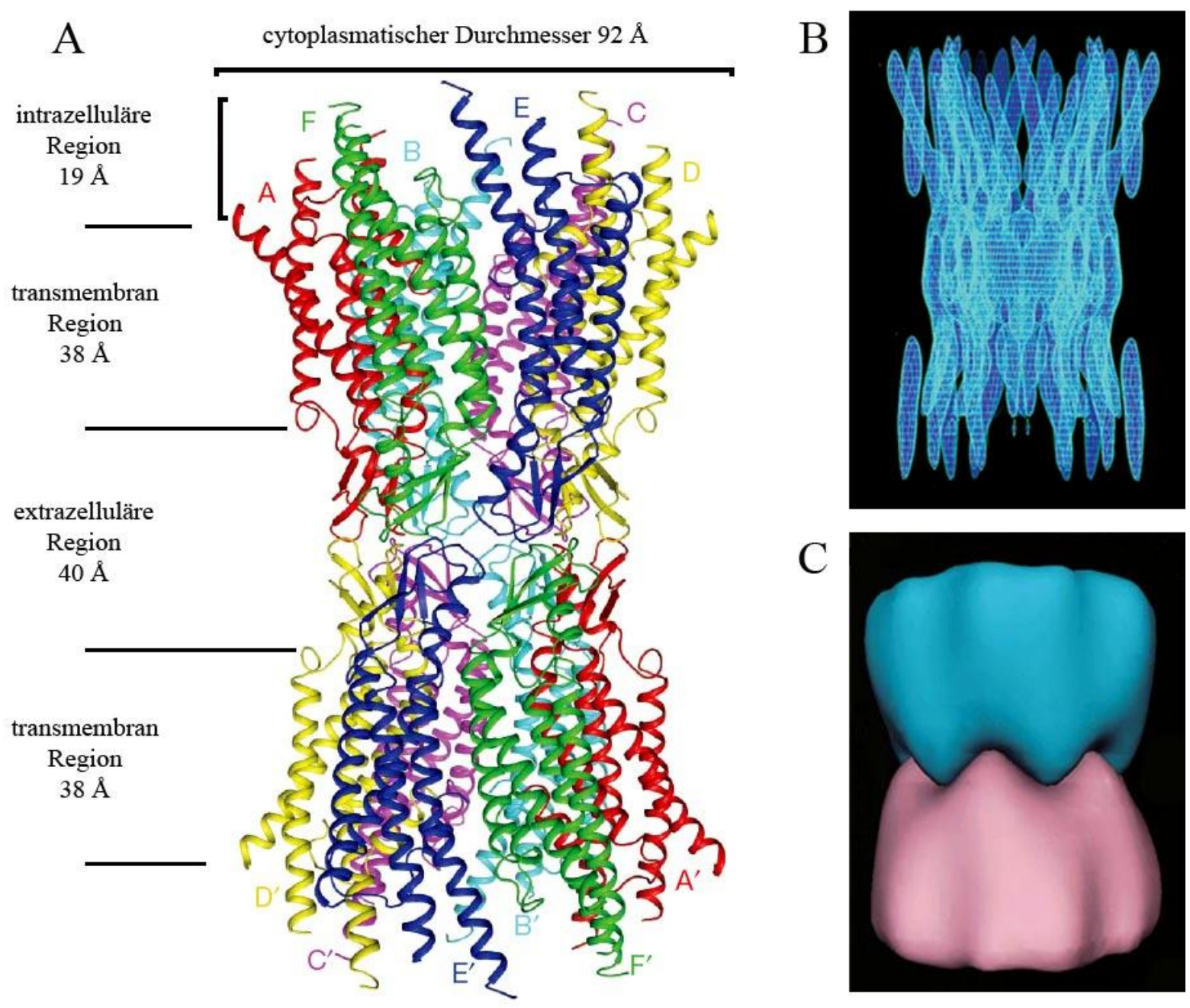

Abb. 1-3: Gesamtdarstellungen von Gap Junctions (GJ) mit verschiedenen molekularen Auflösungen. (A) Bänder-Modell eines Cx26 GJ mit einer Auflösung von $3.5 \AA$ [Maeda et al. 2009]. (B) 3-D Modell eines GJ einer Cx26 Deletionsmutante ohne C-terminale Domäne mit einer Auflösung < $7.5 \AA$ [Unger et al. 1999]. (C) Aus den Strukturinformationen einzelner Connexone computergeneriertes 3-D Modell eines Cx32 GJ mit einer Auflösung < 20 Å [Perkin et al. 1997].

Wird von Perkins et al. [1997] noch ein computergeneriertes 3-D Modell des Gap Junction Kanals mit einer Auflösung < $20 \AA$ vorgeschlagen, so liegt die Auflösung für das Cx26 heute bereits bei $3.5 \AA$ [Maeda et al. 2009].

Bei den untersuchten Gap Junctions handelt es sich um homotypische Kanäle zweier gleichartiger homomerer Connexone, also zwei Halbkanälen aus identischen ConnexinUntereinheiten. Wird ein Gap Junction aus zwei homomeren Connexonen mit jeweils unterschiedlichen Connexin-Monomeren gebildet, spricht man von einem heterotypischen Kanal. Sind die Connexone selbst aus unterschiedlichen Connexinen aufgebaut, spricht man von heteromeren Halbkanälen, die zusammen einen heterotypischen oder einen homotypischen Kanal bilden können [Kumar \& Norten 1996] (Abb. 1-4). 


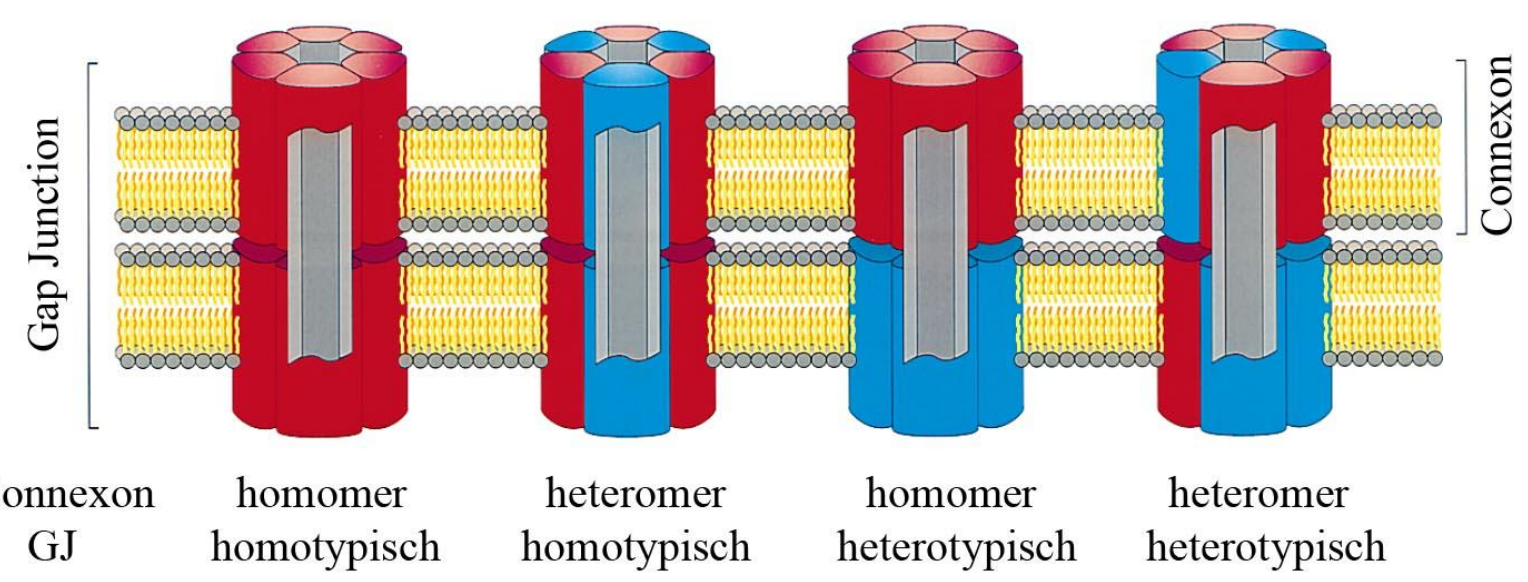

Abb. 1-4: Schematische Darstellung der möglichen Anordnungen von Connexonen bei der Ausbildung von Gap Junctions und deren Klassifizierung [Kumar \& Norten 1996].

Diese Variationsvielfalt wird durch hochkonservierte Bereiche in den Transmembrandomänen und den extrazellulären Domänen der Connexin-Isoformen ermöglicht und macht die regulatorische Vielfalt dieser Membranproteine deutlich. So unterscheiden sich die gebildeten Gap Junctions in der Leitfähigkeit, Permeabilität, Selektivität und den Regulationseigenschaften.

\subsubsection{Regulation von Gap Junctions und Connexonen}

Für die Regulation von Gap Junctions bzw. Connexonen werden diverse Modelle diskutiert. Gehen frühe elektronenmikroskopische Studien noch von einer Rotation aller sechs Connexin-Untereinheiten des Halbkanals aus [Unwin \& Zampighi 1980, Unwin \& Ennis 1984], postulieren moderne, hochauflösende Methoden die Schließung des Kanals durch eine Konformationsänderung der N-terminalen Domäne [Oshima et al. 2007]. Dieser plug-gatingMechanismus kann durch Untersuchungen an Deletionsmutanten ohne N-Terminus weiter bekräftigt werden [Oshima et al. 2008] (Abb. 1-5). 


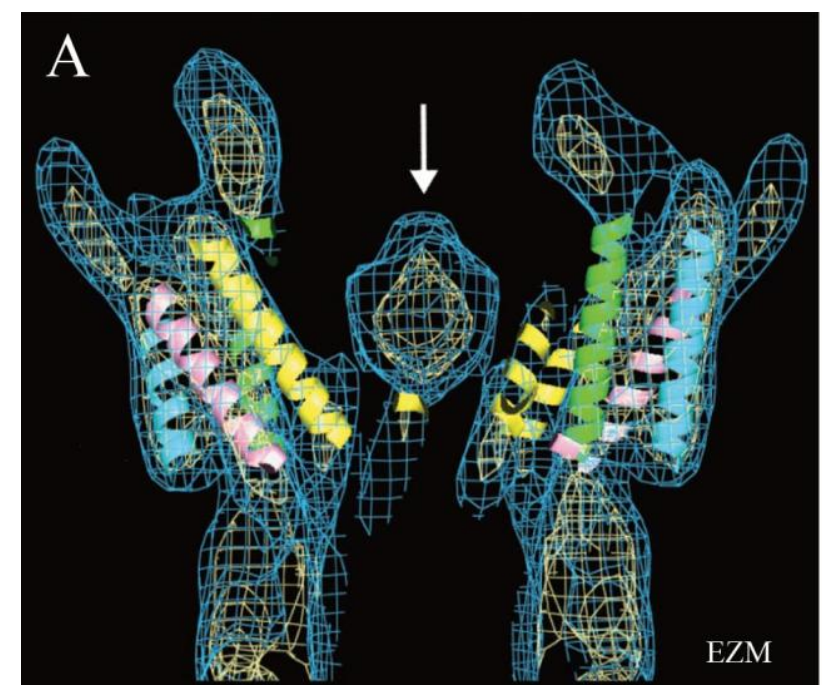

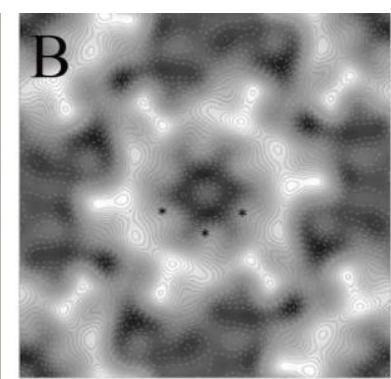

$\mathrm{D}$

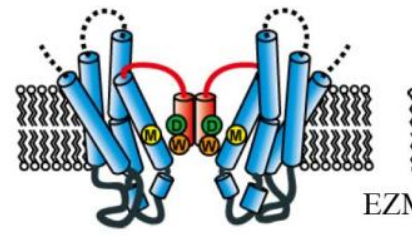

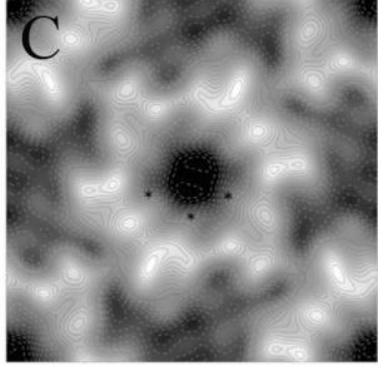

$\mathrm{E}$

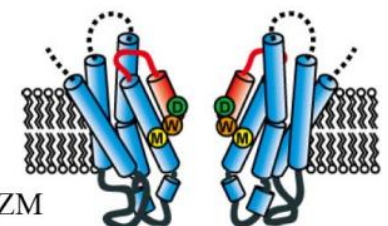

Abb. 1-5: Elektronendichteprojektionen und Modell des plug-gating-Mechanismus zur Regulation von Gap Junctions. $\quad$ EZM = Extrazellularmatrix. (A) Elektronendichte-Darstellung mit Strukturmerkmalen des Querschnitts eines Connexons der M34A Mutante des Cx26 mit einer Auflösung < $7 \AA$ [Oshima et al. 2007]. Klar erkennbar ist ein Bereich erhöhter Elektronendichte im Zentrum der Pore (Pfeil). (B) Elektronendichteprojektion von 2D-Connexon-Kristallen der M34A Mutante des Cx26. Die hohe Elektronendichte im Zentrum des Kanals wird als geschlossene Konformation des Kanals postuliert. (C) Elektronendichteprojektion der Deletionsmutante Cx26M34Adel2-7 ohne N-terminale Domäne. Hier ist keine Elektronendichte im Zentrum der Pore erkennbar [Oshima et al. 2008]. (D) und (E) Schematische Darstellung des plug-gating-Mechanismus nach [Maeda et al. 2009]. Das Schließen des Halbkanals erfolgt hierbei durch Konformationsänderungen der N-terminalen Domänen.

Allen Modellen gemeinsam ist, dass jeder Halbkanal autonom reguliert werden kann, was bereits mit zahlreichen elektrophysiologischen Studien belegt werden kann [Harris 1981; Verselis et al. 1994; Ebihara et al. 1995]. So ist heute auch erwiesen, dass Connexone selbst, also nicht nur in Form von Gap Junctions, eine biologisch relevante Funktion aufweisen [Ebihara 2003] und beispielsweise bei der interzellulären Weiterleitung von Calciumwellen in Gliazellen und Astrozyten des Nervensystems eine entscheidende Rolle spielen [Cotrina et al. 1998; Stout et al. 2002]. Zudem können Hemikanäle durch Injektion ihrer cDNA in Oocyten exprimiert [Ripps et al. 2004; Gonzalez et al. 2006] oder direkt in artifizielle Membransysteme rekonstituiert werden [Falk et al. 1997; Buehler et al. 1995; Gaßmann et al. 2009; Kaneda et al. 2009]. Voltage-clamp Experimente dieses Systems zeigen eine eindeutige Kanalaktivität von Connexonen, allerdings unter unphysiologischen Bedingungen wie etwa der Abwesenheit zweiwertiger Ionen wie Calcium. Da eine unkontrollierte Öffnung der Halbkanäle für Zellen letal wäre, sind sie unter physiologischen Bedingungen durch zweiwertige Ionen und hohe Transmembranpotentiale blockiert [Ebihara 2003].

Es gibt eine Reihe von Regulationsmechanismen, welche die Permeabilität und Selektivität des Kanals beeinflussen. Man unterscheidet voltage-gating und chemical-gating, aber auch posttranslationale Modifikation wie etwa Phosphorylierungen der Connexin-Untereinheiten 
spielen eine Rolle. So zahlreich wie die Möglichkeiten ein Connexon oder einen kompletten Gap Junction Kanal zu regulieren, so zahlreich sind auch die beschriebenen Modelle.

\subsubsection{Voltage-Gating}

Die elektrophysiologischen Untersuchungen gepaarter, Connexon-exprimierender Zellen zeigen, dass die Leitfähigkeiten aller bekannten nativen Gap Junctions spannungssensitiv sind [Harris 2001]. Beim so genannten voltage-gating muss zwischen $V_{\mathrm{j}}$ und $V_{\mathrm{m}}$-Abhängigkeit unterschieden werden. $V_{\mathrm{j}}$, transjunctional voltage, beschreibt die Potentialdifferenz zwischen zwei benachbarten Zellen. Die Transmembranspannung $V_{\mathrm{m}}$ entspricht der Potentialdifferenz zwischen Cytoplasma und dem extrazellulären Raum einer Zelle. Ist die Transmembranspannung $V_{\mathrm{m}}$ zweier benachbarter Zellen gleich groß, also die über den Kanal anliegende Potentialdifferenz $V_{\mathrm{j}}=0$, dann ist die Leitfähigkeit der Gap Junctions typischerweise maximal. Bei Hyper- oder Depolarisation einer der beiden Zellen kommt es zu einer symmetrischen Abnahme der Leitfähigkeit bis zu einem Plateauwert, der zwischen 5 und $30 \%$ der maximalen Leitfähigkeit liegt (Abb. 1-6 A). Auf Einzelkanalniveau wird dies mit Unterleitfähigkeitsstufen begrenzter Leitfähigkeit, also einem partiell geöffneten Kanal, in Verbindung gebracht (Abb. 1-6 B). Ein fast- $V_{j}$-gating-Mechanismus ist nach diesem Modell für schnelle Übergänge ( 1 ms) zwischen dem vollständig geöffneten Zustand des Kanals und einem nur partiell geöffneten Zustand verantwortlich. Ein $s l o w-V_{j^{-}}$gating-Mechanismus wird langsamen Übergängen $(\sim 10 \mathrm{~ms})$ zwischen dem partiell geöffneten und einem vollständig geschlossenen Zustand zugewiesen [Bukauskas \& Verselis 2004] (Abb. 1-6 C).
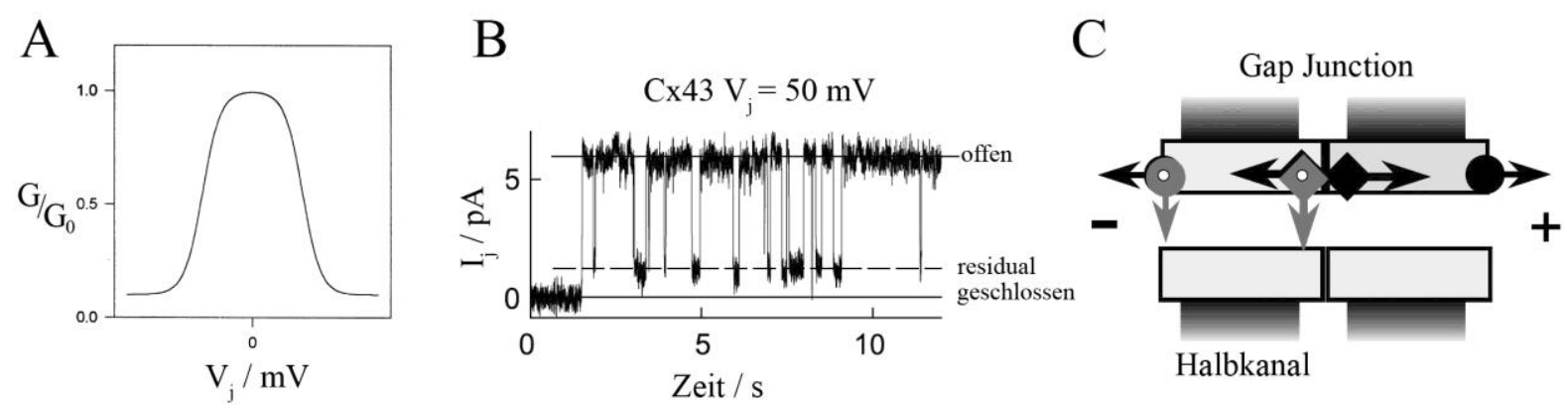

Abb. 1-6: Voltage-gating von Gap Junctions. (A) Typische normierte makroskopische Leitfähigkeit von Gap Junctions in Abhängigkeit von der Potentialdifferenz zwischen zwei benachbarten Zellen [Harris 2001]. (B) Strom-Zeit-Verlauf eines einzelnen funktionellen Cx43 Gap Junction Kanals bei einer interzellulären Potentialdifferenz von $50 \mathrm{mV}$ [Bukauskas \& Verselis 2004]. Der Kanal öffnet sich zunächst vollständig, um dann eine Folge von Übergängen zwischen dem vollständig geöffneten Zustand und einem partiell geöffneten Zustand (residual) einzugehen. (C) Voltage-gating-Modell zweier unabhängig voneinander regulierbaren Halbkanäle mit einem auf extrazellulärer Seite lokalisierten slow- $V_{\mathrm{j}}$-Gate (für Übergänge zwischen geschlossen und residual verantwortlich) und einem auf cytoplasmatischer Seite lokalisierten fast- $V_{\mathrm{j}}$-Gate (für Übergänge zwischen residual und offen verantwortlich) [Bukauskas \& Verselis 2004]. 
Die beiden Halbkanäle können hierbei autonom voneinander geschaltet werden. Beide Mechanismen sind abhängig von der anliegenden Potentialdifferenz und können auf molekularer Ebene unterschiedlichen spannungssensitiven Domänen zugeordnet werden. Für den schnellen Übergang des Kanals in den vollständig geöffneten Zustand scheint vor allem die auf cytoplasmatischer Seite lokalisierte N-terminale Domäne verantwortlich zu sein [Verselis et al. 1994; Oh et al. 2000], was den postulierten plug-gating-Mechanismus [Oshima et al. 2007/2008] stützt. Zudem zeigen C-terminale GFP Fusionsproteine und Cterminale Deletionsmutanten einen Verlust des fast- $V_{j}$-gating Mechanismus [Moreno et al. 2002; Revilla et al. 1999]. Das slow-Vj-gating ist von diesen Veränderungen unbeeinflusst und könnte auf extrazellulärer Seite in der transmembranen Helix TM1 lokalisiert sein [Pfahnl \& Dahl et al. 1998].

\subsubsection{Chemical-Gating}

Abgesehen von elektrisch erregbaren Zellen wie Nerven- oder Muskelzellen ist das Potential von Zellen zeitlich unverändert. Daher spielt die spannungssensitive Regulation von Gap Junctions oder Connexonen in den meisten Geweben keine entscheidende biologische Rolle. Vielmehr ist es eine Vielzahl von Liganden, die bei der interzellulären Kommunikation von zentraler Bedeutung sind. Hierzu zählen u.a. Aminosulfonate wie Taurin [Bevans \& Harris 1999], zweiwertige und dreiwertige Ionen wie Calcium und Lanthan [Gómez-Hernandez et al. 2003; Ye et al.2003], Glycyrrhetinsäure und Derivate wie Carbenoxolon [Davidson et al. 1988] und diverse lipophile Substanzen wie langkettige nAlkyl Alkohole [Délèze \& Hervé 1983; Spray \& Burt 1990], Fettsäuren sowie Fettsäureamide [Lavado et al. 1997; Boger et al. 1998] oder Halothane [Spray \& Burt 1990]. Aber auch direkte Phosphorylierungen [Saez et al. 2005] oder pH-abhängige Protonierungen der Connexine [Trexler et al. 1999] haben Einfluss. So zahlreich die untersuchten chemischen Agenzien auch sind, so wenig sind die zellulären Mechanismen heute verstanden. Häufig stellt sich die Frage, ob es sich bei der Wechselwirkung um eine direkte Interaktion der Substanz mit den Connexin-Untereinheiten handelt, oder ob die Regulation indirekt über zelluläre Signalkaskaden erfolgt.

Bei der pH-abhängigen Regulation scheinen die durch direkte Protonierung von Aminosäuren verursachten Konformationsänderungen der C-terminalen Domäne oder des cytoplasmatischen Loops eine Rolle zu spielen [Bukauskas \& Verselis 2004]. Für die Blockade von Connexonen durch Calcium wird ein Mechanismus vorgeschlagen, welcher die Bindung der zweiwertigen Ionen an einen Ring aus 12 Aspartat-Resten in den extrazellulären Domänen E1 und E2 alle Connexine eines Halbkanals beinhaltet [Gómez- 
Hernandez et al. 2003]. Hierbei würde es sich dann um eine rein physikalische Verschließung des Kanals ohne Konformationsänderung handeln. Doch dieses Motiv ist nicht bei allen Connexinen konserviert. Neben der beschriebenen Verschließung einzelner Halbkanäle werden auch Mechanismen diskutiert, die sich mit der Herabregulation der Expressionsrate der Connexine beschäftigen [Poelzing et al. 2004] oder die Entkopplung des interzellulären Kanals zu zwei Halbkanälen sowie ein Auseinanderdissoziieren von Gap Junction Plaques als Ursache sehen [Groot et al. 2003].

\subsubsection{Gap Junction Plaques}

Gap Junction Plaques sind hochmobile Aggregate von mindestens 300 Gap Junction Kanälen, von denen jedoch nur etwa $15 \%$ funktionell sind [Bukauskas \& Verselis 2004]. Die Connexine werden im Endoplasmatischen Retikulum synthetisiert, oligomerisieren im transGolgi Netzwerk zu Connexonen und werden in Tranportvesikeln entlang der Mikrotubuli transportiert, welche schließlich mit der Plasmamembran fusionieren [Ebihara 2003]. Als Halbkanäle können die Connexone frei in der Membran diffundieren und aggregieren durch laterale Wechselwirkungen mit anderen Connexonen zu so genannten formation plaques, den postulierten Vorläufern von gap junctional plaques (Abb. 1-7). Der Abstand der gegenüberliegenden Plasmamembranen wird innerhalb des Plaques von $20 \mathrm{~nm}$ auf etwa $3.5 \mathrm{~nm}$ verringert.
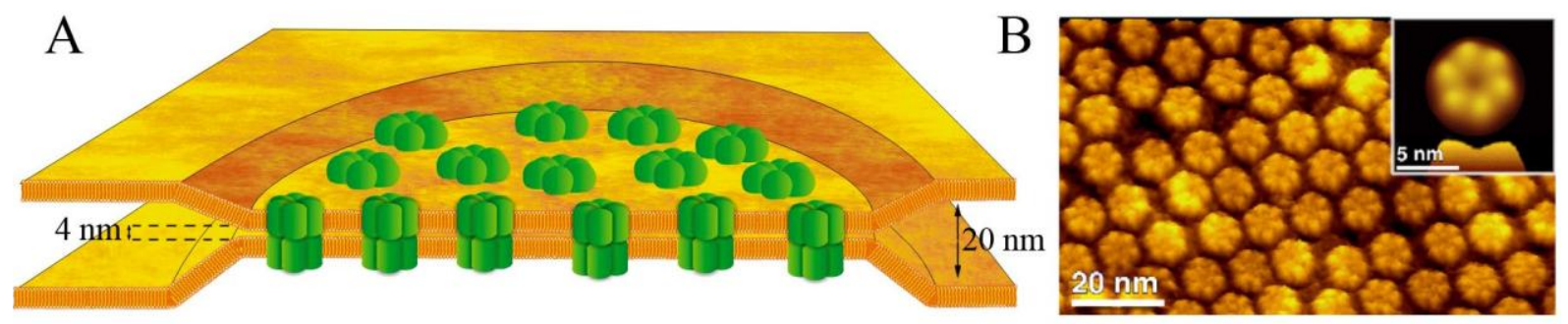

Abb. 1-7: (A) Schematische Darstellung eines Gap Junction Plaques. (B) Rasterkraftmikroskopische Aufnahme der extrazellulären Seite eines auf Glimmer adsorbierten Cx26 Connexonen Plaques in Anwesenheit von $0.5 \mathrm{mM}$ $\mathrm{Ca}^{2+}$ [Müller et al. 2002]. Der Bildeinschub zeigt das gemittelte topografische Profil des geschlossenen Halbkanals.

Nur in Form dieser Plaques findet der interzelluläre Austausch von Molekülen bis etwa $1 \mathrm{kDa}$ statt. Dabei beträgt die Halbwertszeit des Kanals innerhalb der Membran nur einige Stunden [Harris 2001]. 


\subsubsection{Connexinopathie}

Die ubiquitäre Präsenz von Connexonen in nahezu allen Geweben und die Beteiligung an einer Vielzahl entwicklungssteuernder sowie physiologisch relevanter Funktionen innerhalb eines Organismus, lässt vermuten, wie schwerwiegend Defekte der Connexin Expression und Mutationen der Connexin-kodierenden Gensequenz sein können. Mutation resultieren in einer konformativen Änderung der Connexin Untereinheiten, was letztlich Einfluss auf die Proteinfaltung sowie das Zusammenlagern zum hexameren Halbkanal als auch das Verbinden zum vollständigen Gap Junction Kanal oder die laterale Aggregation zu Gap Junction Plaques haben kann [VanSlyke et al. 2000]. Gap Junctions werden demzufolge nicht ausgebildet oder weisen eine abweichende Regulation auf, was letale Entwicklungsstörungen zur Folge haben kann oder sich u.a. in Herzfehlfunktionen, peripherer Neuropathie, Augenlinsentrübung, Taubheit oder diversen Hautkrankheiten äußern kann [Kelsell et al. 2001]. Die Tatsache, dass die meisten Zellen mehr als einen Connexin-Typ exprimieren, macht deutlich, wie hochspezifisch die biologische Funktion einzelner Connexine ist, da ihre Fehlbildung nicht vollständig durch andere Connexine kompensiert werden kann.

\subsubsection{Angeborene Taubheit}

Die angeborene Taubheit ist eine der weitverbreitetsten menschlichen Geburtsdefekte [Zhang et al. 2005]. Etwa 1 von 1000 Neugeborenen ist davon betroffen. In der Hälfte aller Fälle ist eine Mutation des GJB2 Gens Ursache dieses vererbbaren Defektes. Dieses Gen codiert für das Cx26. Bislang sind weit mehr als 100 Mutationen bekannt [Chang et al. 2003], welche Einfuß auf die Funktionalität der Gap Junctions haben können. So kann z.B. die Stabilität der Connexine, deren intrazellulärer Transport, ihre Integration in die Plasmamembran sowie die Aggregation zu Connexonen und Gap Junctions als auch die Permeabilität des gebildeten interzellulären Kanals beeinträchtigt sein. In dieser Arbeit wird das Cx26 verwendet. Dieser Connexin-Typ kommt vorwiegend in den Bindegewebszellen des Cortischen Organs vor.

Als Träger von Sensorzellen im Innenohr aller Säugetiere ist das Cortische Organ die Schnittstelle zwischen aufgenommenen akustischen Signalen und der Weiterleitung von Nervensignalen in die Schnecke des Innenohres (lat. Cochlea) (Abb. 1-8). Die sensorischen Haarzellen sind von einer kaliumreichen $(150 \mathrm{mM})$ Flüssigkeit (Endolymphe) umgeben. Die Übertragung mechanischer Schwingungen auf die Stereozilien (Zellhärchen) der Hörsensorzellen induziert das Öffnen von mechanosensitiven Kalium-Kanälen. Durch den Einstrom von Kaliumionen werden die Haarzellen depolarisiert, wodurch das akustische bzw. 
mechanische Signal in ein elektrisches Signal umgewandelt und über den Hörnerv an das Gehirn weitergeleitet wird. Die Kaliumionen verlassen die Haarzellen und werden von den angrenzenden Stützzellen und Fibrozyten zu einem an der Außenwand des Innenohrs lokalisierten streifenförmigen Organ, dem Stria vascularis überführt, welches durch Sekretion der Kaliumionen in die Endolymphe den hohen Kaliumionengradienten aufrecht erhält [Jentsch 2000].

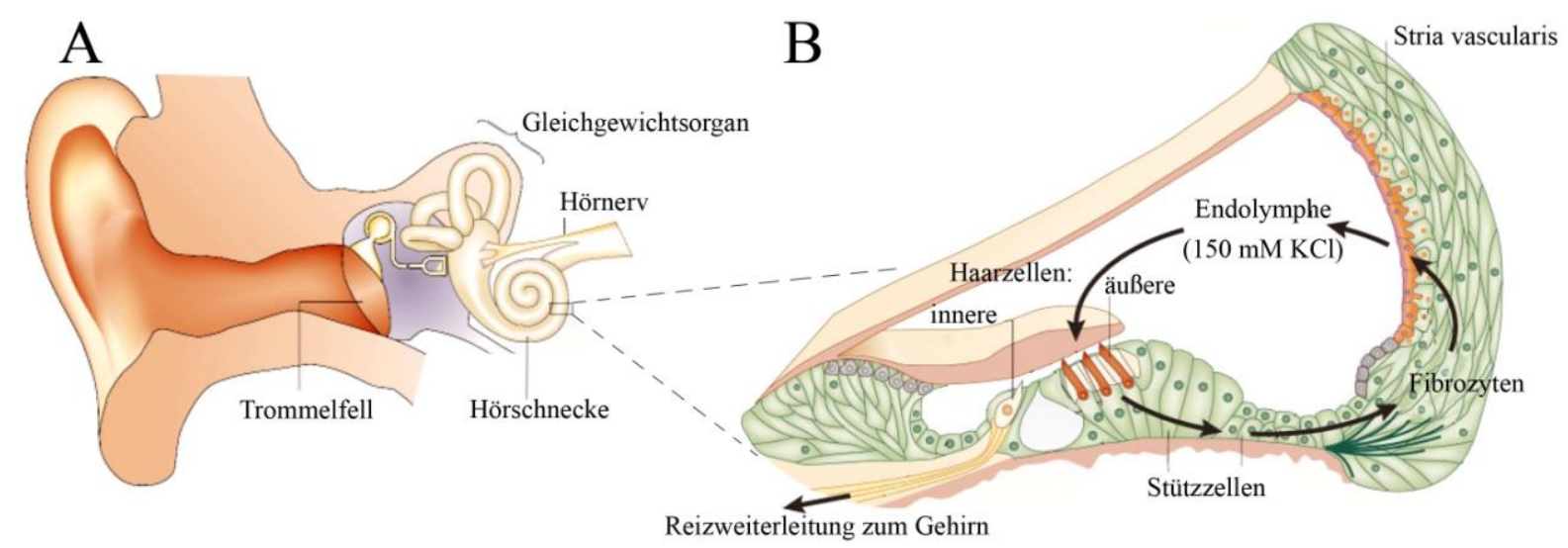

Abb. 1-8: (A) Anatomie des menschlichen Ohres. (B) Aufbau des Cortischen Organs und der Stützzellen vermittelte Kaliumrecyclingweg [Jentsch 2000].

Die Gap Junction vermittelte Permeabilität cytoplasmatischer Signalmoleküle und Metabolite ist essentiell für die Funktion des Hörorgans in Säugetieren [Zhang et al. 2005]. Der für die Aufrechterhaltung der Hörfunktion erforderliche Kaliumionengradient zwischen den sensorischen Haarzellen und der Endolymphe wird unter anderem durch die Stützzellen des Cortischen Organs gewährleistet, welche massiv durch Cx26 Gap Junction Plaques miteinander verbunden sind [Ahmad et al. 2003; Forge et al. 2003; Kikuchi et al. 1995; Lautermann et al. 1999]. Für die biochemisch koordinierte Aktivität dieser Zellen ist u.a. die $\mathrm{IP}_{3}$ (Inositol-1,4,5-trisphosphat, sekundären Botenstoff) induzierte Weiterleitung von $\mathrm{Ca}^{2+}$ Wellen von zentraler Bedeutung. Ist das ionische Gleichgewicht der Innenohrflüssigkeit durch eine mutationsbedingte Funktionsstörungen von Cx26 Gap Junctions gestört, könnten nach Einsetzen der Hörfunktion lokal erhöhte Kalium-Konzentration die Apoptose der Haarzellen einleiten, was einem vollständigen Verlust der Hörfunktion zur Folge hat [Beltramello et al. 2005; Boettger et al. 2002; Lagostena et al. 2001]. Mutationen in dem Cx26 codierenden Gen GJB2 stehen daher im Zusammenhang mit angeborener bzw. vererblicher Taubheit [Kelsell et al. 1997].

Unbeantwortet ist allerdings bislang die Frage, warum der mutationsbedingte Verlust der Funktion von Cx26 nicht durch die Funktion des in den Stützzellen kolokalisierten Cx30 
kompensiert werden kann. In diesem Zusammenhang kann aufgeführt werden, dass der vermutlich für die $\mathrm{Ca}^{2+}$-Wellen Weiterleitung notwendige Transfer des sekundären Botenstoffes $\mathrm{IP}_{3}$ beim $\mathrm{Cx} 30$ in seinem Umfang etwa nur $50 \%$ der Transferrate des Cx26 aufweist. Im Falle einer Dysfunktion von Cx26 wäre die interzelluläre Transferrate von $\mathrm{IP}_{3}$, bei gleich hohen Expressionsraten beider Connexine in den Stützzellen, daher um etwa $67 \%$ reduziert [Beltramello et al. 2005]. Alternativ dazu könnte die Permeabilität bei einer Ausbildung von Cx26-Cx30 heteromeren Connexonen [Forge et al. 2003] vollständig eingeschränkt sein. In beiden Fällen wäre die mit anderen Zellen synchronisierte Weiterleitung von $\mathrm{Ca}^{2+}-$ Wellen nachhaltig beeinträchtigt.

\subsubsection{Mögliche strukturbiologische Ursachen der Taubheit}

Cx26V84L und Cx26M34T sind zwei relativ gut untersuchte Mutationen, wurden in Patienten mit nicht syndromischer Taubheit (keine Cx26-Mutation bedingte Beeinflussung anderer Organe) nachgewiesen [Wang et al. 2003; Bicego et al. 2006] und haben die Substitution einer einzelnen Aminosäure als Ursache. Die Weiterleitung von $\mathrm{Ca}^{2+}$-Wellen ist bei Trägern dieser Mutationen nachweislich nicht gewährleistet [Bicego et al. 2006; Beltramello et al. 2005]. Diese Beeinträchtigung der biochemischen Kopplung könnte demnach eine der Ursachen für angeborene Taubheit bei Menschen sein [Evans \& Martin 2002; White et al. 2002; Zhang et al. 2005].

2009 konnte die Struktur von Cx26 Gap Junctions mit einer Auflösung von $3.5 \AA$ nahezu vollständig gelöst werden [Maeda et al. 2009]. Diese röntgenkristallographische Analyse deckt auf, welche Aminosäurereste potentiell für intra- und intermolekulare Wechselwirkungen verantwortlich sein könnten. Die Aminosäuren Methionin 34 (M34) und Valin 84 (V84) scheinen von zentraler Bedeutung für die Funktionalität eines Cx26 Halbkanals oder des kompletten interzellulären Gap Junction Kanals zu sein. Abb. 1-9 verschafft zunächst eine Vorstellung davon, an welcher Stelle diese Aminosäuren im Cx26 Protomer und im Halbkanal lokalisiert sind. 


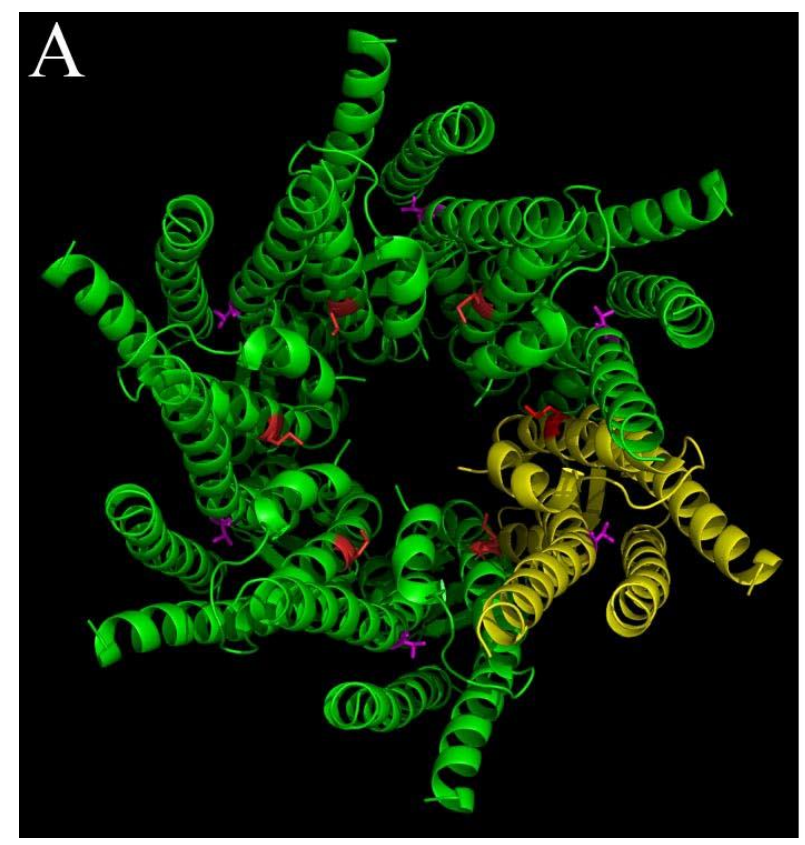

\section{B}

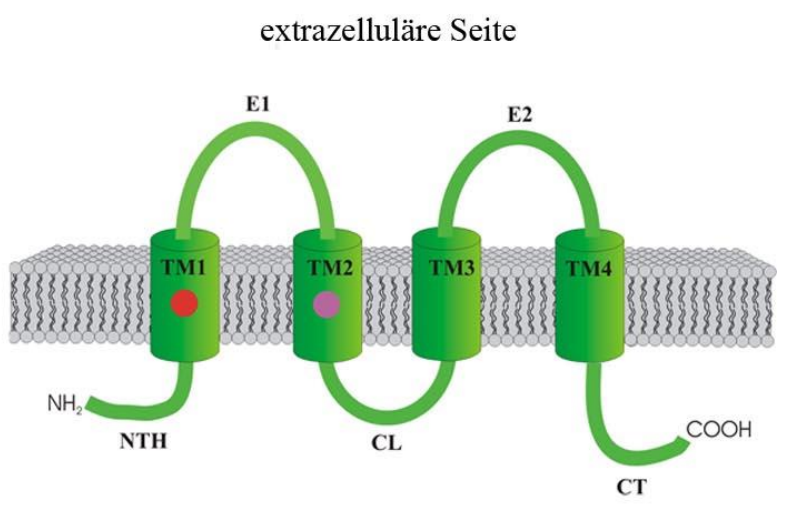

Cytoplasma

Abb. 1-9: Lokalisation von Methionin 34 (M34) und Valin 84 (V84) im Cx26. (A) Aufriss eines Cx26 Connexons im Bändermodell von cytoplasmatischer Seite [PyMOL]. Gelb hervorgehoben ist eine Connexin Untereinheit des hexameren Cx26 Halbkanals. Dargestellt in rot ist die Position von M34 und in magenta von V84. (B) Schematische Darstellung der Membrantopologie eines Cx26 Protomers mit den Sekundärstrukturelementen NTH, TM1-4, E1-2, CL und CT. Farblich hervorgehoben sind die Positionen von M34 (rot) und V84 (magenta).

Abb. 1-9 ist zu entnehmen, dass M34 (rot) als eine Aminosäure der transmembranen Helix TM1 direkt im Zentrum der Pore lokalisiert ist, wohingegen das V84 (magenta) dem Sekundärstrukturelement TM2 zugeordnet werden kann und innerhalb eines Connexin Protomers (gelb in A) anzutreffen ist. Die möglichen strukturellen Veränderungen des Cx26 Halbkanals durch die Mutationen M34T und V84L sind im Folgenden separat aufgeführt.

\section{M34T}

Die Mutationen M34T befinden sich direkt innerhalb der Transmembranregion 1 (TM1). Diese $\alpha$-helikale Domäne des Connexin-Protomers ist zusammen mit der kurzen $\mathrm{N}$-terminalen Domäne (NTH) maßgeblich für die Porenarchitektur eines Cx26 Halbkanals verantwortlich [Maeda et al. 2009]. Hohe kristallographische Temperaturfaktoren lassen vermuten, dass es sich bei der NTH um eine der mobilsten Strukturelemente eines Connexin Protomers handelt. Diese Vermutung kann mittels NMR-Spektroskopie (Kernspinresonanzspektroskopie) belegt werden, welche nachweist, dass der Loop, welcher die NTH mit der TM1 verbindet, hochflexibel ist [Purnick et al. 2000]. Die von cytoplasmatischer Seite aus gesehene trichterförmige Porenstruktur wird hierbei durch zwei wichtige intermolekulare Wechselwirkungen zwischen benachbarten Connexin Untereinheiten des hexameren Connexin-Oligomers stabilisiert (Abb. 1-10). 


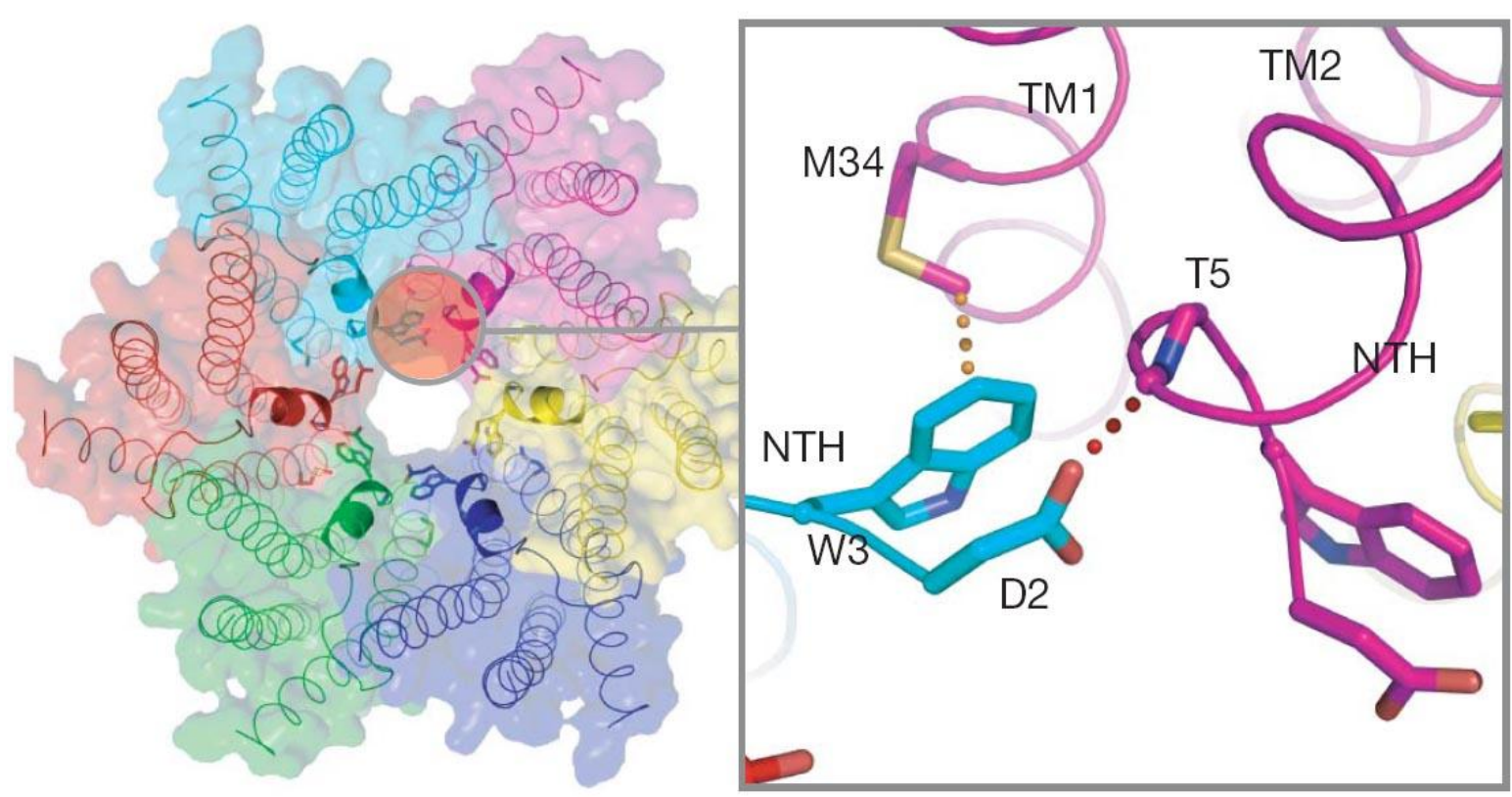

Abb. 1-10: Struktur der Pore des Cx26 Halbkanals von cytoplasmatischer Seite [Maeda et al. 2009]. Die sechs $\mathrm{N}$-terminalen Domänen (NTH) bilden die trichterförmige Struktur des Poreneingangs. Diese werden stabilisiert durch ein ringförmiges Netzwerk aus Wasserstoffbrückenbindungen zwischen D2 und T5 sowie hydrophoben Wechselwirkungen zwischen W3 und M34 benachbarter Connexin Untereinheiten.

So interagiert das Aspartat 2 (D2) der NTH eines Connexin Protomers mit dem Threonin 5 (T5) der NTH des benachbarten Connexin Protomers (siehe Kasten Abb. 1-10). Dadurch wird an der engsten Stelle des Trichters ein ringförmiger Gürtel aus Wasserstoffbrückenbindungen ausgebildet. Diese Konformation kann nur durch zusätzliche hydrophobe Wechselwirkungen zwischen dem Methionin 34 (M34) und dem Tryptophan (W3) benachbarter Connexin Protomere aufrecht erhalten werden. Durch diese Interaktionen werden die sechs hochmobilen NTHs eines Halbkanals an der Innenwandung des Porentrichters fixiert und garantieren so einen inneren Porendurchmesser von $14 \AA$ im geöffneten Zustand des Kanals.

Aufgrund dieser Strukturmerkmale des Cx26 Connexons, ist es verständlich, dass die Mutation M34T eine der häufigsten Ursachen für vererbliche Taubheit ist [Kelsell et al. 1997; Oshima et al. 2003] und mit einer verminderten Leitfähigkeit des Gap Junction Kanals einhergeht [Bicego et al. 2006]. Bei dieser Mutation würde die Substitution der unpolaren und hydrophoben Aminosäure Methionin durch die polare und neutrale Aminosäure Threonin:<smiles>CSCCC(N)C(=O)O</smiles><smiles>C1=CC=C1</smiles><smiles>CC(O)C(N)C(=O)O</smiles> 
die hydrophobe Wechselwirkung zwischen W3 der NTH mit dem M34 des benachbarten Connexin Protomers unterbrechen. Dies könnte letztlich in einem Ablösen der an der Porenwandung fixierter NTHs resultieren, wodurch der Porendurchmesser und damit die Leitfähigkeit des Kanals entscheidend beeinflusst würden.

\section{V84L}

Die Transmembranregion 2 (TM2) ist an der Stelle Prolin 87, dem Mittelpunkt dieses $\alpha$ helikalen Strukturelementes, geknickt. Mutationen innerhalb dieser Region wie L79P, S85P, P87L, L90P oder V84L stehen nachweislich im Zusammenhang mit angeborener Taubheit [Suchyna et al. 1993; Laird 2006; Beltramello et al. 2005]. Dies wird damit begründet, dass an einigen der bedeutendsten intraprotomeren Wechselwirkungen Aminosäuren der TM2 beteiligt sind (Abb. 1-11) [Maeda et al. 2009].

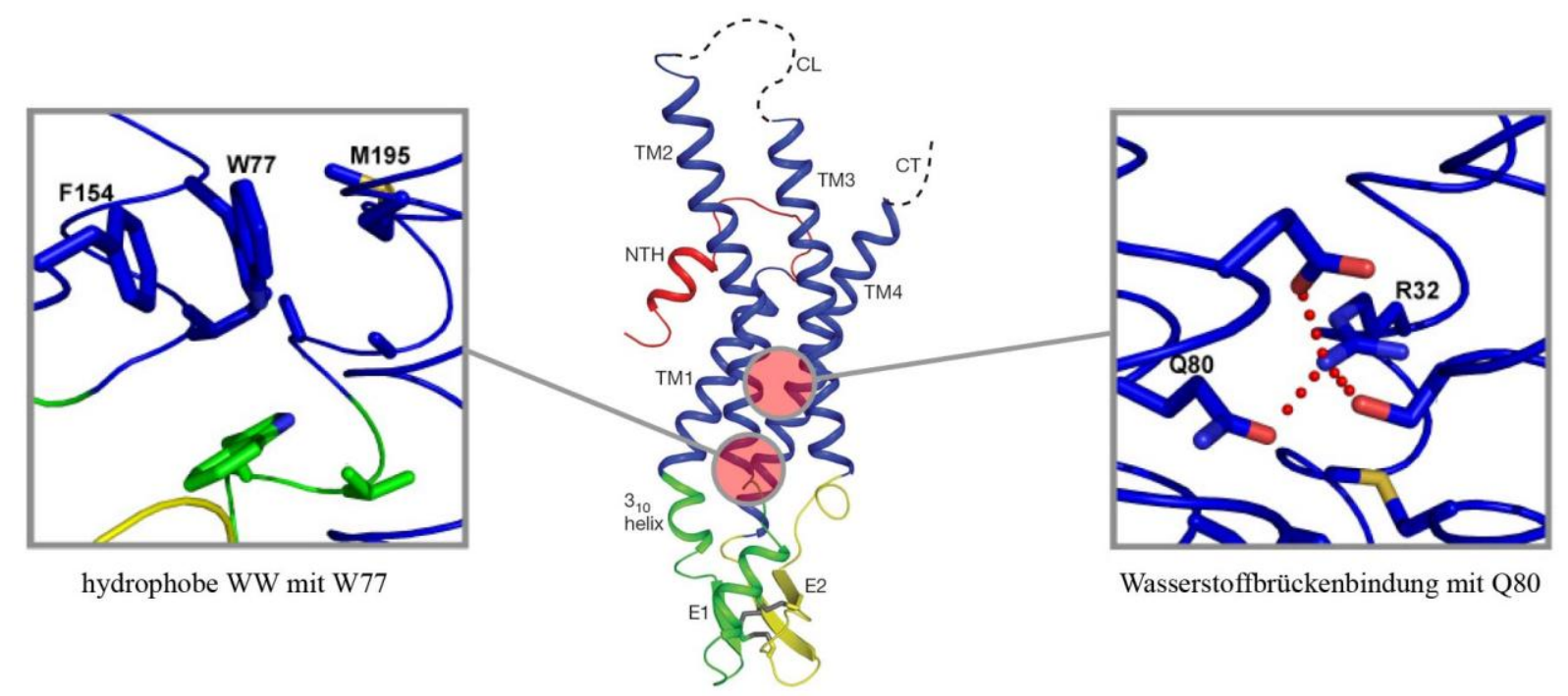

Abb. 1-11: Intra-Protomer Wechselwirkungen im Cx26 Connexin. Die zentrale Abbildung zeigt die Tertiärstruktur des Cx26 Protomers im Bändermodell mit allen Sekundärstrukturelementen. Die Kästen zeigen Nahaufnahmen der rot eingekreisten Bereiche mit den relevanten Aminosäureresten im Stäbchenmodell. Nach [Maeda et al. 2009].

So interagiert das Glutamin 80 (Q80) mit dem Arginin 32 (R32) der TM1 durch Ausbildung einer Wasserstoffbrückenbindung und Tryptophan 77 (W77) stabilisiert die Struktur durch Ausbildung von hydrophoben Wechselwirkungen mit Phenylalanin 154 (F154) der TM3 und Methionin 195 (M194) der TM4. Die Vorhersage der Auswirkungen einer solchen Strukturveränderung ist anhand dieses Modells leider nicht so gezielt möglich wie im Falle der Mutation M34T. Es kann allerdings davon ausgegangen werden, dass Mutationen, die wie das V84L nicht direkt im Zentrum der Pore lokalisiert sind, zu Strukturveränderungen des Connexin Protomers und damit auch des Cx26 Halbkanals führen. Die Substitution der 
neutralen und unpolaren Aminosäure Valin gegen die ebenfalls neutrale und unpolare Aminosäure Leucin:<smiles>CC(C)C(N)C(=O)O</smiles><smiles>CC(C)C[C@H](N)C(=O)O</smiles>

resultiert effektiv in einer molekularen Verlängerung des Aminosäurerestes bei Erhalt der chemischen Eigenschaften. Es wird vermutet, dass mutationsbedingte Strukturveränderungen der TM2 Auswirkungen auf die cytoplasmatischen Domänen des Connexin Protomers einschließlich der N-terminalen Domäne haben könnten [Maeda et al. 2009], welche vermutlich ein wichtiges Strukturelement bei der Regulation von Connexonen ist [Oshima et al. 2007/2008]. Aber auch andere Domänen des Protomers könnten von einer mutationsbedingten Strukturveränderung betroffen sein. So wird beispielsweise im Bereich des Übergangs zwischen M1 und E1 auf extrazellulärer Seite ein spannungssensitives Motiv vermutet [Harris 2001]. Konformationsänderungen solcher Domänen hätten maßgeblichen Einfluss auf die spannungssensitive Regulierung des Cx26 Halbkanals. 


\subsection{Pannexine}

Lange Zeit galten Connexine als einzige Gap Junction bildenden Proteine in Vertebraten (Wirbeltieren). Auch in Invertebraten (wirbellosen Tieren) wurden Gap Junction bildende Proteine identifiziert. Diese sind strukturell identisch zu den Connexinen, weisen allerdings keine Sequenzhomologien auf und werden Innexine genannt [D`hondt et al. 2009]. Vor etwa 10 Jahren wurden Innexin homologe Proteine in Vertebraten identifiziert [Panchin et al. 2000]. Aufgrund ihres Vorkommens in Vertebraten und Invertebraten werden sie Pannexine (altgriechisch: pan = all, ganz, gesamt, ganzheitlich) genannt (Abb. 1-12).

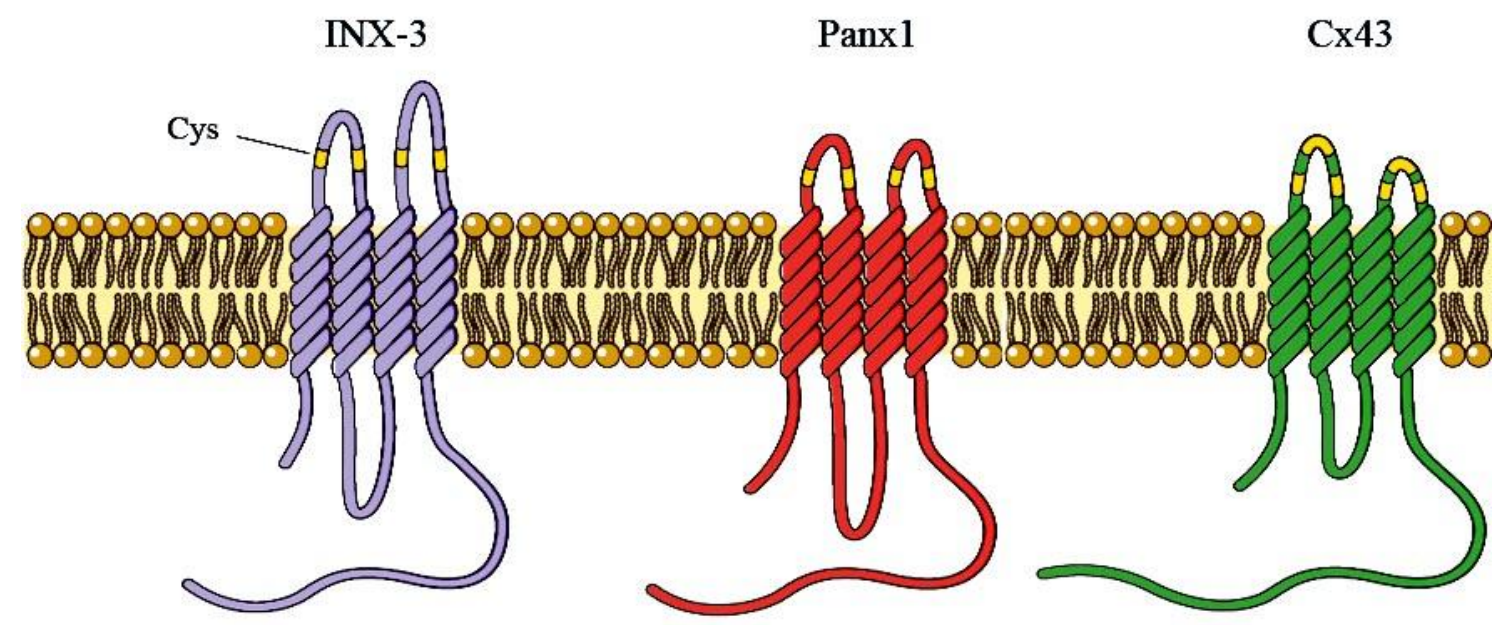

Abb. 1-12: Schematische Darstellung der Membrantopologie von Innexin-3 (C. elegans), Pannexin1 (Ratte) und Connexin43 (Ratte) [Barbe et al. 2006].

In Säugetieren wurden bislang drei Pannexine gefunden, Panx1 (48 kDa), Panx2 (70 kDa) und Panx3 (44.7 kDa), ihre Funktion ist jedoch weitestgehend ungeklärt. Panx1 wird nahezu überall exprimiert, wohingegen Panx2 auf das zentrale Nervensystem beschränkt ist [Baranova et al. 2004]. Trotz großer struktureller Übereinstimmung mit Connexinen weisen Pannexine wesentliche Unterschiede auf. So sind etwa in den extrazellulären Loops nur zwei Cystein-Reste konserviert, wohingegen in Connexinen drei Cystein-Reste vorliegen [Barbe et al. 2006], welche bei der Ausbildung von Gap Junctions vermutlich eine entscheidende Rolle spielen [Dahl et al. 1992]. Während Connexin-Isoformen heteromere Halbkanäle bilden können [Harris 2001], wurden in vivo bislang nur heteromere Panx1/Panx2 Halbkanäle nachgewiesen [Penuela et al. 2009]. Zudem tendiert Panx2 im Gegensatz zu Connexinen und Panx1 zur Ausbildung von Oktameren anstelle von Hexameren [Ambrosi et al. 2010]. Konnte in elektrophysiologischen Studien bereits die Aktivität von Panx1 Halbkanälen und Gap Junctions nachgewiesen werden [Bruzzone et al. 2003], so konnten für eine Funktionalität von Panx2 noch keine Belege erbracht werden. Neuere 
Studien zeigen, dass die biologisch relevante Funktion von Panx1 eher in ungekoppelten Membranen lokalisiert ist, es also nicht zur Ausbildung von Gap Junctions kommt [Locovei et al. 2006; Huang et al. 2007]. 


\subsection{Artifizielle Membransysteme}

In zahlreichen Studien werden die elektrophysiologischen Charakteristika von Cx26 eingehend untersucht. Bis heute handelt es sich hierbei häufig um zellbasierte in vivo Studien, in denen der Fokus auf makroskopischen Cx26 induzierten Strömen liegt. Zum Einsatz kommen wie etwa bei Ripps et al. [2004] einzelne Cx26 exprimierende Xenopus Oocyten, mit welchen Connexin Halbkanäle untersucht werden können. Neben der Untersuchung einzelner Connexin exprimierender Zellen, können in Zellpaar-Studien die Charakteristika von Cx26 Gap Junctions näher untersucht werden. Hier kommen beispielsweise gepaarte HeLa sowie N2A Zellen [Beltramello et al. 2003; Oh et al. 1999] als auch gepaarte Xenopus Oocyten [Mese et al. 2004] zum Einsatz. Eine Connexin exprimierende Zelllinie findet für viele Fragestellungen Anwendung. So kann etwa das spannungsabhängige Verhalten von Halbkanälen und Gap Junctions oder deren Modulierbarkeit mit chemischen Blockern gut untersucht werden. Auch Farbstofftransferstudien liefern einige wertvolle Erkenntnisse. Nachteil dieser Systeme ist jedoch, dass die hier detektierten Ströme meist das gemittelte Signal vieler tausend einzelner Halbkanäle oder Gap Junctions darstellen. Die Untersuchung der elektrophysiologischen Charakteristika auf Einzelkanalniveau ist auf zellulärer Ebene nur bedingt möglich.

Die Aktivität einzelner Gap Junctions kann etwa mit Zellpaaren untersucht werden, welche nur minimal miteinander gekoppelt sind [Suchyna et al. 1999]. Weiterhin besteht die Möglichkeit, die Gap Junction Plaques stark miteinander gekoppelter Zellen durch einen Puffer mit $100 \% \mathrm{CO}_{2}$ Sättigung zu entkoppeln [Beltramello et al. 2005]. Durch diese Azidifizierung werden die aktiven Kanäle geschlossen, so dass in einem Zeitfenster von nur wenigen Sekunden die Aktivität einzelner Gap Junctions beobachtet werden kann. Eine Beeinflussung der elektrophysiologischen Charakteristika des interzellulären Kanals kann bei dieser Methode allerdings nicht ausgeschlossen werden. Zur Untersuchung einzelner Halbkanäle können kleinere Zellmembran-patches z. B. von Xenopus Oocyten ohne Zerstörung der Zellmembran in patch-clamp Elektroden eingesaugt werden (Elektrodendurchmesser an der Spitze etwa $1 \mu \mathrm{m}$ ) [González et al. 2006]. Hierbei handelt es sich um eine so genannte cell-attached Konfiguration. Diese Methoden sind messtechnisch sehr aufwendig, da hierfür die elektrische Kontaktierung einzelner Zellen oder von Zellpaaren notwendig ist. Zudem kann bei der Untersuchung von Connexonen die Wechselwirkungen mit anderen Bestandteilen der Membran oder des komplexen umgebenden Mediums (Cytoplasma und Extrazellularmatrix) nicht ausgeschlossen werden, sodass die isolierte 
Betrachtung der elektrophysiologischen Charakteristika von Connexonen in ihrer nativen Umgebung sehr schwierig ist.

Nur die Verwendung artifizieller Membransysteme ermöglicht die gezielte Untersuchung einzelner Halbkanäle unabhängig von Wechselwirkungen mit zellulären Bestandteilen und liefert damit einige entscheidende Erkenntnisse für das bessere Verständnis dieser wichtigen Proteinklasse. Die Reduzierung des Systems auf wenige Komponenten wie etwa die Integration aufgereinigter Proteine in eine definiert zusammengesetzte Phospholipidmembran bietet vielseitige Möglichkeiten für die funktionelle und strukturelle Aufklärung von Membranproteinen. Artifizielle Membransysteme können den unterschiedlichsten Anforderungen angepasst werden. Die wichtigsten Systeme und ihre Anwendungsmöglichkeiten sollen im Folgenden vorgestellt werden. Neben den Lipidvesikeln wird hierbei ein besonderer Fokus auf die freitragenden und die festkörpergestützten Membranen gelegt, da sich aus diesen beiden Systemen mit den porenüberspannenden Membranen ein artifizielles Membransystem entwickelt hat, welches in besonderer Weise für die Untersuchung von Ionenkanälen geeignet ist.

\subsubsection{Vesikel}

Vesikel oder Liposomen sind das einfachste artifizielle Modellsystem und zugleich den natürlichen zellulären und subzellulären Strukturen am ähnlichsten. Diese sphärischen Gebilde aus geschlossenen Lipiddoppelschichten trennen, wie etwa Zellorganellen oder die Plasmamembran, ein inneres wässriges Kompartiment von einem die Vesikel umgebenden wässrigen Milieu. Man unterscheidet multilamellare Vesikel (multilamellar vesicles, MLVs) mit mehreren konzentrischen Lipiddoppelschichten von unilamellaren Vesikeln mit nur einer Lipiddoppelschicht. Letztere können aus MLVs durch hochfrequente Schallwellen und mit der Extrusionsmethode [Macdonald et al. 1991] hergestellt werden oder entstehen direkt durch Elektroformation [Angelova et al. 1992]. Je nach Herstellungsmethode können Vesikel mit einem Durchmesser von $20 \mathrm{~nm}$ bis $150 \mu \mathrm{m}$ generiert werden. Man unterscheidet hierbei SUVs (small unilamellar vesicles, 20-50 nm), LUVs (large unilamellar vesicles, $100-1000 \mathrm{~nm}$ ) und GUVs (giant unilamellar vesicles, > $1 \mu \mathrm{m}$ ) [Ulrich 2002]. Durch fluoreszenzbasierte Techniken, wie etwa das CLSM (confocal laser scanning microscope) rücken die Vesikel als Modellsysteme wieder näher in den Fokus des wissenschaftlichen Interesses (Abb. 1-13). Neben Lipiddomänenbildung innerhalb einzelner Vesikel [Korlach et al. 1999; Bacia et al. 2005] können auch die Vesikelfusion [Düzgünes et al. 1981] 
oder die laterale Aggregation reiner Lipidvesikel untersucht werden. Durch Rekonstitution membranständiger Proteine eröffnet sich zudem ein breites Spektrum biochemischer oder biophysikalischer Anwendungsmöglichkeiten. So können beispielsweise proteininduzierte Membraninvaginationen [Windschiegl et al. 2009] oder -perforationen [Mally et al. 2007] sichtbar gemacht sowie die Funktionalität lichtinduzierter Protonenpumpen oder anderer aktiver Ionenpumpen nachgewiesen werden [Girard et al. 2004].
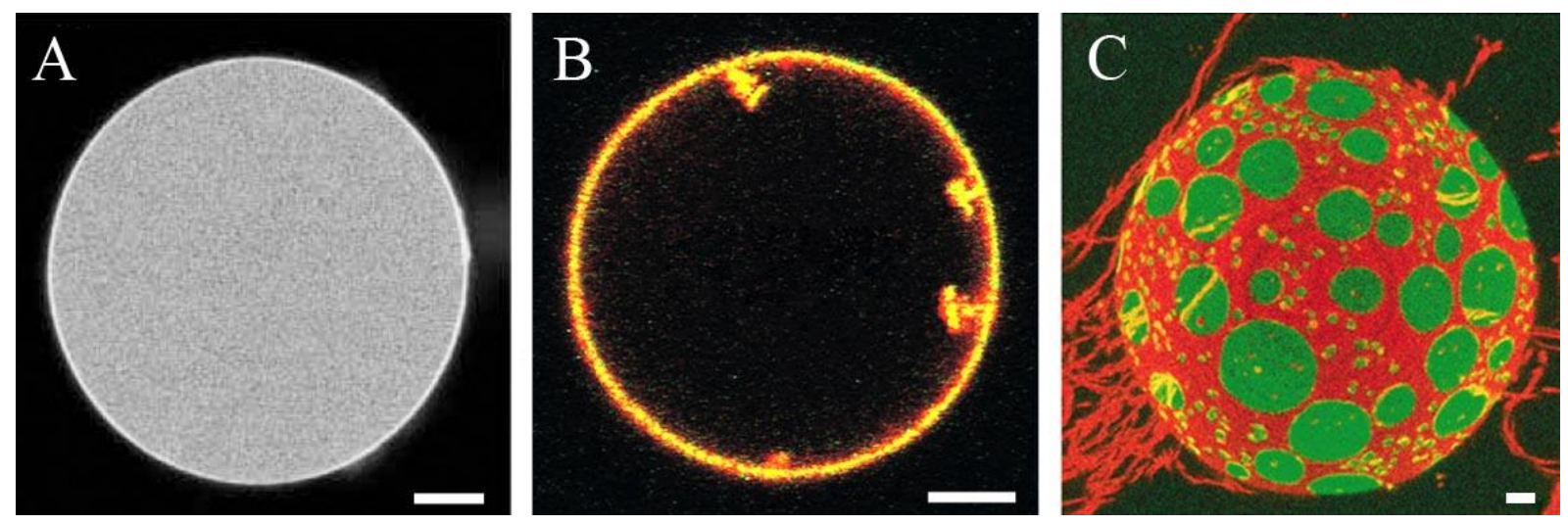

Abb. 1-13: Anwendungsmöglichkeiten von GUVs mittels CLSM. Maßstab $=5 \mu \mathrm{m}$. (A) Nachweis der $\mathrm{Ca}^{2+}$ ATPase Aktivität mittels $\mathrm{Ca}^{2+}$ sensitivem Fluorophor 25 min nach Zugabe von ATP [Girard et al. 2004]. (B) Shigatoxin B induzierte tubulare Membraninvaginationen [Windschiegl et al. 2009]. (C) Lipid-Phasenseparation (42\% DOPC, $42 \%$ SM, $8 \%$ Cholesterol, $8 \%$ Cholesterolsulfat) [Bacia et al. 2009].

Doch gibt es auch Limitationen dieses Modellsystems. So ist es aufgrund der Größe, Mobilität und geringen Stabilität der Vesikel nicht möglich, oberflächenanalytische Methoden wie etwa die Rasterkraftmikroskopie (atomic force microscopy, AFM) einzusetzen oder Proteinbindungen mit Methoden wie der Quarzmikrowaagetechnik (quartz crystal mycrobalance, QCM) oder der Ellipsometrie zu quantifizieren. Hierfür eignen sich vor allem festkörperunterstützte Membranen.

\subsubsection{Festkörperunterstützte Membranen}

Festkörperunterstützte Membranen (solid supported membrane, SSM) sind Modellsysteme, in denen Lipiddoppelschichten auf einer Oberfläche immobilisiert werden (Abb. 1-14). Sie besitzen eine hohe mechanische Stabilität und eignen sich damit in besonderer Weise für oberflächenflächenanalytische Methoden zur Aufklärung der Membranstruktur und -dynamik sowie von Membran-Protein-Wechselwirkungen. Neben spontaner oder proteininduzierter Domänenbildung [Windschiegl et al.2009] kann die Wechselwirkung peripherer Membranproteine [Herrig et al. 2006] oder auch der Einfluss membrandestabilisierender Proteine [Szilluweit et al. 2009] untersucht werden. Als Methoden kommen unter anderem 
AFM, QCM, Ellipsometrie oder Oberflächenplasmonenresonanz-Spektroskopie (surface plasmon resonance, SPR) zum Einsatz.

Für die Bildung von SSMs stehen diverse Techniken zur Verfügung. Hierbei unterscheidet man den Übertrag von Langmuir-Filmen [Blodgett 1935], die Selbstorganisation von Lipiddoppelschichten durch das Spreiten unilamellarer Vesikel [Jass et al. 2000] oder das Lösungsmittel basierte painten von Lipiden [Florin \& Gaub 1993]. Eine weitere Technik basiert auf der Selbstorganisation von Membranen aus Lipid/Detergenz-Mizellen [Heyse et al. 1998].

Bei der Langmuir-Blodgett-Technik wird ein monomolekularer Lipidfilm an der Wasser-LuftGrenzfläche eines wassergefüllten Troges gespreitet. Ein hydrophilisiertes Substrat aus Glimmer oder Siliziumdioxid wird bei konstant gehaltenem Oberflächendruck aus der Subphase gezogen. Dabei werden die hydrophilen Kopfgruppen des Lipidfilmes auf die Oberfläche des Substrates übertragen. Die Vervollständigung der Lipiddoppelschicht wird durch ein erneutes vertikales Eintauchen des nun hydrophoben Substrates in die Wasseroberfläche erzielt. Vorteil dieser Methode ist, dass hiermit asymmetrisch zusammengesetzte Lipidfilme erzeugt werden können. Nachteil ist, dass bei dieser Methode nur bestimmte Phospholipide verwendet werden können [Roberts 1990]. Um dennoch Langmuir-Filme aus Phospholipiden als zweite Monoschicht zu übertragen, kann das hydrophobe Substrat alternativ parallel zur Wasseroberfläche positioniert und eingetaucht werden [Langmuir \& Schäfer 1938].

Wird mit hydrophilen Oberflächen gearbeitet und sollen keine asymmetrischen Lipiddoppelschichten erzeugt werden, können unilamellare Vesikel auf der Oberfläche gespreitet werden [Cremer \& Boxer 1999]. Adhäsionskräfte der hydrophilen Kopfgruppen der Vesikel mit dem Substrat induzieren ein Kollabieren der Vesikel. Thermodynamisch favorisiert ist hierbei die Minimierung der Grenzfläche zwischen den hydrophoben Alkylketten der Lipide und den Wassermolekülen, was die Selbstorganisation der Vesikel zu einer vollständigen Doppelschicht durch Fusion und Spreiten begünstigt [Keller et al. 2000]. Stehen hydrophobe Oberflächen, wie etwa durch Chemisorption von thioltragenden Lipiden oder Alkanthiolen funktionalisierte Goldschichten zur Verfügung [Ulman 1996], kann die obere Monolage aus Lipiden ebenfalls durch Spreiten von Vesikeln erhalten werden [Plant 1999; Steinem et al. 1996].

Bei den so genannten painted membranes wird das Lipid gelöst in Lösungsmitteln wie etwa $n$-Dekan ebenfalls auf eine Monolage an Gold chemisorbierter Alkanthiole oder Thiolipide aufgebracht. Nach Zugabe wässriger Lösung wird das Lösungsmittel verdrängt. Durch 
Selbstorganisation kommt es spontan zu der thermodynamisch begünstigten Ausbildung einer geschlossenen zweiten Lipidschicht [Florin \& Gaub 1993].
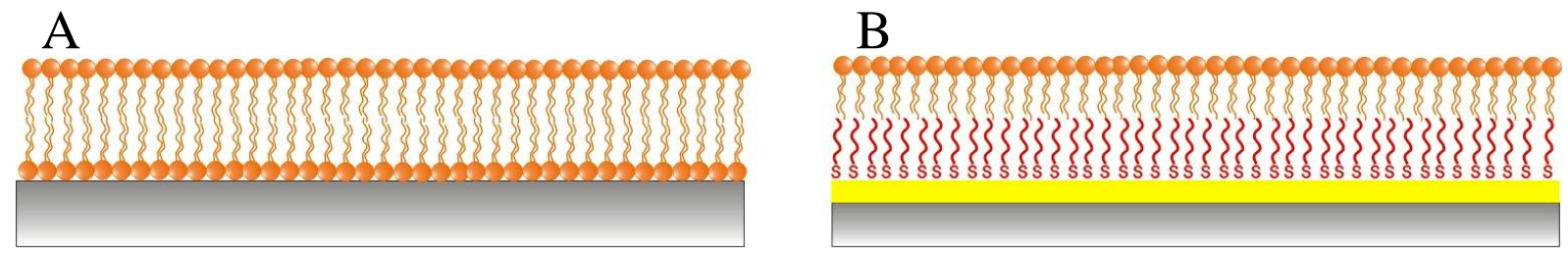

Abb. 1-14: Schematische Darstellung festkörperunterstützter Membranen. (A) Lipiddoppelschicht auf einem hydrophilen Substrat, erhalten durch Langmuir-Blodgett-Technik oder Vesikelspreiten. (B) Hybride Membran aus einer auf Gold chemisorbierten Thiolipid- oder Alkanthiolmonolage und einer oberen Monolage aus Lipidmolekülen.

Die beschriebene direkte Angrenzung der Membranunterseite an Oberflächen wie Glimmer oder Siliziumdioxid hat neben dem Vorteil der erhöhten Stabilität entscheidende Nachteile. So ist etwa die u.a. von der Lipidzusammensetzung abhängige laterale Mobilität der Membran mit Diffusionskoeffizienten zwischen 0.3 und $4 \mu \mathrm{m}^{2} / \mathrm{s}$ [Brozell et al. 2006; Dertinger et al. 2006; Lopez et al. 1988] gegenüber der lateralen Mobilität freitragender Membranen mit Diffusionskoeffizienten im Bereich zwischen 13 und $20 \mu \mathrm{m}^{2} / \mathrm{s}$ [Sonnleitner et al. 1999; Lahda et al. 1996] deutlich eingeschränkt. Es können zwar periphere Proteine gebunden werden, doch ist die funktionelle Rekonstitution integraler Proteine durch den geringen Abstand zwischen Membran und Substrat erschwert. Durch ein fehlendes wässriges Kompartiment zwischen Membran und Substrat ist die funktionelle Integration transmembraner Ionenkanäle mit großen extra- oder intrazellulären Domänen nur bedingt möglichen.

Die Entkopplung der Lipiddoppelschicht von der Substratoberfläche und die Schaffung eines zweiten wässrigen Kompartiments kann durch die Verwendung von Spacer-Molekülen erzielt werden (Abb. 1-15 A). Bei den so genannten tethered membranes kommen Moleküle zum Einsatz, welche mit ihrem meist aus Ethylenoxid-Einheiten bestehenden hydrophilen Abstandshalter über schwefelhaltige Gruppen an eine Goldoberfläche gebunden sind. Durch Verwendung Silan-basierter Kopfgruppen besteht weiterhin die Möglichkeit auch Substrate wie Glas oder $\mathrm{SiO}_{2}$ zu erschließen [Köper et al. 2006]. Die nur unvollständige Oberflächenbelegung ist auf die Molekülgröße und -flexibilität und die damit einhergehenden sterischen Hinderungen untereinander zurückzuführen. Der hydrophobe Anteil des SpacerMoleküls besteht häufig aus Fettsäureketten oder einem Cholesterinrest, dient der Membranintegration und damit der Kopplung einer Lipiddoppelschicht mit einem Abstand von 10-40 $\AA$ an die Substratoberfläche [Lang et al. 1994; Raguse et al. 1998; Krishna et al. 2001; Williams et al. 1997]. Neben dem Spreiten von Vesikeln oder dem 
painten von Lipiden, können auf solchen Substraten Membranen durch Selbstorganisation aus Lipid/Detergenz-Mizellen gebildet werden. Hierbei werden mit Detergenz vollständig solubilisierte Lipide auf die funktionalisierte Oberfläche gegeben. Durch Verdünnung des Detergenz unterhalb der kritischen Mizellenbildungskonzentration (critical micellar concentration, CMC) bilden sich spontan tethered membranes [Heyse et al. 1998].

Es werden auch andere Konzepte beschrieben, in denen die Entkopplung der Membran über flexible Polymer-Netzwerke erzielt wird [Spinke et al. 1992; Tanaka \& Sackmann 2005] (Abb. 1-15 B).
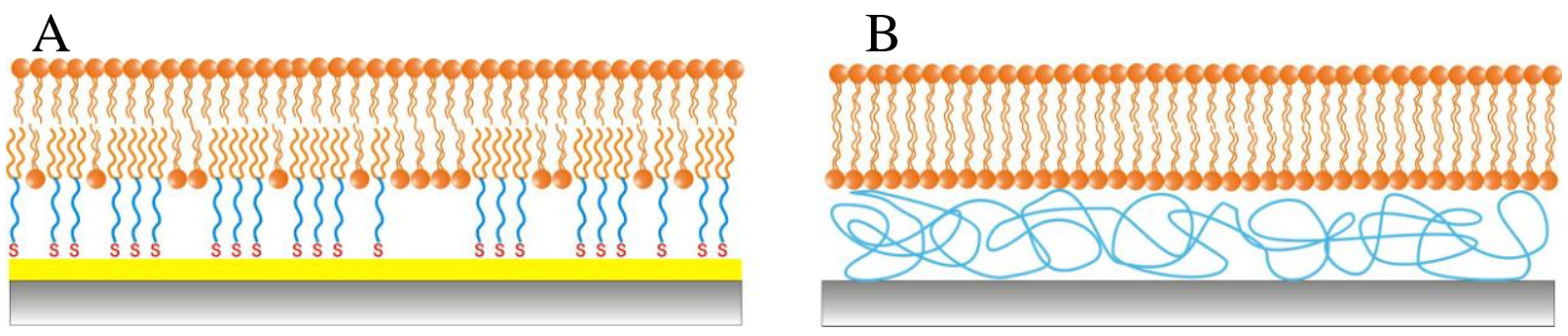

Abb. 1-15: Schematische Darstellung zur Entkopplung der Membran von der Substratoberfläche mit chemisorbierten ampiphilen Spacer-Lipiden (A) oder unter Verwendung von Polymerkissen (B).

Die Schaffung eines wässrigen Reservoirs zwischen Festkörper und Membran und die nur unvollständige Belegung der Oberfläche mit Spacer-Lipiden oder Polymernetzwerken erlauben bei diesem System die funktionelle Integration integraler Peptide und Proteine. Das klassische artifizielle Modellsystem zur Untersuchung transmembraner Ionenkanäle ist allerdings das der freitragenden Membranen.

\subsubsection{Freitragende Membranen}

Die black lipid membranes (BLMs) sind seit ihrer Entwicklung in den 60er Jahren [Müller \& Rudin 1963] für Einzelkanalmessungen an Ionenkanälen ein unverzichtbares Werkzeug. Diese freitragenden Lipiddoppelschichten überspannen eine 0.1-2 $\mathrm{mm}$ breite, runde Öffnung einer dünnwandigen hydrophoben Trennwand zwischen zwei elektrolythaltigen Kompartimenten aus Teflon oder Delrin. Zur Präparation der BLMs nach der Müller-Rudin-Technik werden in einem unpolaren und nicht flüchtigen Lösungsmittel wie $n$-Dekan gelöste Lipide mit einem Pinsel über die Öffnung gestrichen. Es kommt spontan zur Verdrängung des Lösungsmittels an den Rand der Öffnung (Plateau-Gibbs-Grenze) und zum Zusammenlagern der Lipidmoleküle (Abb. 1-16). Bei diesem Ausdünnen entsteht im Zentrum der Öffnung eine Lipiddoppelschicht mit einer Dicke von 4-6 nm. Die direkt an der Puffer/Membran-Grenzfläche reflektierten Lichtstrahlen (rot in Abb. 1-16) erfahren eine 
Phasenverschiebung von $180^{\circ}$. Lichtstrahlen, die in das optisch dichtere Medium der Lipiddoppelschicht eindringen (grün in Abb. 1-16), werden an der Grenzfläche Membran/Puffer ohne Phasenverschiebung reflektiert. Da die Weglängendifferenz beider reflektierter Strahlen im Vergleich zur Wellenlänge minimal ist, ergibt sich eine gesamte Phasenverschiebung von etwa $\lambda / 2$, die zur destruktiven Interferenz führt. Hierdurch erscheint die Membran schwarz [Steinem \& Janshoff 2008]. Aufgrund der Herstellungsmethode sind diese Membranen häufig stark lösungsmittelhaltig.
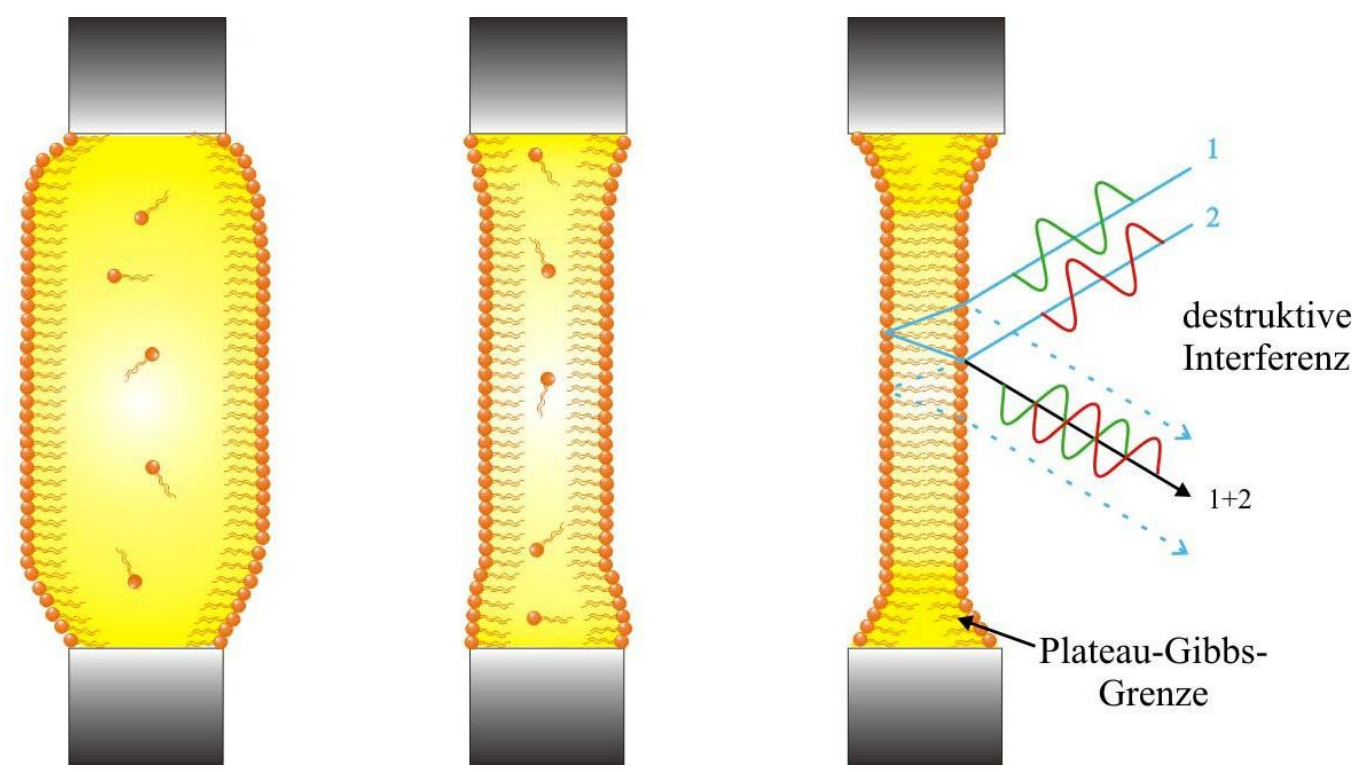

Abb. 1-16: Schematische Darstellung des Ausdünnens einer lösungsmittelhaltigen Membran zur Generierung von BLMs nach Müller-Rudin [1963]. Rechts, schematische Darstellung der destruktiven Interferenzen durch Phasenverschiebung um $\lambda / 2$ bei der Reflektion paralleler Lichtstrahlen an einer Lipiddoppelschicht.

Für die Generierung lösungsmittelfreier, freitragender Membranen kann die Montal-MüllerMethode eingesetzt werden [Montal \& Müller 1972]. Hierbei werden beide Kompartimente der BLM-Kammer bis knapp unter die zu überspannende Aussparung mit Elektrolyt gefüllt. Ähnlich der Langmuir-Blodgett-Technik wird Lipid, gelöst in einem leicht flüchtigen Lösungsmittel, auf der Elektrolytoberfläche beider Kammer gespreitet. Die dadurch erzeugten Monolagen aus Lipidmolekülen werden durch Anheben des Flüssigkeitsspiegels in beiden Kammern zu einer Lipiddoppelschicht vereinigt, wodurch auch asymmetrische Membranen erzeugt werden können.

Als hochohmige elektrische Barrieren trennen diese freitragenden Membranen zwei wässrige Kompartimente voneinander. Ohne sterische Hinderung können so Transmembranproteine mit großen extramembranständigen Domänen rekonstituiert werden, was im Gegensatz zu SSMs die elektrophysiologische Charakterisierung komplexer Ionenkanäle ermöglicht. Ein 
entscheidender Nachteil dieses Modellsystems ist allerdings die geringe mechanische Belastbarkeit und die nur kurze Stabilität von Minuten bis zu einigen Stunden.

\subsubsection{Porenüberspannende Membranen}

Porenüberspannende Lipidmembranen sind ein hybrides Modellsystem, welches die Vorteile der festkörpergestützten und der freitragenden Membranen in sich vereint. Die artifiziellen Membranen werden durch Thiolipide oder Alkanthiole auf den Stegen eines porösen Substrates verankert, was hohe mechanische Stabilität gewährleistet. Über die Poren des Substrates spannen sich freitragende Membranen, welche es ermöglichen zwei wässrige Kompartimente durch eine hochohmige Barriere voneinander zu trennen (Abb. 1-17).
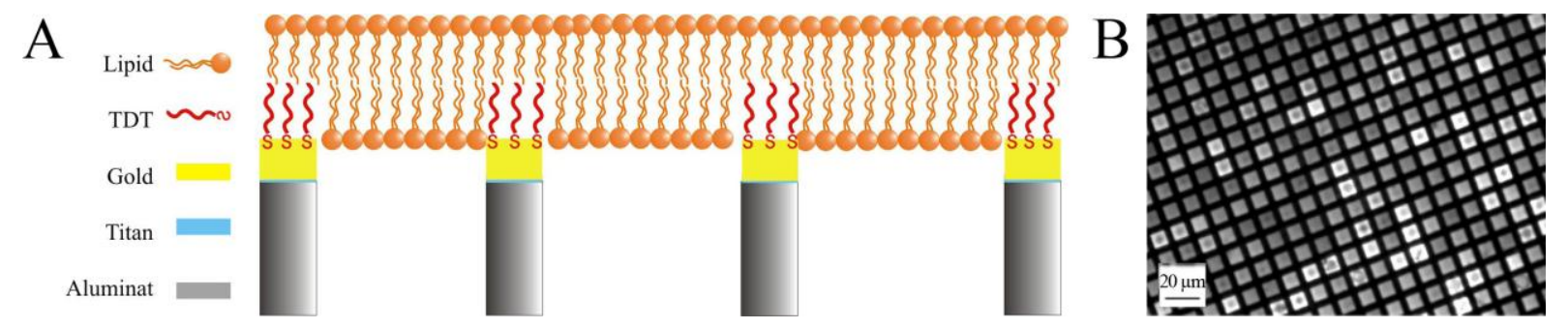

Abb. 1-17: (A) Schematische Darstellung einer porenüberspannenden Membran. Freitragende Membranbereiche sind über Thiolipide oder Alkanthiole mit den Stegbereichen verankert. (B) Fluoreszenzmikroskopische Aufnahme einer Texas Red-DHPE dotierten mikro-BLM [Weiskopf et al. 2007].

Fluoreszenzmikroskopische Studien haben gezeigt, dass einzelne porenüberspannende Membranen unabhängig voneinander reißen, wodurch die Stabilität angrenzender BLMs unbeeinflusst bleibt [Weiskopf et al. 2007]. Dies ermöglicht die Rekonstitution auch strukturell anspruchsvoller transmembraner Ionenkanäle und deren elektrophysiologische Charakterisierung auf Einzelkanalebene [Gaßmann et al. 2009] in einem Modellsystem mit einer Langzeitstabilität von einigen Tagen [Römer \& Steinem 2004]. Des Weiteren werden so oberflächenanalytische Methoden wie AFM ermöglicht, die Informationen über die mechanischen Eigenschaften porenüberspannender Membranen liefern [Mey et al. 2009]. Je nach Porengröße des verwendeten Substrates unterscheidet man mikro- und nano-BLMs. Unter Verwendung hochgeordneter Siliziumporen können Poren im $\mu \mathrm{m}$-Bereich überspannt werden. Auf poröser Aluminate mit Porendurchmessern im Bereich von 10-400 nm [Li et al. 1998] können nano-BLMs hergestellt werden. Es werden aber auch goldbeschichtete Polycarbonatfolien mit Porendurchmessern von etwa $1 \mu \mathrm{m}$ eingesetzt [Favero et al. 2005]. 


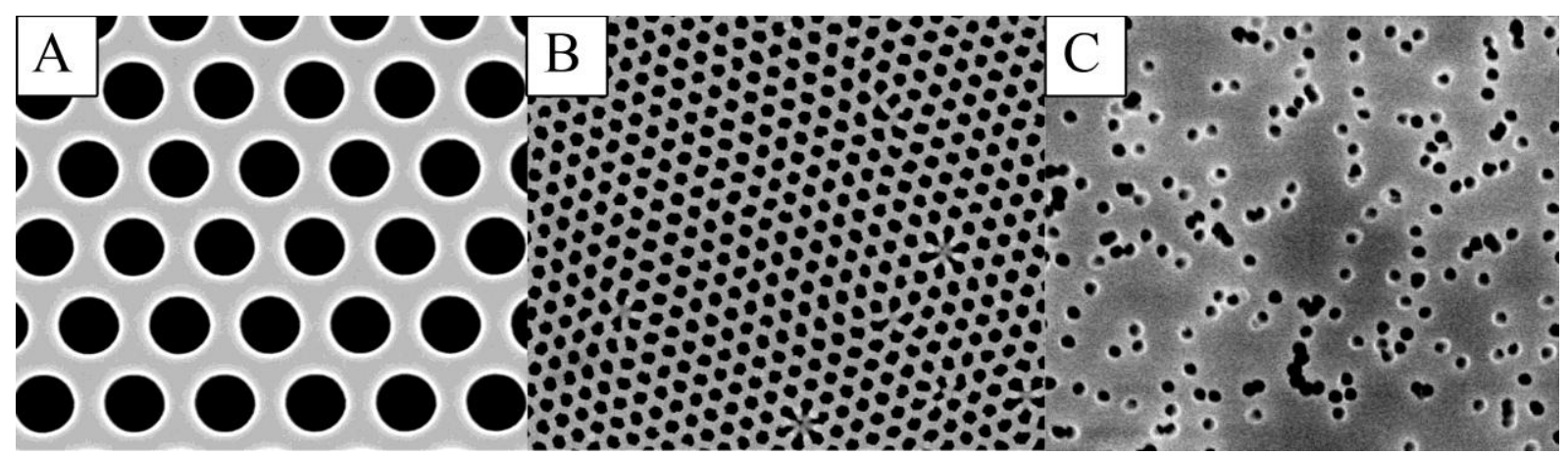

Abb. 1-18: Rasterelektronenmikroskopische Aufnahmen verschiedener poröser Substrate. (A) Silizium Poren $\emptyset=1.2 \mu \mathrm{m}$. (B) poröse Aluminate $\emptyset=60 \mathrm{~nm}$. (C) Polycarbonatfolie $\varnothing=1 \mu \mathrm{m}$ [Favero et al. 2005].

Generell lassen sich zwei unterschiedliche Präparationstechniken für die Herstellung porenüberspannender Membranen unterscheiden. Zum einen besteht die Möglichkeit unilamellare Vesikel zu spreiten [Schmitt et al. 2008], zum anderen können ähnlich der Müller-Rudin-Technik Lipide gelöst in n-Dekan auf das poröse Substrat gestrichen werden [Römer \& Steinem 2004]. Das Vesikelspreiten ermöglicht es nahezu lösungsmittelfreie Membranen zu produzieren, deren elektrischer Widerstand allerdings nicht ausreicht, um Einzelkanaluntersuchungen durchführen zu können. Mit der painting-Technik können solche hochohmigen porenüberspannenden Membranen erzeugt werden, die aber in Teilbereichen lösungsmittelhaltig sind können.
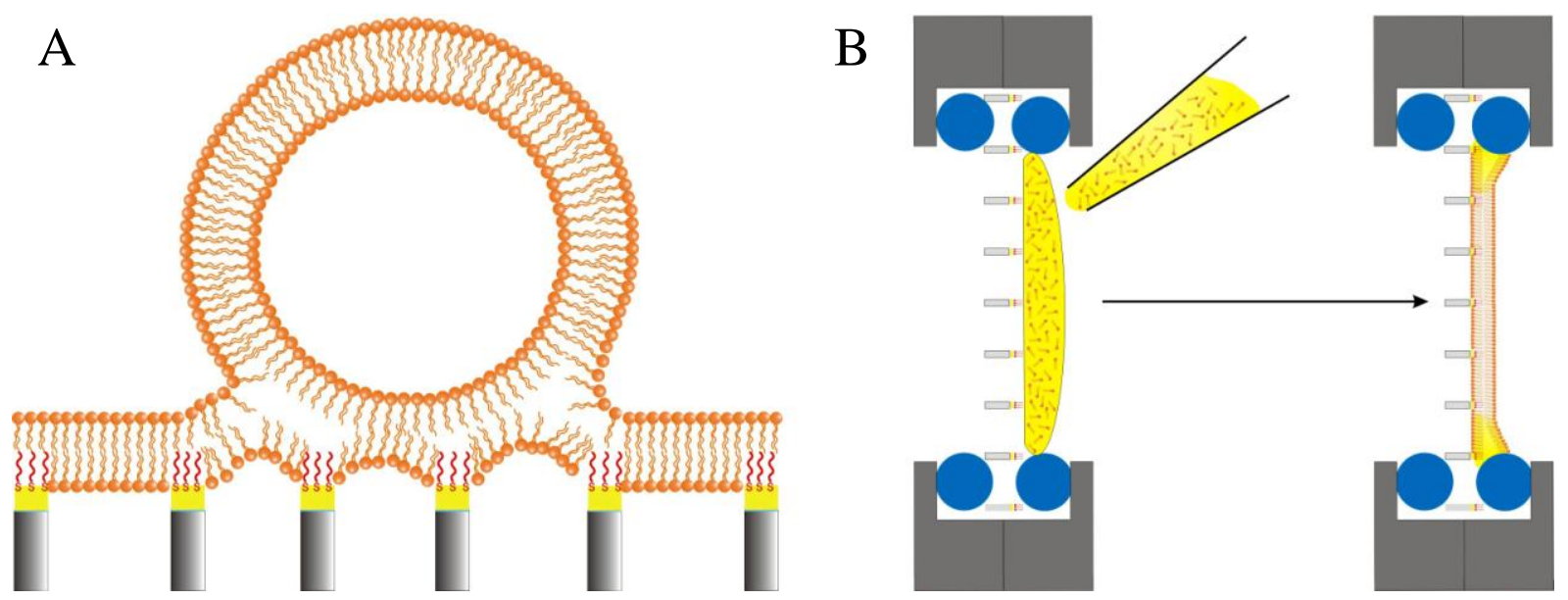

Abb. 1-19: Schematische Darstellung des Vesikelspreitens (A) und der painting-Technik (B) zur Herstellung porenüberspannender Membranen.

Beiden Methoden gemeinsam ist die Funktionalisierung der Substratoberfläche mit Gold und einer geeigneten Monoschicht aus Thiolipiden oder Alkanthiolen. 


\section{$2 \quad$ Zielsetzung}

Erkrankungen des Zentralen Nervensystems (ZNS) wie Alzheimer, Parkinson, Depressionen oder Suchterkrankungen gehören zu den medizinisch und volkswirtschaftlich wichtigsten Herausforderungen. Bei der Suche nach neuen Wirkstoffen stehen daher Ionenkanäle und Rezeptoren von Nervenzellen im Fokus des pharmazeutischen Interesses. Für die Detektion wirkstoffinduzierter Manipulationen der Ionenströme ist bislang die elektrische Kontaktierung beider Seiten der Zellmembran erforderlich. Dies ist messtechnisch sehr aufwendig und ermöglicht immer nur die Untersuchung einer Zelle eines Zellverbundes.

Im Rahmen eines Verbundprojektes soll ein neuartiges Konzept entwickelt werden, mit dem ein für die pharmazeutische Forschung notwendiges high-throughput-screening (HTS) zum Testen der relevanten Wirkstoffdatenbanken ermöglicht wird. Hierbei soll eine elektrische Kopplung von Zellen, die Connexone und den zu untersuchenden Ionenkanal exprimieren, an eine künstliche Connexon-dotierte Lipidmembran ermöglicht werden (Abb. 2-1). Mit einem solchen Biochip-System könnten HTS-fähige elektrische Messungen simultan an einem Kollektiv von Zellen durchgeführt werden, ohne dass die aufwendige elektrische Kontaktierung einzelner Zellen nötig wäre.

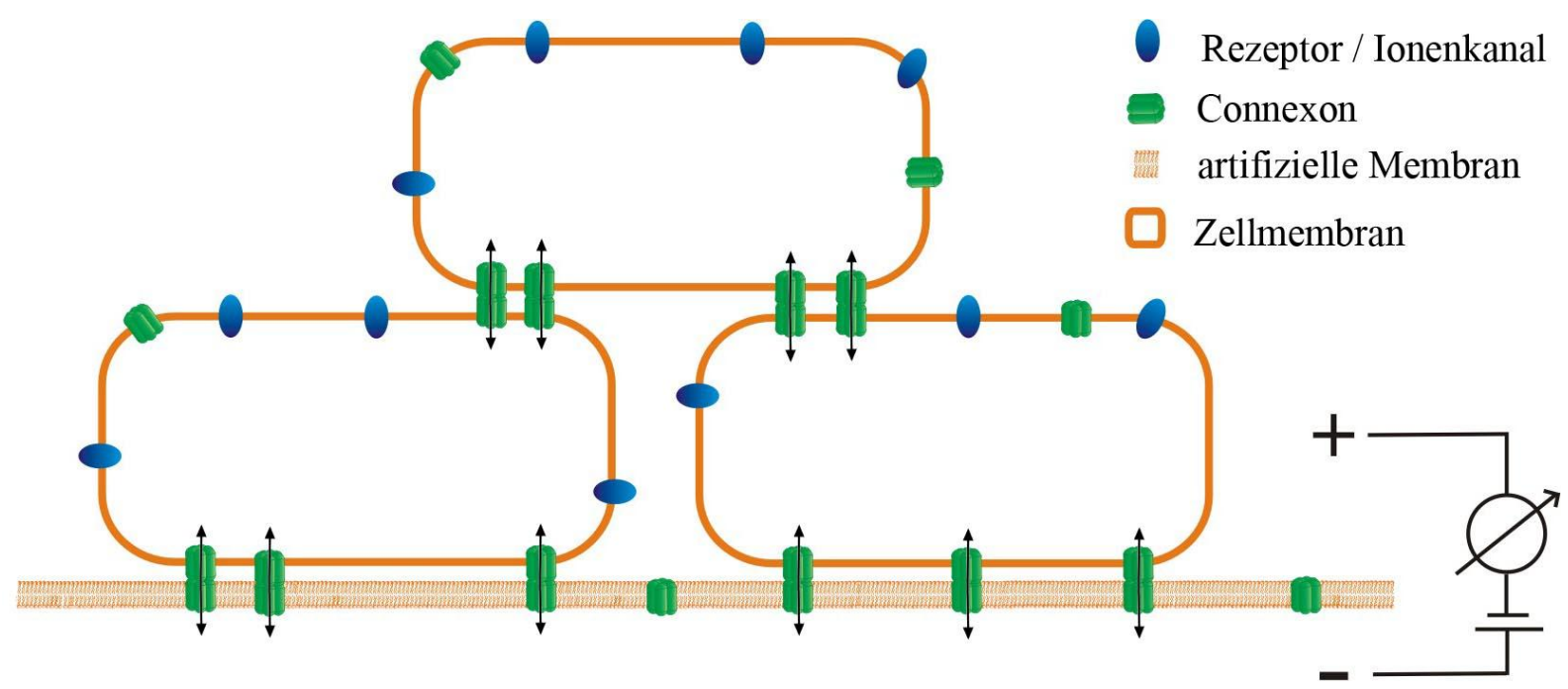

Abb. 2-1: Schematische Darstellung der elektrischen Kopplung von Zellen an porenüberspannende Connexondotierte Lipidmembranen.

In dieser Arbeit soll als Teilvorhaben des Gesamtprojektes mit der Integration von Connexonen in Lipidmembranen auf porösen Oberflächen eine essentielle Grundlage für die Umsetzung des formulierten Gesamtzieles geschaffen werden. Hiefür soll in einem ersten Schritt die funktionelle Rekonstitution der Connexone in artifiziellen Lipidmembranen mit 
einem geeigneten Vesikelassay überprüft werden, welcher gleichzeitig die Möglichkeit zur chemischen bzw. pharmakologischen Modulation der Ionenkanalaktivität bietet. In einem weiteren Schritt soll die Integration der Connexone in porenüberspannenden Membranen etabliert werden. Hierfür werden zwei Strategien verfolgt. Zum einen sollen einzelne Halbkanäle direkt aus einer detergenzhaltigen Lösung in eine bestehende nano-BLM auf Basis poröser Aluminate integriert und mittels voltage-clamp Technik elektrophysiologisch charakterisiert werden. Zum anderen ist geplant den Nachweis der Rekonstitution fluoreszenzmarkierter Connexone in hoher Dichte in einer porenüberspannenden Membran auf Basis eines mikroporösen Substrates mittels konfokaler Laserrastermikroskopie (CLSM) zu erbringen. 


\section{Material und Methoden}

\subsection{Impedanzspektroskopie}

Die Impedanzspektroskopie (IS) ist eine elektrochemische Methode zur Charakterisierung der elektrischen Eigenschaften von Festkörpern, Flüssigkeiten und deren Grenzflächen. Hierzu wird dem zu untersuchenden elektrischen System eine sinusförmige Wechselspannung aufgeprägt, deren Frequenz über einen gewählten Bereich variiert und deren resultierende Stromantwort aufgezeichnet wird. Die Verwendung kleiner Amplituden im Bereich von 10 $30 \mathrm{mV}$ ermöglicht eine zerstörungsfreie Untersuchung fragiler Systeme wie etwa Lipiddoppelschichten.

\subsubsection{Physikalische Grundlagen}

Die Impedanz ist der frequenzabhängige Widerstand $Z(\omega)$ eines Wechselstromkreises. Analog dem ohmschen Gesetz $(\mathrm{R}=\mathrm{U} / \mathrm{I})$ gilt:

$$
Z(\omega)=\frac{U(t, \omega)}{I(t, \omega)}=\frac{U_{0} \exp (i \omega t)}{I_{0} \exp (i(\omega t-\varphi(\omega))}=|Z|(\omega) \exp (i \varphi(\omega))
$$

Bei Anlegen der Wechselspannung $U(t, \omega)$ kann die Stromantwort $I(t, \omega)$ aufgrund von Blindwiderständen eine Phasenverschiebung $\varphi(\omega)$ aufweisen. Die komplexe Impedanz kann in einen Realteil $Z^{\text {Re }}$ und einen Imaginärteil $Z^{\mathrm{Im}}$ unterteillt werden:

$$
Z(\omega)=Z^{\mathrm{Re}}(\omega)+i Z^{\mathrm{Im}}(\omega)
$$

und in Form eines Zeigerdiagramms veranschaulicht werden (Abb. 3-1).

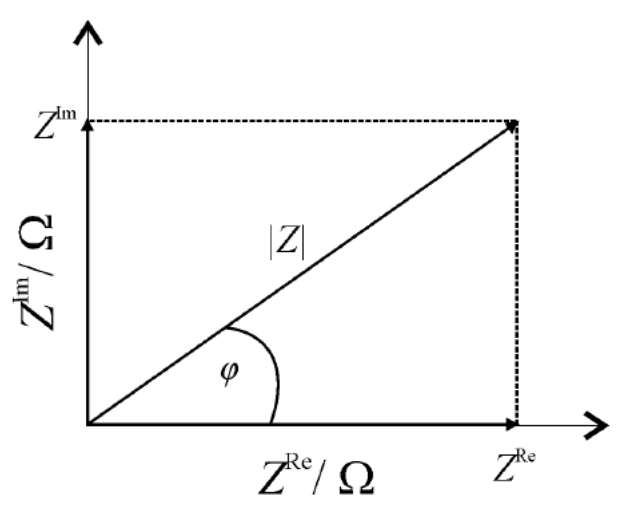

Abb. 3-1: Zeigerdiagramm zur Darstellung der Impedanz in der Gaußschen Zahlenebene. 
$|Z|$ wird als Betrag der Impedanz bezeichnet. Nach Pythagoras ergibt sich folgender Zusammenhang:

$$
|Z|=\sqrt{\left(Z^{\mathrm{Re}}\right)^{2}+\left(Z^{\mathrm{Im}}\right)^{2}}
$$

Die Phasenverschiebung $\varphi(\omega)$ zwischen Strom und Spannung ergibt sich aus:

$$
\varphi=\arctan \left(\frac{Z^{\mathrm{Im}}}{Z^{\mathrm{Re}}}\right)
$$

\subsubsection{Impedanzspektroskopie an Membransystemen}

Im Rahmen dieser Arbeit dient die Impedanzspektroskopie der Charakterisierung festkörperunterstützter, freitragender Membranen. Grundlage für die Auswertung der Daten ist die Generierung geeigneter Ersatzschaltbilder, welche das zu untersuchende System in ausreichendem Maße anhand idealer Komponenten beschreiben.

Das physikalische Modell einer porenüberspannenden Membranen ist in Abb. 3-2 dargestellt.

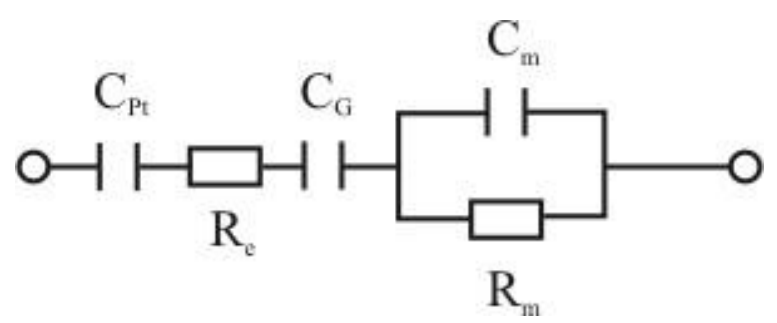

Abb. 3-2: Ersatzschaltkreis zur elektrischen Beschreibung von porenüberspannenden Lipidmembranen.

Die elektrische Beschreibung der Lipidmembran wird durch eine Parallelschaltung aus Membranwiderstand $R_{\mathrm{m}}$ und Membrankapazität $C_{\mathrm{m}}$ erzielt. Der Elektrolytwiderstand $R_{\mathrm{e}}$, die Doppelschichtkapazitäten der Platin/Elektrolyt-Grenzflächen der Messelektroden $C_{\mathrm{Pt}}$ sowie der Membran/Elektrolyt-Grenzfläche $C_{\mathrm{G}}$ vervollständigen den Ersatzschaltkreis.

Die Kapazitäten der elektrochemischen Doppelschichten können im Impedanzspektrum nicht voneinander unterschieden werden. Bei der Reihenschaltung von Kondensatoren ist die Gesamtkapazität gleich dem Kehrwert der Summe der Kehrwerte der Einzelkapazitäten. Da die Kapazität der elektrochemischen Doppelschichten bedeutend größer ist als die der zu untersuchenden Lipidmembran, wird sie vernachlässigt. 


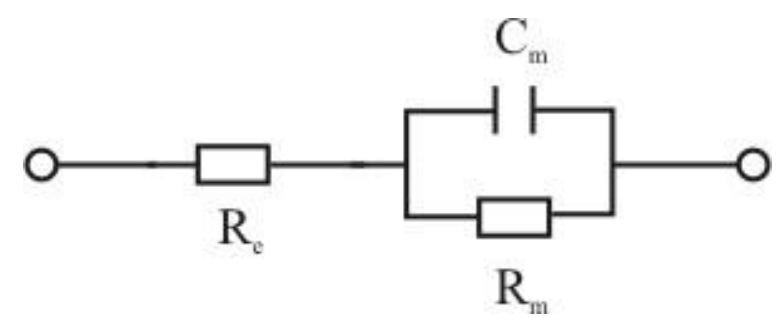

Abb. 3-3: Vereinfachter Ersatzschaltkreis zur elektrischen Beschreibung von Lipidmembranen.

Der in Abb. 3-3 dargestellte vereinfachte Ersatzschaltkreis wird im Folgenden als RRC-Kreis bezeichnet. Kann der Membranwiderstand im beobachteten Frequenzfenster nicht detektiert werden, folgt die Vereinfachung zum RC-Kreis (Abb. 3-4).

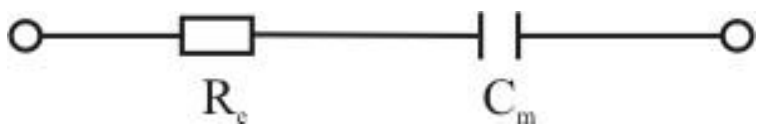

Abb. 3-4: Vereinfachter Ersatzschaltkreis zur elektrischen Beschreibung von Lipidmembranen mit sehr hohem, im angelegten Frequenzbereich nicht detektierbaren, Membranwiderstand.

\subsubsection{Darstellung und Auswertung von Impedanzspektren}

Die Darstellung von Impedanzspektren erfolgt in dieser Arbeit in Form eines BodeDiagramms, wobei der Betrag der Impedanz $|Z|$ und der Phasenwinkel $\varphi$ gegen die Frequenz der angelegten Spannung aufgetragen sind. Für eine idealisierte Membran können im BodeDiagramm drei wesentliche Bereiche (I-III) unterschieden werden.

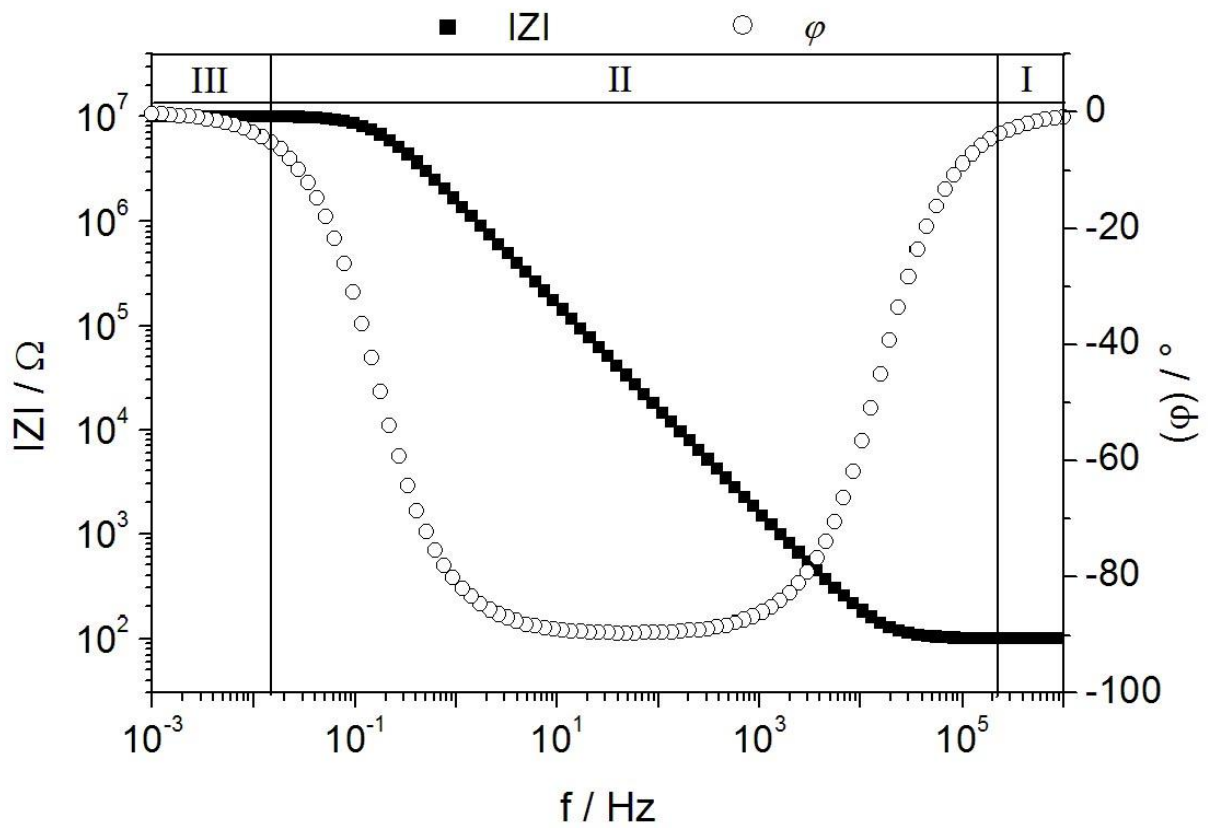

Abb. 3-5: Bode-Plot des Impedanzspektrums einer idealisierten Membran mit $R_{\mathrm{e}}=100 \Omega, C_{\mathrm{m}}=10^{-7} \mathrm{~F}$ und $\mathrm{R}_{\mathrm{m}}=10^{7} \Omega$. 
Bei hohen Frequenzen (Bereich I) sind Wechselstrom und -spannung in Phase $(\varphi=0)$. Der Wert der Impedanz ist ausschließlich durch den Widerstand des Elektrolyten $R_{e}$ bestimmt. Von diesem typischen Impedanzverhalten für ohmsche Widerstände ausgehend, steigt der kapazitive Einfluss des Systems in Bereich II an. Der Betrag der Impedanz $|Z|$ steigt frequenzabhängig und kann mit der Beziehung $\log (|Z|)=-\log (2 \pi f C)$ bestimmt werden. Die Phasenverschiebung erreicht $\varphi=-90^{\circ}$, bis in Bereich III, bei sehr kleinen Frequenzen, der Einfluss des Membranwiderstandes dominiert. Bei einer Phasenverschiebung $\varphi=0$ ist der Membranwiderstand, wie auch der Elektrolytwiderstand, frequenzunabhängig. Der Betrag der Impedanz berechnet sich aus $R_{\mathrm{e}}+R_{\mathrm{m}}$.

Mit dem geeigneten Ersatzschaltkreis erfolgt die nicht-lineare Kurvenanpassung zur Analyse erhaltener Impedanzspektren. Die Beschreibung einer Membran mit den idealen Komponenten ohmscher Widerstand und Kapazität stellt einen Idealfall dar, der bei der Auswertung reeller Daten, aufgrund von Inhomogenitäten des untersuchten Systems, schnell an seine Grenzen stößt. Die Auswertung kann dann durch Verwendung eines constant phase elements (CPE) erfolgen (Abb. 3-6 B), welches in diesen Fällen die Kapazität ersetzt [Cole \& Cole 1941]. Die Impedanz berechnet sich mit:

$$
Z=A^{-1}(i \omega)^{-\alpha}
$$

Der Parameter $\alpha$ ist hierbei ein Maß für die Abweichung vom idealen Verhalten des Systems und wird in einem Bereich von 0 bis 1 angegeben. $A$ trägt die Einheit $\mathrm{Fs}^{\alpha-1}$ und kann im Falle eines idealen Systems $(\alpha=1)$ mit der Kapazität $C$ gleichgesetzt werden. Die Berechnung der Kapazität nicht idealer Systeme mit $\alpha<1$ erfolgt nach Jovic [2003]:

$$
C=A\left(\omega_{\max } "\right)^{\alpha-1}
$$

Hierbei ist $\omega_{\max }$ die Frequenz, bei welcher der Betrag des Imaginärteils $Z^{\mathrm{Im}}$ bei einer Auftragung in Abhängigkeit von der Kreisfrequenz $\omega$ maximal wird (siehe Beispiel Abb. 3-6 A). 


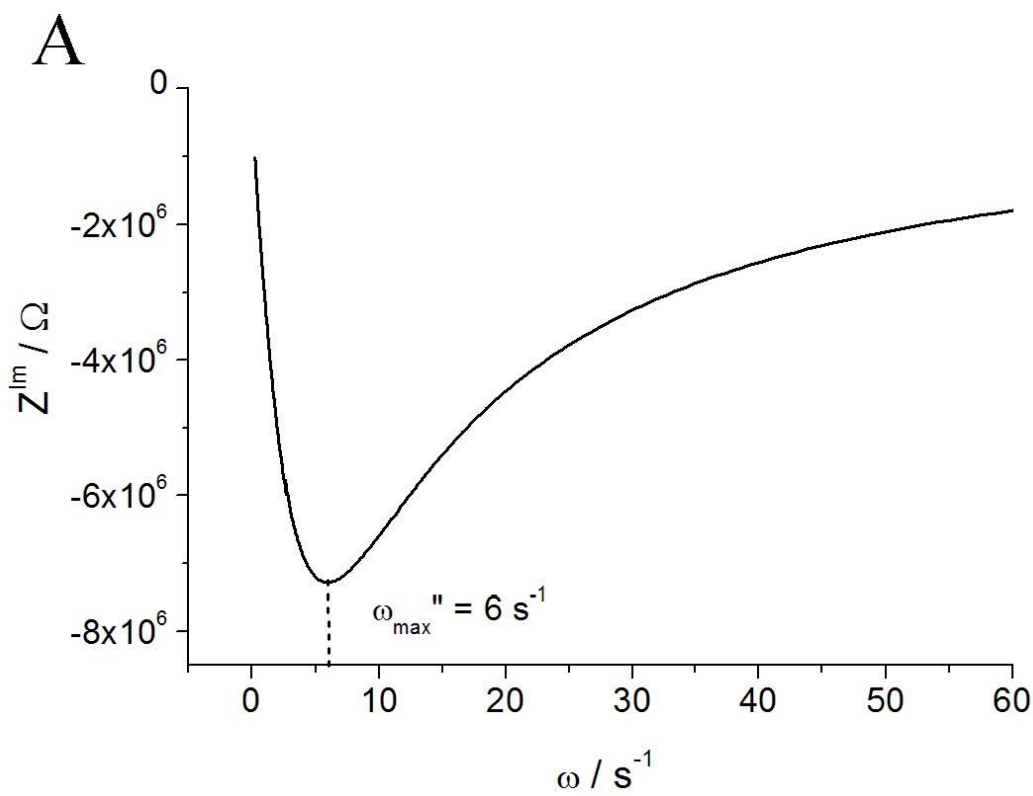

$\mathrm{B}$

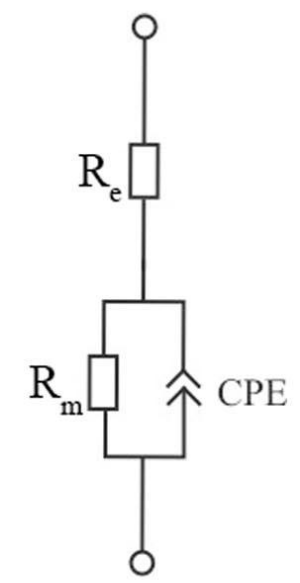

Abb. 3-6: (A) Exemplarische Bestimmung von $\omega_{\max }$ nach Jovic [2003]. (B) Ersatzschaltkreis zur Beschreibung nicht idealen Verhaltens von Membranen mittels CPE.

Durch die Verwendung eines CPE stimmt das Ergebnis der Anpassung besser mit den Messpunkten überein. Zur Aufnahme der Daten wird ein Frequenzganganalysator (Impedance Gain-Phase Analyser) SI 1260 in Kombination mit dem Dielectric Interface SI 1296, Solartron Instruments) bestehend aus Generator und Analysator verwendet. Die Steuerung erfolgt über einen PC mit der Software ZPlot.

\subsubsection{Parameter und Messkammer}

In dieser Arbeit wird die Impedanzspektroskopie zur Charakterisierung porenüberspannender Membranen auf Basis poröser Aluminate verwendet. Der Generator appliziert hierbei eine sinusförmige Spannungsamplitude (peak to peak) von $30 \mathrm{mV}$ in einem Frequenzbereich von $10^{-3}-10^{6} \mathrm{~Hz}$. Der Analysator detektiert die Stromantwort des Systems. Über einen Computer werden die gewonnenen Daten mittels ZView analysiert. Weiterhin kann der Membranbildungsprozess bei der Herstellung von nano-BLMs mittels painting-Technik zeitaufgelöst bei einer konstanten Frequenz von $10^{6} \mathrm{~Hz}$ beobachtet und dargestellt werden.

Die Ausbildung von nano-BLMs erfolgt in einem Zwei-Kammer-Messsystem. Die funktionalisierten porösen Aluminate sind mit $3.1 \mathrm{~mm}$ Viton-Dichtringen (Fahrenholz $\mathrm{GmbH}$ ) zwischen zwei gleich großen, mit Elektrolyt gefüllte Teflonkammern $(\mathrm{V}=1.5 \mathrm{ml})$ gespannt (Abb. 3-7). 


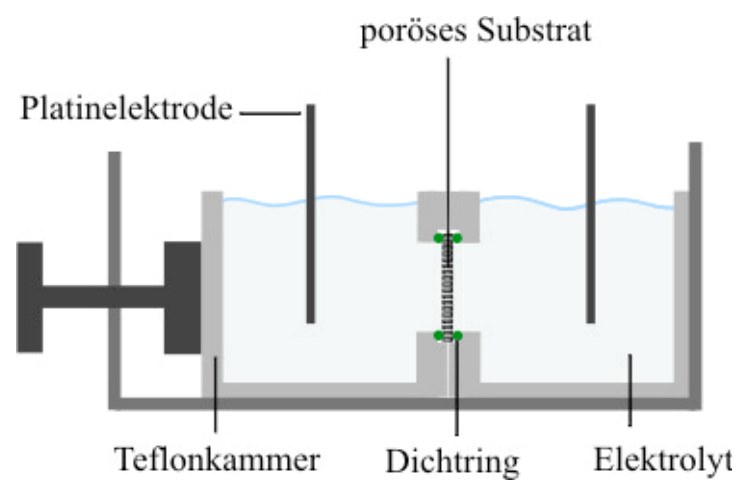

Abb. 3-7: Schematische Darstellung der Messeinheit zur Herstellung von nano-BLMs mittels painting-Technik.

Als Elektroden dienen zwei platinierte Platindrähte. Nach Herstellung und Eignungsprüfung der nano-BLM werden in diesen Messeinheiten die voltage-clamp Experimente durchgeführt. 


\subsection{Einzelkanalmessungen}

Im Rahmen dieser Arbeit werden Ionenkanäle in artifiziellen porenüberspannenden Membranen rekonstituiert, deren ohmscher Widerstand im G $\Omega$-Bereich liegt. Durch Anlegen transmembraner Spannungen im mV-Bereich werden im Falle eines aktiven Kanals transmembrane Ionenströme in der Größenordnung einiger pA induziert. Um diese Leitfähigkeit zu detektieren, bedarf es einer sehr sensitiven Messtechnik, die zusätzlich eine hochfrequente Datenerfassung im $\mu$ s-Bereich gewährleistet.

\subsubsection{Voltage-clamp Technik}

Die voltage-clamp Technik wurde in der Mitte des letzten Jahrhunderts von K. Cole entwickelt [Cole 1949]. Hierbei wird die angelegte Membranspannung $U_{\mathrm{m}}$ durch einen negativen Rückkopplungsmechanismus mit Hilfe eines kompensatorischen Stroms auf einen konstanten vorgegebenen Wert fixiert [BLT]. Wird die Leitfähigkeit $G$ der Membran durch die Aktivität einzelner Kanäle erhöht bzw. der Membranwiderstand verkleinert, muss der Kompensationsstrom zur Aufrechterhaltung des Membranpotentials erhöht werden und entspricht damit in seiner Höhe dem kanalinduzierten Transmembranstrom $I_{\mathrm{m}}$. Dieser Zusammenhang ist durch das ohmsche Gesetz definiert.

$$
U_{\mathrm{m}}=\text { konst }=R_{\mathrm{m}} I_{\mathrm{m}} \quad \text { und } \quad G=\frac{1}{R_{\mathrm{m}}}=\frac{I_{\mathrm{m}}}{U_{\mathrm{m}}}
$$

\subsubsection{Messaufbau}

Die verwendete Messkammer entspricht der in Abb. 3-7 dargestellten Anordnung und ist zur elektrostatischen Abschirmung in einem geerdeten Faraday-Käfig untergebracht. Dieser ist durch einen schwingungsgedämpften Tisch von mechanischen Vibrationen und Erschütterungen der Umgebung entkoppelt. $\mathrm{Ag} / \mathrm{AgCl}$-Elektroden tauchen in die Elektrolytlösung der beiden Kammern. Die cis-Kammer enthält die Arbeitselektrode, die trans-Kammer die Referenzelektrode (geerdet). 


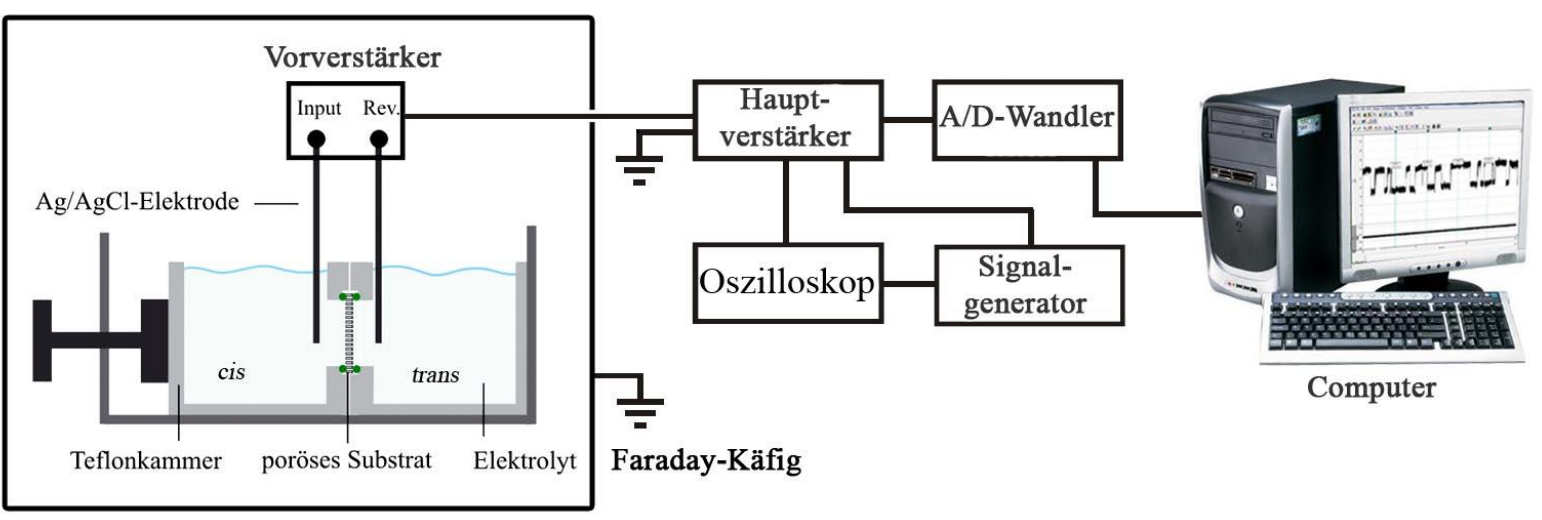

Abb. 3-8: Schematische Darstellung des Aufbaus von voltage-clamp Einzelkanalmessungen.

Zwischen diesen beiden Elektroden wird dem System über einen Signalgenerator ein definiertes Membranpotential aufgeprägt. Die Elektroden sind mit einem Vorverstärker, der Peltierelement-gekühlten Headstage, verbunden. Dieser misst und verstärkt das tatsächliche Membranpotential und leitet das Signal aus dem Faraday-Käfig an den Hauptverstärker, welcher zusätzlich mit dem Signalgenerator verbunden ist. Das gemessene Membranpotential wird mit dem voreingestellten Membranpotential verglichen. Abweichungen werden verstärkt und über die Arbeitselektrode kompensiert. Über diese Rückkopplungsschleife generierte Kompensationsströme werden über einen A/D-Wandler digitalisiert, am PC in Abhängigkeit von der Zeit ausgegeben und aufgezeichnet.

\subsubsection{Messbedingungen}

In dieser Arbeit wird mit dem Axopatch 200B Amplifier (Axon Instruments) mit einer Ausgabeverstärkung von $10 \mathrm{mV} / \mathrm{pA}$ und einer maximalen Abtastrate von $10 \mathrm{kHz}$ gearbeitet. Hierbei wird im V-Clamp-Modus ein Membranpotential zwischen 150 und $-150 \mathrm{mV}$ appliziert. Zuvor wird die Offset-Spannung des Systems auf Null reguliert. Vor Digitalisierung mit dem A/D-Wandler DIGIDATA 1322A (Axon Instruments), wird das Messsignal mit einem $1 \mathrm{kHz}$ 4-Pol-Tiefpass-Besselfilter gefiltert. Zur Visualisierung und Aufzeichnung der Daten wird die Software pClamp 9.1 (Axon Instruments) verwendet, die Auswertung erfolgt mit der Software Clampfit 9.2 (Axon Instruments). Die aufgezeichneten Signale werden nachträglich mit einem $100 \mathrm{~Hz}$ Gauß-Tiefpassfilter gefiltert. 


\subsubsection{Auswertung von Einzelkanaldaten}

Für die Auswertung von Einzelkanalereignissen kann eine Vielzahl von Methoden verwendet werden. Ziel ist es, aus den aufgezeichneten Daten ein Maximum an Information zu extrahieren, um die untersuchten Ionenkanäle möglichst genau elektrophysiologisch anhand von Leitfähigkeit, Öffnungsdauer und Öffnungswahrscheinlichkeit charakterisieren zu können. Dies kann zudem bei verschiedenen Membranpotentialen, unterschiedlichen Puffern oder variierenden Membranzusammensetzungen untersucht werden.

\section{Verwendung von Punktamplituden-Histogrammen}

Werden die digitalisierten Datenpunkte einer Messung zusammen in einem normierten Histogramm dargestellt, erhält man ein so genanntes Punktamplituden-Histogramm (Abb. 3-9 A und B, rechts). Durch Anpassung einer Gaußfunktion an diese Daten, können Informationen über die gemittelte Leitfähigkeit des Kanals und dessen Öffnungswahrscheinlichkeit im Beobachtungszeitraum gewonnen werden. Die Leitfähigkeit $G$ ergibt sich bei bekannter Transmembranspannung $U_{\mathrm{m}}$ direkt aus der Differenz beider Maxima. Die Öffnungswahrscheinlichkeit wird aus der Fläche der Gaußverteilungen gewonnen. Nachteil dieser Methode ist, dass hiermit lediglich die gemittelte Leitfähigkeit aller im Beobachtungszeitraum aufgezeichneten Leitfähigkeitsstufen erhalten wird. Man könnte zwar jedes einzelne Ereignis nach dieser Methode auswerten, doch reichen häufig die ermittelten Datenpunkte nicht aus, um ein eindeutiges Histogramm zu erhalten. Zusätzlich wäre der Aufwand einer solchen Analyse ernorm und eignet sich nicht für die statistische Auswertung von Einzelkanalereignissen.

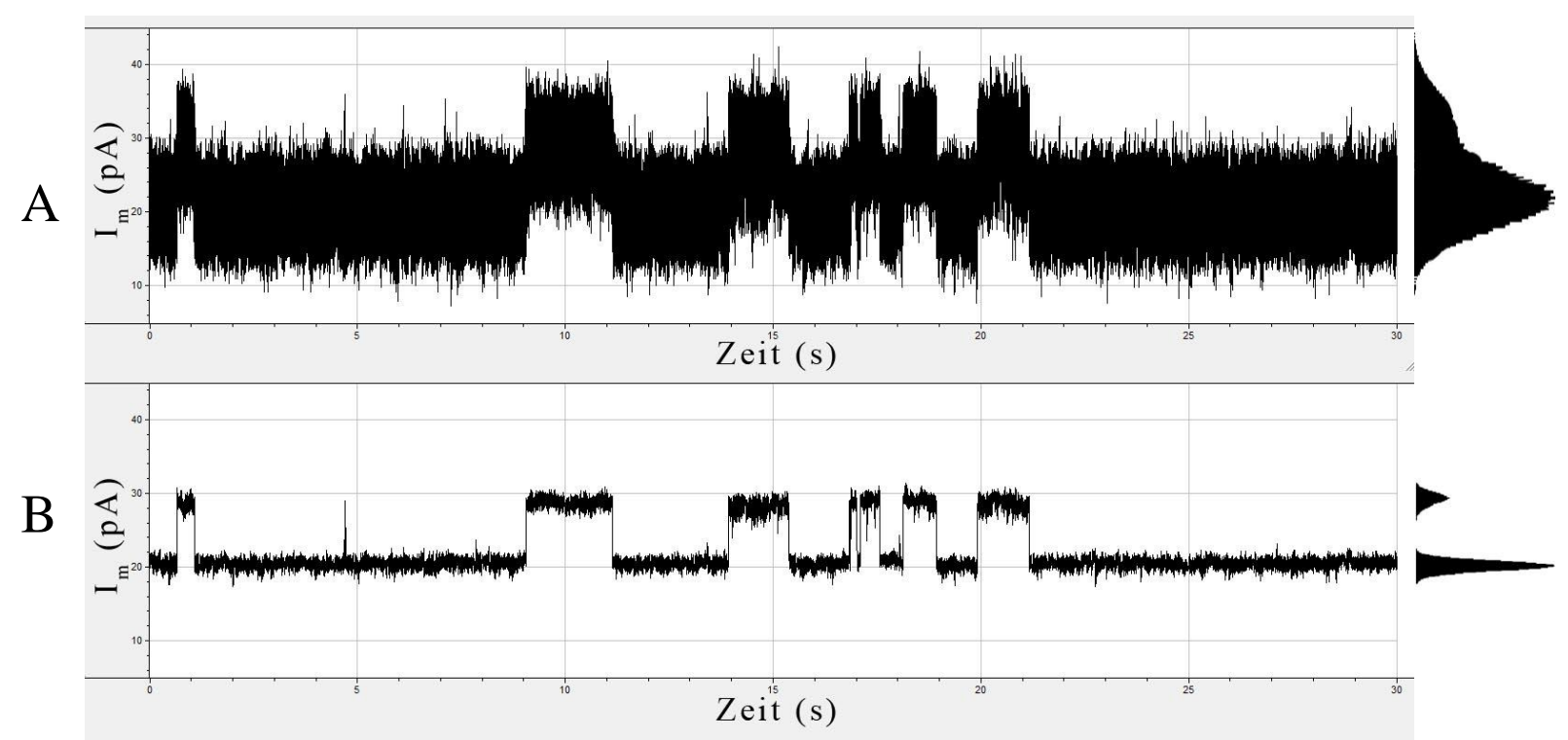

Abb. 3-9: Analyse von Einzelkanalereignissen mittels Punktamplituden-Histogramm. (A) Datensatz einer voltage-clamp Messung nach Filtern mit einem 4-Pol-Tiefpass-Besselfilter und Histogramm. (B) Gleicher Datensatz nach digitaler Nachfilterung mit einem $100 \mathrm{~Hz}$ Gauß-Tiefpassfilter und Histogramm. 
Abb. 3-9 verdeutlicht zudem, warum die mit einem $1 \mathrm{kHz}$ 4-Pol-Tiefpass-Besselfilter vorgefilterten Daten für diese Methode digital mit einem $100 \mathrm{~Hz}$ Gauß-Tiefpassfilter nachgefiltert werden müssen. Bereits vor dem Filtern sind stufenartige Anstiege des Transmembran- bzw. des dazu äquivalenten Kompensationsstromes erkennbar. Das Punktamplituden-Histogramm aller Datenpunkte zeigt zwei ineinander übergehende, nicht Basislinien-getrennte Normalverteilungen, deren Datenanpassung mittels Gaußfunktionen nur mit unzureichender Genauigkeit erfolgen kann. Durch die digitale Nachfilterung werden zwei klar voneinander getrennte Verteilungen erhalten, die nach Kurvenanpassung für den aufgenommenen Datensatz hinreichend genaue Ergebnisse liefern.

Ein Nachteil des Nachfilterns ist der Verlust von Information. Nach Walter [2004] ist die detektierbare Minimaldauer von Ereignissen nach $t_{\mathrm{R}}=0.35 / f$ von der Filterfrequenz $f$ abhängig. So wird bei einer Datenerfassung von $10 \mathrm{kHz}$ zwar alle $100 \mu$ s ein Datenpunkt aufgenommen, bei Verwendung eines 4-Pol-Tiefpass-Besselfilter können jedoch nur Signale die länger als $350 \mu$ s sind mit einer vollständigen Amplitude aufgezeichnet werden. Wird das Signal zusätzlich mit einem $100 \mathrm{~Hz}$ Gauß-Tiefpassfilter digital nachgefiltert, können nur noch Ereignisse die länger als $3.5 \mathrm{~ms}$ sind vollständig aufgelöst werden.

\section{Auswertung durch Treshhold-Analyse}

Auch bei dieser Methode bedarf es systembedingt einer digitalen Nachfilterung der aufgezeichneten Datensätze. Mit der Software Clampfit werden den Daten zwei Niveaus vorgegeben (rote Linien Abb. 3-10). Das untere Niveau liegt auf Höhe der Basislinie, bzw. dem Stromverlauf bei geschlossenem Kanal. Die hier detektierten Ströme sind der Leitfähigkeit der Membran bei der angelegten Transmembranspannung zuzuweisen. Bei einer Membran mit einem Widerstand von $10 \mathrm{G} \Omega$ und einem angelegten Membranpotential von $100 \mathrm{mV}$ sollte entsprechend dem ohmschen Gesetz dieses Niveau bei 10 pA verlaufen. Das zweite Niveau wird auf etwa die halbe Höhe der detektierten Ereignisstufen gelegt und dient als Schwellenwert, dessen Überschreitung als Ereignis gewertet wird.

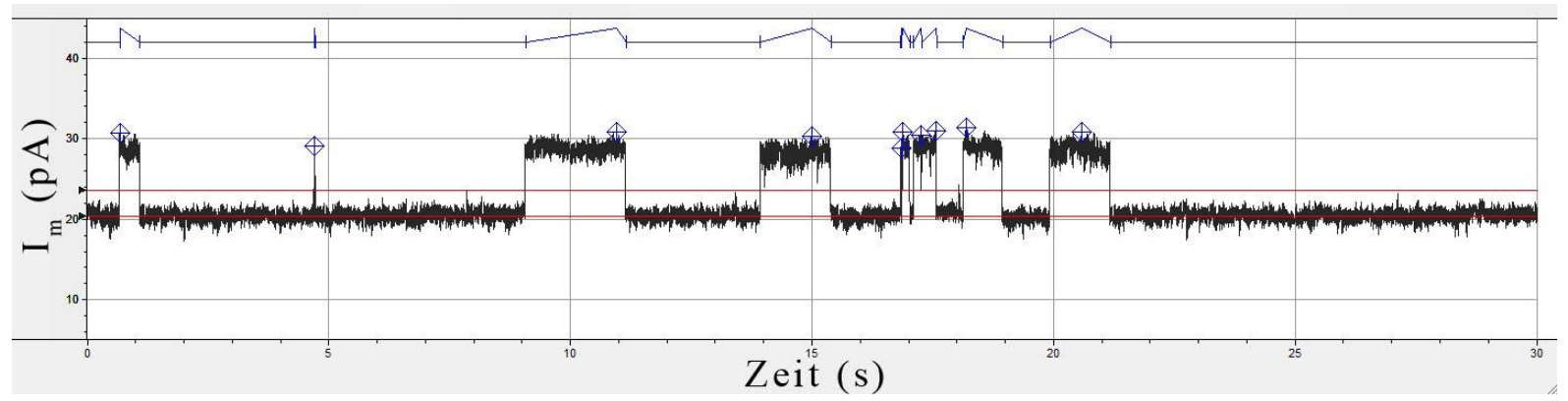

Abb. 3-10: Auswertung von Einzelkanalereignissen mittels Treshold-Analyse. Festlegung der Basislinie und des Schwellenwertes (rote Linien). 
Die Software ermittelt den Zeitpunkt der Überschreitung des oberen Niveaus und bestimmt die Dauer bis zur erneuten Unterschreitung dieses Niveaus, wodurch die Ereignislänge bzw. die Öffnungsdauer einer einzelnen Kanalöffnung ermittelt wird. Zusätzlich wird die Verweildauer bestimmt in der ein Kanal geschlossen ist, sich die Datenpunkte also auf Höhe des unteren Niveaus befinden. Werden alle erhaltenen Verweildauern für beide Zustände, offen und geschlossen, addiert, erhält man die Öffnungswahrscheinlichkeit eines Kanals für den untersuchten Beobachtungszeitraum. Entscheidender Vorteil der Treshhold-Analyse ist, dass hier einzelne Ereignisse hinsichtlich ihrer Öffnungsdauer erfasst werden können. Legt man diese Daten einer Histogrammanalyse zu Grunde, kann zusätzlich die mittlere Öffnungsdauer eines Kanals bestimmt werden. Nachteil dieser Methode ist, dass keine Informationen über die Ereignishöhe einer Kanalöffnung ermittelt werden.

\section{Softwaregestützte Einzelerfassung von Einzelkanalereignissen}

Das Softwarepaket Clampfit bietet weiterhin die Möglichkeit zur Ereignisdetektierung mittels „Single Channel Search“. Hierbei werden in den ebenfalls digital nachgefilterten Datensatz zwei Niveaus (grüne Linien Abb. 3-11) gelegt.

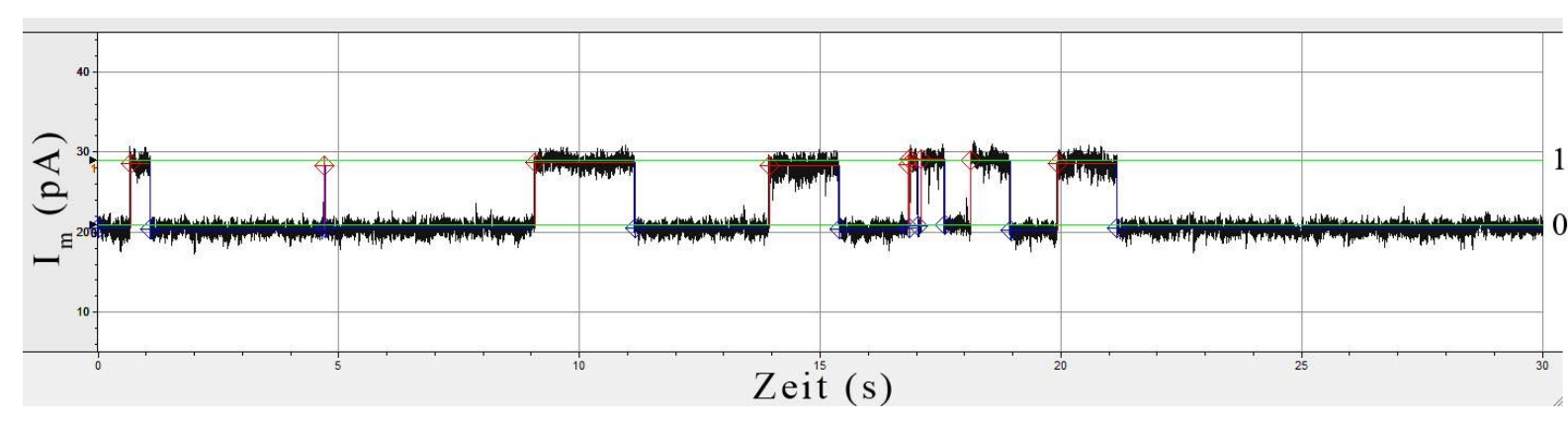

Abb. 3-11: Auswertung von Einzelkanalereignissen mittels Single Channel Search. Vorgegebene Niveaus für offenen und geschlossenen Zustand (grün), Kanal geschlossen (Level $0=$ blau), Kanal offen (Level $1=$ rot).

Das untere Niveau (Level 0) markiert den geschlossenen Zustand des Kanals, das obere Niveau (Level 1) verweist auf den geöffneten Zustand. Hierbei ist darauf zu achten, dass sich bei der Aufzeichnung von Ereignissen mit negativem Membranpotential die Verhältnisse umkehren, d.h., das obere Niveau liegt nun auf Höhe der Basislinie und muss dementsprechend als Level 0 festgelegt werden. Mit diesen Vorgaben ermittelt die Software automatisch die mittlere Höhe der Transmembranströme von Level 0 und Level 1. Aus der Differenz dieser Daten ergibt sich die Ereignishöhe als Stromdifferenz in pA, mit welcher bei bekannter Transmembranspannung die Leitfähigkeit jeder einzelnen Kanalöffnung bestimmt werden kann. Zusätzlich werden die Anfangs- und Endzeitpunkte der gefundenen 
Niveauabschnitte bestimmt. Ein Verlassen von Level 0 wird hierbei als Kanalöffnung gewertet, ein Verlassen von Level 1 als Schließen des Kanals. Aus der Differenz der so erhaltenen Wertepaare können die Verweildauer einzelner Zustände bzw. die Öffnungsdauer bestimmt werden. Folglich kann mit Hilfe dieser Methode sowohl die Leitfähigkeit einzelner Kanalereignisse als auch die Öffnungswahrscheinlichkeit und die mittlere Öffnungsdauer effizient ermittelt werden. Für die Auswertung der Einzelkanalereignisse in dieser Arbeit wird daher mit dieser Methode gearbeitet. 


\subsection{UV/VIS-Spektroskopie}

Die Wechselwirkung monochromatischer elektromagnetischer Strahlung mit Materie bildet die Grundlage der Spektroskopie. Werden elektromagnetische Wellen des ultravioletten (UV, $1-380 \mathrm{~nm}$ ) und des sichtbaren (VIS, $380-780 \mathrm{~nm}$ ) Bereichs verwendet, spricht man von UV/VIS-Spektroskopie. Die Wechselwirkung beruht auf der Absorption der Strahlung durch Chromophore in organischen oder anorganischen Verbindungen. Hierbei werden Moleküle durch elektronische Übergänge vom energiearmen Grundzustand $S_{0}$ in einen angeregten Zustand $S_{1}$ überführt. Dies wird in der Regel durch den Übergang eines Elektrons aus dem höchsten besetzten Molekülorbital (highest occupied molecular orbital, HOMO) in das niedrigste unbesetzte Molekülorbital (lowest unoccupied molecular orbital, LUMO) ermöglicht. Die Energie des absorbierten Photons muss genau der Energiedifferenz beider Energiezustände entsprechen. Die Energie eines Photons kann mit der Einstein-BohrGleichung berechnet werden:

$$
E=h f=\frac{h c}{\lambda}
$$

Hierbei ist $h$ das Planksche Wirkungsquantum, $c$ die Lichtgeschwindigkeit, $f$ die Frequenz und $\lambda$ die Wellenlänge der elektromagnetischen Strahlung [Atkins 2001].

Die Rückkehr des angeregten Moleküls in den Grundzustand erfolgt durch Energieabgabe. Erfolgt dies strahlungslos, z.B. durch Schwingungen, spricht man von Relaxation. Wird die Energie in Form einer elektromagnetischen Strahlung abgegeben, der Emission, können zwei Strahlungsübergange unterschieden werden. Den direkten Übergang von $S_{1}$ in $S_{0}$ nennt man Fluoreszenz (genauer siehe 3.4). Der Phosphoreszenz geht eine Deaktivierung des angeregten Singulett-Zustandes $S_{1}$ durch Spinumkehr in den angeregten Triplett-Zustand $T_{1}$ voraus, welcher strahlungslos erfolgt (intersystem crossing). Diese Zusammenhänge können durch ein vereinfachtes Jablonski-Diagramm dargestellt werden [Dick \& Yersin] (Abb. 3-12). 


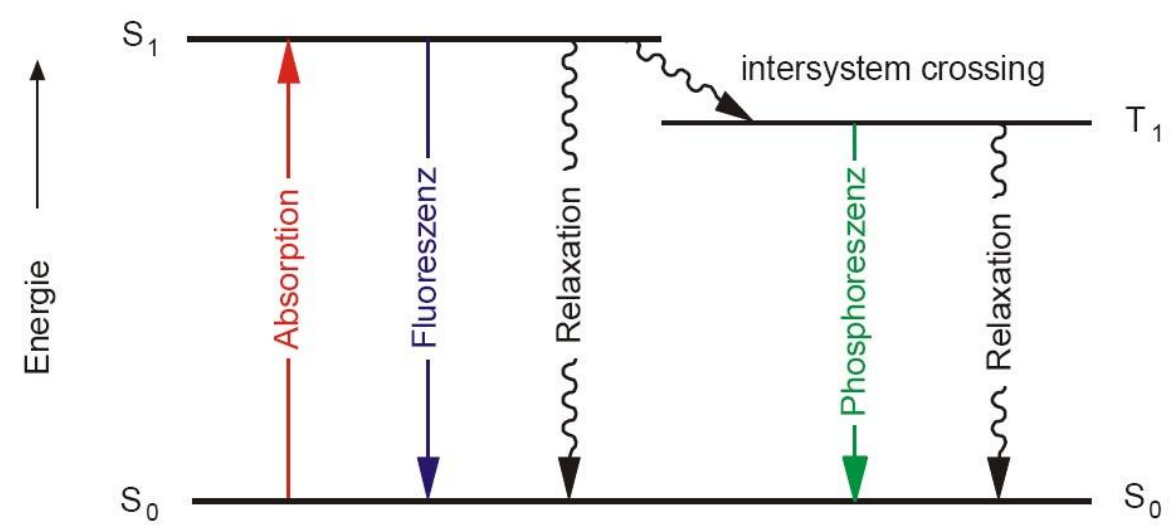

Abb. 3-12: Vereinfachtes Jablonski-Diagramm [Dick \& Yersin].

Die beschriebene Absorption wird zusammen mit der Beugung, Streuung und Reflexion zur Extinktion $E$ zusammengefasst. Diese ist ein Maß für die Abschwächung einer elektromagnetischen Strahlung in einem Medium. Die Extinktion ist abhängig von der Wellenlänge und kann mit dem Lambert-Beerschen Gesetz beschrieben werden, welches bereits im Jahr 1729 entdeckt [Bouguer 1729] und 1852 [Beer 1852] zu nachstehender Form erweitert wurde:

$$
E=\lg \left(\frac{I_{0}}{I}\right)=\varepsilon \cdot c \cdot d
$$

Hierbei ist $I_{0}$ die Intensität des eingestrahlten Lichts, $I$ die Intensität des austretenden Lichts, $c$ die Konzentration der absorbierenden Substanz, $\varepsilon$ der Wellenlängen-abhängige Absorptionskoeffizient und $d$ die Dicke der durchstrahlten Probe [Meyer 2008]. Die Messapparatur (Abb. 3-13) wird häufig durch eine Anordnung realisiert, in welcher eine Strahlungsquelle elektromagnetische Wellen eines bestimmten Wellenlängenbereiches emittiert. Das durch eine Blende eingegrenzte Strahlenbündel wird beim Durchtritt des Monochromators (hier Prisma) stufenlos aufgefächert. Die zweite Blende filtert ein monochromatisches Strahlenbündel heraus, welches die Probe passiert. Das Strahlenbündel wird durch Blende 3 von Streustrahlung getrennt und erreicht, abgeschwächt durch Extinktion, den Photo-Detektor. 


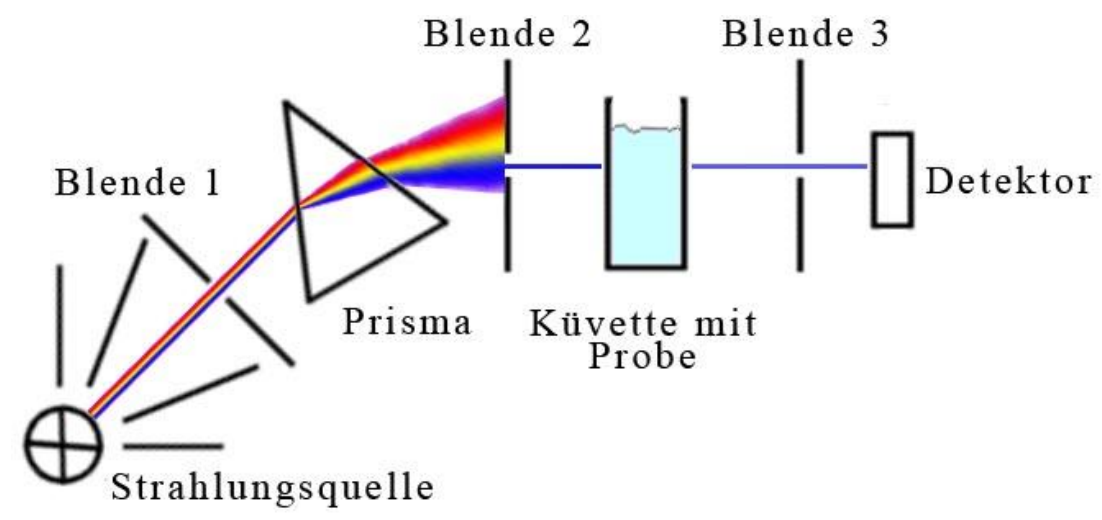

Abb. 3-13: Schematischer Aufbau eines Einstrahl-UV/VIS-Spektrometers.

Neben den beschriebenen Einstrahlphotometern werden häufig auch Zweistrahlphotometer verwendet. Hierbei wird das nach Blende 2 erzeugt monochromatische Strahlenbünden über Strahlenteiler und Spiegel durch die Referenzprobe zum Detektor geleitet. In dieser Arbeit wird mit dem V-650 (Jasco) Spektrometer gearbeitet. Datenerfassung und Teilauswertung erfolgen mit der Software Spectra Manager (Jasco). 


\subsection{Konfokale Laserrastermikroskopie}

Das Konfokale Laserrastermikroskop (confocal laser scanning microscope, CLSM) ist eine Weiterentwicklung klassischer Epifluoreszenzmikroskope. Sie basieren auf dem gleichen Prinzip, haben aber entscheidende Vorteile.

Epifluoreszenzmikroskope (Abb. 3-15 A) gleichen im Aufbau einem Auflichtmikroskop oder einem inversen Mikroskop. Eine Strahlenquelle emittiert Licht eines bestimmten Frequenzspektrums. Ein optischer Anregungsfilter selektiert Licht eines bestimmten Wellenlängenbereiches, welches über einen Strahlteiler und ein Objektiv auf die fluoreszierende Probe geleitet wird. Das emittierte längerwellige Fluoreszenzlicht wird im Objektiv gebündelt, passiert einen Strahlteiler und wird über einen Emissionsfilter in das Okular oder einen entsprechenden Photodetektor geleitet (Abb. 3-16 A). Diese Art der Mikroskopie basiert auf der Fluoreszenz so genannter Fluorophore oder Fluorochrome. Hierbei unterscheiden sich die Intensitätsmaxima des Absorptionsspektrums von denen des Emissionsspektrums. Die Ursache dieser Erscheinung kann mit einer quantenmechanischen Gesetzmäßigkeit, dem Frank-Condon-Prinzip, erklärt werden (Abb. 3-14).

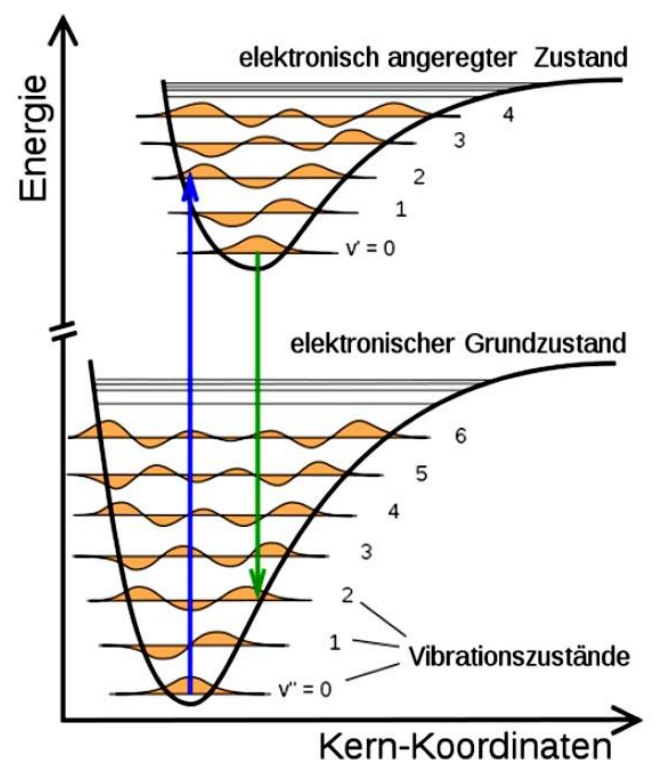

Abb. 3-14: Vibronische Übergänge zur Veranschaulichung des Franck-Condon-Prinzips als Ursache der Stokesverschiebung bei der Fluoreszenz [Gabriel 2007].

Der Fluorophor wird durch Absorption eines Photons mit der Anregungswellenlänge vom energiearmen Grundzustand $S_{0}$ in einen höheren Schwingungszustand eines elektronisch angeregten Zustand $S_{1}$ gleicher Multiplizität überführt. Durch strahlungsfreie Relaxation wird dieses Systems zunächst in den Schwingungsgrundzustand $(v=0)$ überführt. Es folgt der Übergang in einen schwingungsangeregten elektronischen Grundzustand. Die emittierten 
Photonen haben dabei eine im Vergleich zu den absorbierten Photonen geringere Energie [Atkins 2001]. Durch diese Stokesverschiebung werden also Photonen geringerer Frequenz bzw. vergrößerter Wellenlänge emittiert, welche mit einem Dichroitischen Spiegel (Strahlteiler) vom Anregungslicht getrennt werden können. Das Prinzip des optischen Strahlteilers basiert dabei auf der Interferenz von Lichtwellen an einer Abfolge mehrerer dielektrischer Schichten. Mikroskope dieses Typs beleuchten das gesamte Präparat. Die emittierte Fluoreszenz setzt sich daher aus der überlagerten Abbildung der Fokalebene und der Ebenen außerhalb des Fokus zusammen. Durch diese Überlagerungen ist die Auflösung begrenzt.

Bei der Konfokalmikroskopie (Abb. 3-15 B) wird im Gegensatz zur Epifluoreszenzmikroskopie zu jedem Zeitpunkt nur ein Teil der Probe in einer bestimmten Ebene beleuchtet. Um ein Gesamtbild der Probe zu erhalten, wird diese durch so genannte Scan-Spiegel Punkt für Punkt abgerastert. Da hierbei meist Laser zum Einsatz kommen, wird diese Methode auch Konfokale Laserrastermikroskopie (confocal laser scanning microscopy, CLSM) genannt. Durch Einbringen einer Illuminationslochblende wird die Schärfentiefe soweit herabgesetzt, dass nur ein scheibenförmiger Objektbereich beleuchtet wird. Dies verringert die Beleuchtungsintensität außerhalb des Fokus und vermindert so die Überlagerung von Fluoreszenzen aus verschiedenen Ebenen. Eine zweite Lochblende in der aufnehmenden Optik minimiert zusätzlich den Anteil emittierter Fluoreszenzen aus Objektebenen außerhalb der Fokusebene am Detektor, da diese nicht auf die Lochblende fokussiert werden [Clarke et al. 1995; Roderfeld et al.2003].
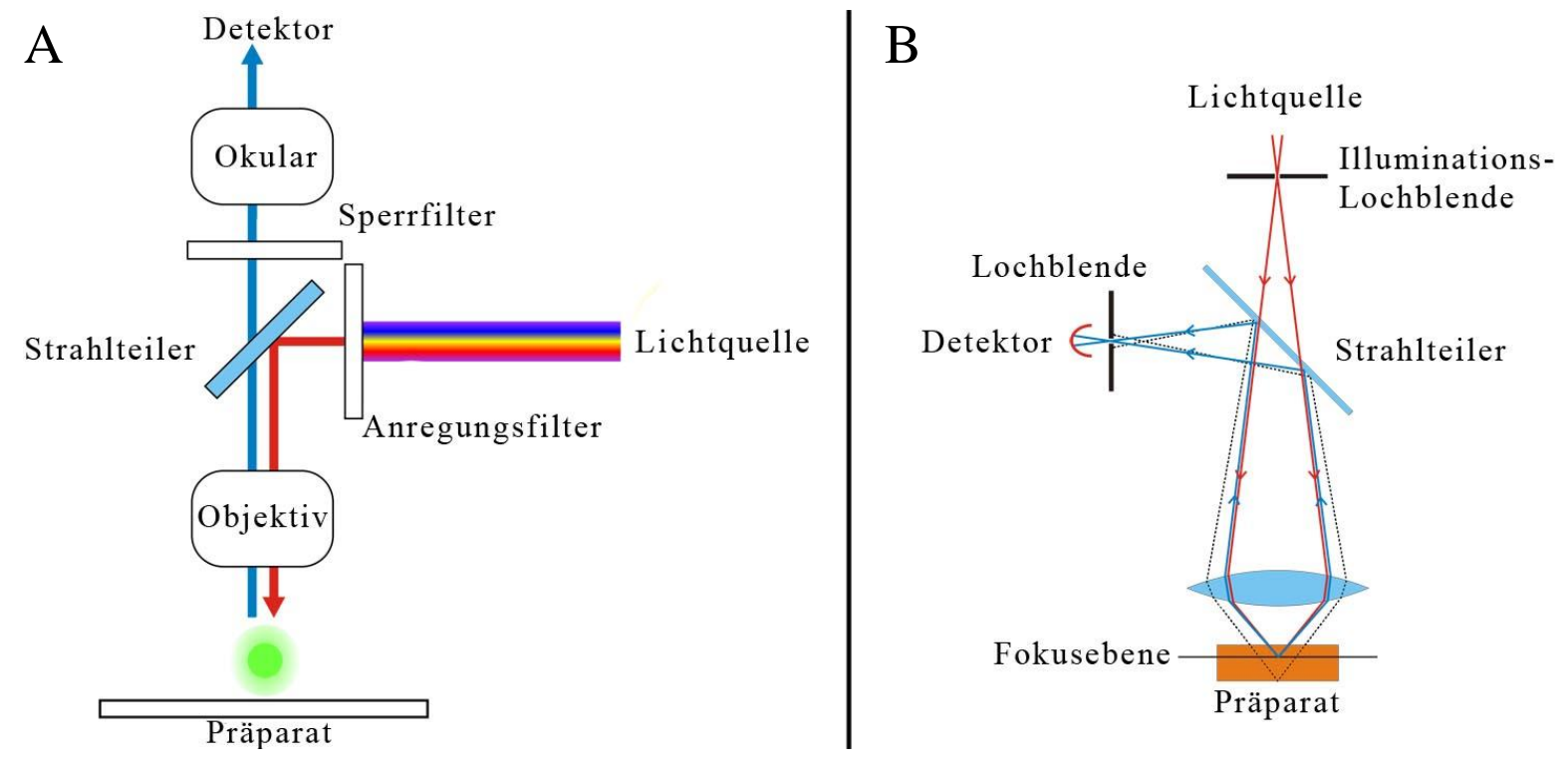

Abb. 3-15: Aufbau und Strahlengang eines Epifluoreszenzmikroskops [Mühlpfordt 2008] (A) und eines Konfokalmikroskops [Danh 2006] (B). 
Mit diesem System kann in der Praxis entlang der optischen Achse eine Auflösung von etwa $700 \mathrm{~nm}$ und parallel zur optischen Achse von $300 \mathrm{~nm}$ erzielt werden [Esa et al. 2000]. Dies ermöglicht optische Serienschnitte, aus denen 3D Grafiken generiert werden können. Zudem ist diese Methode der Mikroskopie nicht invasiv, wodurch biologische Prozesse in vitro verfolgt werden können.

In dieser Arbeit wird das LSM 710 Examiner (Zeiss) verwendet. Als Lichtquellen dienten Laser im Bereich von 408 - 568 nm.

\subsubsection{FRAP}

Das verwendete CLSM bietet die Möglichkeit zur Durchführung von FRAP (fluorescence recovery after photobleaching) Experimenten. Diese werden zur Bestimmung der lateralen Mobilität von Membrankomponenten wie Lipiden oder Proteinen verwendet. Die Lipide sind hierfür kovalent an einem entsprechenden Fluorophor gebunden, die Proteine können z.B. mittels fluoreszenzmarkierter Antikörper detektiert werden. Durch einen hochintensiven Laserimpuls wird der Fluorophor in einer definierten kreisförmigen Region, der ROI (region of interest), vollständig fotochemisch zerstört. Durch zweidimensionale laterale Diffusion innerhalb der Membran regeneriert die Fluoreszenzintensität innerhalb der ROI in Abhängigkeit von der Zeit. Die Datenauswertung basiert auf den theoretischen Beschreibungen von Axelrod et al. [1976]. Hierbei wird von einer zweidimensionalen Diffusion eines homogen verteilten Fluorophors innerhalb der Membran ausgegangen. Dem Bleichen des Fluorophors wird eine irreversible Reaktion erster Ordnung zu Grunde gelegt. Mit einem Gauß-förmigen Intensitätsprofil des Bleichspots lässt sich nach:

$$
F_{\mathrm{K}}(t)=\frac{q P_{0} C_{0}}{A} \sum_{n=0}^{\infty}\left[\frac{(-K)^{n}}{n !}\right] \cdot\left[1+n\left(1+\frac{2 t}{\tau_{\mathrm{D}}}\right)^{-1}\right]
$$

die Fluoreszenzintensität zum Zeitpunkt $t$ nach Beenden des Bleichens berechnen. Hierbei ist $q$ die Gesamtquantenausbeute, $P_{0}$ die Gesamtlaserleistung, $C_{0}$ die homogen verteilte Ausgangskonzentration des ungebleichten Fluorophors, $A$ der Abschwächungsfaktor des Laserstrahls zwischen dem Bleichen und dem anschließenden Messen der Intensität und $K$ ist ein Bleichparameter, zusammengesetzt aus dem Produkt der Bleichdauer und der Geschwindigkeitskonstante der Reaktion. Diese Gleichung gilt für alle $K$ und $t$ und wird für die Kurvenanpassung im Rahmen der Auswertung der FRAP-Experimente verwendet. Die 
damit berechnete charakteristische Diffusionszeit $\tau_{\mathrm{D}}$ entspricht der Zeit, die benötigt wird, um nach dem Bleichen auf $50 \%$ der final erreichten Fluoreszenzintensität anzusteigen. Der Diffusionskoeffizient berechnet sich mit:

$$
D=\frac{\omega^{2}}{4 \tau_{\mathrm{D}}}
$$

Hierbei ist $\omega$ der Gauß-Radius des Bleichspots, welcher aus der Anpassung einer GaußFunktion an das Intensitätsprofil des Bleichspots erhalten wird. Dieser Wert entspricht der Halbwertsbreite des Gauß-Profils bei einer Intensität auf Höhe von $\mathrm{e}^{-2}$ des normierten Profilmaximums. Für die korrekte Auswertung der FRAP-Experimente muss neben der ROI zusätzlich der Intensitätsverlauf einer Region außerhalb des Bleichspots aufgezeichnet werden (background). Dieser Bereich dient der Korrektur der recovery-Kurve der ROI und berücksichtigt das Bleichen der Hintergrundfluoreszenz im Verlauf der Messung (Abb. 3-16).
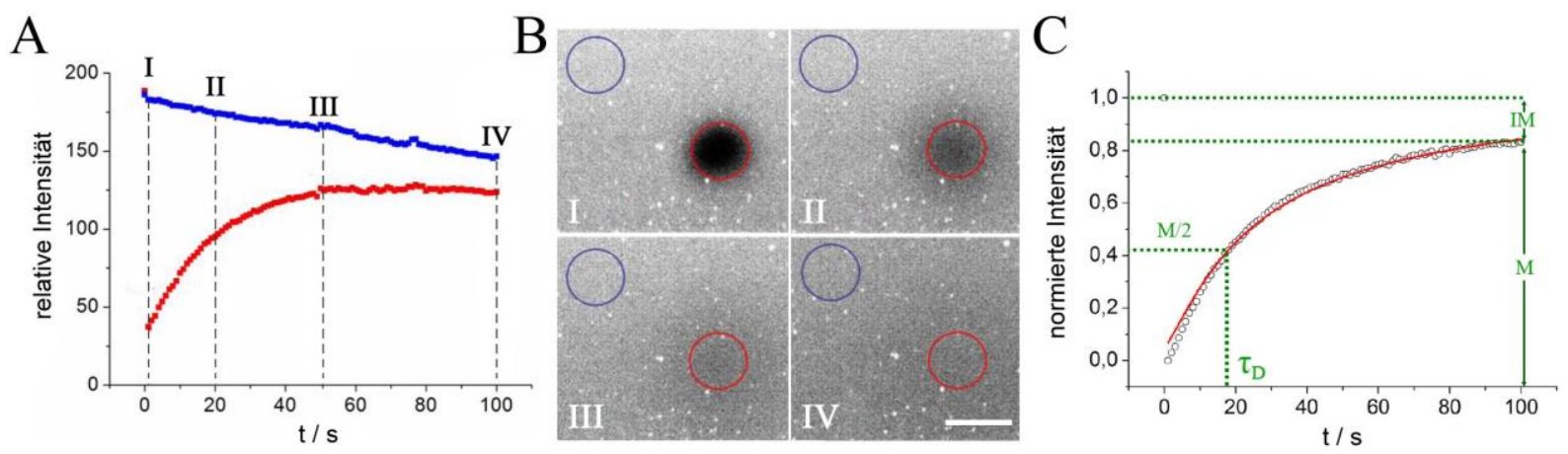

Abb. 3-16: Auswertung von FRAP-Experimenten. (A) Beispiel für den Verlauf der Fluoreszenzintensität des Bleichspots (- u) und des Hintergrunds (ロ). (B) Fluoreszenzmikroskopische Aufnahmen einer festkörperunterstützten, fluoreszenzmarkierten Membran direkt nach dem Bleichen (I), $20 \mathrm{~s}$ (II), $50 \mathrm{~s}$ (II) und $100 \mathrm{~s}$ (IV) nach dem Bleichen (siehe A). Maßstab $=20 \mu \mathrm{m}$. (C) Verlauf der auf die Hintergrundfluoreszenz (blauer Kreis in B) normierten Fluoreszenz innerhalb der ROI (roter Kreis in B). Den Datenpunkten ist eine Kurve nach Gleichung 3-10 angepasst. Der mobile Anteil der Fluoreszenzintensität (M), der immobile Anteil (IM) und der charakteristische Diffusionszeit $\tau_{\mathrm{D}}$ bei M/2 können aus der Kurve abgelesen werden. [Frese 2009].

Die Datenauswertung erfolgt in dieser Arbeit mit Igor Pro 6.0.3 (WaveMetrics) nach Axelrod. 


\subsection{Rasterelektronenmikroskopie}

Die Rasterelektronenmikroskopie (REM) diente in dieser Arbeit der Überprüfung und Charakterisierung poröser Aluminate verschiedener Größen, sowie der Überwachung der zahlreichen Teilschritte ihrer Herstellung. Anhand von Stichproben kann so die Qualität einzelner Chargen ständig überprüft und der Herstellungsprozess gegebenenfalls optimiert werden.

Grundprinzip ist die zeilenweise Abtastung einer Oberfläche bzw. einer scharfen Ebene durch ein fokussiertes Bündel von Elektronen im Hochvakuum. Der maximal technisch realisierbare Vergrößerungsfaktor liegt bei etwa 1.000.000. Die Elektronenstrahlerzeugung erfolgt mittels Glühkathoden oder Feldemissionskathoden. Die emittierten Elektronen werden über eine Anode mit bis $\mathrm{zu} 30 \mathrm{kV}$ beschleunigt. Das Elektronenstrahlenbündel wird durch eine Aperturblende begrenzt und durch elektrische oder magnetische Linsen gebündelt. Ein XYAblenksystem auf Basis von Magnetspulen erzeugt das Zeilenraster (Abb. 3-17 C). Beim Auftreffen dieses Primärelektronenstrahls treten die Elektronen in Wechselwirkung mit der Probe (Abb. 3-17 A). Hierbei unterscheidet man elastische und inelastische Streuung. Bei der elastischen Streuung (Abb. 3-17 B) findet keine Energieübertragung der Primärelektronen (PE) auf die Probe statt. Die Elektronen passieren die Probe ohne Wechselwirkung (direkt beam) oder werden durch Coulomb-Wechselwirkungen z.T. vollständig zurückgestreut (backscattert electrons, BSE). Die Intensität dieses Signals ist von der Ordnungszahl des untersuchten Materials abhängig, weshalb hiermit Rückschlüsse auf Materialunterschiede des Substrates gemacht werden können (Rückstreuelektronenkontrast). Bei der inelastischen Streuung kommt es zur direkten Energieübertragung der Primärelektronen auf Atome der Probe. Die Austrittsenergie der Primärelektronen ist geringer als die Eintrittsenergie. Die übertragene Stoßenergie resultiert in emittierter energiereicher Strahlung und der Emission von Sekundärelektronen (SE) mit einigen eV aus den Atomen der Probe. Diese können mit speziellen inlens- oder SE2-Teilchendetektoren erfasst und verstärkt werden. Mit diesem Sekundärelektronenkontrast lässt sich die Topographie einer Probe genauer untersuchen [Flegler et al. 1995; Reimer \& Pfefferkorn 1999]. 
A

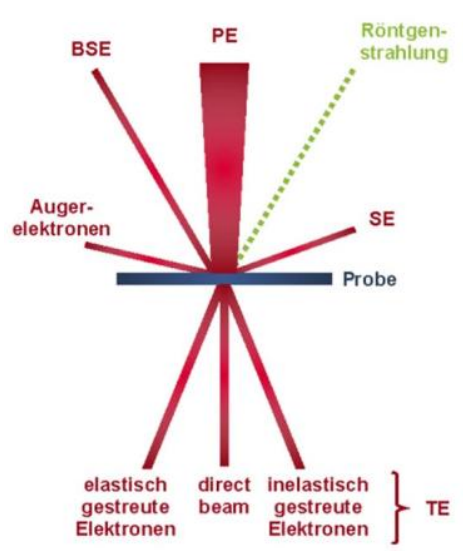

B

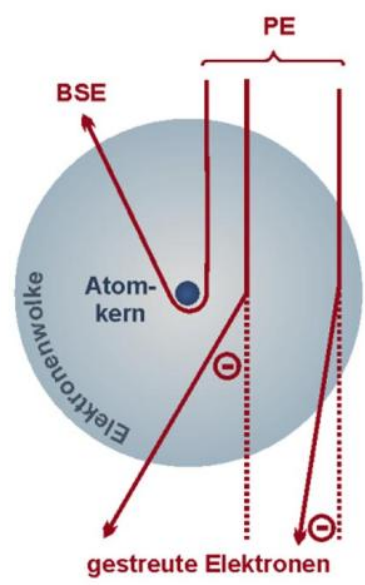

$\mathrm{C}$

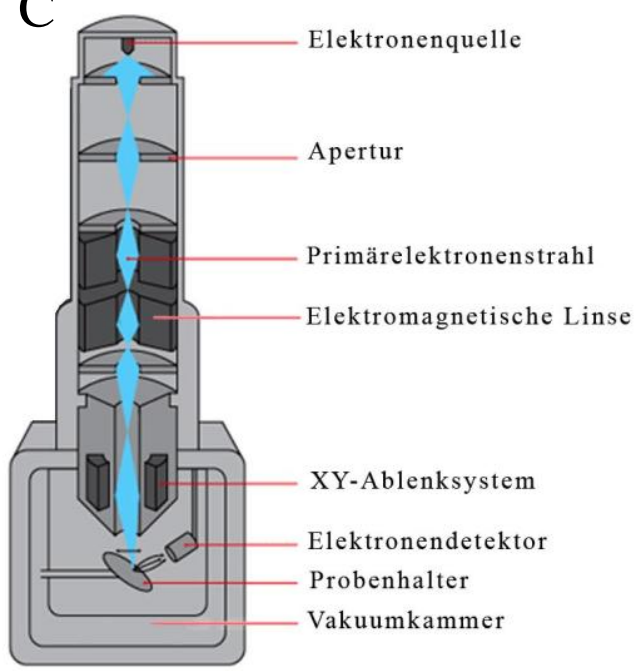

Abb. 3-17: (A) Mögliche Wechselwirkung von Primärelektronen mit einer Probe bei der Elektronenmikroskopie. (B) Varianten der elastischen Streuung von Primärelektronen. (C) Schematische Aufbau eines Elektronenmikroskops. $\mathrm{PE}=$ Primärelektronen, $\mathrm{BSE}=$ backscattert electrons, $\mathrm{SE}=$ Sekundärelektronen. $\mathrm{A} / \mathrm{B}$ nach [Krumreich], C nach [SDU].

Nachteil der Rasterelektronenmikroskopie ist, dass die Probe vakuumstabil sein muss. Deshalb können keine biologischen Proben untersucht werden. Des Weiteren muss die Probe leitend sein, da sonst Aufladungseffekte eine detailreiche Abbildung verhindern. Nicht leitende Substrate können allerdings durch Beschichtung mit einem leitenden Material untersucht werden. Hierfür reichen z.B. einige nm Gold.

Die REM Messungen werden mit einem Zeiss Supra ${ }^{\mathrm{TM}}$ 55VP bei einer Anodenspannung von 5 - $10 \mathrm{kV}$ und einer Apertur von $35 \mu \mathrm{m}$ durchgeführt. Als Detektor wurde ein inlens-Detektor für Sekundärelektronen verwendet. 


\subsection{Präparative Methoden}

\subsubsection{Herstellung poröser Aluminate}

Im Rahmen dieser Arbeit werden Connexone in porenüberspannenden Membranen auf einem funktionalisierten, nanoporösen Trägermaterial rekonstituiert. Essentiell für die Herstellung dieser so genannten nano-BLMs sind planare, hochgeordnete, poröse Trägersubstrate, deren Herstellung im Folgenden beschrieben wird.

\subsubsection{Grundlagen der Oxidbildung}

Das Leichtmetall Aluminium ist ein weit verbreiteter Werkstoff, der aufgrund einer an Luft ausgebildeten dünnen Oxidschicht $\left(\mathrm{Al}_{2} \mathrm{O}_{3}\right)$ sehr korrosionsbeständig ist. Diese natürlich ausgebildete Schicht erreicht eine Dicke von etwa $3 \mathrm{~nm}$ und schützt vor einer fortschreitenden Oxidation (Passivierung). Durch elektrische Oxidation, dem Eloxieren, kann unter Verwendung geeigneter Säuren und dem Anlegen einer Gleichspannung der Oxidationsprozess aufrecht erhalten werden.

$$
\begin{array}{ll}
\text { Anode: } & 2 \mathrm{Al}+3 \mathrm{H}_{2} \mathrm{O} \rightarrow \mathrm{Al}_{2} \mathrm{O}_{3}+6 \mathrm{H}^{+}+6 \mathrm{e}^{-} \\
\text {Kathode: } & 6 \mathrm{H}^{+}+6 \mathrm{e}^{-} \rightarrow 3 \mathrm{H}_{2}
\end{array}
$$

Hierbei werden Wassermoleküle an der Oxid/Elektrolyt-Grenzfläche zu $\mathrm{O}^{2-}$ und $\mathrm{OH}^{-}$-Ionen gespalten. Diese können direkt mit Al-Ionen reagieren oder wandern entlang des elektrischen Feldes durch das bereits gebildete Oxid zur Metalloberfläche. An der Metall/OxidGrenzfläche wird elementares $\mathrm{Al} \mathrm{zu} \mathrm{Al}{ }^{3+}$-Ionen oxidiert. Diese reagieren mit den $\mathrm{O}^{2-}$ und $\mathrm{OH}^{-}$ -Ionen $\mathrm{zu} \quad \mathrm{Al}_{2} \mathrm{O}_{3}$ oder wandern entlang des elektrischen Feldes zur Oxid/ElektrolytGrenzfläche. Innerhalb der Oxidschicht findet keine chemische Reaktion statt, die Grundvoraussetzung zur Entstehung poröser Aluminate [Hassel et al. 1994]. Die gebildeten Protonen werden an der Kathode zu Wasserstoff reduziert. Die Charakteristika des gebildeten Eloxals werden entscheidend durch die Wahl des Elektrolyten beeinflusst.

Unter Verwendung von Elektrolyten mit sehr geringer Löslichkeit für $\mathrm{Al}_{2} \mathrm{O}_{3}$ wie Bor-, Zitronen- oder Weinsäure, kann die Grenzschicht zwischen Elektrolyt und Oxidschicht nicht aufgelöst werden. Dies führt zur Ausbildung eines homogenen Barriereoxids. In der Folge kommt der Ionentransport aufgrund der immer größer werdenden Potentialbarriere zum Erliegen. Die Dicke der Oxidschicht ist proportional zum Oxidationspotential und auf etwa $1 \mu \mathrm{m}$ limitiert [Franklin 1957; Thompson et al. 1987]. 
Im Gegensatz zu diesem Prozess wird die gebildete Oxidschicht unter Verwendung von Elektrolyten mit mäßig bis starker Löslichkeit für $\mathrm{Al}_{2} \mathrm{O}_{3}$ direkt nach der Bildung aufgelöst [Despic \& Parkhutik 1989]. Hierzu zählen u.a. konzentrierte Schwefel- und Phosphorsäure. Rauheitsspitzen werden unter diesen Bedingungen schneller abgetragen bzw. geglättet als Rauheitstäler. Dieser Effekt tritt auf, da sich die elektrische Stromdichte an Rauheitsspitzen erhöht, wodurch eine schnellere Oxidbildung stattfindet als in Rauheitstälern, an welchen die elektrische Stromdichte herabgesetzt ist. Durch dieses elektrochemische Abtragverfahren wird die Oberflächenrauhigkeit stark reduziert, weshalb auch von Elektropolieren gesprochen wird. [Neufeld \& Southall 1975]. Werden Elektrolyten mit geringer Löslichkeit eingesetzt entstehen unter geeigneten Bedingungen poröse Aluminate. Hierauf soll im Folgenden näher eingegangen werden.

\section{Verwendung von Elektrolyten mit geringer Löslichkeit für $\mathrm{Al}_{2} \mathrm{O}_{3}$}

Die Ausbildung poröser $\mathrm{Al}_{2} \mathrm{O}_{3}$-Schichten wurde erstmals in den 1920er-Jahren beobachtet [Bengough \& Stuard 1923; Zaidan et al. 1924; Gower et al. 1968]. Typischerweise werden hierfür Schwefel-, Phosphor- oder Oxalsäure eingesetzt [Parkhutik \& Shershulsky 1992; Keller et al. 1953]. Am Oxidwachstum sind hierbei nur die $\mathrm{O}^{2-} / \mathrm{OH}^{-}-$Ionen beteiligt, welche direkt an der Oxid/Metall-Grenzschicht $\mathrm{zu} \mathrm{Al}_{2} \mathrm{O}_{3}$ umgewandelt werden. Durch die Porosität ist die Dicke der Oxidschicht, anders als bei Elektrolyten mit sehr geringer Löslichkeit, nicht länger vom Oxidationspotential abhängig, sondern wird in linearer Abhängigkeit durch die Oxidationsdauer bestimmt.

Die Initialisierung des Porenbildungsprozesses nach Anlegen einer konstanten Spannung lässt sich in vier Bereiche unterteilen (Abb. 3-18).

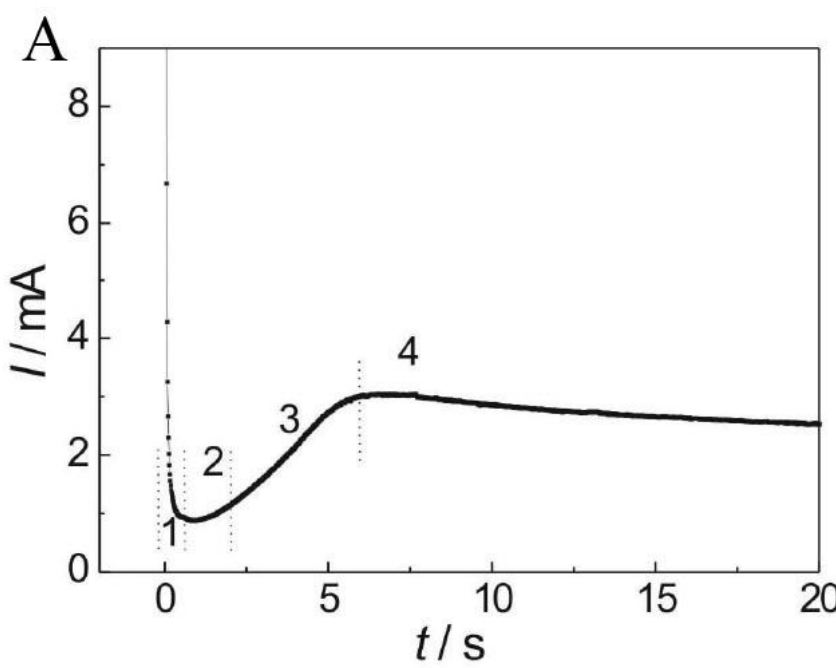

B
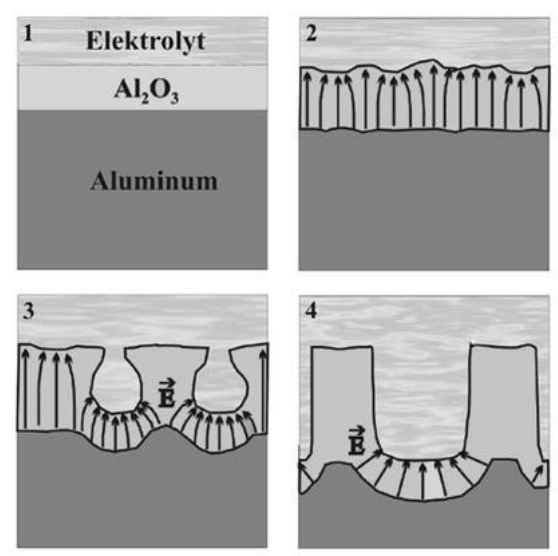

Abb. 3-18: Kinetik des Porenwachstums bei der elektrochemischen Anodisierung von Aluminium mit $0.3 \mathrm{M}$ Oxalsäure. (A) Stromverlauf und (B) schematische Darstellung [Horn 2005]. 
Zunächst bildet sich ein homogenes Barriereoxid. Der Strom fällt in Regime 1 exponentiell bis auf etwa $10 \%$ des Ausgangswertes ab. Unterschiede in der Oberflächenrauheit der gebildeten Oxidschicht führen in der Folge zu einer Fokussierung der Feldlinien in Rauhigkeitstälern. Im Gegensatz zu Elektrolyten mit sehr geringen Löslichkeiten für $\mathrm{Al}_{2} \mathrm{O}_{3}$ führt dies durch die stärkere Polarisierung der Al-O-Bindungen in Regime 2 lokal zu einer erhöhten Oxidauflösung [O'Sullivan \& Wood 1970]. Die ausgebildeten Vertiefungen dienen daher als Keime für das Porenwachstum. Neben der feldinduzierten erhöhten Oxidauflösung führt der erhöhte Ionenfluss zu einer lokal beschleunigten Oxidbildung und insgesamt zu einem Anstieg des Oxidationsstromes in Regime 3. Ist die gesamte Substratoberfläche mit zufällig verteilten Poren bedeckt, führen Wechselwirkungen der Poren untereinander zu einem stabilen mittleren Porenabstand. In Regime 4 stellt sich ein Gleichgewicht zwischen Oxidbildung an der Oxid/Metall-Grenzfläche und Oxidauflösung an den Porenböden (Oxid/Elektrolytgrenzfläche) ein. Konzentrationsänderungen des Elektrolyten führen anschließend zu einem leichten Abfalls des Stromes.

\section{Anodisierungsparameter}

Neben der Regulierung der Schichtdicke bzw. Porentiefe über die Anodisierungsdauer können im Zuge dieses Prozesses weitere Parameter variiert werden. Porenabstand und Durchmesser, sowie die Dicke der Porenböden können durch die Höhe der angelegten Anodisierungsspannung variiert werden. In Kombination mit unterschiedlichen Elektrolytlösungen können so Porendurchmesser im Bereich zwischen 10-400 nm hergestellt werden [Li et al. 1998]. Zudem können unterschiedliche Wachstumsraten der Oxidschicht erzielt werden [Jessensky 1997; Jessensky et al. 1998], was in Verbindung mit der Anodisierungstemperatur wiederum einen Einfluss auf den Ordnungsgrad der gebildeten Porenstruktur hat.

\section{Verwendung der zweistufigen Anodisierung}

Für die Herstellung hochgeordneter poröser Aluminate muss die Oberflächenrauhigkeit des Aluminiums zunächst durch den beschrieben Prozess des Elektropolierens minimiert werden. Bei der anschließenden ersten Anodisierung entsteht, wie oben beschrieben, zunächst eine poröse Oxidschicht, deren Ordnungsgrad sehr niedrig ist. Durch eine Selbstorganisation wird im Verlauf der Oxidation der Ordnungsgrad der Poren erhöht. Durch Ablösen dieser so genannten Vorstrukturierung erhält man im Idealfall eine hexagonal vorstrukturierte 
Substratoberfläche, deren Vertiefungen als Keime für die Generierung durchgängig geordneter $\mathrm{Al}_{2} \mathrm{O}_{3}$-Poren in einer zweiten Anodisierung dienen [Masuda \& Fukuda, 1998].

\subsubsection{Herstellung hochgeordneter poröser Aluminate}

In dieser Arbeit werden hauptsächlich poröse Aluminate mit einem Porendurchmesser von $60 \mathrm{~nm}$ hergestellt. Diese dienen als Substrate zur Generierung von nano-BLMs. Zudem werden Substrate mit einem Porendurchmesser von 20 und $200 \mathrm{~nm}$ hergestellt, welche allerdings keine Anwendung fanden.

\section{Ausgangsmaterial}

Als Ausgangsmaterial dienen $500 \mu \mathrm{m}$ dicke, hochreine Aluminiumscheiben (Goodfellow, $99.999 \%$ ) mit einer Kantenlänge von 1,5 cm.

\section{Ausheizen}

Ein Satz Aluminiumscheiben wird zunächst für $3 \mathrm{~h}$ bei $500{ }^{\circ} \mathrm{C}$ unter einem kontinuierlichen Stickstoffstrom ausgeheizt. Die hiermit erzielte Vergrößerung der Subkristallite [Jessensky 1997] hat zusammen mit dem sich anschließenden Elektropolieren einen Einfluss auf den Ordnungsgrad der späteren porösen Aluminate.

\section{Elektropolieren}

Die ausgeheizten Aluminiumscheiben werden auf der Unterseite mit Schleifpapier aufgeraut, mit Ethanol gereinigt und getrocknet. Ein Gemisch aus Schwefelsäure (konz.), Phosphorsäure (85\%) und Reinstwasser im Massenverhältnis 1:1:1 dient als Elektrolyt mit starker Löslichkeit für $\mathrm{Al}_{2} \mathrm{O}_{3}$. Die elektrochemische Poliereinheit besteht aus einem als Anode geschalteten massiven Kupferblock mit becherförmigem Teflon-/Delrinaufsatz. Zwischen diese beiden Elemente werden die Aluminiumscheiben mittels Dichtringen eingespannt. Nach Erhitzen des Elektrolyten auf etwa $60{ }^{\circ} \mathrm{C}$ wird ein mit einem Platinnetz bespannter und als Kathode geschalteter Aufsatz in den Elektrolyten eingetaucht. Bei einer Spannung von $2 \mathrm{~V}$ (2400 Source Meter, Keithley) werden die Aluminiumscheiben dreimal für $45 \mathrm{sec}$ poliert, hierbei fällt der Strom jeweils auf ein Niveau von $0.3-0.4 \mathrm{~A}$ ab. Die nun glänzenden Scheiben mit stark verminderter Oberflächenrauhigkeit werden mit Reinstwasser gespült und getrocknet. 


\section{Vorstrukturierung}

Die elektrochemisch polierten Aluminiumscheiben werden in eine weitere elektrochemische Zelle (Ätzkammer) eingespannt, deren Aufbau im Wesentlichen der Poliereinheit entspricht (Abb. 3-19).

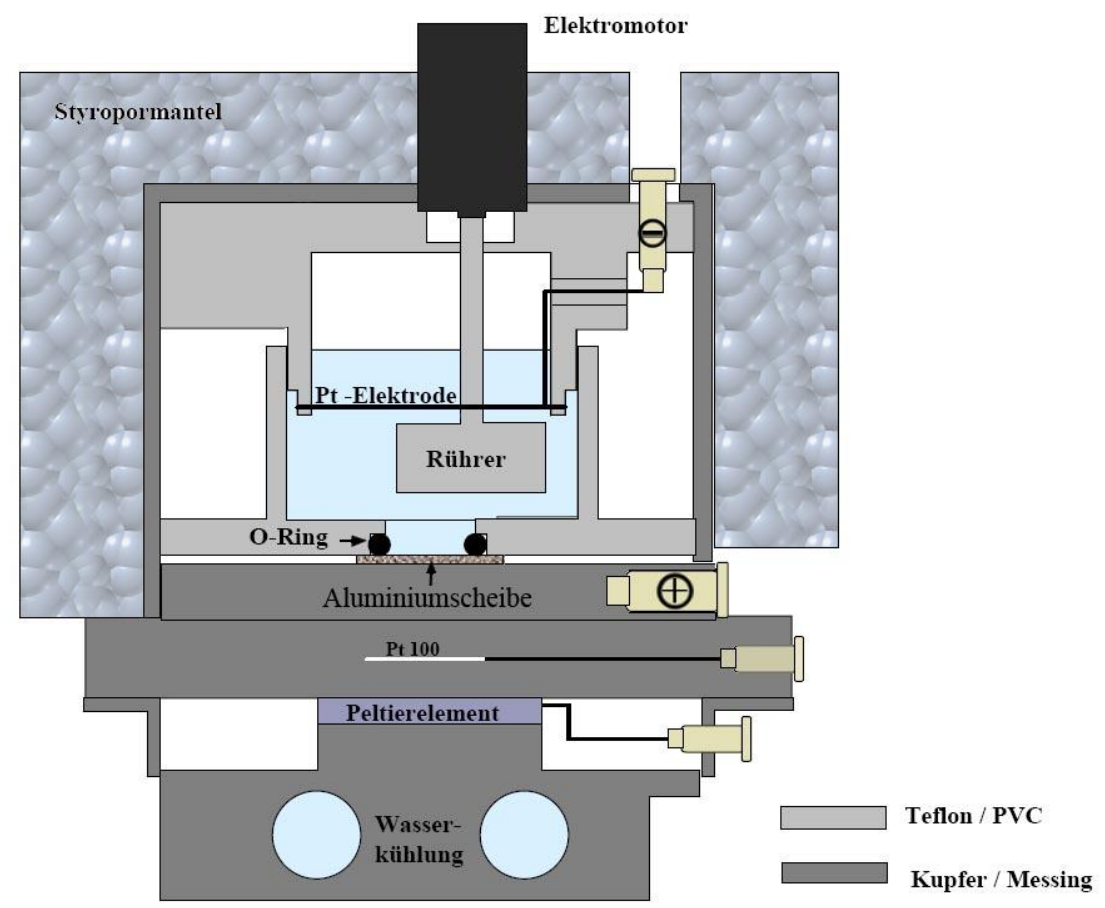

Abb. 3-19: Schematische Darstellung der elektrochemischen Zelle zur Anodisierung von Aluminium. Abgewandelt [Nielsch 2002].

Auch hier wird das Substrat mittels Dichtringen zwischen einem becherförmigen Aufsatz aus Delrin und einer als Anode geschalteten Kupfergrundplatte eingespannt. Ein thermisch isolierter, mit Platindraht und Rühreinheit versehener Aufsatz, wird als Kathode geschaltet. Zusätzlich wird das System durch ein Peltierelement in Verbindung mit einem Temperaturregler (Greisinger Elektronik GmbH) und einem Pt100 Temperaturfühler bei konstanter Temperatur gehalten. Die Rühreinheit verhindert den Aufbau von Konzentrationsund Temperaturgefällen im eingesetzten Elektrolyten während der etwa $12 \mathrm{~h}$ andauernden ersten Anodisierung. Die Anodisierungsbedingungen für verschieden Porendurchmesser sind in Tabelle 1 aufgelistet sind.

Tabelle 1: Anodisierungsbedingungen für verschiedenen Porendurchmesser.

\begin{tabular}{ccccc}
\hline Porengröße / $\mathbf{~ m}$ & Spannung $/ \mathbf{V}$ & Temperatur $/{ }^{\circ} \mathbf{C}$ & Elektrolyt & Wachstum $/ \boldsymbol{\mu m h} \mathbf{~}^{-1}$ \\
\hline 20 & 25 & 1.5 & $0.3 \mathrm{M} \mathrm{H}_{2} \mathrm{SO}_{4}$ & $2-3.5$ \\
60 & 40 & 1.5 & $0.3 \mathrm{M} \mathrm{C}_{2} \mathrm{H}_{2} \mathrm{O}_{4}$ & 1.2 \\
280 & 160 & 1.5 & $10 \% \mathrm{H}_{3} \mathrm{PO}_{4}$ & $4-5$ \\
\hline
\end{tabular}




\section{Ablösen der Vorstrukturierung}

Die Vorstrukturierung wird bei $65^{\circ} \mathrm{C}$ über eine Dauer von $5 \mathrm{~h}$ mit saurer Chrom(VI)-OxidLösung (1.8 Gew. \% $\mathrm{CrO}_{3}, 7.06$ Gew. $\left.\% \mathrm{H}_{3} \mathrm{PO}_{4}\right)$ entfernt. Die Substrate werden mit Reinstwasser gespült.

\section{Hauptätzung}

Die elektrochemische Zelle und die Anodisierungsbedingungen entsprechen denen der Vorstrukturierung (Abb. 3-19). Die Dauer der Ätzung beträgt, je nach gewünschter Dicke der porösen Aluminiumoxidschicht, 3 bis 5 Tage. Hierbei ist darauf $\mathrm{zu}$ achten, dass die Wachstumsgeschwindigkeiten für unterschiedliche Anodisierungsbedingungen variieren und teilweise sehr unterschiedlich sind. So werden bei den in Tabelle 1 beschriebenen Bedingungen für Oxalsäure 1-2 $\mu \mathrm{m} / \mathrm{h}$, für Schwefelsäure 2-3.5 $\mu \mathrm{m} / \mathrm{h}$ und für Phosphorsäure 4-5 $\mu \mathrm{m} / \mathrm{h}$ angegeben [Nielsch 2002]. Nach dieser zweiten Anodisierung werden die Substrate gespült und $1 \mathrm{~h}$ in Reinstwasser gelagert, was die Entfernung des Elektrolyten aus den gebildeten Poren zum Ziel hat.

\section{Selektive Entfernung des Aluminiumsubstrates}

Für die spätere Anwendung des porösen Aluminates als Träger porenüberspannender Membranen in einem wässrigen Zweikompartimentensystem ist es notwendig, die Unterseite des Aluminates zugänglich zu machen. Hierfür muss der Träger dieser Oxidschicht, das Aluminiumsubstrat, selektiv durch den Einsatz einer gesättigten $\mathrm{HgCl}_{2}$-Lösung bei Raumtemperatur (RT) entfernt werden:

$$
2 \mathrm{Al}+3 \mathrm{HgCl}_{2} \rightarrow 2 \mathrm{AlCl}_{3}+3 \mathrm{Hg}
$$

Das verbleibende Aluminat wird gespült und $1 \mathrm{~h}$ in Reinstwasser gelagert, um $\mathrm{HgCl}_{2}$-Reste aus den Poren zu entfernen.

\section{Öffnung der Porenböden}

Um die elektrische Leitfähigkeit zwischen zwei wässrigen Kompartimenten zu gewährleisten, bedarf es abschließend der Öffnung der im Verlauf der zweiten Anodisierung ausgebildeten Porenböden. Hierfür wird das Oxid einseitig in einem definierten Bereich 90 min bei $30{ }^{\circ} \mathrm{C}$ durch $\mathrm{H}_{3} \mathrm{PO}_{4}$ (10 Gew. \%) entfernt (Abb. 3-20). 


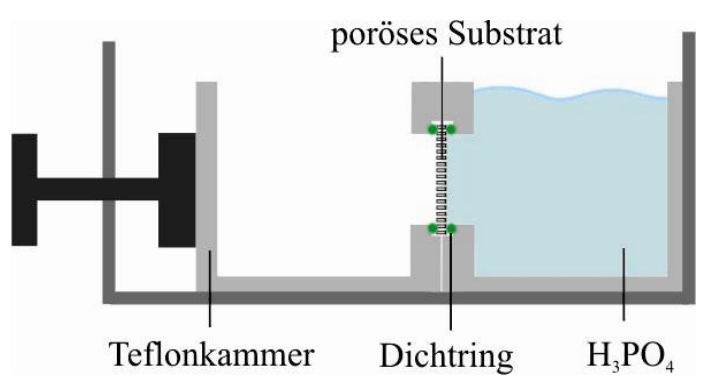

Abb. 3-20: Schematische Darstellung der selektiven Öffnung der Porenböden mit $\mathrm{H}_{3} \mathrm{PO}_{4}$ in einer Teflonkammer.

Es entsteht Aluminiumorthophosphat:

$$
\mathrm{Al}_{2} \mathrm{O}_{3}+2 \mathrm{H}_{3} \mathrm{PO}_{4} \rightarrow 2 \mathrm{AlPO}_{4}+3 \mathrm{H}_{2} \mathrm{O}
$$

Neben der Öffnung der Porenböden wird der Porendurchmesser durch diesen Prozess vergrößert [Li et al. 1998/1999]. Das nun durchgängig poröse Substrat wird gespült und $1 \mathrm{~h}$ in Reinstwasser gelagert.

\subsubsection{Herstellung von nano-BLMs und Rekonstitution von Connexonen}

Als Ausgangssubstrate zur Herstellung von nano-BLMs dienen poröse Aluminate mit einem Porendurchmesser von etwa $60 \mathrm{~nm}$. Diese werden zunächst $10 \mathrm{~min}$ in einem Argon-Plasma (Plasma Cleaner PDC 32 G-2, Harrick) gereinigt. Das Aufbringen einer haftvermittelnden Schicht aus $2.5 \mathrm{~nm}$ Titan und einer Schicht aus $25 \mathrm{~nm}$ Gold erfolgt mit einem Kathodenzerstäuber (Sputter Coater 108 auto, Cressington) im Argonplasma. Zur Funktionalisierung der Goldoberfläche werden die Substrate über Nacht bei RT in $1 \mathrm{mM}$ Tetradekanthiol (TDT) (in Ethanol p.A.) inkubiert. Vor Einbau der über Chemisorption funktionalisierten Substrate in die entsprechenden Messzellen, werden diese gründlich mit Ethanol p.A. gespült und im Stickstoffstrom getrocknet. Nach Einbau der Substrate in die Messzelle müssen die Poren zunächst mit Ethanol p.A. benetzt werden, um eingeschlossene Luft zu verdrängen, anschließend kann die Messzelle mit Elektrolytlösung (200 mM KCl, 10 mM HEPES, 0.02 mM EDTA pH 7.4) befüllt werden.

Für die Herstellung der nano-BLMs mittels painting-Technik werden etwa $7.5 \mu 1$ einer $20 \mathrm{mM}$ Lösung von 1,2-Diphytanoyl-sn-glycero-3-phospholcholin (DPhPC) in $n$-Dekan/nOktan 1:1 (v/v) auf das mit TDT funktionalisierte poröses Substrat pipettiert (Abb. 3-21). 


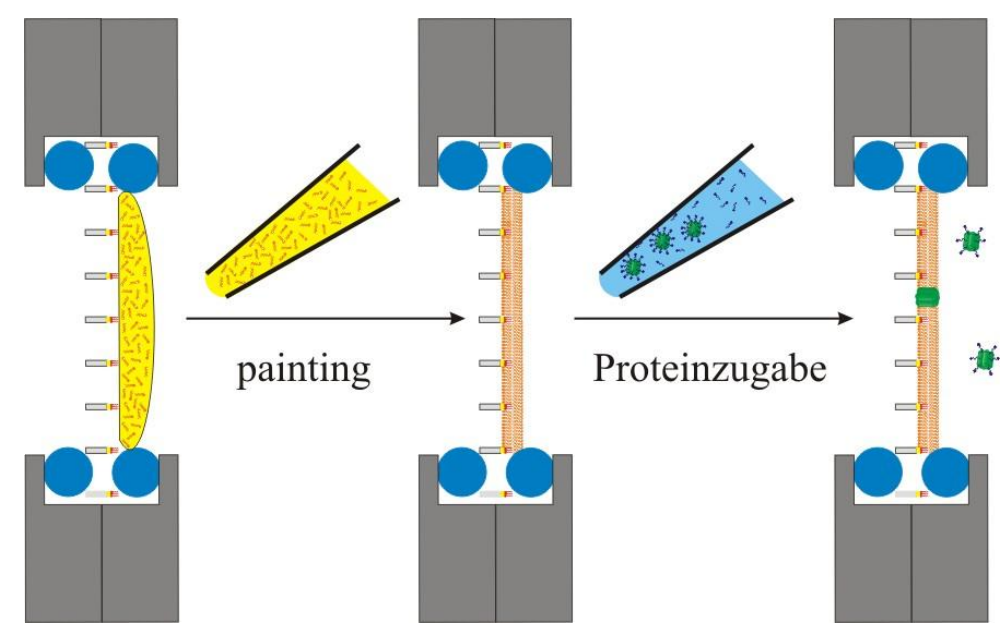

Abb. 3-21: Schematische Darstellung der Präparation von nano-BLMs auf funktionalisierten porösen Aluminaten mittels painting-Technik und detergenzvermittelter Rekonstitution von Transmembranproteinen.

Als Messzelle dient das in Abb. 3-7 dargestellte Zwei-Kammer-System. Allerdings müssen für die Einzelkanalmessung $\mathrm{Ag} / \mathrm{AgCl}$-Elektroden verwendet werden. Zur Visualisierung des Ausdünnvorgangs und zur Charakterisierung der ausgebildeten porenüberspannenden Membran, wird die Impedanzspektroskopie (3.1) genutzt. Die Rekonstitution von Transmembranproteinen erfolgt durch Zugabe von $1 \mu 1$ einer $2-3 \mu \mathrm{g} / \mathrm{ml}$ Proteinlösung in Messpuffer mit $1 \%(v / v) n$-Octylpolyoxyetylen (POE).

Die anhand von Einzelkanalmessungen untersuchten Proteine Cx26WT, Cx26M34A und Cx26V84L liegen in Stammlösungen (1 M NaCl, 300 mM L-His, $300 \mathrm{mM} \mathrm{HCl}, 0.28 \mathrm{mM}$ $\mathrm{NaOH}, 20 \mathrm{mM}$ HEPES, $0.1 \%$ DoDM, $0.0025 \% \mathrm{NaN}_{3}$, pH 7-8) mit Konzentrationen von 2-3 mg/ml vor und werden bei $4{ }^{\circ} \mathrm{C}$ gelagert.

\subsubsection{Präparation von platinierten Platinelektroden}

Die Herstellung von Platinelektroden mit möglichst großer Elektrodenoberfläche basiert auf dem Prinzip der elektrochemischen Materialabscheidung. Die dadurch erzielte Vergrößerung der elektrischen Kapazität an der Elektroden/Elektrolyt Grenzfläche ist notwendig, um den Einfluss der Messelektroden bei der Impedanzspektroskopie soweit zu minimieren, dass sie bei der Erstellung eines Ersatzschaltkreises, zur Auswertung der Daten, nicht berücksichtigt werden müssen (siehe 3.1.2).

Platindraht (Goodfellow GmbH) mit einem Durchmesser von $1 \mathrm{~mm}$ wird an der späteren Elektrolytkontaktfläche mit Schleifpapier aufgeraut und in Ethanol gereinigt. Beide Elektroden werden etwa $2 \mathrm{~cm}$ tief in die Platinierlösung (3\% (w/v) $\mathrm{PtCl}_{4}, 0.025 \%(w / v)$ $\mathrm{Pb}\left(\mathrm{OOCCH}_{3}\right)_{4}, 25 \mathrm{mM} \mathrm{HCl}$ ) eingetaucht und an die Spannungsquelle (DC Power Supply PS 280, Textronics) angeschlossen. Die Platinabscheidung erfolgt für $1.5 \mathrm{~min}$ bei $1.5 \mathrm{~V}$. Durch 
Umpolen wird dieser Vorgang für beide Elektroden zweimal wiederholt. Anschließend werden beide Drähte 1.5 min bei 3.5 V platiniert. Nach Ablösen loser Materialabscheidungen in Reinstwasser für 2 min im Ultraschallbad (Sonorex, Bandelin), wird der Vorgang des elektrochemischen Platinierens mit anschließender Ultraschallbehandlung etwa 3-4 mal wiederholt. Ist eine deutlich sichtbare mattschwarze Platinabscheidungen zu erkennen, welche sich nicht durch Ultraschallbehandlung entfernen lässt, können die Elektroden in Reinstwasser gelagert und für die Impedanzspektroskopie verwendet werden.

\subsubsection{Präparation von $\mathrm{Ag} / \mathrm{AgCl}-E l e k t$ roden}

Bei der voltage-clamp Methode (siehe 3.2.1) werden elektrische Ströme im pA-Bereich detektiert. Hierfür ist es erforderlich $\mathrm{Ag} / \mathrm{AgCl}$-Elektroden $\mathrm{zu}$ verwenden, da diese bei einem Elektronenübergang nicht polarisiert werden und unverfälschte Messungen ermöglichen.

Silber hat die höchste elektrische Leitfähigkeit aller Metalle [Riedel \& Janiak 2007]. Die Oberflächenvergrößerung wird durch eine elektrochemische Materialabscheidung erzielt. Hierfür werden Silberdrähte (Goodfellow $\mathrm{GmbH}$ ) mit einem Durchmesser von $1 \mathrm{~mm}$ vor jeder Messung an der späteren Elektrolytkontaktfläche mit Schleifpapier angeraut und in Ethanol gereinigt. Anschließend werden die Elektroden zusammen mit einer identisch präparierten Gegenelektrode etwa $1 \mathrm{~cm}$ tief in $0.5 \mathrm{M} \mathrm{KCl}$ eingetaucht und an eine Spannungsquelle (DC Power Supply PS 280, Textronics) angeschlossen. Die angelegte Spannung wird so hoch gewählt, dass eine Wasserstoffbildung an der Kathode zu beobachten ist. Durch mehrmaliges Umpolen wird eine ausreichende Abscheidung von Silberchlorid an der Messelektrode erzielt. Gut präparierte Elektroden zeichnen sich durch eine mattschwarze Färbung aus.

\subsubsection{Herstellung von unilamellaren Liposomen und Proteoliposomen}

Die Rekonstitution transmembraner Ionenkanäle in unilamellare Lipidvesikel bildet die Grundlage zum Nachweis der Proteinaktivität mittels UV/VIS Spektroskopie und CLSM. Hierfür wird Lipid in Chloroform gelöst, in ein Reagenzglas pipettiert und $30 \mathrm{~min}$ bei $30{ }^{\circ} \mathrm{C}$ unter einem kontinuierlichen Stickstoffstrom wieder vom Lösungsmittel getrennt. Der Lipidfilm wird in Puffer und $n$-Octyl- $\beta$-D-Glucopyranosid (OG) bei $4{ }^{\circ} \mathrm{C}$ solubilisiert. Nach vollständiger Solubilisierung des Films wird das Gesamtvolumen in einem Eppendorfgefäß durch Zugabe der entsprechenden Proteinstammlösungen auf $1 \mathrm{ml}$ aufgefüllt. Die Transmembranproteine liegen in $1 \mathrm{M} \mathrm{NaCl}, 300 \mathrm{mM}$ L-His, $300 \mathrm{mM} \mathrm{HCl}, 0.28 \mathrm{mM} \mathrm{NaOH}$, 
$20 \mathrm{mM}$ HEPES, $0.1 \%$ DoDM, $0.0025 \% \mathrm{NaN}_{3}$, pH 7-8 vor. Bei der Herstellung der Kontrollvesikel ohne Protein, wird entsprechend nur dieser Puffer verwendet, um ein Gesamtvolumen von $1 \mathrm{ml}$ einzustellen. Zur Herstellung unilamellarer Vesikel wird das Detergenz OG über Nacht bei $4{ }^{\circ} \mathrm{C}$ mittels Bio-Beads SM-2 unter Schwenken (CAT ST5, Zipperer $\mathrm{GmbH}$ ) entzogen. Für den Detergenzentzug ist folgende Staffelung vorgesehen: $100 \mathrm{mg}$ Beads, $90 \mathrm{~min} / 140 \mathrm{mg}$ Beads, $90 \mathrm{~min} / 160 \mathrm{mg}$ Beads, über Nacht. Die trübe Suspension wird von den Biobeads getrennt und bei $4{ }^{\circ} \mathrm{C}$ aufbewahrt.

\subsubsection{Herstellung Cytochrom $c$-haltiger Proteoliposomen}

Für die UV/VIS spektroskopischen Aktivitätsuntersuchungen der transmembranen Ionenkanäle, werden Proteoliposomen mit eingeschlossenem Cytochrom $c$ benötigt. Hiefür werden $75 \mu \mathrm{g} / \mathrm{ml}$ des kanalbildenden Proteins und $6 \mathrm{mg} / \mathrm{ml}$ des Cytochrom $c$ zu einer mit $22 \mathrm{mg} / \mathrm{ml} n$-Octyl- $\beta$-D-Glucopyranosid vollständig solubilisierten POPC Suspension (10 mg/ml POPC in $50 \mathrm{mM}, 20 \mathrm{mM}$ TRIS, pH 7.4) gegeben. Dies entspricht einem LipidProtein-Verhältnis von etwa 130:1. Nach sukzessivem Entzug des Detergenz mittels Biobeads über Nacht bei $4{ }^{\circ} \mathrm{C}$ entstehen hieraus Proteoliposomen mit einem intraliposomalen Depot an Cytochrom $c$ (Abb. 3-22).

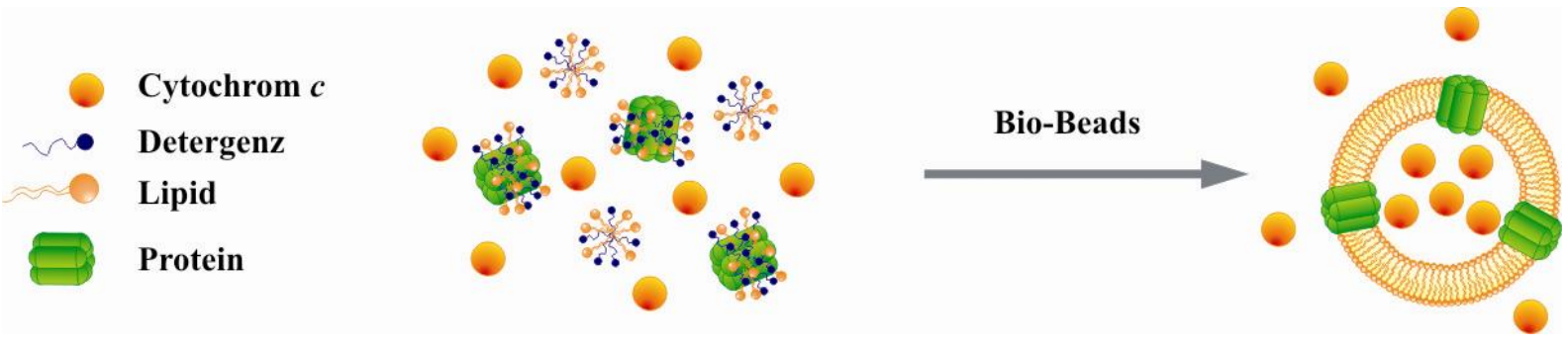

Abb. 3-22: Schematische Darstellung zur Herstellung unilamellarer Proteoliposomen mit intravesikulärem Cytochrom $c$ mittels Detergenzentzug durch Bio-Beads SM-2.

Zur Beseitigung des extravesikulären Cytochrom $c$ muss eine Größenausschlusschromatographie (size exclusion chromatography, SEC) mit Sephadex G-75 durchgeführt werden (Abb. 3-23). 


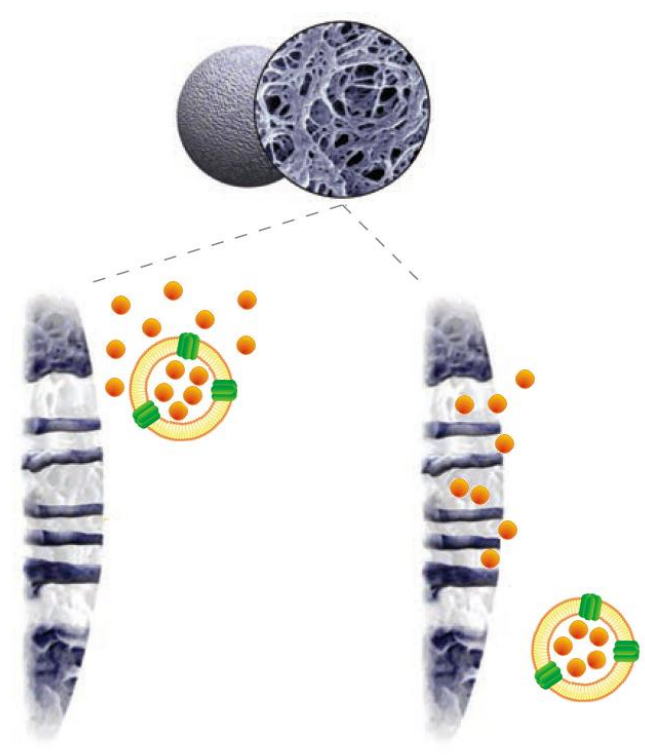

Abb. 3-23: Schematische Darstellung einer Größenausschlusschromatographie zur Trennung von extraliposomalem Cytochrom $c$ von Proteoliposomen mit eingeschlossenem Cytochrom $c$. Nach [GE 2007].

Bei diesem Säulenmaterial handelt es sich um ein körniges Gel quervernetzter DextranUntereinheiten mit einem Cutoff von $80 \mathrm{kDa} .1 \mathrm{ml}$ der Vesikelsuspension wird auf die etwa $20 \mathrm{~cm}$ lange Säule mit einem Gesamtvolumen von ca. $50 \mathrm{ml}$ gegeben. Als Laufmittel wird $50 \mathrm{mM} \mathrm{KCl}, 20 \mathrm{mM}$ TRIS, pH 7.4 verwendet. Es werden $1 \mathrm{ml}$ Fraktionen aufgefangen und bei 630 und $417 \mathrm{~nm}$ im UV/VIS Spektrometer vermessen.

\subsubsection{Herstellung von riesigen unilamellaren Vesikeln}

Die Herstellung riesiger unilamellarer Vesikel (giant unilamellar vesicle, GUV) basiert auf der Technik der Elektroformation [Angelova \& Dimitrov 1986]. Die Erweiterung dieser Methode wurde erstmals 1992 beschrieben [Angelova et al. 1992]. Grundprinzip ist die durch ein elektrisches Wechselfeld induzierte Rehydratisierung getrockneter lamellarer Lipidstrukturen und deren anschließender Membranfusion [Doeven et al. 2005]. Die Vesikel können Durchmesser von 1 - $150 \mu \mathrm{m}$ erreichen und eignen sich damit für lichtmikroskopische oder fluoreszenzmikroskopische Studien. Für die Umsetzung dieser Methode werden jeweils $25 \mu \mathrm{l}$ einer $5 \mathrm{mM}$ Lipidlösung in Chloroform auf zwei Objektträger (Präzisionsglas \& Optik $\mathrm{GmbH}$ ) aufgebracht. Diese besitzen durch eine Beschichtung mit Indiumzinnoxid (indium tin oxide, ITO) eine leitende Oberfläche. Nach vollständiger Entfernung des Lösungsmittels für mindestens $3 \mathrm{~h}$ im Vakuumtrockenschrank bei $30^{\circ} \mathrm{C}$, werden die beiden Objektträger zusammen mit einer Hämatokrit-Dichtungsmasse zu einer Elektroformationskammer zusammengebaut (Abb. 3-24). 


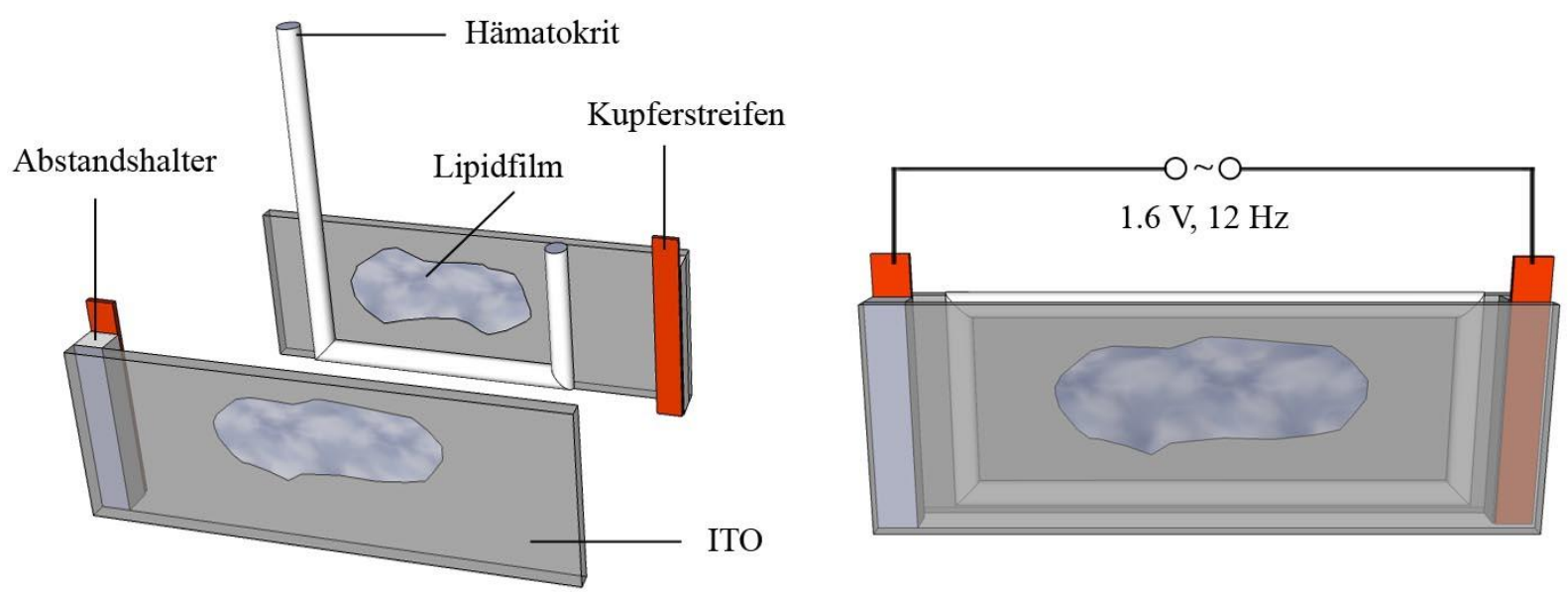

Abb. 3-24: Schematische Darstellung der Kammer zur Herstellung von GUVs mittels Elektroformation.

Als Abstandshalter dienen hierbei Streifen aus Teflon, die Kontaktierung der ITObeschichteten Oberfläche wird durch Kupferstreifen gewährleistet. Die Kammer wird mit Reinstwasser oder Rehydratisierungslösung (z.B. $210 \mathrm{mM}$ Sorbitol) befüllt und an einen Funktionsgenerator (33220A, Agilent) angeschlossen. Die Elektroformation erfolgt für $3 \mathrm{~h}$ bei mit einer sinusförmigen Wechselspannung von $12 \mathrm{~Hz}$ bei $1.6 \mathrm{~V}$. Das „Ablösen“ der gebildeten GUVs erfolgt 10 min bei einer Rechteckspannung mit $5 \mathrm{~Hz}$ und $1.6 \mathrm{~V}$.

Für die Rekonstitution transmembraner Ionenkanäle werden drei Ansätze verfolgt. Bei Methode a werden zunächst GUVs hergesellt. Anschließend erfolgt die Inkubation der GUVs mit $0.01 \%$ POE $(\mathrm{CMC}=1 \%)$ und Protein bis zu einer Konzentration von $0.01 \mathrm{mg} / \mathrm{ml}$. Das Detergenz wird mit $160 \mathrm{mg} / \mathrm{ml}$ für $1 \mathrm{~h}$ bei RT entzogen. Methode $b$ orientiert sich an dem von Girard et al. [2004] etablierten Verfahren. Hierbei handelt es sich um eine partielle Dehydratisierung von Proteoliposomen mit anschließender Rehydratisierung unter Anlegen eines Wechselspannungsfeldes. Dazu werden zunächst, wie unter 3.6 .5 beschrieben, Proteoliposomen hergestellt. Von diesem Ansatz werden $2 \mu 1$ Tröpfchen auf dem ITObeschichteten Glas verteilt und über Nacht in einem Exsikkator über gesättigter NaCl-Lösung getrocknet. Die Elektroformationskammer wird zusammengebaut und $\mathrm{zu}$ den genannten Bedingungen $3 \mathrm{~h}$ an den Funktionsgenerator angeschlossen. Methode $c$ kommt ohne partielle Dehydratisierung der Proteoliposomen aus. Hierbei werden die ITO-beschichteten Objektträger mit dem gewünschten Lipidfilm beschichtet und getrocknet. Nach Zusammenbau der Elektroformationskammer folgt die Zugabe von Proteoliposomen und der Rehydratisierungslösung. Die Elektroformation erfolgt unter Standardbedingungen.

Für die Herstellung fluoreszenzmarkierter GUVs werden den in Chloroform gelösten Lipiden entsprechende Mengen an Fluorophor zugegeben. Für die Herstellung Carboxyfluorescein (CF) gefüllter GUVs erfolgt die Elektroformation in Rehydratisierungspuffer mit $1 \mu \mathrm{M} \mathrm{CF}$. 
Genauere Angaben der jeweils verwendeten Puffer sowie Fluorophor-, Protein- und Lipidkonzentrationen können den Kapiteln 4.3 und 4.4 entnommen werden.

\subsubsection{Spreiten von riesigen unilamellaren Vesikeln auf mikroporösen Substraten}

Für das Spreiten der GUVs auf mikroporösen Substraten werden $1.2 \mu \mathrm{m}$ Siliziumnitrid-Poren (fluXXion) 10 min in einem Argon-Plasma (Plasma Cleaner PDC 32 G-2, Harrick) gereinigt. Analog der Herstellung von funktionalisierten porösen Aluminaten erfolgt zunächst das Aufbringen einer haftvermittelnden Schicht aus $2.5 \mathrm{~nm}$ Titan mit einem Kathodenzerstäuber (Sputter Coater 108 auto, Cressington) im Argonplasma. Danach folgt eine Schicht aus $45 \mathrm{~nm}$ Gold. Zur Funktionalisierung der Goldoberfläche werden die Substrate über Nacht bei RT in $1 \mathrm{mM}$ TDT (in EtOH p.A.) inkubiert. Vor Einbau der mittels Chemisorption funktionalisierten Substrate in die entsprechenden Messzellen, werden diese gründlich mit Ethanol p.A. gespült und im Stickstoffstrom getrocknet. Nach Einbau der Substrate in die Messzelle müssen die Poren zunächst mit Ethanol p.A. benetzt werden, um eingeschlossene Luft zu verdrängen. Anschließend wird die Messzelle (Abb. 3-25) mit $666 \mu$ l Elektrolytlösung (100 mM KCl, 10 mM TRIS, pH 7.4) und 333 l GUV Suspension befüllt.

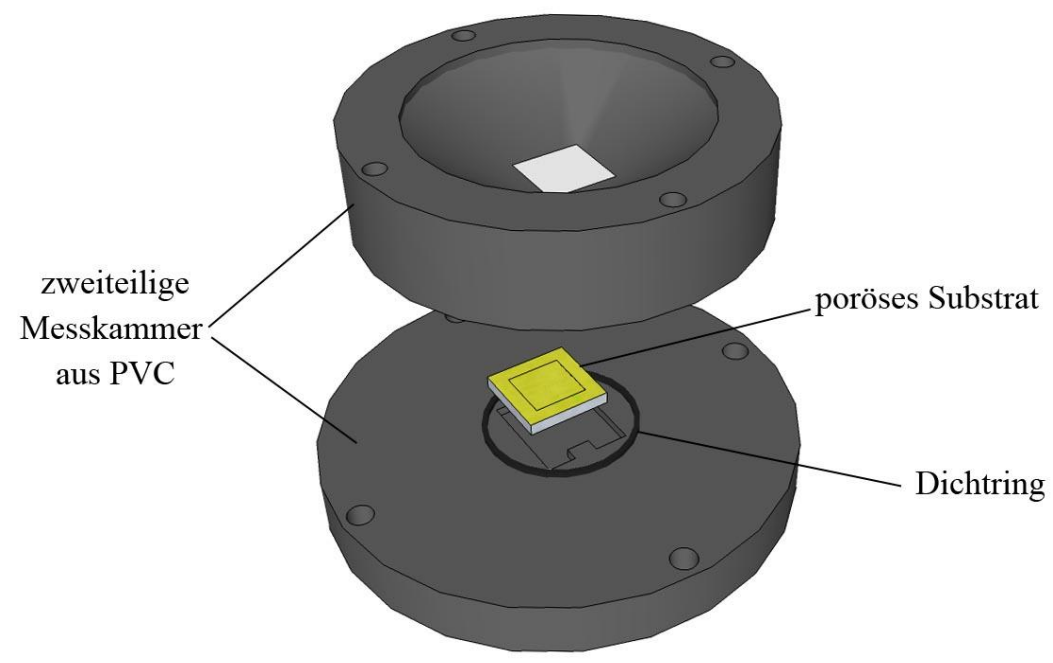

Abb. 3-25: Schematische Darstellung der Messeinheit zum Nachweis der Herstellung von mikro-BLMs mittels CLSM.

Die Messzelle wird anschließend mit Parafilm (Pechiney Plastik Packaging) verschlossen und 1-2 h bei $37{ }^{\circ} \mathrm{C}$ im Trockenschrank inkubiert. Nach Spülen des Substrates mit Puffer können die fluoreszenzmarkierten porenüberspannenden Membranen mittels CLSM untersucht werden. 


\section{$4 \quad$ Ergebnisse}

\subsection{Cytochrom $c$ basierter Vesikelassay}

Für das Ziel einer Integration von Connexonen in Lipidmembranen auf porösen Oberflächen ist es zunächst erforderlich, die verwendeten Proteine hinsichtlich ihrer Funktionalität in einem artifiziellen Membransystem zu überprüfen. Hierfür soll ein Assay etabliert werden, welcher gleichzeitig die Möglichkeit bietet, die Connexon-spezifische Aktivität durch chemische Blocker zu modulieren. Diese Anforderungen können von dem Cytochrom $c$ basierten Vesikelassay erfüllt werden.

\subsubsection{Theoretische Grundlagen}

Cytochrom $c$ (Abb. 4-1 A) ist ein wasserlösliches Protein mit einer molekularen Masse von 12.4 kDa. Die charakteristisch starke Lichtabsorption im sichtbaren Spektralbereich dieser Proteinklasse ist auf eine zentral lokalisierte eisenhaltige prosthetische Gruppe zurückzuführen. Beim so genannten Häm $c$ kann das oktaedrisch komplexierte Fe-(III)-Ion nach Aufnahme eines Elektrons $\mathrm{zu}$ einem $\mathrm{Fe}$-(II)-Ion reduziert werden. Diese elektrochemische Zustandsänderung macht sich auch im Absorptionsspektrum des Cytochrom $c$ bemerkbar (Abb. 4-1 B).
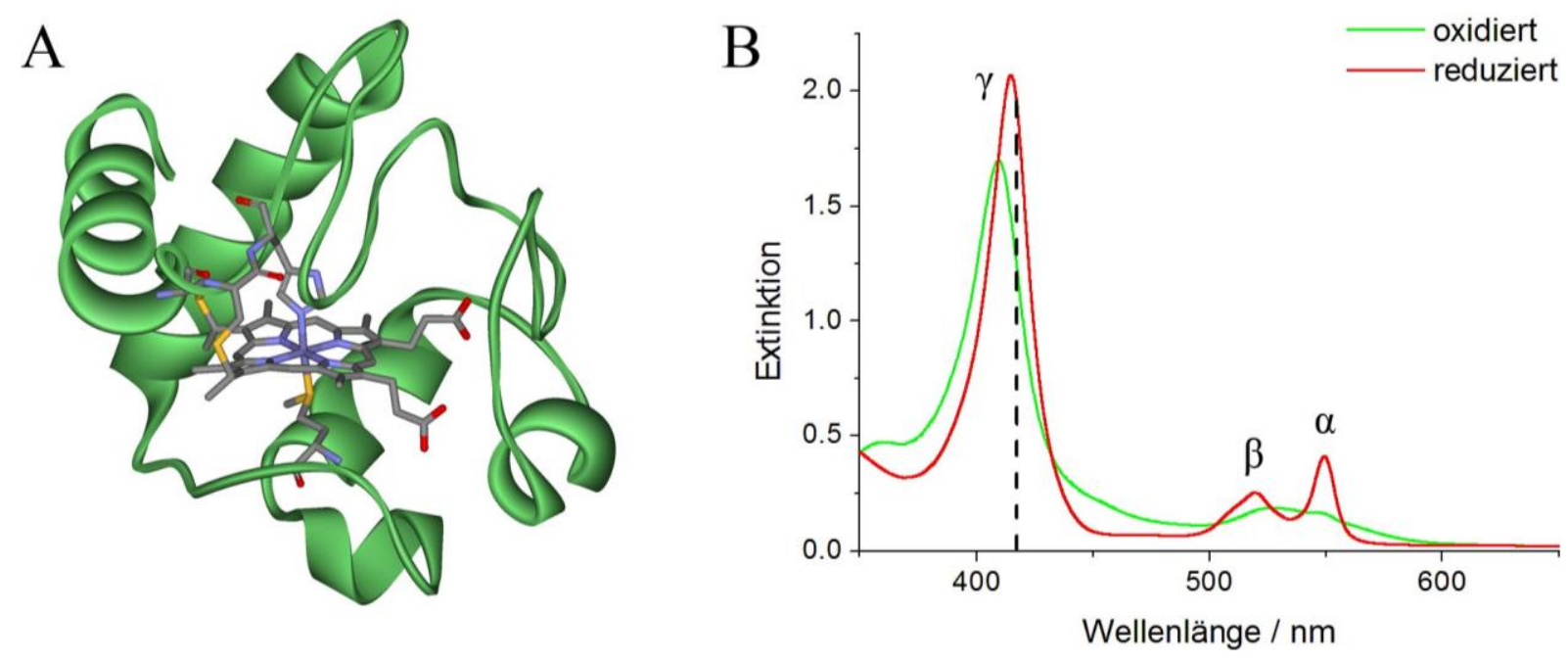

Abb. 4-1: (A) Bändermodell des Cytochrom $c$. Die prosthetische Gruppe Häm $c$ ist als Stäbchenmodell dargestellt. Das Zentralatom Fe (III) kann mittels reduzierender Agenzien in Fe (II) überführt werden. (B) Absorptionsspektrum der oxidierten (grün) und der reduzierten Form (rot) des Cytochrom $c$ im sichtbaren Wellenlängenbereich. Die durch Peakverschiebung induzierte Absorptionsdifferenz ist bei $417 \mathrm{~nm}$ (---) maximal.

Im reduzierten Zustand des Cytochrom $c$ können 3 charakteristische Absorptionsmaxima voneinander unterschieden werden. Diese werden als $\alpha-, \beta-$, und $\gamma$-Bande bezeichnet. Im 
Vergleich zur oxidierten Form ist die $\gamma$-Bande zudem in einen Bereich längerer Wellenlängen verschoben [Lehninger et al. 2009]. Die Differenz des Absorptionsspektrums zwischen reduzierter und oxidierter Form ist bei $417 \mathrm{~nm}$ maximal. Wird einer Cytochrom $c$-haltigen Lösung ein Reduktionsmittel wie etwa Ascorbat hinzugegeben, kann der Übergang zwischen den Redoxzuständen der Proteine zeitaufgelöst bei $417 \mathrm{~nm}$ mittels UV/VIS-Spektroskopie dargestellt werden. Diese im sichtbaren Wellenlängenbereich detektierbare elektrochemische Zustandsänderung ist Grundlage eines bereits in der Literatur etablierten Assays für den Nachweis der funktionellen Rekonstitution von Connexonen in Lipidvesikel [Díez \& Villalobo 1996; Gooden et al. 1985; Locke et al. 2004; Ramundo-Orlando et al. 2005].

\subsubsection{Prinzip des Vesikelassays}

Grundidee des Assays sind Connexonen dotierte Proteoliposomen mit einem intravesikulären Depot an Cytochrom $c$ in der oxidierten Form (Abb. 4-2 A). Mit einer molekularen Masse von etwa $12.4 \mathrm{kDa}$ ist Cytochrom $c$ zu groß, den membrandurchspannenden Kanal eines Connexons $\mathrm{zu}$ passieren. Ascorbat ist mit einer Masse von nur $0.17 \mathrm{kDa}$ nicht permeabilitätsbeschränkt und kann den Kanal passieren. Im Falle einer funktionellen Rekonstitution des Ionenkanals sollte also der intravesikuläre Transfer von Ascorbat ermöglicht werden, was zur Reduktion des Cytochrom $c$ führt und bei einer Wellenlänge von $417 \mathrm{~nm}$ nachgewiesen werden kann. Ramundo-Orlando et al. [2005] gelingt es anhand dieses Prinzips die Aktivität von Cx32 erfolgreich nachzuweisen (Abb. 4-2 B).
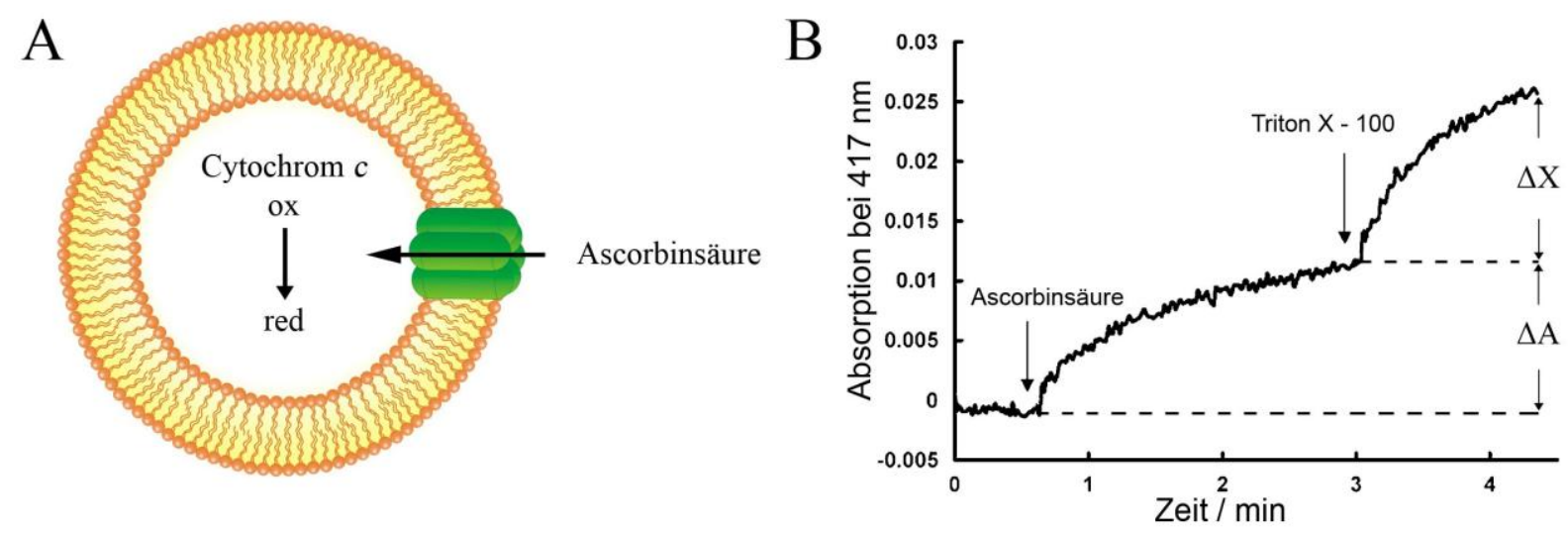

Abb. 4-2: (A) Schematische Darstellung des Cytochrom $c$ Vesikelassays. Das Grundprinzip basiert auf der Kanal-vermittelten intraliposomalen Reduktion von Cytochrom $c$ mittels Ascorbat. (B) Reduktion von intraliposomalem Cytochrom $c$ in $\mathrm{Cx} 32$ dotierten Proteoliposomen. Nachweis der Reduktion durch Absorptionszunahme bei $417 \mathrm{~nm}$ nach Ascorbatzugabe (bei $30 \mathrm{~s}$ ). Solubilisierung der Vesikel mit Triton X - 100 (bei $3 \mathrm{~min}$ ) zur Bestimmung der maximal erreichbaren Absorption. $\Delta \mathrm{A}$ ist der Anteil der Absorption bei $417 \mathrm{~nm}$ welcher auf die Kanal-vermittelte intraliposomale Reduktion von Cytochrom $c$ zurückzuführen ist, $\Delta \mathrm{X}$ ist der Anteil an reduzierbarem Cytochrom $c$, welcher erst nach vollständiger Solubilisierung der Vesikel zur Verfügung steht. Abgewandelt nach [Ramundo-Orlando et al. 2005]. 
Nach Zugabe von Ascorbat zu Cx32 dotierten Proteoliposomen kann ein Anstieg der Absorption bei $417 \mathrm{~nm}$ detektiert werden. Dies ist auf eine Kanal-vermittelte intraliposomale Reduktion von Cytochrom $c$ zurückzuführen. Durch die vollständige Solubilisierung der Proteoliposomen mit Triton-X 100 wird intravesikuläres Cytochrom $c$ freigesetzt, welches zuvor nicht reduziert werden konnte. Hier nicht dargestellt, zeigen Liposomen ohne integriertes Cx32 keinen Anstieg der Absorption nach Zugabe von Ascorbat. Bei diesen Kontrollvesikeln kann erst nach Zugabe von Triton X ein Anstieg der Absorption bei $417 \mathrm{~nm}$ nachgewiesen werden. Bei den von Rammundo-Orlando et al. [2005] durchgeführten Versuchen handelt es sich um Messungen mit einem Zweistrahlphotometer mit Referenzküvette.

\subsubsection{Umsetzung und Durchführung des Assays}

Für die Umsetzung des in 4.1 .1 beschriebenen Vesikelassays müssen einige Grundlagen geschaffen werden. Zunächst ist es erforderlich, Proteoliposomen mit einem intraliposomalem Cytochrom $c$ herzustellen. Diese Vesikel müssen in einem nächsten Schritt von nicht eingeschlossenem also extravesikulärem Cytochrom $c$ getrennt werden. Im Anschluss wird das grundlegende Prinzip des Assays in der Praxis überprüft.

\subsubsection{Herstellung von Cytochrom $c$-haltigen Proteoliposomen}

Der Durchführung des Assays geht eine Rekonstitution des Proteins in unilamellare Cytochrom $c$-haltige Vesikel voraus. Zur Beseitigung des extravesikulären Cytochrom $c$ wird eine Größenausschlusschromatographie mit Sephadex G-75 durchgeführt. Das Ergebnis einer charakteristischen Auftrennung ist Abb. 4-3 zu entnehmen.

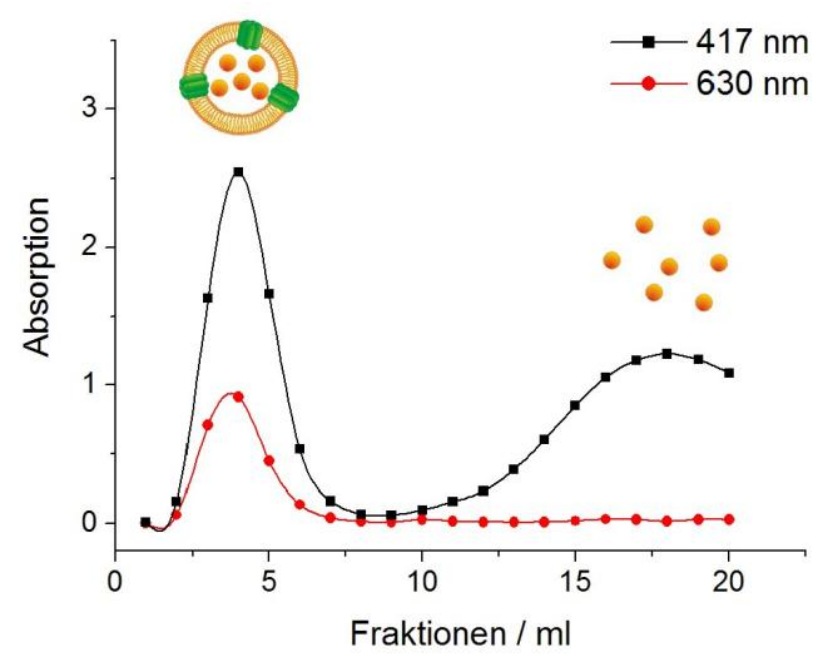

Abb. 4-3: Fraktionen einer charakteristischen Größenausschlusschromatographie zur Trennung von extraliposomalem Cytochrom $c$ von POPC-Proteoliposomen mit intraliposomalem Cytochrom $c$. Die Trübung der Vesikelsuspension wird bei einer Wellenlange von $630 \mathrm{~nm}$ nachgewiesen. Die Cytochrom $c$ enthaltenden Fraktionen werden bei $417 \mathrm{~nm}$ identifiziert. 
Sephadex G-75 ist ein hochmolekulares, neutrales Biopolysaccharid aus quervernetzten Dextran-Untereinheiten und hat eine Ausschlussgrenze (Cutoff) von etwa $80 \mathrm{kDa}$. Hierdurch ist die Retentionszeit des freien Cytochrom $c(12.4 \mathrm{kDa})$ wesentlich größer als die der Proteoliposomen (200 nm Durchmesser). Das Eluat wird in $1 \mathrm{ml}$ Fraktionen aufgefangen und UV/VIS-spektroskopisch analysiert. Die Konzentration des Cytochrom $c$ wird bei $417 \mathrm{~nm}$ detektiert. Die Trübung der Proteoliposomen kann bei $630 \mathrm{~nm}$ nachgewiesen werden. Abb. 4-3 B zeigt das charakteristische Ergebnis einer solchen Auftrennung. Das freie Cytochrom $c$ kann vollständig von den Proteoliposomen mit eingeschlossenem Cytochrom $c$ getrennt werden. Die Vesikelfraktionen werden vereinigt und stehen anschließend für den Assay zur Verfügung.

\subsubsection{2 Überprüfung des Assay-Grundprinzips}

Zunächst werden Versuche durchgeführt, in welchen die generelle Eignung bzw. das Grundprinzip dieses Systems überprüft wird. Die Messungen erfolgen im Einstrahlmodus eines UV/VIS-Spektrometers, daher werden die Proteoliposomen und die Kontrollvesikel ohne Protein unabhängig voneinander untersucht. Steigende Volumina der nach Größenausschlusschromatographie erhaltenen Vesikelfraktionen $(0 \mu 1,25 \mu 1,50 \mu 1,75 \mu 1$, $100 \mu \mathrm{l})$ werden bis zu einem Gesamtvolumen von $990 \mu \mathrm{l}$ zum Messpuffer $(50 \mathrm{mM} \mathrm{KCl}$, $20 \mathrm{mM}$ TRIS, pH 7.4) in eine Küvette pipettiert. Nach Bestimmung der Absorption bei $417 \mathrm{~nm}$ wird mit der zeitaufgelösten Messung begonnen. Voraussetzung für die Zugabe von $10 \mu 130 \mathrm{mM}$ Ascorbat bei $30 \mathrm{sec}$ ist der Erhalt einer stabilen auf Null gesetzten Basislinie. Die Zunahme der Extinktion bei $417 \mathrm{~nm}$ wird über einen Zeitraum von 9 min aufgezeichnet. Anschließend werden $4 \mu 120 \%(v / v)$ Triton X zur vollständigen Solubilisierung des Ansatzes hinzugegeben. Die nach Zugabe von Ascorbat und Triton $\mathrm{X}$ erhaltenen Anstiege $\Delta \mathrm{A}$ und $\Delta \mathrm{X}$ (siehe Abb. 4-2 B) werden in Abhängigkeit von der Absorption der verwendeten Suspension für beide Ansätze (Proteoliposomen und Kontrollvesikel) aufgetragen. Diese Methode soll am Beispiel der Ergebnisse für Panx2 veranschaulicht werden (Abb. 4-4). 

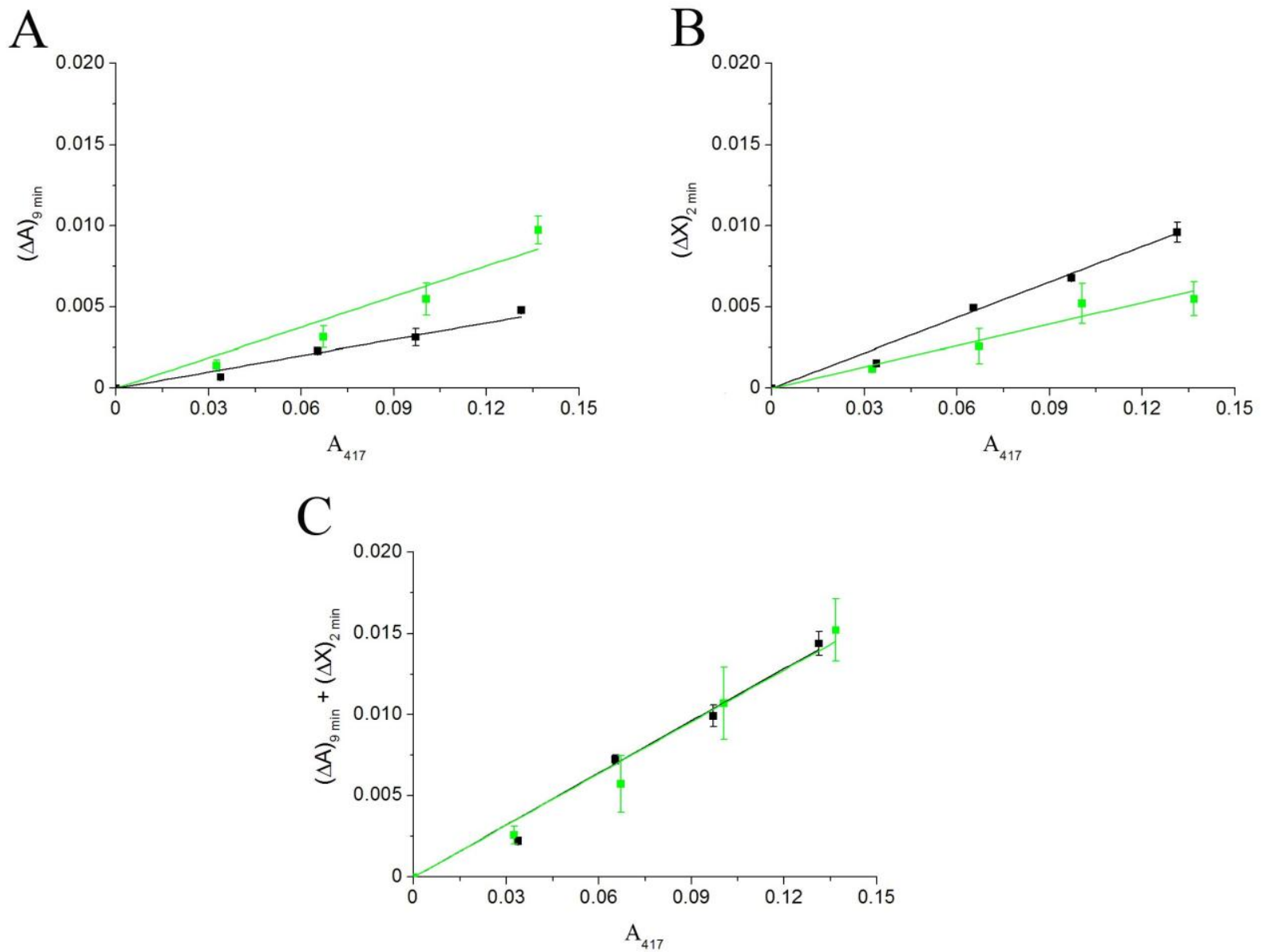

Abb. 4-4: Änderungen der Absorptionen $\Delta \mathrm{A}$ und $\Delta \mathrm{X}$ (siehe Abb. 4-2 B) bei Kontrollvesikeln ohne rekonstituiertes Protein (schwarz) und Panx2 Proteoliposomen (grün) in Abhängigkeit von der eingesetzten Menge an Vesikeln $\left(\mathrm{A}_{417}\right)$. Den Ansätzen werden 0, 25, 50, 75, $100 \mu \mathrm{l}$ der zu untersuchenden Vesikel bis zu einem Gesamtvolumen von $990 \mu \mathrm{l}$ hinzugegeben und die Absorption bei $417 \mathrm{~nm}\left(\mathrm{~A}_{417}\right)$ wird bestimmt. (A) Absorptionsänderung $\Delta \mathrm{A} 9 \mathrm{~min}$ nach Zugabe von $10 \mu \mathrm{l} 30 \mathrm{mM}$ Ascorbat. (B) Absorptionänderung $\Delta \mathrm{X} 2 \mathrm{~min}$ nach vollständiger Solubilisierung mit $4 \mu \mathrm{l} 20 \%$ (v/v) Triton X. (C) Summe aus $\Delta \mathrm{A}$ und $\Delta \mathrm{X}$. An die Datenpunkte wird eine Ursprungsgerade unter Berücksichtigung der Fehler angepasst.

Zunächst wird festgestellt, dass zwischen eingesetzter Menge an Vesikeln und den detektierten $\Delta$-Werten ein linearer Zusammenhang besteht. Liegt das $\Delta \mathrm{A} 9$ min nach Zugabe von Ascorbat bei den Proteoliposomen deutlich höher als bei den Kontrollvesikeln, so werden für das $\Delta \mathrm{X}$ der Proteoliposomen im Vergleich zu den Vesikeln ohne Protein deutlich geringere Absorptionen bestimmt. In beiden Fraktionen wird nach:

$$
(\Delta \mathrm{A}+\Delta \mathrm{X})_{\text {Kontrollvesikel }}=(\Delta \mathrm{A}+\Delta \mathrm{X})_{\text {Proteoliposomen }}
$$

die gleiche Menge an Cytochrom $c$ nachgewiesen (Abb. 4-4 C). Insgesamt könnte dies auf eine kanalvermittelte intraliposomale Reduktion von Cytochrom $c$ zurückzuführen sein. Dieser Zusammenhang kann auch bei Cx26-Proteoliposomen gefunden werden. Festzuhalten bleibt allerdings, dass die Kontrollvesikel, anders als erwartet, ebenfalls ein nicht vernachlässigbares $\Delta \mathrm{A}$ nach Zugabe von Ascorbat aufweisen. Für die geplanten 
Folgeexperimente ist daher die Verwendung einer Zweistrahlmessung unumgänglich. Für alle nachfolgenden Messungen kommen jeweils $100 \mu$ l Liposomen zum Einsatz.

\subsubsection{Experimentelle Umsetzung des Assays}

Da es nur schwer möglich ist, in zwei Küvetten gleichzeitig die Zugabe von Ascorbat oder Triton X bei vollständiger Durchmischung zu gewährleisten, wird zunächst der Ascorbatinduzierte zeitabhängige Anstieg der Absorption unter Verwendung der Proteoliposomen aufgezeichnet. Anschließend erfolgt das gleiche Experiment mit den Kontrollvesikeln ohne Protein. Werden für beide Ansätze jeweils die gleichen Volumina an Liposomen eingesetzt $(100 \mu \mathrm{l})$, unterscheiden sich die Absorptionen bei $417 \mathrm{~nm}$ häufig sehr deutlich voneinander. Dies ist auf unterschiedliche Konzentration aufgrund des Herstellungsprozesses zurückzuführen. So adsorbieren beispielsweise die verwendeten Biobeads einen nicht immer gleichen Anteil an Cytochrom $c$ und auch die nach Durchführung der SEC erhaltenen Fraktionen variieren in ihrer Absorption bei $417 \mathrm{~nm}$. Um beide Ansätze direkt miteinander vergleichen zu können, werden die ermittelten zeitabhängigen Absorptionsänderungen auf die Gesamtcytochrom $c$-Konzentration normiert. Hierfür wird ein Teil der nach SEC vereinigten Fraktion dazu verwendet, die Konzentration an reduzierbarem Cytochrom $c$ zu bestimmen. Ausgehend von dieser Normierung können die zeitabhängig ermittelten $\Delta \mathrm{A}$ der Kontrollvesikel von den Daten der Proteoliposomen abgezogen werden (Abb. 4-5). 

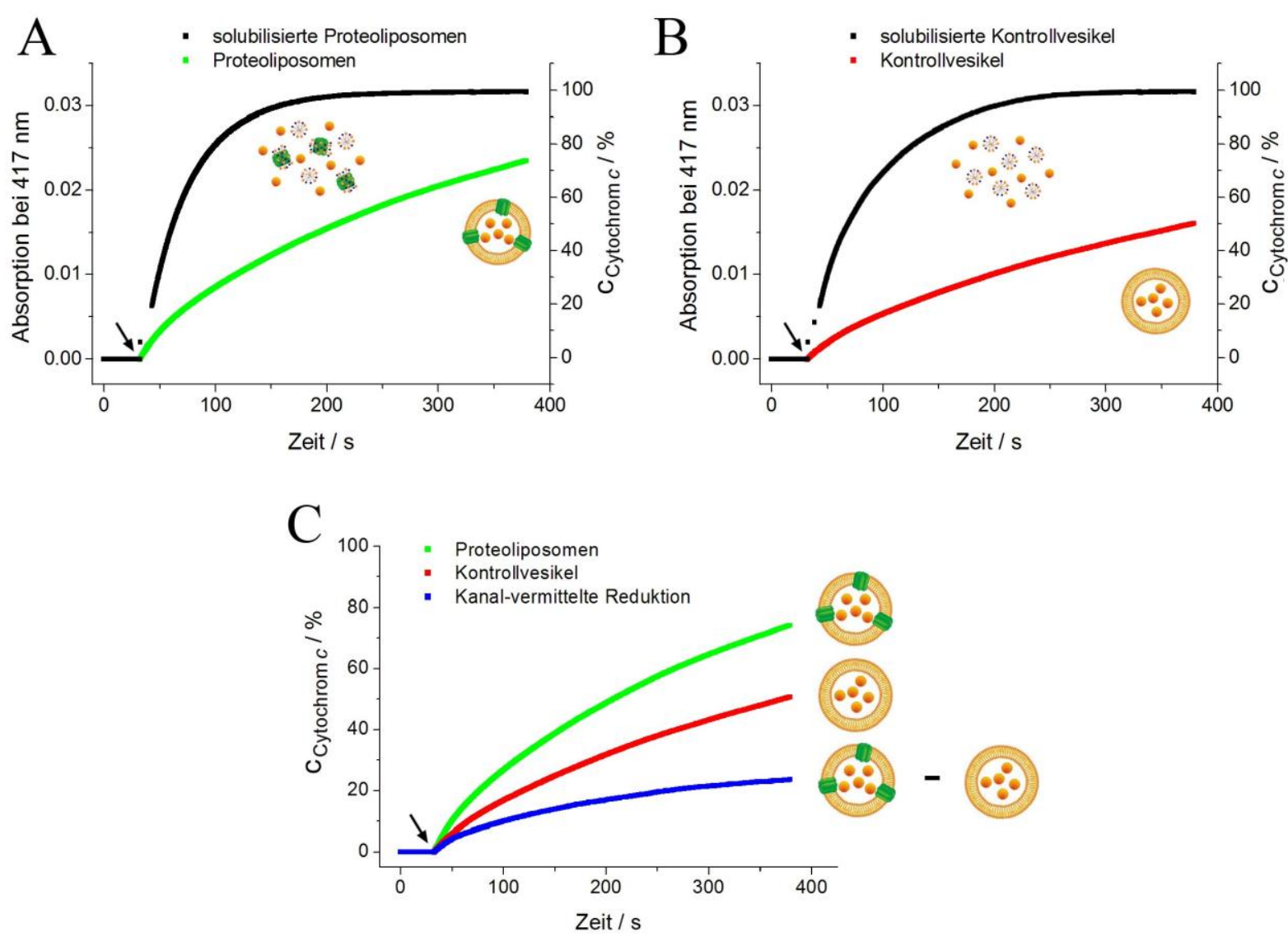

Abb. 4-5: Exemplarische Darstellung der Simulation eines Zweistrahl-Absorptionsexperiments mittels UV/VISSpektroskopie bei $417 \mathrm{~nm}$. Der Pfeil markiert den Zeitpunkt der Ascorbatzugabe. (A) Absorptionszunahme bei $417 \mathrm{~nm}$ nach Zugabe von Ascorbat zu vollständig solubilisierten Cytochrom $c$ haltigen Proteoliposomen ( $\mathbf{a})$ und zu Proteoliposomen mit eingeschlossenem Cytochrom $c$ ( $\square$ ). Die Reduktion des durch Solubilisierung freigesetzten Cytochrom $c$ dient der Bestimmung der maximal erzielbaren Absorption. (B) Wie (A) für vollständig solubilisierte Cytochrom $c$ haltige reine Lipidvesikel (घ) und intakte Lipidvesikel (घ) jeweils ohne rekonstituiertes Protein. (C) Ermittlung des relativen Anteils der Kanal-vermittelten Reduktion von Cytochrom $c$ (घ) durch Subtraktion der erhaltenen Kurven für Proteoliposomen ( $\square$ ) und Kontrollvesikel ( $\square$ ).

Nach dem in Abb. 4-5 beschriebenen Prinzip kann schließlich die Reduktion von Cytochrom $c$ zeitaufgelöst dargestellt werden.

\subsubsection{Modulation der Kanalaktivität mittels chemischer Blocker}

Ist die intraliposomale Reduktion tatsächlich auf einen kanalvermittelten Transfer von Ascorbat zurückzuführen, müsste die beobachtete Permeabilität von Ascorbat durch den Einsatz bekannter Connexon- oder Pannexin-Blocker modulierbar sein. Daher wurden Experimente durchgeführt werden, in denen $\mathrm{zu}$ den Vesikelsuspensionen Blockeragentien pipettiert und mindestens $1 \mathrm{~h}$ inkubiert wurden. Für jede Konzentration an eingesetztem Blocker werden drei Kurven unter Verwendung der Kontrollvesikel aufgezeichnet und gemittelt. Gleiches gilt für die Verwendung der Proteoliposomen. Die gemittelten Kurven werden dann nach dem in Abb. 4-5 C beschriebenen Prinzip voneinander abgezogen und aufgetragen (siehe exemplarisch Abb. 4-6 A). Für die konzentrationsabhängige Blockade der 
Ionenkanäle werden anschließend die Anfangssteigungen (0-25 sec) der Kurven, normiert auf die Steigung der Kurve ohne Blocker, aufgetragen (Abb. 4-6 B).
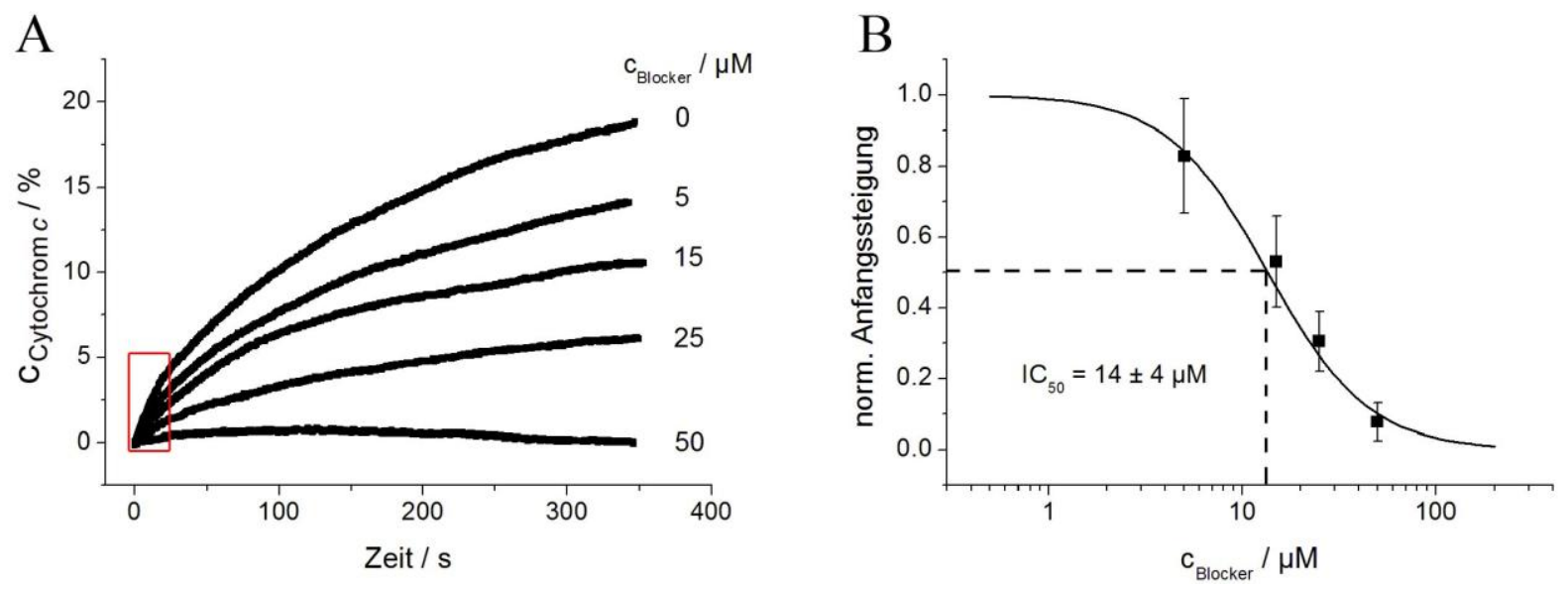

Abb. 4-6: Methode zum Nachweis der Blockade von Cx- oder Panx-Ionenkanälen mittels Cytochrom $c$ basiertem Vesikelassay. (A) Zeitaufgelöste Kanal-vermittelte intraliposomale Reduktion von Cytochrom $c$ nach Ascorbatzugabe (gesetzt auf $0 \mathrm{~s}$ auf der y-Achse) in Abhängigkeit von der Konzentration an eingesetztem Blocker. Bei ausreichender Konzentration an Blocker (hier $50 \mu \mathrm{M}$ ) kann nach Ascorbatzugabe kein intraliposomales Cytochrom $c$ reduziert werden. (B) Semilogarithmische, normierte Auftragung der konzentrationsabhängigen Blockade der Ionenkanäle. Hierfür wird die Anfangssteigung (0 - $25 \mathrm{sec} /$ roter Kasten Abb. A) der in (A) dargestellten Kurven bestimmt. Zur Auswertung wird an die Daten eine Hill Funktion (siehe Formel 4-2) angepasst. Die gestrichelten Linien (---) markieren die Konzentration, welche zur halbmaximalen Blockade des Kanals notwendig ist, hier im Beispiel $I C_{50}=(14 \pm 4) \mu \mathrm{M}$.

Üblicherweise werden die anhand dieser Methode gewonnenen Ergebnisse in einer semilogarithmischen Auftragung wie in Abb. 4-6 B dargestellt. An diese Daten kann eine Hill Funktion angepasst werden:

$$
m_{\mathrm{i}}=m_{\mathrm{iMAX}}\left(\frac{c_{\text {Blocker }^{-n}}{ }^{-n}}{\left[I C_{50}\right]^{-n}+{c_{\text {Blocker }}}^{-n}}\right)
$$

Hierbei ist $m_{\mathrm{imAX}}$ die Anfangsteigung in Puffer ohne Blocker (normiert auf 1). Der $I C_{50}$ ist die Konzentration, welche zur halbmaximalen Blockade der Kanäle benötigt wird, $c_{\text {Blocker }}$ ist die eingesetzte Blockerkonzentration und $n$ ist der Hill Koeffizient.

Nach dem in diesem Abschnitt beschriebenen Prinzip kann sowohl der Protein-mediierte Transfer von Ascorbat über Cx26 als auch über Pannexin1 und Pannexin2 nachgewiesen werden. Hierzu werden die chemische Blocker $\alpha$-Cyclodextrin $(\alpha-\mathrm{CD}), \mathrm{Ca}^{2+}$ und Carbenoxolon $(\mathrm{CBX})$ verwendet. 


\subsubsection{Funktionalitätsnachweis von $\mathrm{Cx} 26$}

Mit der in Abb. 4-5 beschriebenen Methode gelingt es zunächst für die Cx26 Proteoliposomen eine im Vergleich $\mathrm{zu}$ den Kontrollvesikeln erhöhte intraliposomale Reduktion von Cytochrom $c$ nachzuweisen. Handelt es sich hierbei um einen Connexon vermittelten Transfer von Ascorbat, müsste diese Permeabilität mit Connexon-spezifischen Blockern reduziert werden können. Die Ergebnisse diese Studie sind für drei verschiedene Blocker in Abb. 4-7 dargestellt.

A

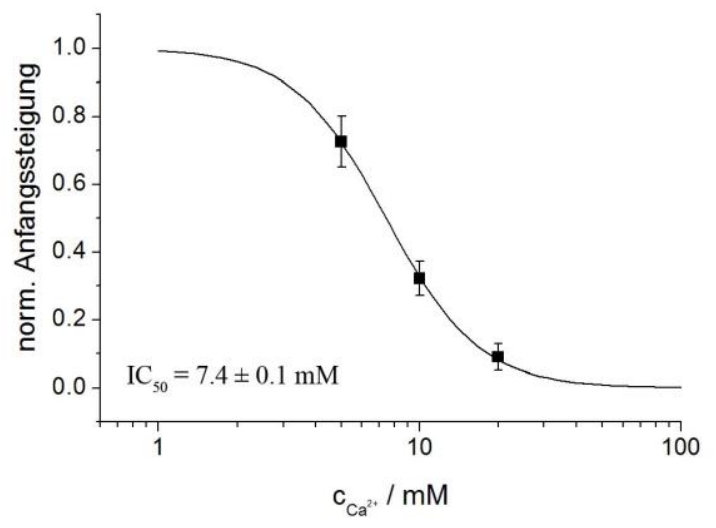

B

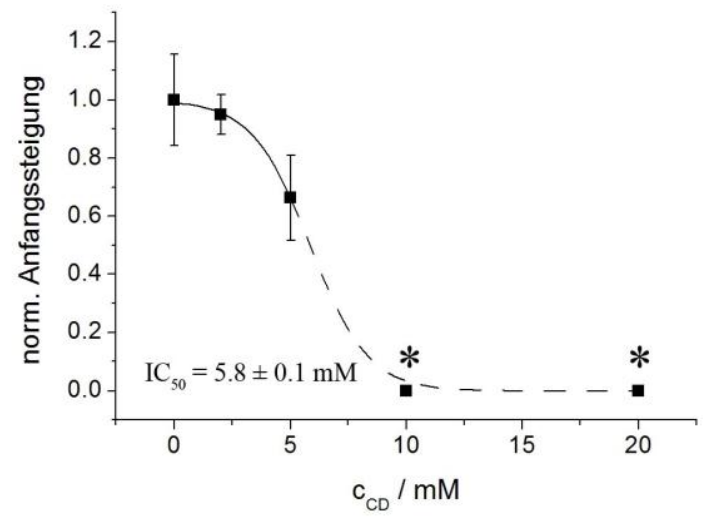

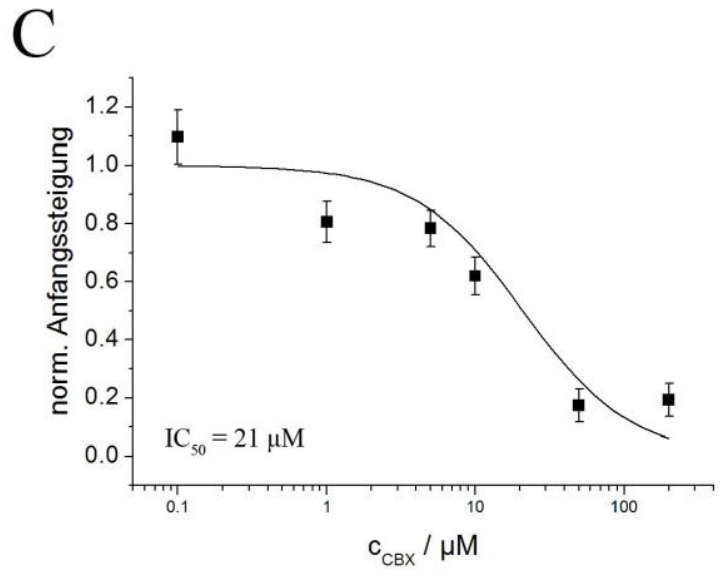

Abb. 4-7: Ergebnisse des Cytochrom $c$ Vesikelassays zum Funktionalitätsnachweis von Cx26 sowie zur Blockade der Halbkanäle mit Calcium, $\alpha$-CD und Carbenoxolon (CBX). (A) Semilogarithmische Auftragung der normierten Datenpunkte zur Blockade von Cx26 mittels Calcium. An die Daten ist eine Hill Funktion (siehe Formel 4-2) mit einem $I C_{50}$ von $7.4 \pm 0.1 \mathrm{mM}$ und $n=2.4 \pm 0.1$ angepasst. (B) Blockade von Cx26 Halbkanälen mit $\alpha$-CD. Den Daten ist eine Boltzmann Funktion mit $m=\left(m_{\mathrm{MIN}}-m_{\mathrm{MAX}}\right) /\left(1+\exp \left(\left(\mathrm{c}-I C_{50}\right) / m_{50}\right)\right)+\mathrm{m}_{\mathrm{MAX}}$ angepasst. Hierbei ist $m_{\mathrm{MAX}}$ die maximale Anfangssteigung (normiert und festgesetzt 1 ), $m_{\mathrm{MIN}}$ die minimale Anfangssteigung (festgesetzt auf 0), $\mathrm{c}$ die Konzentration an eingesetztem $\alpha$-CD und $I C_{50}$ die Blockerkonzentration bei der $\mathrm{m}=0.5$ gilt und an welcher die Funktion eine Steigung $m_{50}$ aufweist. $I C_{50}=5.8 \pm$ $0.1 \mathrm{mM}, m_{50}=1.3 \pm 0.1$. Die mit Stern ( ) markierten Datenpunkte sind simuliert (Erklärung siehe Text), daher ist der Boltzmann Fit $>5 \mathrm{mM} \alpha$-CD als gestrichelte Kurve (---) dargestellt. (C) Semilogarithmische Auftragung der normierten Datenpunkte zur Blockade von Cx26 mit CBX. Die durchgezogene Linie ist die simulierte Hill Funktion mit $I C_{50}=21 \mu \mathrm{M}$ und $n=1.2$.

Die Verwendung von $\mathrm{Ca}^{2+}$ führt $\mathrm{zu}$ einer konzentrationsabhängigen Blockade der rekonstituierten Cx26 Halbkanäle (Abb. 4-7 A). Den halblogarithmisch aufgetragenen Daten 
kann eine Hill Funktion (siehe Formel 4-2) mit einem $I C_{50}$ von $7.4 \pm 0.1 \mathrm{mM}$ und einem Hill Koeffizient von $2.4 \pm 0.1$ angepasst werden. Bei einer Konzentration von $20 \mathrm{mM}$ Calcium im Puffer wird nahezu keine intraliposomale Reduktion von Cytochrom $c$ festgestellt.

Wird das zyklische Oligosaccharid $\alpha$-Cyclodextrin verwendet (Abb. 4-7 B), kann bis zu einer Konzentration von $5 \mathrm{mM}$ ein verminderter Anstieg der Absorption bei $417 \mathrm{~nm}$ nachgewiesen werden. Höhere Konzentrationen führen zu einer starken Trübung der Suspension mit einem, den Boden bedeckenden Niederschlag. Bei der Zugabe von Ascorbat wird dieser aufgewirbelt, was zu einer erheblichen Anstieg der Absorption bei $417 \mathrm{~nm}$ führt, deren Schwankungen enorm sind. Es ist davon auszugehen, dass es sich bei dem Niederschlag um das Fällprodukt aus Proteoliposomen und $\alpha$-CD handelt (siehe Diskussion 5.1.1.1). Diesen Kurvenverläufen kann kein Anstieg zugewiesen werden, welcher mit der Reduktion von Cytochrom $c$ in Verbindung steht. Daher sind diese Datenpunkte in der Abbildung auf Null gesetzt und mit einem Stern ( ) markiert. Weiterhin ist die angepasste Boltzmann-Funktion für Konzentrationen > $5 \mathrm{mM} \alpha-\mathrm{CD}$ aufgrund des beschriebenen Beobachtung gestrichelt dargestellt.

Unter Verwendung des Connexon-spezifischen Blockers CBX, ein synthetisches Derivat der Glycyrrhitinsäure, werden Daten erhalten, welchen in sehr guter Näherung eine aus der Literatur bekannte Hill Funktion mit einem $I C_{50}$ von $21 \mu \mathrm{M}$ und einem Hill Koeffizient von 1.2 angepasst werden kann (siehe 5.1.1.2). Die Übereinstimmung der Daten mit den in der Literatur gewonnen Ergebnissen ist ein Indikator für die Qualität des durchgeführten Cytochrom $c$ basierten Vesikelassays und macht diesen in besonderer Weise geeignet für die Untersuchung von Ionenkanälen wie Panx2, deren Funktionalität bislang weder in Zellstudien noch anderen Experimenten nachgewiesen werden konnte.

\subsubsection{Funktionalitätsnachweis von Panx1 und Panx2}

Sowohl für das Panx2 als auch für Panx1 kann mit der in Abb. 4-5 beschriebenen Methode eine im Vergleich zu den Kontrollvesikeln erhöhte intraliposomale Reduktion von Cytochrom $c$ nachgewiesen werden. Aus Zellstudien ist zudem bekannt, dass sich Panx1 unter Verwendung von CBX im mikromolaren Konzentrationsbereich blockieren lässt [Bruzzone et al. 2005]. Diese Ergebnisse können ebenfalls mit dem Cytochrom $c$ basierten Vesikelassay bestätigt werden. So kann den in Abb. 4-8 A anhand semilogarithmischer Auftragungen dargestellten Daten eine Hill Funktion (siehe Formel 4-2) mit einem $I C_{50}$ von $(14 \pm 4) \mu \mathrm{M}$ und einem Hill Koeffizient von $1.7 \pm 0.6$ angepasst werden. 
A

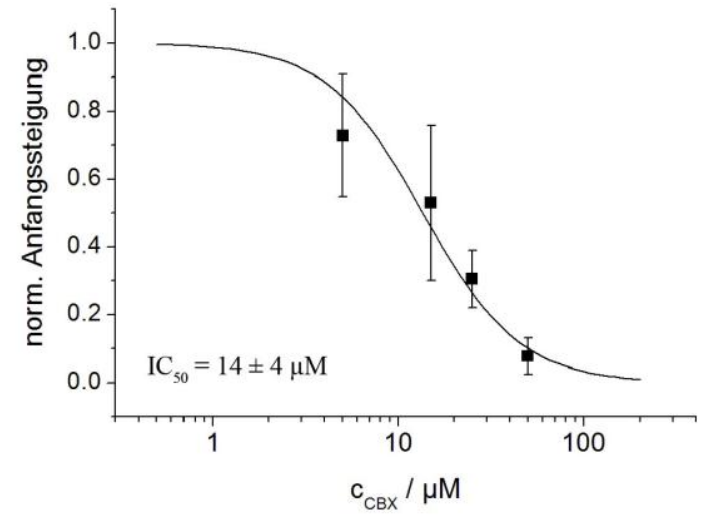

B

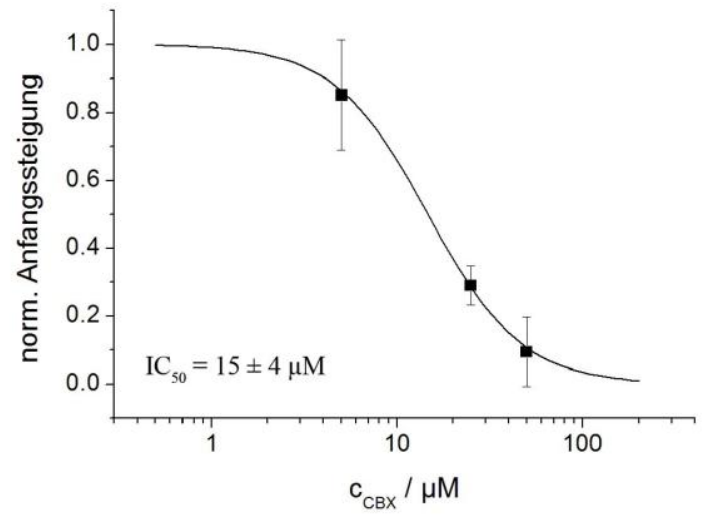

Abb. 4-8: Ergebnisse des Cytochrom $c$ Vesikelassays zum Funktionalitätsnachweis von Pannexin1 und Pannexin2 sowie zur Blockade der Halbkanäle mit Carbenoxolon (CBX). (A) Semilogarithmische Auftragung der normierten Datenpunkte zur Blockade von Pannexin1 mittels CBX. Den Daten ist eine Hill Funktion (siehe Formel 4-2) mit einem $I C_{50}$ von $14 \pm 4 \mu \mathrm{M}$ und $n=1.7 \pm 0.6$ angepasst. (B) Wie (A) für Pannexin2 mit $I C_{50}=15$ $\pm 4 \mu \mathrm{M}$ und $n=1.7 \pm 0.7$.

Konnte die Aktivität von Panx2 bereits mit den exemplarisch in Abb. 4-4 dargestellten Ergebnissen eindeutig belegt werden, so zeigen auch diese Halbkanäle in Abb. 4-8 B eine konzentrationsabhängige Blockade mittels CBX. Aus der angepassten Hill Funktion ergibt sich ein $I C_{50}$ von $(15 \pm 4) \mu \mathrm{M}$ und ein Hill Koeffizient von $(1.7 \pm 0.7)$.

Anhand dieser Ergebnisse kann zum einen die funktionelle Rekonstitution dieser Proteinklasse in Cytochrom $c$ haltige Proteoliposomen bestätigt werden, zum anderen ist dies die erste Studie, in welcher eine Pannexin2 spezifische Aktivität nachweisbar ist. 


\subsection{Integration von Connexonen in Lipidmembranen auf nanoporösen Oberflächen}

Für den Nachweis einer Integration von Connexonen in porenüberspannenden Membranen werden im Rahmen dieser Arbeit Einzelkanalmessungen von Cx26 in nano-BLMs durchgeführt. Im Gegensatz zum Cytochrom $c$ basierten Vesikelassay werden hierfür einzelne Halbkanäle in eine porenüberspannende, artifizielle Membran auf einem nanoporösen Substrat integriert. Die funktionelle Rekonstitution kann mittels voltage-clamp Technik überprüft werden. Grundvoraussetzung für eine umfassende elektrophysiologisch Charakterisierung des Halbkanals ist die Herstellung hochohmiger und langzeitstabiler, porenüberspannender Membranen. Als Trägermaterial dieser artifiziellen Membransysteme dienen funktionalisierte poröse Aluminate. Daher wird zunächst auf die Herstellung dieser Substrate und die Charakteristika der darauf ausgebildeten nano-BLMs eingegangen, um anschließend die Ergebnisse der darin funktionell rekonstituierten Proteine vorzustellen.

\subsubsection{Herstellung poröser Aluminate}

Für die Herstellung von nano-BLMs ist es essentiell, hochgeordnete poröse Aluminate optimaler Qualität herzustellen. Nach Funktionalisierung der Oberfläche mit Gold und TDT (Tetradekanthiol) dienen diese Substrate als Träger der porenüberspannenden Lipidmembranen, welche eine für die Einzelkanalmessung notwendige Hochohmigkeit in Verbindung mit einer im Vergleich zu klassischen BLMs enormen Langzeitstabilität gewährleisten müssen. Der gesamte Herstellungsprozess der porösen Aluminate wird aufgrund dieser speziellen Anforderungen stichprobenartig überwacht und bei Abweichungen der Qualität gegebenenfalls optimiert. Diese Qualitätssicherung erfolgt mit dem Rasterelektronenmikroskop. Das schlecht elektrisch leitende Aluminiumoxid wird für diese Untersuchungen mit einer Schicht von $20 \mathrm{~nm}$ Gold beschichtet.

Für die Herstellung poröser Aluminate gilt es zunächst, die ausgeheizten Aluminiumscheiben hinsichtlich ihrer Oberflächenbeschaffenheit zu optimieren. Weisen diese Substrate vor dem Prozess des Elektropolierens noch deutliche Oberflächenrauhigkeiten auf (Abb. 4-9 A bis C), welche für den Fertigungsprozess grundsätzlich ungeeignet sind, so ist diese Unzulänglichkeit nach Verwendung dieses elektrochemischen Abtragverfahrens hinreichend beseitigt (Abb. 4-9 $\mathrm{D}$ bis F). 

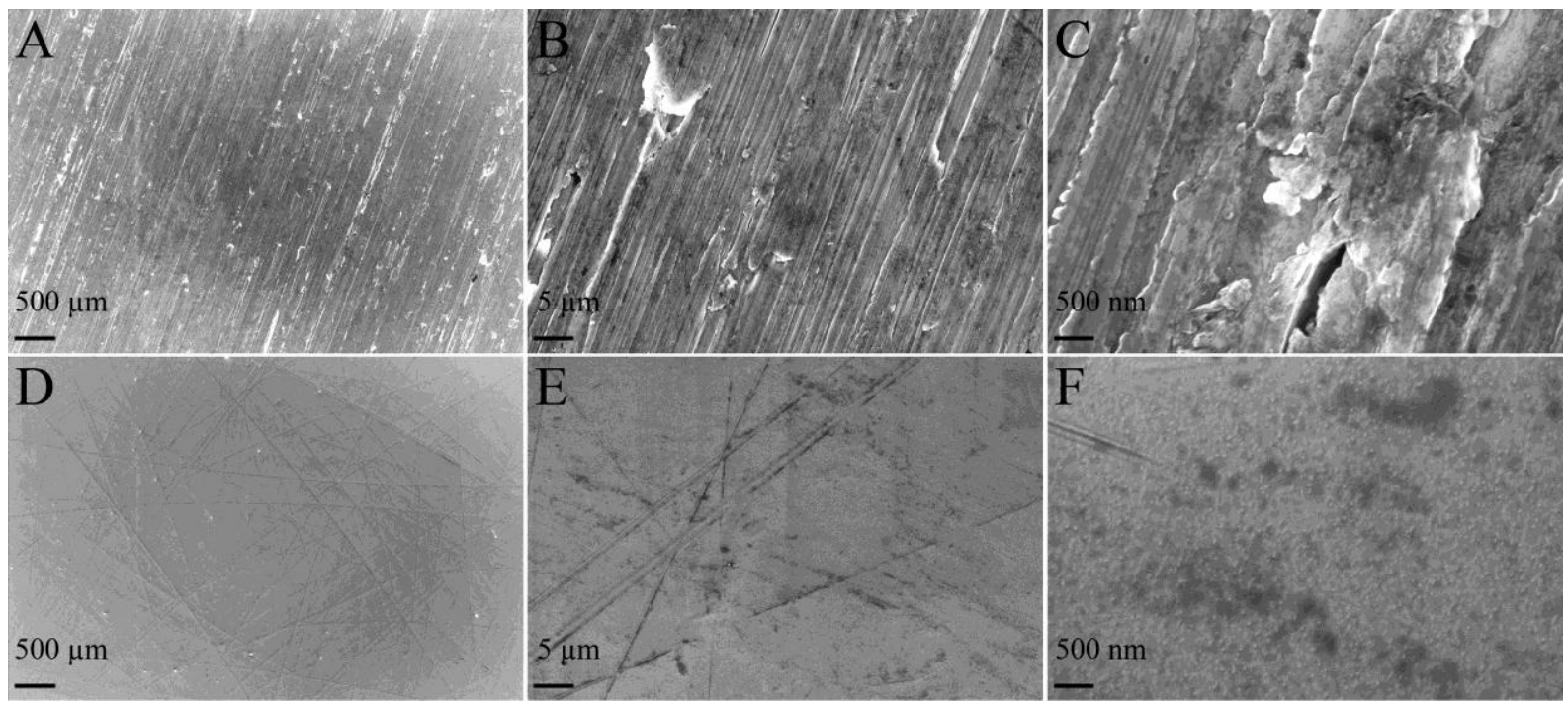

Abb. 4-9: Einfluss des Elektropolierens auf die Oberflächenrauhigkeit der zur Herstellung von porösen Aluminaten verwendeten Aluminiumsubstrate. (A) bis (C) REM-Aufnahmen eines Aluminiumsubstrates bei verschiedenen Vergrößerungen. $\mathrm{A}=400 \mathrm{fache}, \mathrm{B}=4000 \mathrm{fache}, \mathrm{C}=40000 \mathrm{fache}$ Vergrößerung. (D) bis (F) REMAufnahmen der Aluminiumsubstrate nach dem Elektropolieren. $\mathrm{D}=400 \mathrm{fache}, \mathrm{E}=4000 \mathrm{fache}, \mathrm{F}=40000 \mathrm{fache}$ Vergrößerung.

Ausgehend von diesen polierten Substraten können unter Verwendung einer zweistufigen Anodisierung poröse Aluminate hoher Güte hergestellt werden. Dies soll am Beispiel der 60 nm Poren im Folgenden näher beschrieben werden. Die Notwendigkeit eines zweistufigen Prozesses kann zunächst mit Abb. 4-10 veranschaulicht werden.

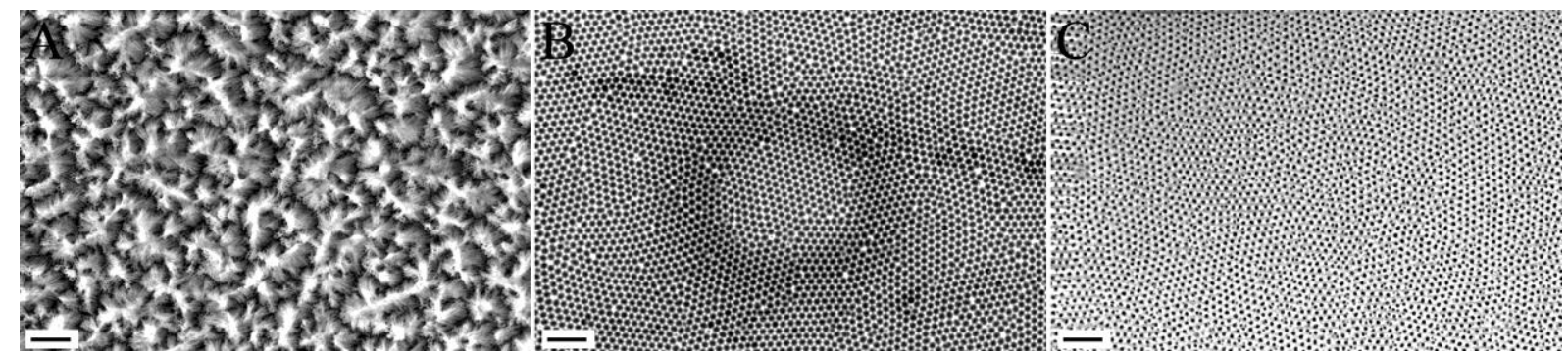

Abb. 4-10: REM-Aufnahmen zur Veranschaulichung des Einflusses der Vorstrukturierung auf den Ordnungsgrad nanoporöser Aluminate. Maßstab =500 nm. (A) Oberflächenbeschaffenheit poröser Aluminate nach der ersten Anodisierung. Eine klare Porenstruktur ist bei 40000facher Vergrößerung nicht erkennbar. (B) Hexagonal vorstrukturierte Aluminiumoberfläche nach chemischer Entfernung der ersten porösen $\mathrm{Al}_{2} \mathrm{O}_{3^{-}}$ Schicht. (C) Im Vergleich zu (A) deutlich erhöhter Ordnungsgrad poröser Aluminate nach der zweiten Anodisierung.

Die elektronenmikroskopische Aufnahme verdeutlicht, dass der Ordnungsgrad der Poren auf der Oberseite des Substrates bei der erster Anodisierung häufig noch sehr ungenügend ist (Abb. 4-10 A) und dieses daher nicht als Träger von nano-BLMs verwendet werden kann. Erst im Verlauf dieser ersten Anodisierung (12 h) erhöht sich der Ordnungsgrad des Porenwachstums. Nach Ablösen der porösen Aluminiumoxidschicht erhält man daher eine hexagonal vorstrukturierte Aluminiumsubstrat-Oberfläche (Abb. 4-10 B), deren Vertiefungen als Keime für die Generierung einer zweiten, von Beginn an wesentlich höher geordneten 
$\mathrm{Al}_{2} \mathrm{O}_{3}$-Schicht dienen (Abb. 4-10 C). Im Vergleich zur ersten Anodisierung sind die auf der Oberfläche des Substrates generierten Poren wesentlich höher geordnet. Im Verlauf der zweiten Anodisierung ( 3 bis 5 Tage) wird aus dieser Präordnung ein häufig nahezu perfekter Porenordnungsgrad auf der Unterseite der porösen Aluminatschicht erzielt (Abb. 4-11).
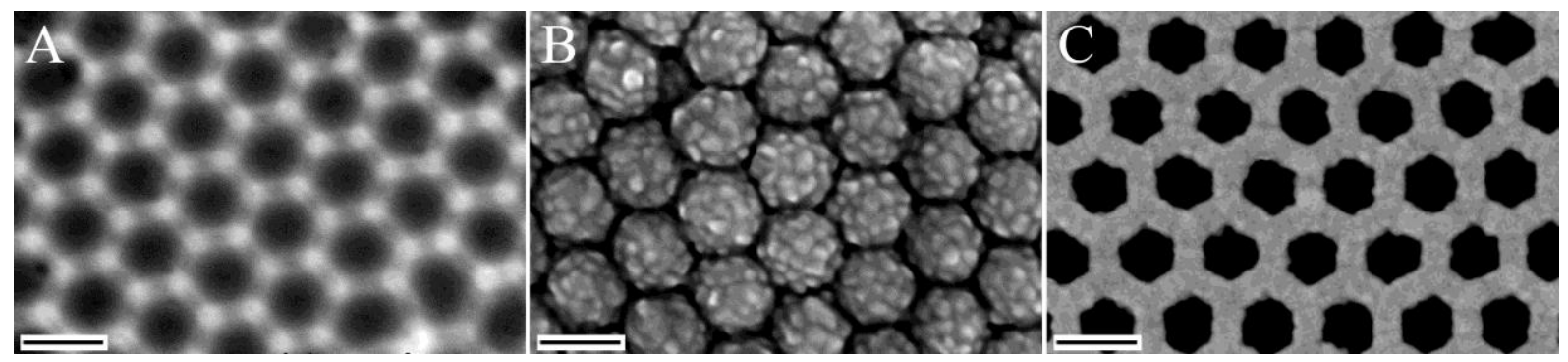

Abb. 4-11: REM-Aufnahmen erhaltener Substrate bei der Herstellung hochgeordneter poröser Aluminate mit $60 \mathrm{~nm}$ Porendurchmesser. Maßstab $=100 \mathrm{~nm}$. (A) Nach chemischer Entfernung der porösen $\mathrm{Al}_{2} \mathrm{O}_{3} \mathrm{Schicht}$ (erster Anodisierung) erhaltene Vorstrukturierung der Aluminiumoberfläche. (B) Porenböden poröser Aluminate nach selektiver Entfernung des Aluminiumsubstrates mit Quecksilberchlorid nach zweiter Anodisierung. (C) Hochgeordnete hexagonale $60 \mathrm{~nm}$ Poren nach Öffnen der Porenböden mit Phosphorsäure.

Durch die Vorstrukturierung nach erster Anodisierung (Abb. 4-11 A) werden in Folge der zweiten Anodisierung und nach selektivem Ablösen des verbleibenden Aluminiums, hochgeordnete hexagonale Porenböden erhalten (Abb. 4-11 B). Diese können nach Porenbödenöffnung mit Phosphorsäure in die charakteristischen vollständig geöffneten hexagonalen $60 \mathrm{~nm}$ Poren überführt werden (Abb. 4-11 C und Abb. 4-12 B).

Unter Verwendung anderer Anodisierungsbedingungen ist es weiterhin möglich, poröse Aluminate mit anderen Porendurchmessern herzustellen (Abb. 4-12).

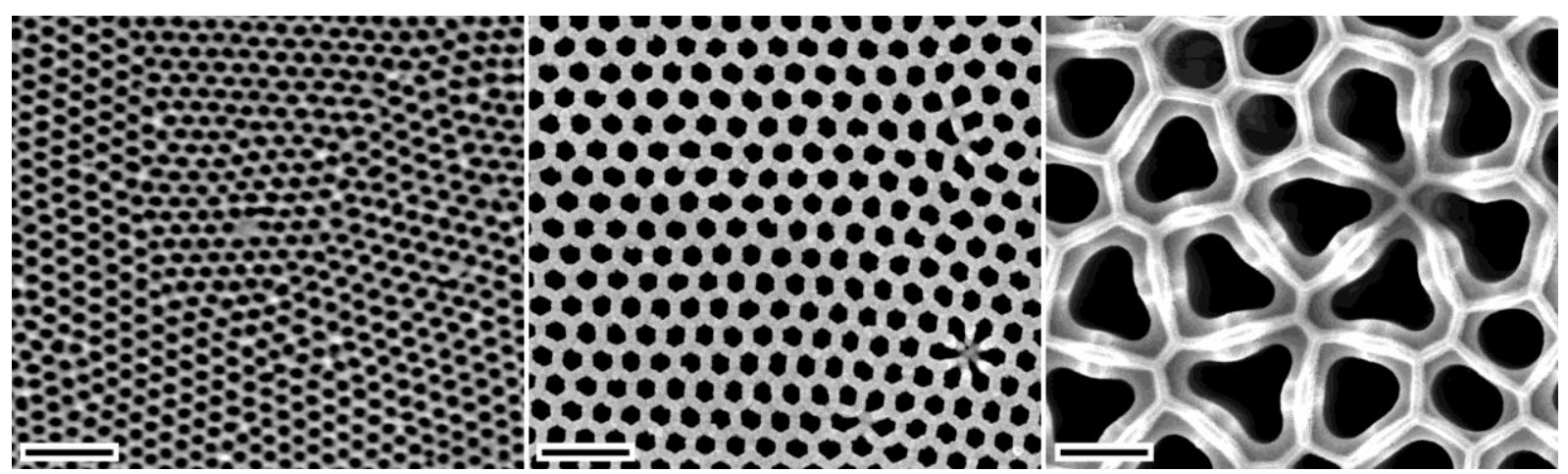

Abb. 4-12: REM-Aufnahmen poröser Aluminate mit unterschiedlichen Porendurchmessern. Maßstab = $300 \mathrm{~nm}$. (A) $20 \mathrm{~nm}$ Poren, Aufsicht. (B) $60 \mathrm{~nm}$ Poren, nach Öffnung der Porenböden. (C) $280 \mathrm{~nm}$ Poren, nach Öffnung der Porenböden.

Mit einer Anodisierungsspannung von $25 \mathrm{~V}$ und $0.3 \mathrm{M}$ Schwefelsäure können bei $1.5^{\circ} \mathrm{C}$ hochgeordnete poröse Aluminate mit einem Porendurchmesser von $20 \mathrm{~nm}$ hergestellt werden (Abb. 4-12 A). Bei einer Anodisierungsspannung von $160 \mathrm{~V}$ unter Verwendung von $10 \%$ iger Phosphorsäure bei $1.5^{\circ} \mathrm{C}$ ist es möglich, poröse Aluminate mit einem Porendurchmesser von 
etwa $280 \mathrm{~nm}$ herzustellen (Abb. 4-12 C). Anders als bei den Poren mit kleinerem Durchmesser können hier keine hexagonal geordneten Strukturen erzeugt werden. Die Poren unterscheiden sich deutlich in Form und Größe und weisen dementsprechend einen sehr geringen Ordnungsgrad auf.

Im Rahmen dieser Arbeit dienen die porösen Aluminate mit einem Porendurchmesser von $60 \mathrm{~nm}$ als Ausgangssubstrate für die Generierung von nano-BLMs.

\subsubsection{Herstellung von nano-BLMs}

Für die Herstellung von nano-BLMs auf den porösen Aluminaten mit einem Porendurchmesser von $60 \mathrm{~nm}$ wird die painting-Technik verwendet. Hierfür wird der nanoporöse Träger auf der Seite der geöffneten Porenböden mit $2.5 \mathrm{~nm}$ Titan und anschließend $25 \mathrm{~nm}$ Gold beschichtet. Durch Chemisorption wird die Goldoberfläche mit Tetradekanthiol (TDT) funktionalisiert. Dieses Substrat wird mittels Dichtringen zwischen den Kompartimenten der Einzelkanalmesszelle (Abb. 3-7) fixiert. Die Teflonkammern werden mit jeweils $1.5 \mathrm{ml}$ Messpuffer befüllt. Anschließend wird durch Aufbringen von etwa 7.5 $\mu 1$ DPhPC (1,2-Diphytanoyl-sn-glycero-3-phosphocholin) gelöst in $n$-Dekan/n-Oktan 1:1 $(v / v)$ mit einer Pipette, auf der cis-Seite des funktionalisierten porösen Aluminates eine nanoBLM präpariert. Die Überwachung des Ausdünnprozesses und die anschließende Eignungsprüfung der Membran erfolgt mittels Impedanzspektroskopie (Abb. 4-13).
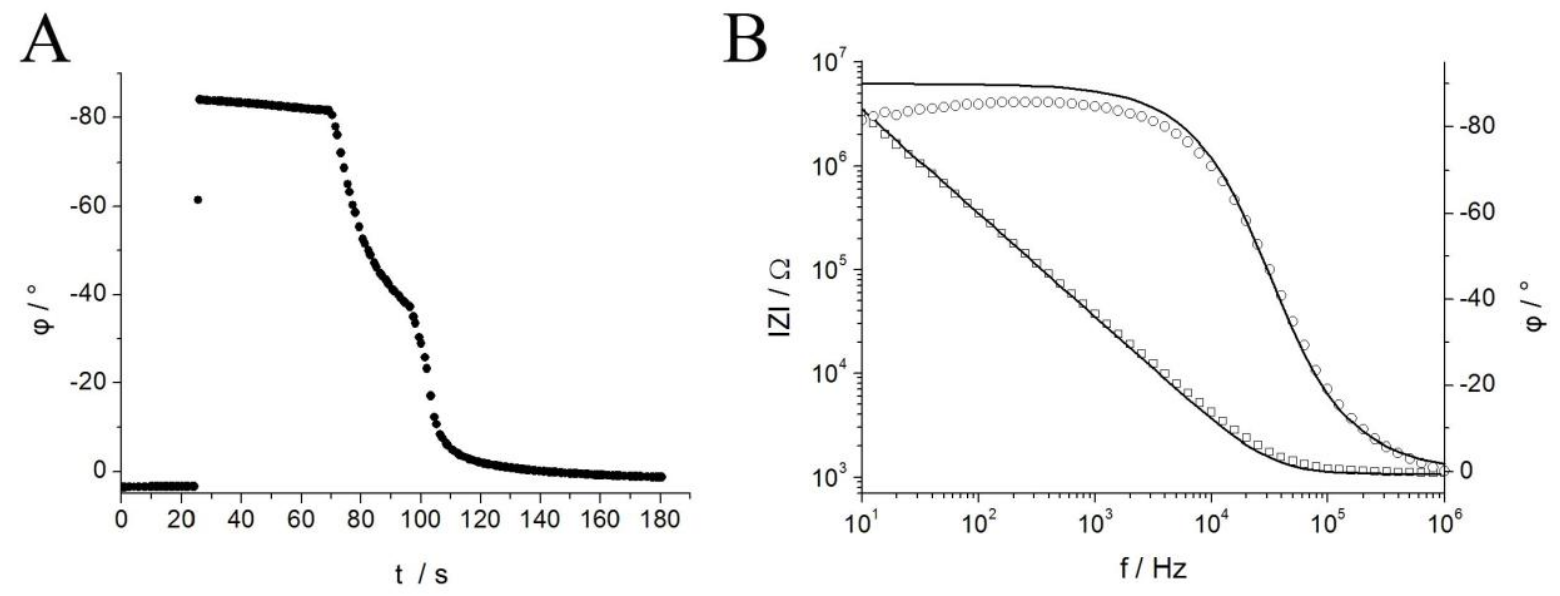

Abb. 4-13: Impedanzspektroskopische Analyse der Ausbildung von nano-BLMs und deren elektrischer Charakteristika. (A) Beobachtung des Ausdünnverhaltens eines Lipidtropfens (20 mM DPhPC in $n$-Dekan $/ n$ Oktan 1:1 $(v / v)$ ) auf einem mit TDT funktionalisierten porösen Aluminat (Porendurchmesser $=60 \mathrm{~nm}$ ). Die Abbildung zeigt den Phasenwinkel $\varphi$ in Abhängigkeit von der Zeit $t$ bei einer Frequenz von $10^{6} \mathrm{~Hz}$. (B) Impedanzspektrum einer nano-BLM in einem Frequenzbereich von $10^{1}-10^{6} \mathrm{~Hz}$. Die Abbildung zeigt den Phasenwinkel $\varphi(\circ)$ und den Betrag der Impedanz $|Z|(\square)$ in Abhängigkeit von der Frequenz $f$ und die Ergebnisse der nichtlinearen Kurvenanpassung (-) mit einem $R C$-Schaltkreis. $C_{\mathrm{m}}=0.44 \mu \mathrm{F} / \mathrm{cm}^{2}$. Puffer: $200 \mathrm{mM} \mathrm{KCl}$, $10 \mathrm{mM}$ HEPES, $0.02 \mathrm{mM}$ EDTA, pH 7.4. 
Abb. 4-13 A zeigt das charakteristische Ausdünnverhalten einer nano-BLM bei einer Frequenz von $10^{6} \mathrm{~Hz}$. Durch Aufbringen der Lipidlösung bei $t=25 \mathrm{~s}$ ist die funktionalisierte Substratoberfläche zunächst vollständig mit einer dicken Schicht aus Lösungsmittel benetzt. Der Phasenwinkel $\varphi$ fällt daher zunächst von etwa $0^{\circ}$ sprunghaft auf etwa $-85^{\circ} \mathrm{ab}$. Im weiteren Verlauf steigt die Phase zunächst langsam auf etwa $-80^{\circ}$ an, um anschließend in einem zweistufigen Prozess innerhalb von $50 \mathrm{~s}$ auf über $-10^{\circ}$ anzusteigen. Das vollständige Ausdünnen des Lipidtropfens ist bei einem Phasenwinkel von $0^{\circ}$ erreicht und dauert weitere 60 s. Die Charakteristika der ausgebildeten porenüberspannenden Membran werden im Anschluss durch Aufnahme eines Impedanzspektrums analysiert. Abb. 4-13 B zeigt ein typisches Impedanzspektrum einer nano-BLM. Der Membranwiderstand ist so hoch, dass er im gezeigten Frequenzbereich $\left(10^{1}-10^{6} \mathrm{~Hz}\right)$ nicht aufgelöst werden kann. Die Kurvenanpassung erfolgt daher für dieses Beispiel mit einem vereinfachten $R C$-Schaltkreis, bestehend aus dem Elektrolytwiderstand $R_{\mathrm{e}}$ in Reihe mit der Membrankapazität $C_{\mathrm{m}}$. Mit einer Substratoberfläche von $0.0314 \mathrm{~cm}^{2}$ und einer Porosität der Aluminate von $33 \%$, berechnet sich eine spezifische Kapazität von $0.44 \mu \mathrm{F} / \mathrm{cm}^{2}$. Generell sind für Einzelkanalmessungen Membranen mit einer Kapazität im Bereich von $0.2-0.5 \mu \mathrm{F} / \mathrm{cm}^{2}$ geeignet. Der Membranwiderstand einer solchen langzeitstabilen nano-BLMs liegt häufig im Bereich $\geq$ $10^{9} \Omega$ und eignet sich damit für rauscharme Einzelkanalmessungen.

\subsubsection{Elektrophysiologische Charakterisierung von Cx26 sowie seiner Mutanten M34A und V84L in nano-BLMs}

Für den elektrophysiologischen Aktivitätsnachweis in porenüberspannenden Membranen wird das kanalbildende Protein Cx26 in nano-BLMs rekonstituiert und unter voltage-clamp Bedingungen mit Transmembranspannungen zwischen $-150 \mathrm{mV}$ und $150 \mathrm{mV}$ untersucht. Bei ausreichender Datenmenge ermöglichen diese Einzelkanalmessungen eine genaue und umfassende elektrophysiologische Charakterisierung des Ionenkanals. So können die für den Wildtyp des Cx26 erhaltenen Daten im Rahmen dieser Arbeit mit den Charakteristika der Mutanten M34A und V84L verglichen werden.

Hierfür werden der cis-Seite der Einzelkanalmesszelle im Bereich der nano-BLM 0.5-2 $\mu 1$ einer Cx26 Lösung ( $2 \mu \mathrm{g} / \mathrm{ml} \mathrm{Cx26} \mathrm{in} \mathrm{Messpuffer} \mathrm{mit} 1 \%(v / v)$ POE) zugegeben. Dies entspricht einer Proteinkonzentration von etwa $0.7-2.7 \mathrm{ng} / \mathrm{ml}$. In einem Zeitraum von etwa 10 min bis $2 \mathrm{~h}$ erfolgt die spontane Rekonstitution einzelner Kanäle (Abb. 4-14), deren 
Aktivität über eine Dauer von wenigen Sekunden bis einigen Minuten untersucht werden kann.
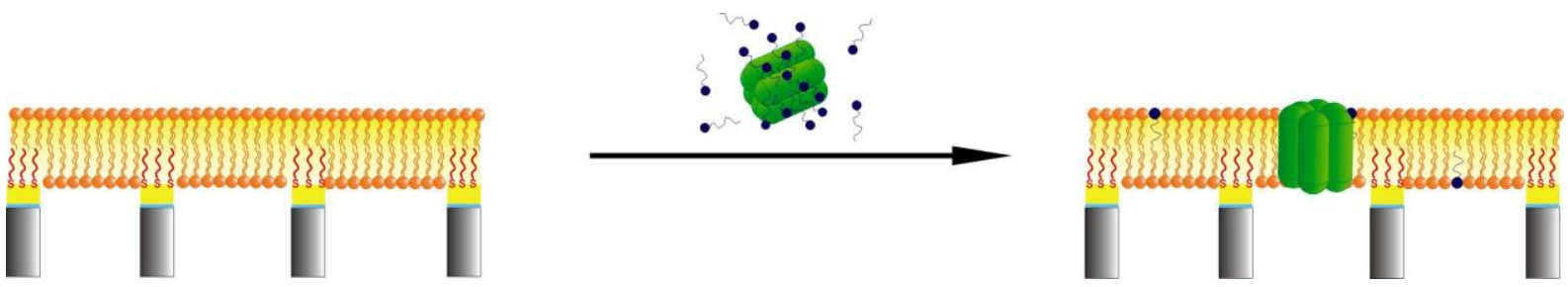

Abb. 4-14: Schematische Darstellung der detergenzbasierten Rekonstitution von Connexonen in nano-BLMs.

Bei konstanter Transmembranspannung werden Intervalle von $30 \mathrm{~s}$ aufgezeichnet und ausgewertet.

Abb. 4-15 zeigt exemplarische Einzelkanalereignisse des Cx26WT und seiner Mutanten M34A sowie V84L in nano-BLMs. Die sprunghaften, stufenartigen Erhöhungen des Transmembranstromes entsprechen hierbei der Öffnung eines einzelnen Halbkanals. Die Rückkehr zur Basislinie ist auf das Schließen des Kanals zurückzuführen. Die gemittelte Leitfähigkeit $G$ eines geöffneten Connexons im Beobachtungszeitraum kann nach Gleichung 3-7 mittels eines Punktamplituden-Histogramms (siehe 3.2.4) bestimmt werden.

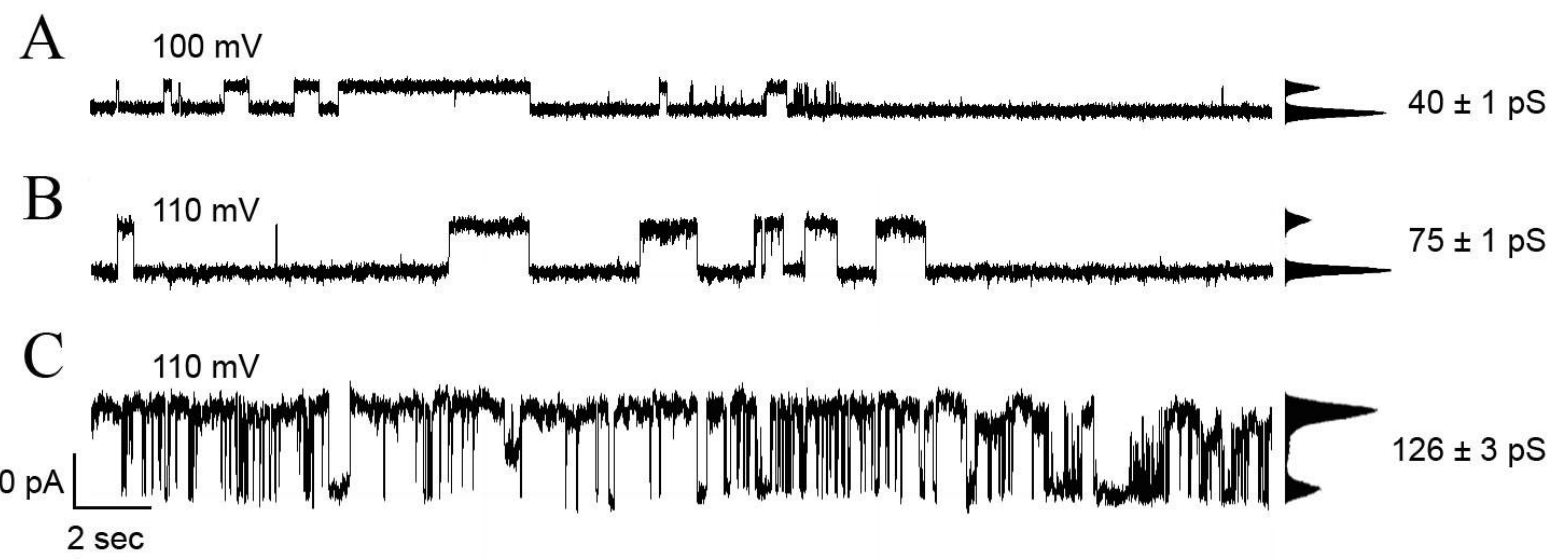

Abb. 4-15: Einzelkanalmessungen von Cx26WT sowie seinen Mutanten M34A und V84L in nano-BLMs. (A) Exemplarische voltage-clamp Messung an einer nano-BLM mit rekonstituiertem Cx26WT $\left(\mathrm{V}_{\mathrm{m}}=+100 \mathrm{mV}\right.$, Puffer: $200 \mathrm{mM} \mathrm{KCl}, 10 \mathrm{mM}$ HEPES, $0.02 \mathrm{mM}$ EDTA, pH 7.4). Die stufenartigen Anstiege des Transmembranstromes sind auf einzelne Kanalöffnungen des funktionell integrierten Halbkanals zurückzuführen. Über ein Punktamplituden-Histogramm (rechts) lässt sich eine gemittelte Leitfähigkeit von $\mathrm{G}=(40 \pm 1) \mathrm{pS}$ bestimmen. (B) Wie (A) mit Cx26M34A bei $\mathrm{V}_{\mathrm{m}}=+110 \mathrm{mV} . \mathrm{G}=(75 \pm 1) \mathrm{pS}$. (C) Wie (A) mit CxV84L bei $\mathrm{V}_{\mathrm{m}}=100 \mathrm{mV} . \mathrm{G}=(126 \pm 3) \mathrm{pS}$.

Bei annähernd gleichen Transmembranspannungen $V_{\mathrm{m}}$ unterscheiden sich die ermittelten Leitfähigkeiten des Cx26WT und der Mutante M34A zwar deutlich voneinander, ansonsten können die Charakteristika anhand dieser Auftragung nur schwer voneinander unterschieden werden. Im Gegensatz zur Mutante V84L weisen sie stabile niederfrequente Öffnungen zu 
einem einheitlichen Stromplateau auf, wohingegen die Mutante V84L hochfrequente und stark uneinheitliche Kanalöffnungen zu unterschiedlichen Stromplateaus aufweist. Für eine aussagekräftige und statistisch gesicherte elektrophysiologische Charakterisierung ist die Detektion und Auswertung einiger tausend Kanalereignisse erforderlich. Die Ergebnisse dieser Analyse sollen im Folgenden vorgestellt werden. Für den WT des Cx26 werden etwa 2700 Kanalöffnungen aufgezeichnet. Für die Auswertung der Mutante M34A und V84L stehen etwa 4100 bzw. 4600 Einzelereignisse zur Verfügung.

\subsubsection{Histogrammanalyse zur Bestimmung der Leitfähigkeit}

Zunächst bietet es sich an, eine Histogrammanalyse aller ermittelten Leitfähigkeiten durchzuführen. Anders als bei der Mittelung der Leitfähigkeiten eines Aufzeichnungsintervalls anhand von Punktamplituden-Histogrammen, werden hierfür alle detektierten Kanalereignisse einzeln und unabhängig voneinander erfasst und hinsichtlich ihrer Leitfähigkeit ausgewertet (siehe 3.2.4 Softwaregestützte Einzelerfassung von Kanalereignissen). Die Ergebnisse dieser Analyse sind in nachstehender Abbildung zusammengefasst. 

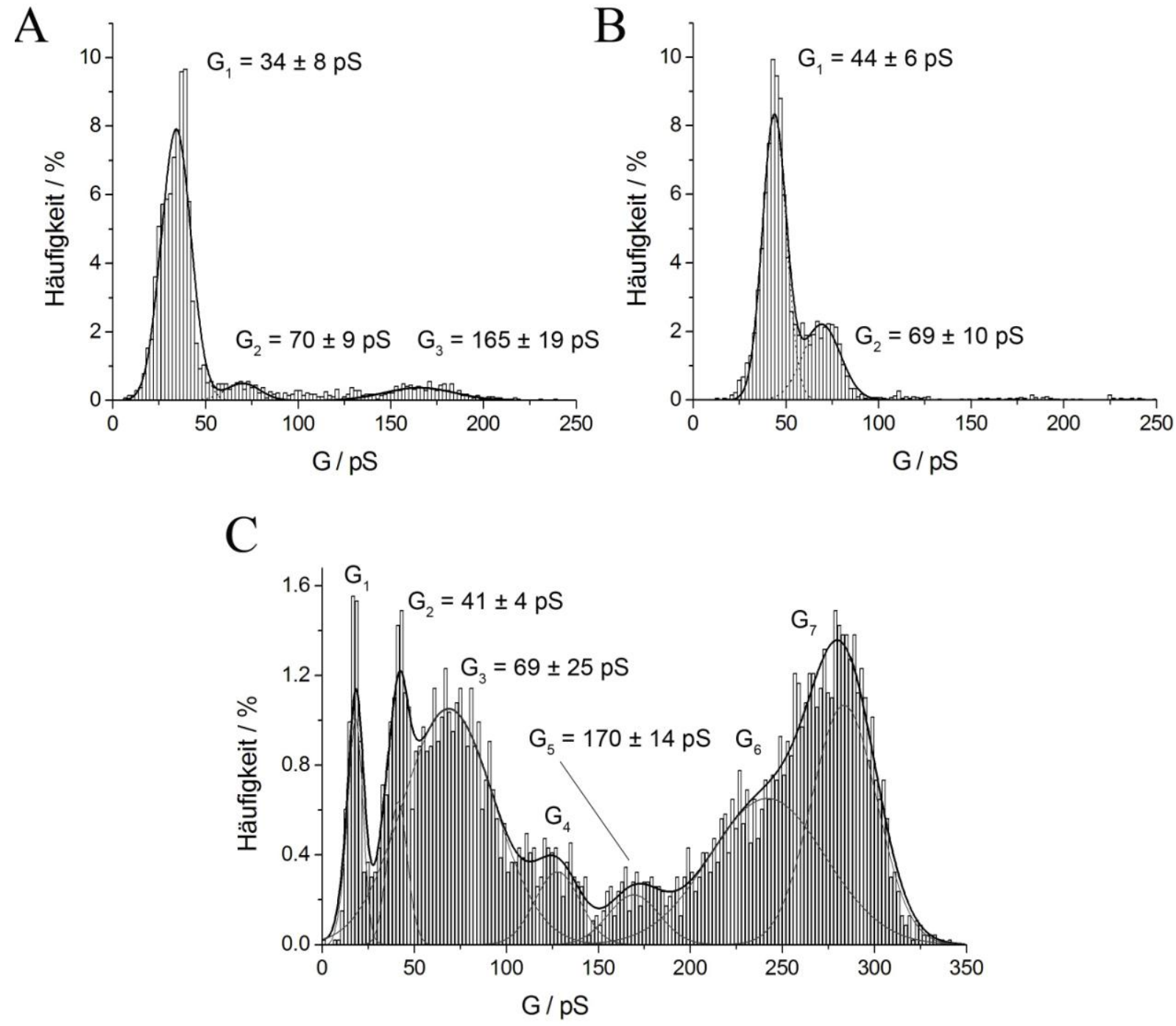

Abb. 4-16: Ereignis-Histogrammanalyse von Cx26WT sowie seinen Mutanten M34A und V84L. (A) EreignisHistogramm aller detektierten Kanalöffnungen des Cx26WT (2691 Ereignisse, Intervallbreite $=2$ pS $)$ in nanoBLMs ( $\mathrm{V}_{\mathrm{m}}$ zwischen -150 und $+150 \mathrm{mV}$, Puffer: $200 \mathrm{mM} \mathrm{KCl}, 10 \mathrm{mM}$ HEPES, $0.02 \mathrm{mM}$ EDTA, pH 7.4). Den Daten kann eine überlagerte Gauß-Verteilung 3ter Ordnung angepasst werden (-). Es können drei Hauptleitfähigkeitsstufen $G_{1}=(34 \pm 8) \mathrm{pS}, G_{2}=(70 \pm 8) \mathrm{pS}$ und $G_{3}=(165 \pm 19)$ voneinander unterschieden werden. (B) Wie (A) für Cx26M34A. Für die 4137 aufgezeichneten Ereignisse können mittels einer überlagerten Gausverteilung 2ter Ordnung (-) die Hauptleitfähigkeitsstufen $G_{1}=(34 \pm 8) \mathrm{pS}$ und $G_{2}=(70 \pm 8) \mathrm{pS}$ ermittelt werden. (C) Wie (A) für Cx26V84L. Bei den 4634 aufgezeichneten Ereignissen können mittels einer überlagerten Gausverteilung 7ter Ordnung (-) sieben Hauptleitfähigkeitsstufen voneinander unterschieden werden: $G_{1}=(17 \pm 3) \mathrm{pS}, G_{2}=(41 \pm 4) \mathrm{pS}, G_{3}=(69 \pm 25) \mathrm{pS}, G_{4}=(127 \pm 12) \mathrm{pS}, G_{5}=(170 \pm 14) \mathrm{pS}$, $G_{6}=(242 \pm 31) \mathrm{pS}$ und $G_{7}=(284 \pm 17) \mathrm{pS}$.

Die Histogrammanalyse zeigt, dass die ermittelten Leitfähigkeiten in überlagerten Normalverteilungen resultieren, welche durch Anpassung normierter Gaußfunktionen beschrieben werden können:

$$
f\left(G_{\mathrm{Cx}}\right)=\sum_{i=1}^{n} \frac{A_{\mathrm{i}}}{\sigma_{G_{\mathrm{i}}} \sqrt{2 \pi}} \cdot \exp \left(\frac{-\left(G_{\mathrm{Cx}}-G_{\mathrm{i}}\right)^{2}}{2 \sigma_{\mathrm{G}_{\mathrm{i}}}{ }^{2}}\right)
$$


Hierbei ist $G_{\mathrm{Cx}}$ die experimentell bestimmte Leitfähigkeit der Einzelkanalereignisse, $G_{\mathrm{i}}$ die Leitfähigkeit, an welcher die Gaußfunktion zentriert ist, $\sigma_{\mathrm{Gi}}$ die Standardabweichung der Leitfähigkeit, $A_{\mathrm{i}}$ die Fläche der angepassten Gaußfunktion und $n$ die Anzahl der überlagerten Gaußverteilungen. Für den WT des Cx26 wird eine Gaußfunktion 3ter Ordnung an die Daten angepasst. Etwa $86 \%$ aller detektierten Ereignisse können der Hauptleitfähigkeitsstufe $G_{1, \mathrm{WT}}=(34 \pm 8) \mathrm{pS}$ zugeordnet werden. Die Leitfähigkeitsstufen $G_{2, \mathrm{WT}}=(70 \pm 8) \mathrm{pS}$ und $G_{3, \mathrm{WT}}=(165 \pm 19) \mathrm{pS}$ werden bei $5 \%\left(G_{2, \mathrm{WT}}\right)$ bzw. $9 \%\left(G_{3, \mathrm{WT}}\right)$ der Ereignisse nachgewiesen. Die Mutante M34A erweist sich im Rahmen dieser Auswertung als annähernd komplementär zum WT des Cx26. Im Vergleich können allerdings nur zwei Hauptleitfähigkeitsstufen definiert werden, welche in etwa denen des WT entsprechen. Auch hier sind Ereignisse der Hauptleitfähigkeitsstufe $G_{1, \mathrm{M} 34 \mathrm{~A}}=(44 \pm 6) \mathrm{pS}$ mit einem erhöhten Anteil von $71 \%$ vertreten. $29 \%$ der ausgewerteten Kanalöffnungen haben Leitfähigkeiten in einem Bereich von $G_{2, \mathrm{M} 34 \mathrm{~A}}=(69 \pm 10) \mathrm{pS}$. Wie bereits bei den exemplarisch dargestellten Einzelkanalmessungen angedeutet, ist die Leitfähigkeitsverteilung der Mutante V84L bei gleicher Binbreite deutlich inhomogener und wesentlich breiter. Hier können insgesamt sieben Hauptleitfähigkeitsstufen voneinander unterschieden werden: $G_{1, \mathrm{~V} 84 \mathrm{~L}}=(17 \pm 3) \mathrm{pS}, \quad G_{2, \mathrm{~V} 84 \mathrm{~L}}=(41 \pm 4) \mathrm{pS}$, $G_{3, \mathrm{~V} 84 \mathrm{~L}}=(69 \pm 25) \mathrm{pS}, \quad G_{4, \mathrm{~V} 84 \mathrm{~L}}=(127 \pm 12) \mathrm{pS}, \quad G_{5, \mathrm{~V} 84 \mathrm{~L}}=(170 \pm 14) \mathrm{pS}, \quad G_{6, \mathrm{~V} 84 \mathrm{~L}}=(242 \pm$ 31) $\mathrm{pS}$ und $G_{7, \mathrm{~V} 84 \mathrm{~L}}=(284 \pm 17) \mathrm{pS}$.

\subsubsection{Analyse der Strom-Spannungs-Abhängigkeit}

Die in Abb. 4-16 dargestellten Leitfähigkeiten der Halbkanäle werden bei unterschiedlichen Transmembranspannungen detektiert. Die Darstellung der Daten in einem gemeinsamen Histogramm setzt ein ohmsches Verhalten der Halbkanäle voraus. Dieses Verhalten ist dann gegeben, wenn sich die Ionenkanäle bei angelegter Transmembranspannung wie ein ohmscher Widerstand verhalten. In diesem Fall wäre eine lineare Strom-Spannungs-Abhängigkeit zu erwarten, welche die Ordinate bei $I=0$ pA schneidet. Wie Abb. 4-17 verdeutlicht, ist dies für alle untersuchten Halbkanäle eindeutig nachzuweisen. 

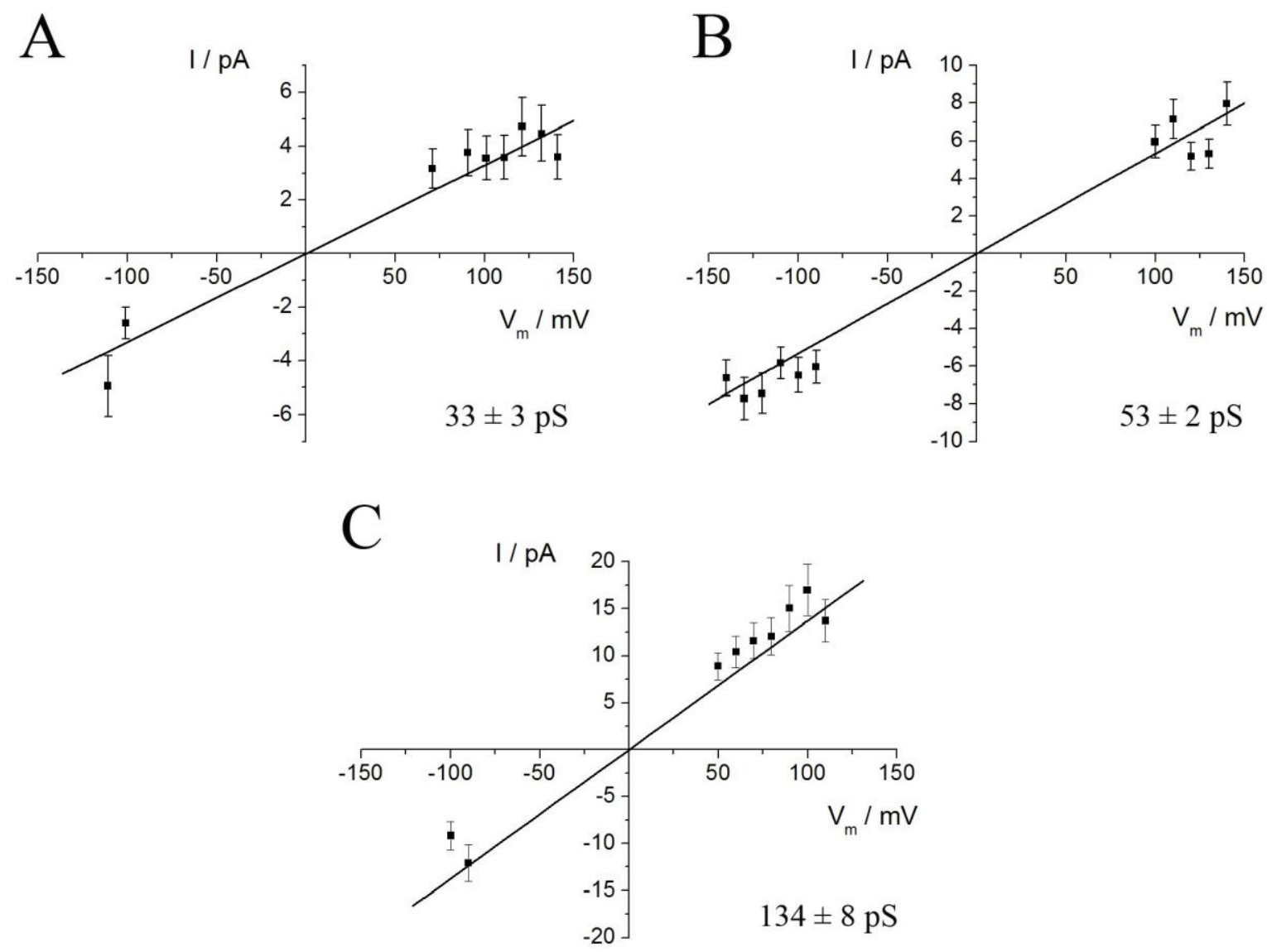

Abb. 4-17: Strom-Spannungs-Abhängigkeit des Cx26WT sowie seiner Mutanten M34A und V84L in nanoBLMs. (A) $I$ - $V$-Abhängigkeit der detektierten Kanalereignisse des Cx26WT in nano-BLMs ( $V_{\mathrm{m}}$ zwischen -150 und $+150 \mathrm{mV}$, Puffer: $200 \mathrm{mM} \mathrm{KCl}, 10 \mathrm{mM}$ HEPES, $0.02 \mathrm{mM}$ EDTA, pH 7.4). Grundlage dieser Analyse sind 2169 Ereignisse, welche der Hauptleitfähigkeitsstufe $\mathrm{G}_{1}$ (siehe Abb. 4-16 A) in einem Bereich zwischen 0 und $63 \mathrm{pS}$ zugeordnet werden können und für jedes $\mathrm{V}_{\mathrm{m}}$ gemittelt werden. Die lineare I-V-Abhängigkeit lässt auf ein ohmsches Verhalten des Kanals schließen. Aus der Steigung kann nach $G=I / U$ eine Leitfähigkeit von (33 \pm 3) $\mathrm{pS}$ berechnet werden. (B) Wie (A) für Cx26M34A. Grundlage sind 3476 Ereignisse, welche der Hauptleitfähigkeitstufe $\mathrm{G}_{1}$ (siehe Abb. 4-16 B) in einem Bereich von 0 - 70 pS zugeordnet werden können. Aus der linearen I-V-Abhängigkeit kann eine Leitfähigkeit von $(53 \pm 2) \mathrm{pS}$ berechnet werden. (C) Wie (A) für Cx26V84L. Grundlage sind 414 Ereignisse, deren $I$-V-Abhängigkeit ebenfalls linear ist. $G=(134 \pm 8) \mathrm{pS}$.

Für die Darstellung der $I$-V-Abhängigkeit der Kanäle werden für den WT des Cx26 und die Mutante M34A alle Vertreter der Hauptleitfähigkeitsstufe $G_{1}$ verwendet. Aufgrund des inhomogenen Verhaltens der Mutante V84L dienen 414 Ereignisse eines einzelnen Messtages als Grundlage der Auswertung. Den Datenpunkten kann eine Ursprungsgerade angepasst werden, anhand deren Steigung für den WT nach $G=I / U$ eine Leitfähigkeit von $(33 \pm 3) \mathrm{pS}$ ermittelt wird. Die Leitfähigkeit von $(53 \pm 2) \mathrm{pS}$ der Mutante M34A liegt in etwa in der gleichen Größenordnung. Eine deutlich höhere Leitfähigkeit von $(143 \pm 1)$ pS kann für V84L ermittelt werden.

Bei der Histogrammanalyse (Abb. 4-16) können für den WT des Cx26 und die Mutante M34A deutlich voneinander abgegrenzte Leitfähigkeitsstufen unterschieden werden. Die in Abb. 4-15 exemplarisch dargestellten 30s-Intervalle beider Proteine lassen jedoch nur ein 
Leitfähigkeitsplateau erkennen. Dies gilt für alle aufgezeichneten voltage-clamp Messungen. Für die Aufklärung dieser Widersprüchlichkeit können die Leitfähigkeitsverteilungen bei unterschiedlichen Transmembranspannungen $V_{\mathrm{m}}$ näher untersucht werden. Hierbei werden nur Spannungen in Betracht gezogen, bei welchen eine ausreichende Anzahl an Kanalereignissen vorliegt (siehe Tabelle 2).

Tabelle 2: Anzahl der detektierten Kanalereignisse für Cx26WT sowie M34A und V84L bei unterschiedlichen Transmembranspannungen $V_{\mathrm{m}}$.

\begin{tabular}{ccc}
\hline Cx26 & $\boldsymbol{V}_{\mathbf{m}} / \mathbf{m V}$ & Ereignisse \\
\hline WT & 101 & 692 \\
& 111 & 770 \\
& 132 & 704 \\
M34A & 120 & 2489 \\
& -130 & 282 \\
& 140 & 413 \\
V84L & 111 & 1564 \\
& 130 & 559 \\
& 151 & 571 \\
\hline
\end{tabular}

Für den WT des Cx26 liegen jeweils etwa 700 Kanalereignissen für $101 \mathrm{mV}, 111 \mathrm{mV}$ und $132 \mathrm{mV}$ vor. Bei den Mutanten M34A und V84L dominieren die Kanalereignisse bei 120 bzw. $\quad 111 \mathrm{mV}$. Die Leitfähigkeitsverteilungen in Abhängigkeit von der Transmembranspannung $V_{\mathrm{m}}$ sind in nachstehender Abbildung für alle untersuchten Proteine zusammengefasst. Für eine bessere Veranschaulichung der Daten werden die Ergebnisse dieser Histogrammanalyse nicht als Balken sondern in Linienform dargestellt (Abb. 4-18). 
A

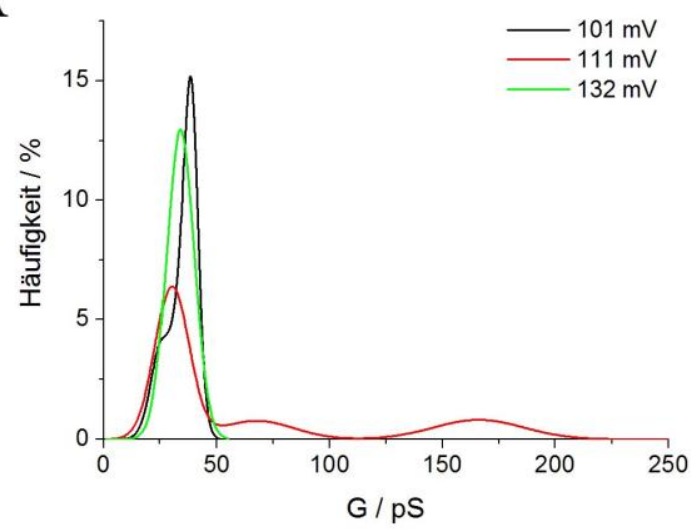

B

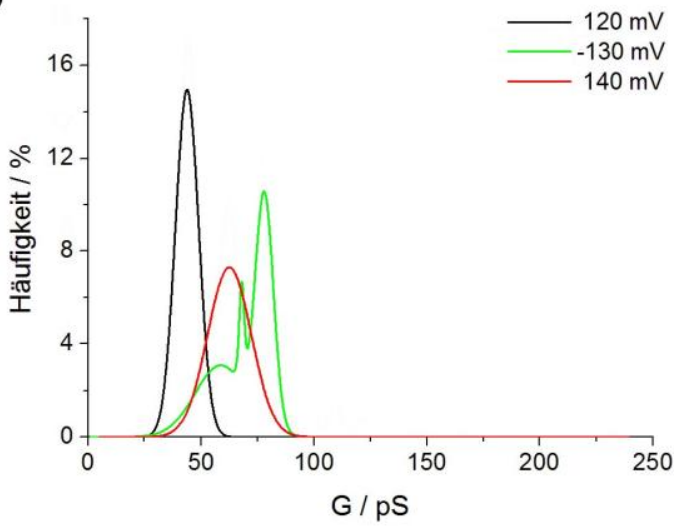

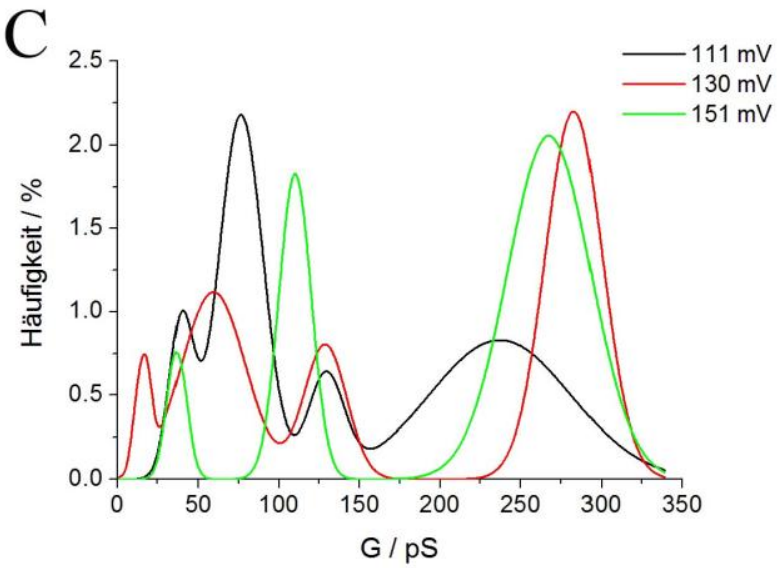

Abb. 4-18: Ereignis-Histogrammanalyse von Cx26WT sowie seinen Mutanten M34A und V84L in Abhängigkeit von der Transmembranspannung $V_{\mathrm{m}}$ in nano-BLMs. Die Abbildungen zeigen einfache oder überlagerte GaußVerteilungen welche an die Daten angepasst werden. (A) Ereignis-Histogrammanalyse aller detektierten Kanalöffnungen des Cx26WT bei $V_{\mathrm{m}}=101 \mathrm{mV}(-), V_{\mathrm{m}}=111 \mathrm{mV}(-)$ und $V_{\mathrm{m}}=132 \mathrm{mV}$ (一). Puffer: $200 \mathrm{mM} \mathrm{KCl}, 10 \mathrm{mM}$ HEPES, $0.02 \mathrm{mM}$ EDTA, pH 7.4. (B) Wie (A) für Cx26M34A. Bei $V_{\mathrm{m}}=120 \mathrm{mV}$ detektierte Ereignisse (-), $V_{\mathrm{m}}=-130 \mathrm{mV}$ (-) und $V_{\mathrm{m}}=140 \mathrm{mV}$ (-). (C) Wie (A) für Cx26V84L. $V_{\mathrm{m}}=111 \mathrm{mV}(-), V_{\mathrm{m}}=130 \mathrm{mV}(-)$ und $V_{\mathrm{m}}=151 \mathrm{mV}(-)$.

Die ermittelten Leitfähigkeiten bei gewählter $V_{\mathrm{m}}$ setzten sich aus den Ergebnissen mehrerer Messungen zusammen. Beim WT des Cx26 konzentrieren sich die Leitfähigkeiten unterschiedlicher $V_{\mathrm{m}}$ um den Bereich der Hauptleitfähigkeitsstufe $G_{1, \mathrm{wT}}(34 \pm 8 \mathrm{pS})$. Nur Ereignisse bei $V_{\mathrm{m}}=111 \mathrm{mV}$ können den Leitfähigkeitsstufen $G_{2, \mathrm{wT}}(70 \pm 9 \mathrm{pS})$ und $G_{3, \mathrm{WT}}$ $(165 \pm 19 \mathrm{pS})$ zugeordnet werden (Tabelle 3).

Tabelle 3: Ermittelte Maxima der Gauß-Verteilungen für Cx26WT aus (Abb. 4-18).

\begin{tabular}{ccc}
\hline $\boldsymbol{V}_{\mathbf{m}} / \mathbf{m V}$ & $\boldsymbol{G} / \mathbf{p S}$ & Fehler \\
\hline 101 & 26 & 4 \\
& 38 & 2 \\
\hline \multirow{2}{*}{111} & 30 & 7 \\
& 68 & 16 \\
& 166 & 20 \\
\hline
\end{tabular}


Bei der Mutante M34A wird die Hauptleitfähigkeitsstufe $G_{1, \mathrm{M} 34 \mathrm{~A}}(44 \pm 6 \mathrm{pS})$ durch die Ereignisse bei $V_{\mathrm{m}}=120 \mathrm{mV}$ repräsentiert. Vertreter der Leitfähigkeitsstufe $G_{2, \mathrm{M} 34 \mathrm{~A}}$ $(69 \pm 10$ pS) können klar höheren Transmembranspannungen zugeordnet werden (Tabelle 4).

Tabelle 4: Ermittelte Maxima der Gauß-Verteilungen für Cx26M34A aus (Abb. 4-18).

\begin{tabular}{ccc}
\hline $\boldsymbol{V}_{\mathbf{m}} / \mathbf{m V}$ & $\boldsymbol{G} / \mathbf{p S}$ & Fehler \\
\hline 120 & 44 & 5 \\
-130 & 62 & 9 \\
140 & 59 & 11 \\
& 68 & 1 \\
\hline
\end{tabular}

Die Mutante V84L fällt wie schon zuvor beobachtet durch eine breite und undefinierte Verteilung der Ereignisse auf, welche bei allen untersuchten Spannungen zu beobachten ist. Die detektierten Einzelkanalöffnungen können trotz konstanter Spannung mehreren Leitfähigkeitsniveaus zugeordnet werden (Tabelle 5).

Tabelle 5: Ermittelte Maxima der Gauß-Verteilungen für Cx26V84L aus (Abb. 4-18).

\begin{tabular}{ccc}
\hline$V_{\mathbf{m}} / \mathbf{m V}$ & $\boldsymbol{G} / \mathbf{p S}$ & Fehler \\
\hline 111 & 40 & 7 \\
& 76 & 13 \\
& 129 & 44 \\
130 & 237 & 2 \\
& 16 & 20 \\
& 59 & 13 \\
& 129 & 17 \\
& 283 & 5 \\
\hline
\end{tabular}

\subsubsection{Bestimmung der mittleren Öffnungsdauer}

Für die Unterscheidung der elektrophysiologischen Eigenschaften von Ionenkanälen kann neben einer Leitfähigkeitsanalyse zusätzlich eine Untersuchung der mittleren Öffnungsdauer $\tau$ durchgeführt werden. Bei der softwaregestützten Auswertung der Einzelkanalereignisse (siehe 3.2.4) wird neben der Leitfähigkeit zusätzlich die Dauer jeder Kanalöffnung, also die 
Verweilzeit auf dem Stromniveau des geöffneten Kanals, bestimmt. Hierbei ist zu beachten, dass aufgrund der Filterfrequenz nur Ereignisse $>4 \mathrm{~ms}$ berücksichtigt werden können. Die Histogrammanalyse dieser Daten ist in Abb. 4-19 für alle untersuchten Connexintypen zusammengefasst.
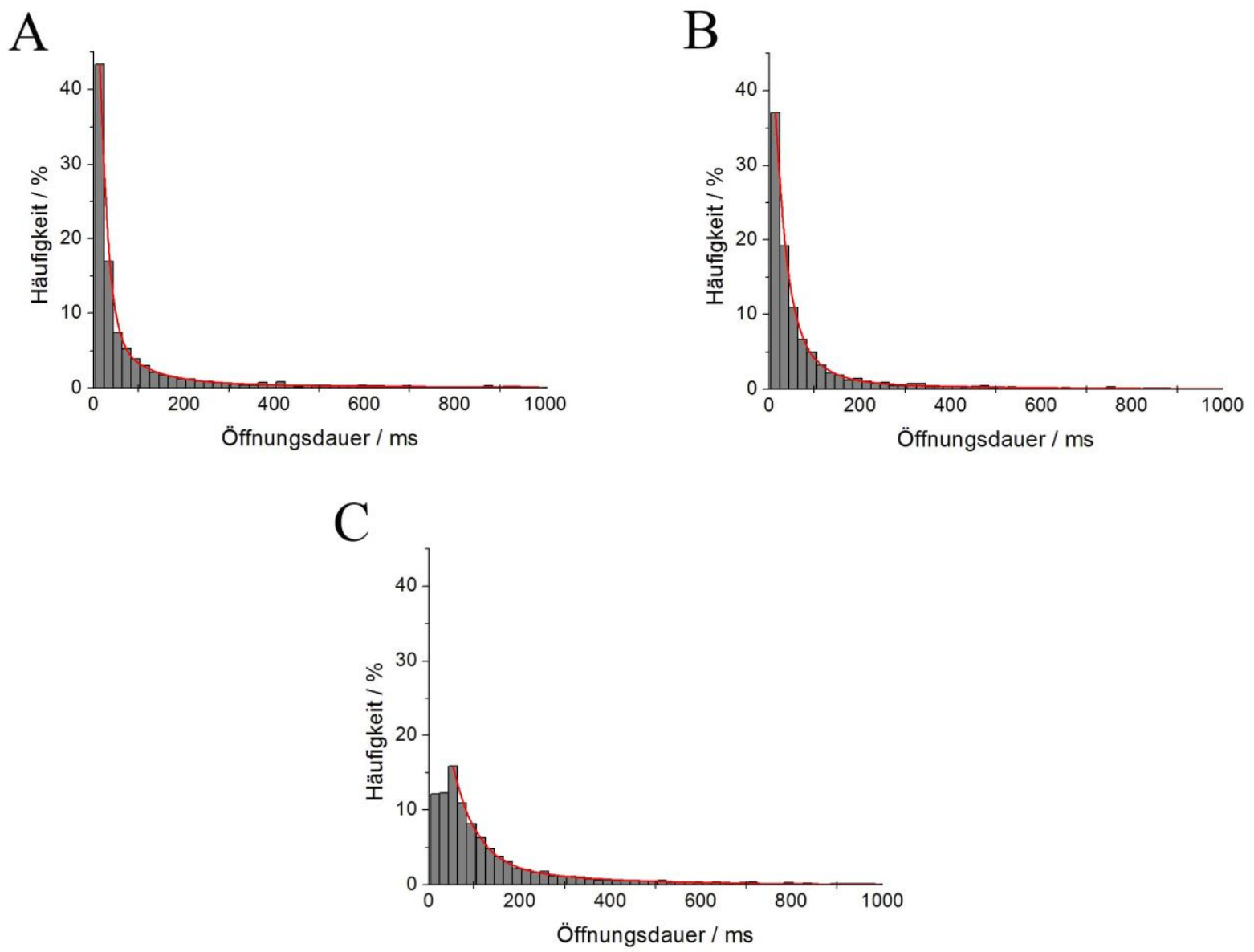

Abb. 4-19: Histogrammanalyse zur Bestimmung der mittleren Öffnungsdauern von Cx26WT sowie seinen Mutanten M34A und V84L. Das Ergebnis (-) zeigt die Anpassung einer Exponentialfunktion. (A) Histogrammanalyse der Öffnungsdauern des Cx26WT in nano-BLMs (2293 Ereignisse, 20 ms Intervallbreite, $V_{\mathrm{m}}$ zwischen -150 mV und $150 \mathrm{mV}$, Puffer: $200 \mathrm{mM} \mathrm{KCl,} 10 \mathrm{mM}$ HEPES, $0.02 \mathrm{mM}$ EDTA, pH 7.4) und an die Daten angepasste Exponentialfunktion 3ter Ordnung. (B) Wie (A) für Cx26M34A (3984 Ereignisse, $20 \mathrm{~ms}$ Intervallbreite, Fit 3ter Ordnung). (C) Wie (A) für Cx26V84L (4304 Ereignisse, 20 ms Intervallbreite, Fit 2ter Ordnung). Die Ergebnisse der anhand von Exponentialfunktionen ermittelten mittleren Öffnungsdauern sind Tabelle 6 zu entnehmen.

Die Auswertung der Histogramme erfolgt durch Anpassung einer Exponentialfunktion gemäß:

$$
f(t)=\sum_{i=1}^{n} A_{\mathrm{i}} \cdot \exp \left(\frac{-t}{\tau_{\mathrm{i}}}\right)
$$

Hierbei ist $A$ die Amplitude der Funktion, $t$ die experimentell bestimmte Öffnungsdauer, $\tau_{\mathrm{i}}$ die mittlere Öffnungsdauer der Einzelkanalereignisse. Da die Ordnung $n$ bzw. Anzahl der 
enthaltenen mittleren Öffnungsdauern anhand dieser Auftragung häufig nicht eindeutig definiert werden kann, muss eine Linearisierung der Daten erfolgen:

$$
f(t)=\ln A+\left(-\frac{1}{\tau_{\text {lin }}}\right) \cdot t
$$

Die Auftragung der linearisierten Daten gemäß Abb. 4-20 resultiert in deutlich voneinander unterscheidbaren linearen Bereichen. Mittels linearer Regression lassen sich damit die mittleren Öffnungsdauern berechnen. Die Steigung der Geraden entspricht hierbei dem negativen Kehrwert der mittleren Öffnungsdauer $\tau$.

A

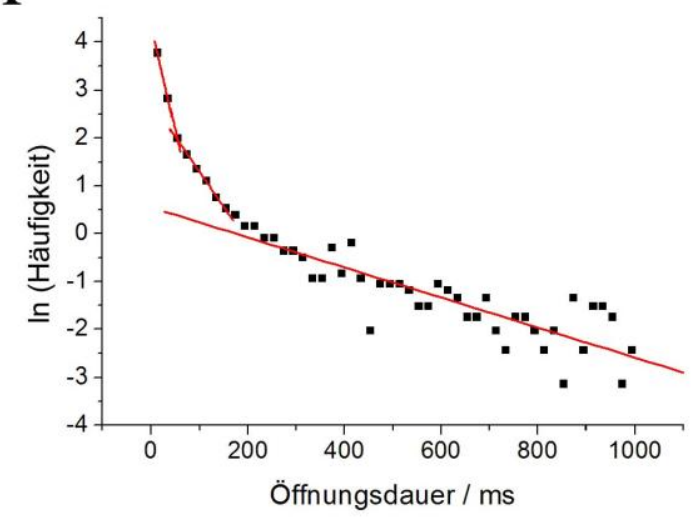

B

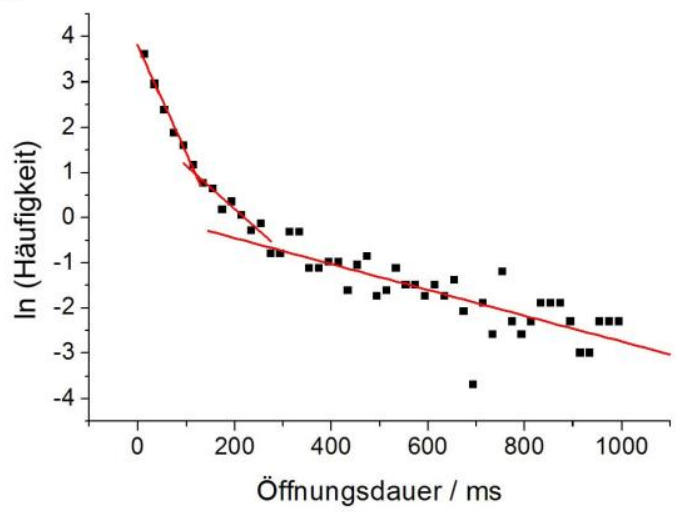

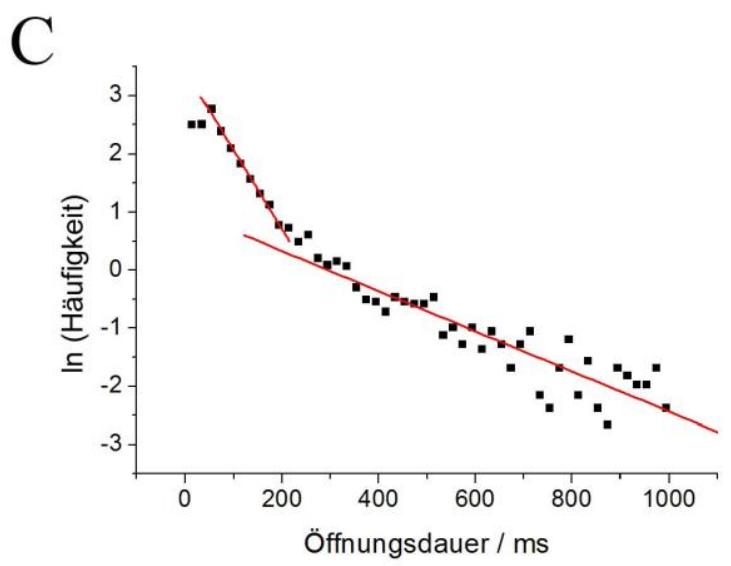

Abb. 4-20: Bestimmung der mittleren Öffnungsdauern von Cx26WT sowie seinen Mutanten M34A und V84L durch Linearisierung. (A) Linearisierung der Öffnungsdauern des Cx26WT in nano-BLMs (2293 Ereignisse, $20 \mathrm{~ms}$ Intervallbreite, $\mathrm{V}_{\mathrm{m}}$ zwischen $-150 \mathrm{mV}$ und $150 \mathrm{mV}$, Puffer: $200 \mathrm{mM} \mathrm{KCl}, 10 \mathrm{mM}$ HEPES, $0.02 \mathrm{mM}$ EDTA, pH 7.4) und durch lineare Regression erhaltene Geraden (-). (B) Wie (A) für Cx26M34A (3984 Ereignisse, $20 \mathrm{~ms}$ Intervallbreite). (C) Wie (A) für Cx26V84L (4304 Ereignisse, $20 \mathrm{~ms}$ Intervallbreite). Die Ergebnisse dieser Analyse sind Tabelle 6 zu entnehmen. 
Die Ergebnisse der in Abb. 4-20 dargestellten Auswertung der mittleren Öffnungsdauer $\tau$ mittels linearer Regression werden in Tabelle 6 den Ergebnissen der Anpassung von Exponentialfunktionen (Abb. 4-19) gegenüber gestellt.

Tabelle 6: Ergebnisse zur Bestimmung der mittleren Öffnungsdauern von Cx26WT sowie seinen Mutanten M34A und V84L anhand von Exponentialfunktionen (Abb. 4-19) und durch Linearisierung (Abb. 4-20).

\begin{tabular}{ccccc} 
& \multicolumn{2}{c}{ Lineare Regression } & \multicolumn{2}{c}{ Exponentialfunktion } \\
\hline Cx26 & $\boldsymbol{\tau} / \mathbf{m s}$ & Fehler & $\boldsymbol{\tau} / \mathbf{m s}$ & Fehler \\
\hline WT & 23 & 1 & 16 & 1 \\
& 68 & 2 & 79 & 14 \\
& 318 & 28 & 488 & 208 \\
M34A & 42 & 3 & 21 & 2 \\
& 105 & 14 & 55 & 9 \\
& 348 & 42 & 354 & 82 \\
V84L & 74 & 2 & 50 & 2 \\
& 289 & 20 & 248 & 20 \\
\hline
\end{tabular}

Die in Tabelle 6 aufgeführten Ergebnisse zeigen, dass bei dem WT des Cx26 und der Mutante M34A drei annähernd identische mittlere Öffnungsdauern voneinander unterschieden werden können. Abweichend davon können bei der Mutante V84L nur zwei mittlere Öffnungsdauern beobachtet werden. Sich anschließende Analysen der mittleren Öffnungsdauer beschränken sich auf die Angabe der Ergebnisse, welche mittels Linearisierung gewonnen werden.

\subsubsection{Darstellung der Öffnungsdauern nach Sigworth \& Sine}

Die Bestimmung der mittleren Öffnungsdauern $\tau$ ist ein wichtiges Werkzeug für die elektrophysiologische Charakterisierung von Ionenkanälen. Die Analyse von $\tau$ anhand einer linearen Auftragung birgt jedoch einige Limitationen. So kann erst durch Linearisierung der durch Histogrammanalyse gewonnenen Daten auf die Ordnung der anzuwendenden Exponentialfunktion geschlossen werden (siehe Abb. 4-20). Zudem kann aus den erhaltenen Daten nur ungenügend auf die Verteilung der Öffnungsdauern geschlossen werden, wodurch die Vergleichbarkeit der Proteine stark eingeschränkt ist und nur anhand der ermittelten Werte für $\tau$ erfolgen kann.

Eine Methode zur eingängigeren Visualisierung ist die direkte Auftragung der Daten in einem einfach logarithmischen Histogramm [Sigworth \& Sine 1987]. Die experimentell ermittelten Öffnungsdauern der Einzelkanalereignisse werden hier logarithmisch wachsenden Intervallbreiten zugewiesen. Ein dimensionsloser Faktor $\delta x$ bestimmt die Intervallbreite nach: 


$$
t_{\mathrm{i}} \leq t \leq t_{\mathrm{i}} \exp (i \delta x)
$$

Für die Darstellung der Daten werden die ermittelten Öffnungsdauern logarithmiert und Intervallen der Breite $\delta x$ zugeteilt (Abb. 4-21 B). Nachstehende Abbildung zeigt die nahezu identische Verteilung der Öffnungsdauern von Cx26WT und M34A und verdeutlicht zugleich den Unterschied dieser Auftragung zur nicht logarithmischen Standardauftragung (Abb. 4-21 A).

A

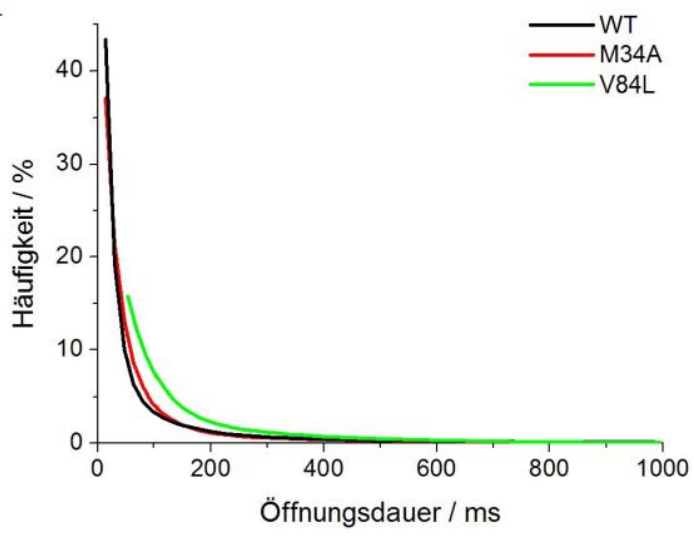

B

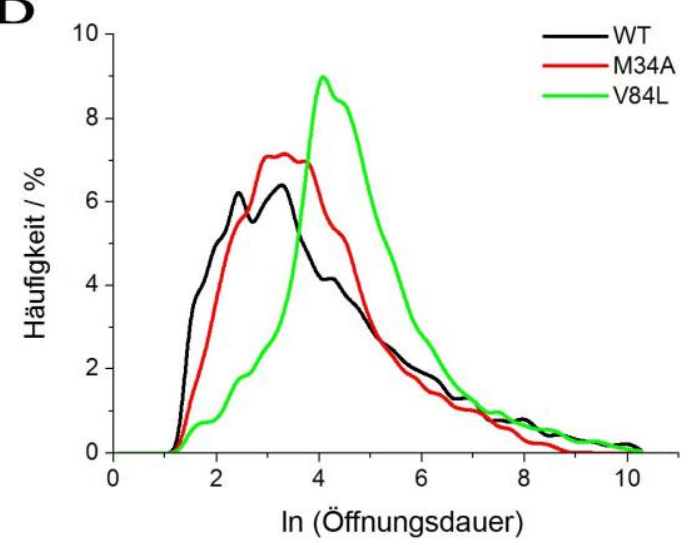

Abb. 4-21: Verschiedene Darstellungen der Öffnungsdauern des Cx26WT (-) sowie seiner Mutanten M34A (-) und V84L (-) in nano-BLMs. (A) An die Daten der Histogrammanalyse angepasste Exponentialfunktionen (siehe Abb. 4-19). (B) Auftragung der logarithmierten Öffnungsdauer nach Sigworth \& Sine [1987] mit $\delta x=0.231$.

Für den WT des Cx26 und seine Mutante M34A können etwa $50 \%$ der detektierten Ereignisse einem Bereich kleiner $90 \mathrm{~ms}\left(\mathrm{e}^{3.5}\right)$ zugeordnet werden. Die Maxima beider Verteilungen konzentrieren sich in einem Bereich um etwa $75 \mathrm{~ms}\left(\mathrm{e}^{3.3}\right)$. Im Gegensatz hierzu liegt das Maximum der Verteilung für V84L bei etwa $200 \mathrm{~ms}\left(\mathrm{e}^{4.3}\right)$ und nur etwa $18 \%$ aller Ereignisse sind einem Bereich kleiner $90 \mathrm{~ms}$ zuzuordnen. Dies bedeutet, dass die Öffnungsdauern der Mutante V84L im Vergleich zum WT des Cx26 und M34A tendenziell länger sind.

\subsubsection{5 Öffnungsdauer in Abhängigkeit von $G$ und $V_{m}$}

Bei der Auswertung der Daten können für Cx26 und seine Mutanten mehrere mittlere Öffnungsdauern ermittelt werden (Tabelle 6). Da für alle Proteine ebenfalls mehrere Hauptleitfähigkeitsstufen identifiziert werden können (Abb. 4-16) und die Kanäle zudem bei unterschiedlichen $V_{\mathrm{m}}$ untersucht werden, gilt es in der folgenden Betrachtung mögliche Zusammenhänge zu prüfen und Unterschiede von Mutante und WT herauszuarbeiten. Hierbei 
soll auf die Darstellung linearer Histogramme und deren Linearisierung verzichtet werden. Die mittels linearer Regression erhaltenen mittleren Öffnungsdauern $\tau_{1}$ werden weiterhin ergänzend $\mathrm{zu}$ den einfach logarithmischen Histogrammen nach Sigworth \& Sine in Tabellenform angegeben.

\section{Öffnungsdauer in Abhängigkeit von der Leitfähigkeit}

Für den WT des Cx26 können drei Hauptleitfähigkeitsstufen ermittelt werden (siehe Abb. 4-16 A). Die separate Betrachtung der Öffnungsdauern getrennt nach $G_{1}-G_{3}$ ergibt nachstehenden Zusammenhang (Abb. 4-22).

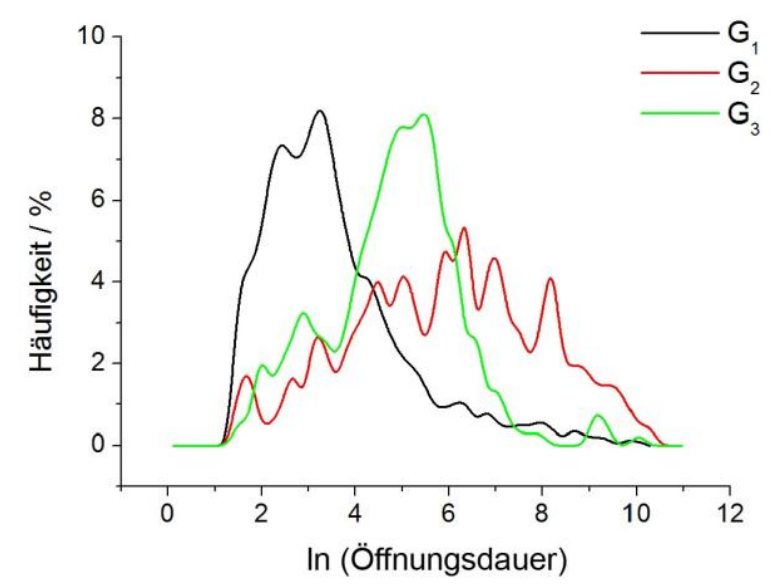

Tabelle 7: Ergebnisse zur Bestimmung der mittleren Öffnungsdauer $\tau_{1}$ von $\mathrm{Cx} 26$ in Abhängigkeit von den ermittelten Leitfähigkeitsstufen.

\begin{tabular}{ccc}
\hline Cx26WT & $\boldsymbol{\tau}_{\mathbf{1}} / \mathbf{m s}$ & Fehler \\
\hline$G_{1}$ & 30 & 3 \\
$G_{2}$ & 109 & 8 \\
$G_{3}$ & 174 & 32 \\
\hline
\end{tabular}

Abb. 4-22: Öffnungsdauern des CX26WT in Abhängigkeit von den ermittelten Hauptleitfähigkeitsstufen (siehe Abb. 4-16 A). Auftragung der logarithmierten Öffnungsdauern nach Sigworth \& Sine [1987] mit $\delta x=0.231$.

Anhand Abb. 4-22 ist deutlich erkennbar, dass den drei Leitfähigkeiten unterschiedliche Verteilungen der Öffnungsdauern zugewiesen werden können. Ereignisse welche den Leitfähigkeiten $G_{2, \text { WT }}$ und $G_{3 \text {,WT }}$ zugeordnet werden können, haben dabei eine tendenziell längere Öffnungsdauer im Vergleich zu Ereignissen der Leitfähigkeitsstufe $G_{1, \text { wT }}$. Dieser Trend kann von den in Tabelle 7 mittels linearer Regression bestimmten Werten für $\tau_{1}$ bestätigt werden. So beträgt die mittlere Öffnungsdauer $\tau_{1}$ bei Ereignissen der Leitfähigkeitsstufe $G_{1 \text {,wT }}$ etwa $30 \mathrm{~ms}$ und steigt für $G_{2 \text {,wT }}$ und $\mathrm{G}_{3 \text {,wT }}$ auf etwa $110 \mathrm{~ms}$ bzw. $170 \mathrm{~ms}$.

Die Mutante M34A zeigt in der einfach logarithmischen Auftragung nach Sigworth \& Sine für $G_{1, \mathrm{M} 34 \mathrm{~A}}$ und $G_{2, \mathrm{M} 34 \mathrm{~A}}$ eine ähnliche Abhängigkeit wie der WT des Cx26 (Abb. 4-23). 


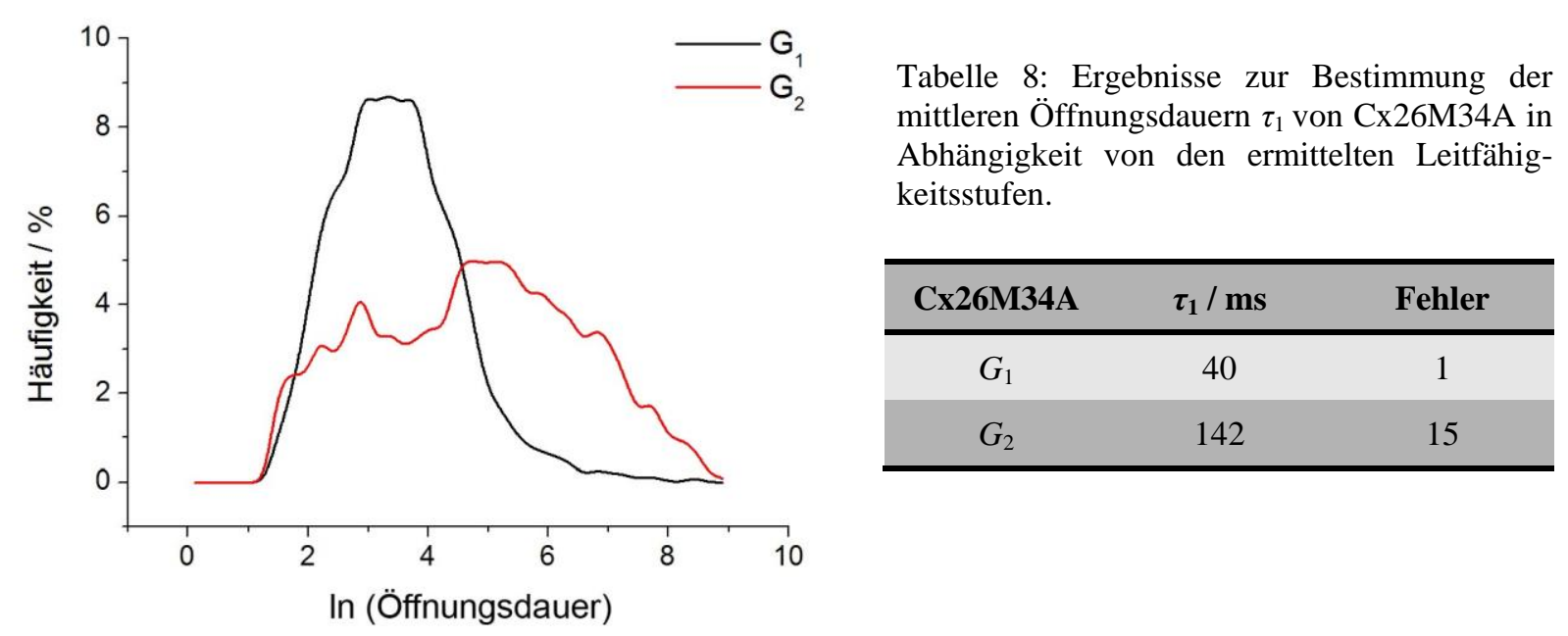

Abb. 4-23: Öffnungsdauern des CX26M34A in Abhängigkeit von den ermittelten Hauptleitfähigkeitsstufen (siehe Abb. 4-16 B). Auftragung der logarithmierten Öffnungsdauern nach Sigworth \& Sine [1987] mit $\delta x=0.231$.

Auch hier sind die Öffnungsdauern bei Ereignissen der Leitfähigkeitsstufe $G_{2, \mathrm{M} 34 \mathrm{~A}}$ breiter verteilt, wobei das Maximum der Verteilung im Vergleich zu Ereignissen der Leitfähigkeitsstufe $G_{1, \mathrm{M} 34 \mathrm{~A}}$ in Richtung längerer Öffnungsdauern verschoben ist. Dieser Zusammenhang kann auch bei der Analyse von $\tau_{1}$ festgestellt werden. Haben Ereignisse im Bereich von $G_{1, \mathrm{M} 34 \mathrm{~A}}$ eine mittlere Öffnungsdauer von etwa $40 \mathrm{~ms}$, so steigt dieser Wert auf etwa 140 ms für Ereignisse der Leitfähigkeitsstufe $\mathrm{G}_{2, \mathrm{M} 34 \mathrm{~A}}$.

Für V84L ist aufgrund des inhomogenen Verhaltens und der stark überlagerten Normalverteilungen die Analyse einzelner Leitfähigkeitsstufen nicht möglich. Daher werden die ermittelten Öffnungsdauern für diesen Zusammenhang einem Bereich $G_{\mathrm{I}}<150 \mathrm{pS}$ und $G_{\mathrm{II}}$ $\geq 150 \mathrm{pS}$ zugeteilt.

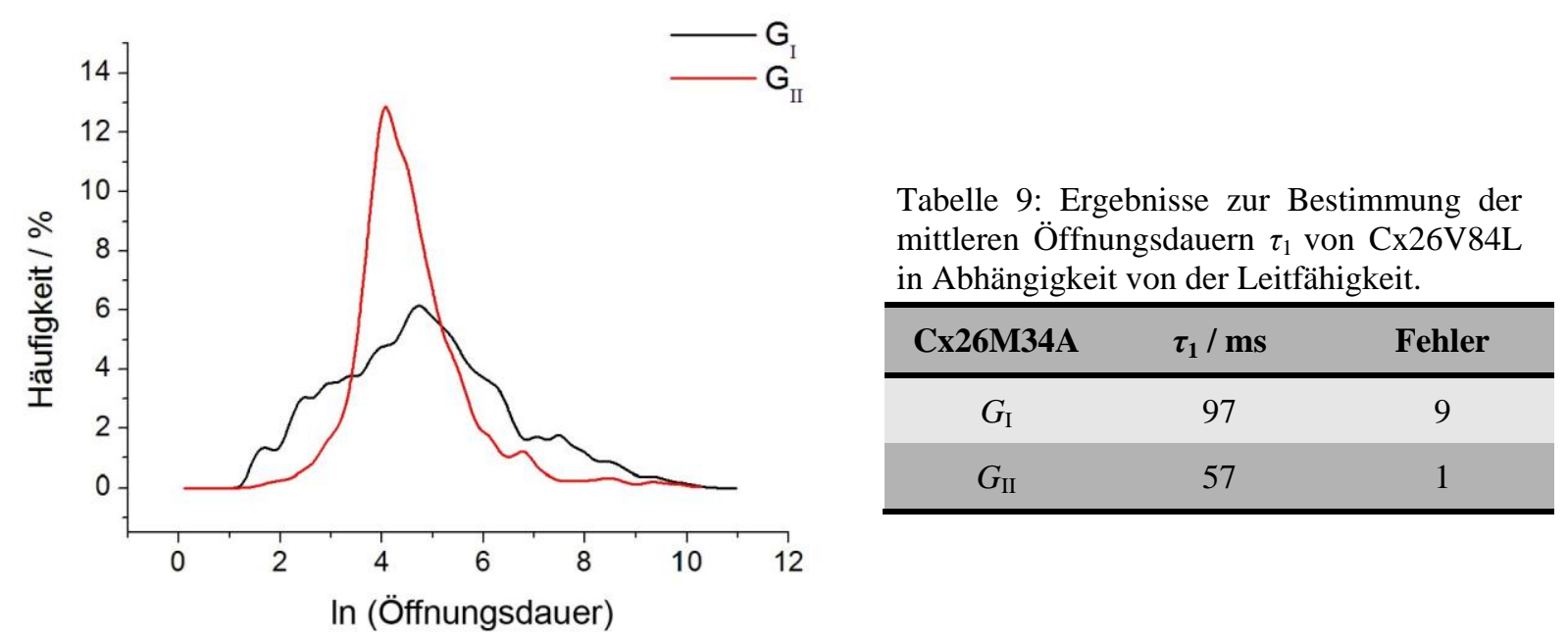

Abb. 4-24: Öffnungsdauern des CX26V84L in Abhängigkeit von den Hauptleitfähigkeitsstufen $G_{\mathrm{I}}<150 \mathrm{pS}$ und $G_{\mathrm{II}}>150 \mathrm{pS}$. Auftragung der logarithmierten Öffnungsdauern nach Sigworth \& Sine [1987] mit $\delta x=0.231$. 
Die Sigworth-Verteilung von Ereignissen hoher Leitfähigkeit $\left(G_{\mathrm{II}}\right)$ ist im Vergleich zu der Verteilung von Ereignissen niedriger Leitfähigkeit $\left(G_{\mathrm{I}}\right)$ schmaler und in Richtung kürzerer Öffnungsdauern verschoben. Dieser Trend geht auch aus den Ergebnissen schneller Ereignisse für $\tau_{1}$ hervor. So haben Ereignisse mit Leitfähigkeiten $\geq 150 \mathrm{pS}$ etwa $55 \mathrm{~ms}$ eine tendenziell kürzere mittlere Öffnungsdauer im Vergleich zu Ereignisse $<150 \mathrm{pS}$ mit einem $\tau_{1}$ von etwa $95 \mathrm{~ms}$.

\section{Öffnungsdauer in Abhängigkeit von der Transmembranspannung}

Das verwendete Protokoll kann ebenfalls für die differenzierte Betrachtung der Öffnungsdauern bei verschiedenen Transmembranspannungen $V_{\mathrm{m}}$ angewendet werden. Hierfür steht der gleiche Datensatz zur Verfügung, der bereits für die differenzierte Betrachtung der Leitfähigkeiten verwendet wird (siehe Tabelle 2 und Abb. 4-18).

A

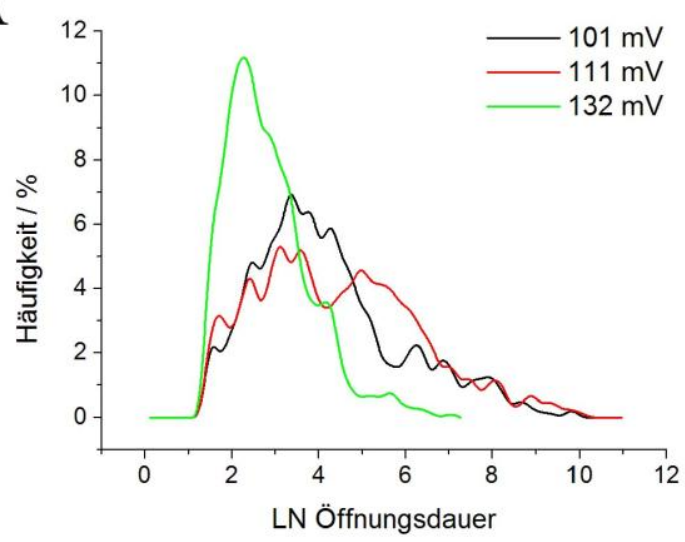

B

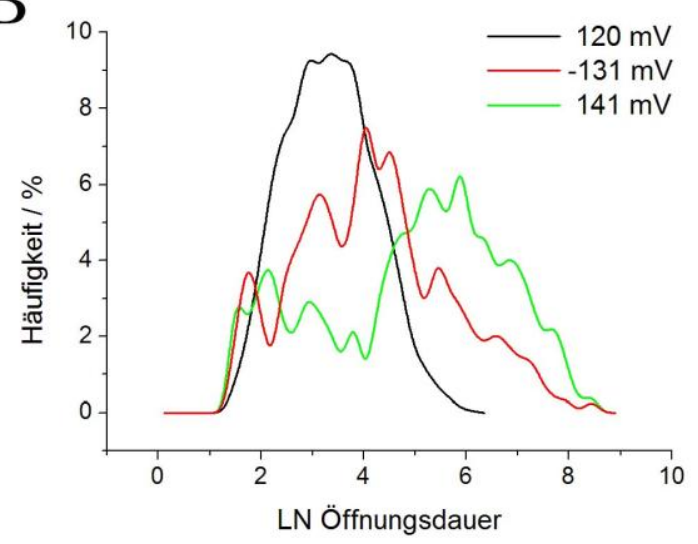

$\mathrm{C}$

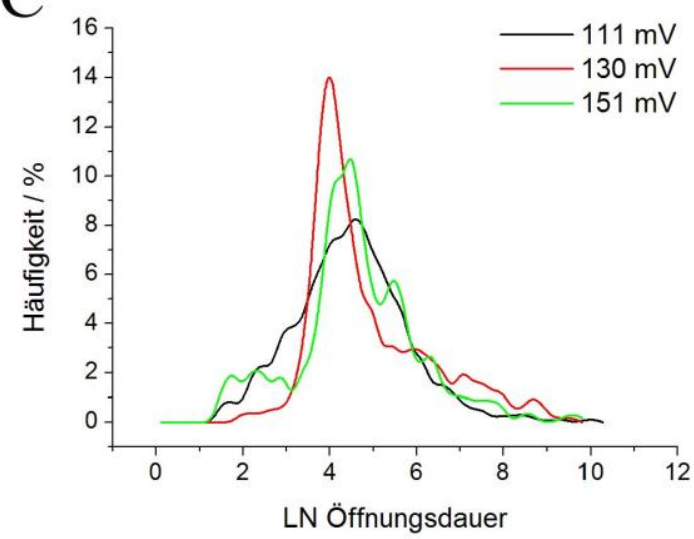

Abb. 4-25: Öffnungsdauern des CX26WT sowie seiner Mutanten M34A und V84L in Abhängigkeit von der Transmembranspannung $\mathrm{V}_{\mathrm{m}}$. (A) Auftragung der logarithmierten Öffnungsdauern des Cx26WT nach Sigworth \& Sine [1987] mit $\delta x=0.231$ bei $V_{\mathrm{m}}=101 \mathrm{mV}(-), V_{\mathrm{m}}=111 \mathrm{mV}(-)$ und $V_{\mathrm{m}}=132 \mathrm{mV}$ (-). (B) Wie (A) für Cx26M34A mit $V_{\mathrm{m}}=120 \mathrm{mV}(-), V_{\mathrm{m}}=-131 \mathrm{mV}(-)$ und $V_{\mathrm{m}}=141 \mathrm{mV}(-)$. (C) Wie (A) für Cx26V84L mit $V_{\mathrm{m}}=111 \mathrm{mV}(-), V_{\mathrm{m}}=130 \mathrm{mV}\left(\right.$ - ) und $V_{\mathrm{m}}=151 \mathrm{mV}(-)$. 
Im Gegensatz zu den bisher ermittelten Ergebnissen scheint es nach den in Abb. 4-25 dargestellten Daten für die Mutante M34A und den WT des Cx26 hier wesentliche Unterschiede zu geben. Beim WT resultiert eine Erhöhung von $V_{\mathrm{m}}$ tendenziell in einer Verkürzung der Öffnungsdauern, wohingegen M34A einen gegensätzlichen Trend erkennen lässt. Im Gegensatz dazu stehen die Ergebnisse, welche für die Mutante V84L ermittelt werden. Hier ist kein eindeutiger Trend feststellbar.

Diese Abhängigkeiten können durch die Analyse der mittleren Öffnungsdauern $\tau_{1}$ bestätigt werden (siehe Tabelle 10).

Tabelle 10: Ergebnisse zur Bestimmung der mittleren Öffnungsdauer $\tau_{1}$ von Cx26WT sowie seinen Mutanten M34A und V84L in Abhängigkeit von der Transmembranspannung $V_{\mathrm{m}}$. Grundlage dieser Auswertung ist die Linearisierung der Daten schneller Ereignisse bis $200 \mathrm{~ms}$ und die lineare Regression der daraus erhaltenen Geraden.

\begin{tabular}{cccc}
\hline Cx26 & $\boldsymbol{V}_{\mathbf{m}} / \mathbf{m V}$ & $\boldsymbol{\tau}_{\mathbf{1}} / \mathbf{m s}$ & Fehler \\
\hline & 101 & 52 & 3 \\
WT & 111 & 30 & 3 \\
& 132 & 26 & 2 \\
M34A & 120 & 34 & 5 \\
& -131 & 54 & 336 \\
\hline
\end{tabular}

Tabelle 10 zeigt sehr deutlich, dass die mittlere Öffnungsdauer $\tau_{1}$ für den WT des Cx26 mit steigender Potentialdifferenz kleiner wird, wohingegen beim M34A ein gegenläufiger Trend erkennbar ist. V84L zeigt keine eindeutige Tendenz.

\subsubsection{Bestimmung der Öffnungswahrscheinlichkeit}

Werden bei der Bestimmung der mittleren Öffnungsdauer $\tau$ lediglich die Zeitintervalle berücksichtigt, in denen ein Kanal geöffnet ist, so gehen in die Bestimmung der Öffnungswahrscheinlichkeit $p_{\text {offen }}$ auch die Zeitintervalle mit ein, in denen der Kanal geschlossen ist. Diese Daten können für einzelne Messungen (30 s Zeitintervall) aus der normierten Fläche der Normalverteilungen anhand von Punktamplituden-Histogrammen bestimmt werden. Genauere Ergebnisse können allerdings durch softwaregestützte Einzelerfassung von Kanalereignissen erhalten werden (siehe 3.2.4). Mit dieser Methode wird nicht nur die Dauer jeder Kanalöffnung, also die Verweilzeit auf dem Stromniveau des 
geöffneten Kanals, bestimmt, sondern es werden auch die Zeitintervalle zwischen den einzelnen Kanalereignissen erfasst. Die Aktivität eines Kanals bzw. seine Öffnungswahrscheinlichkeit $p_{\text {offen }}$ in \% ergibt sich aus:

$$
p_{\text {offen, } V_{\mathrm{m}}}=\frac{\sum t_{\text {offen, } \mathrm{V}_{\mathrm{m}}}}{\sum t_{\text {offen, }, \mathrm{V}_{\mathrm{m}}}+\sum t_{\text {geschloss } \mathrm{N}, \mathrm{V}_{\mathrm{m}}}} \cdot 100
$$

Diese Betrachtung wird üblicherweise in Abhängigkeit von der Transmembranspannung durchgeführt, d.h. es werden alle Verweildauern auf dem Stromniveau des geöffneten Kanals $t_{\text {offen }}$ und alle Verweildauern auf dem Stromniveau des geschlossenen Kanals bzw. des kanalunabhängigen Transmembranstromes $t_{\text {geschlossen }}$ bei gleichem $V_{\mathrm{m}}$ addiert. Zur besseren Veranschaulichung wird an die gewonnenen Daten in Abb. 4-26 eine symmetrische Boltzmann-Verteilung der Form:

$$
p_{\text {offen }}=\frac{p_{\text {offen/MIN }}-p_{\text {offen/MAX }}}{1+e^{\left(V-V_{50} / m_{50}\right)}}+p_{\text {offen/MAX }}
$$

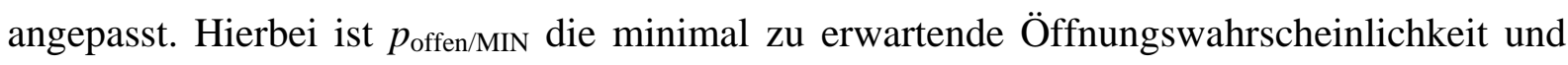

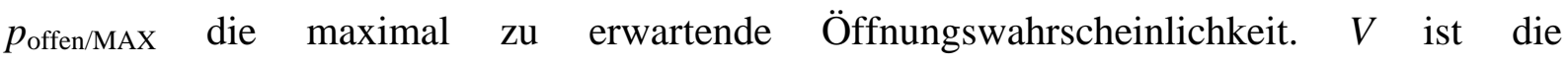
Transmembranspannung $V_{\mathrm{m}}, V_{50}$ ist die Transmembranspannung bei welcher $p_{\text {offen }}=50 \%$ gilt und an welcher die Funktion eine Steigung $\mathrm{m}_{50}$ aufweist. 

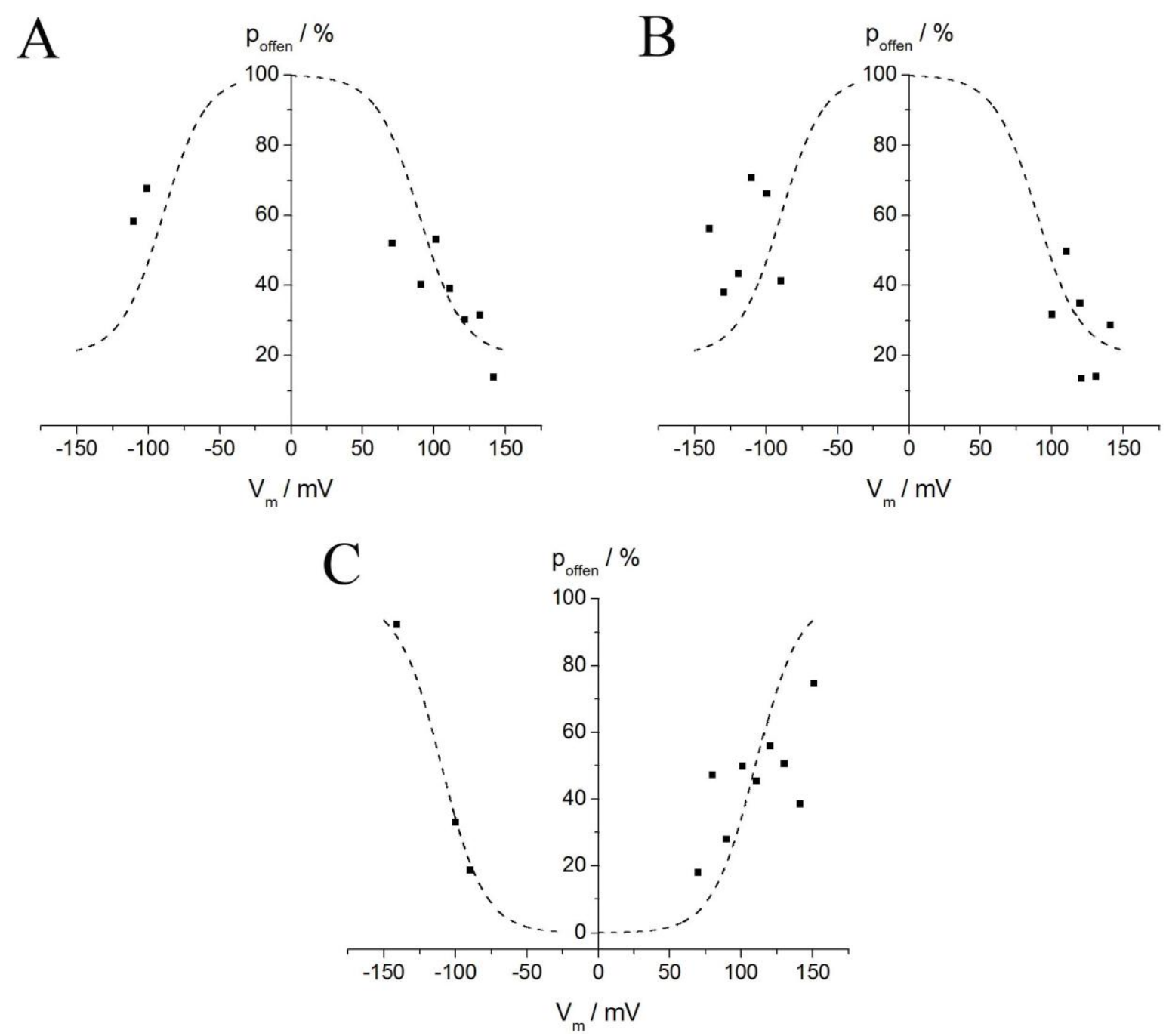

Abb. 4-26: Öffnungswahrscheinlichkeit des Cx26WT sowie seiner Mutanten M34A und V84L in nano-BLMS in Abhängigkeit von der Transmembranspannung $V_{\mathrm{m}}$. Simulierte symmetrischen Boltzmann-Verteilungen (- - ) veranschaulichen den Trend der Abhängigkeit. (A) Öffnungswahrscheinlichkeit des Cx26WT in nano-BLMs $\left(V_{\mathrm{m}}\right.$ zwischen $-150 \mathrm{mV}$ und $+150 \mathrm{mV}$, Puffer: $200 \mathrm{mM} \mathrm{KCl}, 10 \mathrm{mM}$ HEPES, $0.02 \mathrm{mM}$ EDTA, pH 7.4). Grundlage dieser Analyse sind 2448 Ereignisse, welche innerhalb einer Gesamtaktivitätsdauer von etwa 42 min detektiert werden. Die Boltzmann-Verteilung wird mit den Parametern $p_{\text {offen } / \mathrm{MAX}}=100, p_{\text {offen/MIN }}=20, V_{50}= \pm 90$ und $m_{50}= \pm 15$ simuliert. (B) Wie (A) für Cx26M34A. Grundlage sind 4153 Ereignisse bei einer Gesamtaktivitätsdauer von etwa 36 min. Die Parameter der Boltzmann-Verteilung entsprechen denen des Cx26WT. (C) Wie (A) für Cx26V84L. Hierfür stehen 4654 Ereignisse zur Verfügung, welche innerhalb einer Gesamtaktivitätsdauer von etwa 67 min detektiert werden. Die Simulation der Boltzmann-Verteilung erfolgt mit den Parametern $p_{\text {offen/MAX }}=0, p_{\text {offen/MIN }}=100, V_{50}= \pm 110$ und $m_{50}= \pm 15$.

Bei dieser Auftragung können nur Transmembranspannungen berücksichtigt werden, bei denen genügend Kanalereignisse $(\geq 10)$ erfasst wurden. Die Öffnungswahrscheinlichkeit nimmt für den WT des Cx26 und die Mutante M34A mit steigender Transmembranspannung eindeutig ab. An die Datenpunkte kann jeweils eine symmetrische Boltzmann-Verteilung mit $p_{\text {offen/MAX }}=100, \quad p_{\text {offen/MIN }}=20, \quad V_{50}= \pm 90$ und $m_{50}= \pm 15$ angepasst werden. Die Verteilungen sind simuliert und orientieren sich an den von Bruzzone et al. [2003] gefundenen Parametern für Cx26WT Gap Junctions. Die Öffnungswahrscheinlichkeit des V84L scheint im Gegensatz dazu mit steigender Potentialdifferenz größer zu werden. An die 
gewonnenen Daten kann dementsprechend eine im Vergleich zum WT und M34A vertikal gespiegelte, symmetrische Boltzmann Verteilung mit $p_{\text {offen/MAX }}=0, \quad p_{\text {offen } / \mathrm{MIN}}=100$, $V_{50}= \pm 110$ und $m_{50}= \pm 15$ angepasst werden.

\subsubsection{Modulation der Leitfähigkeit mit Calciumionen}

Die chemische Blockade des Cx26 Halbkanals kann am Beispiel der Mutante V84L eindeutig nachgewiesen werden. Hierzu wird die Calciumionenkonzentration im Messpuffer auf $10 \mathrm{mM}$ eingestellt. Durch Zugabe von EGTA (Ethylenglykol-bis(aminoethylether)-N,N'tetraessigsäure), einem Calcium-spezifischen Chelator, können die zweiwertigen Ionen schnell und vollständig komplexiert werden(Abb. 4-27).

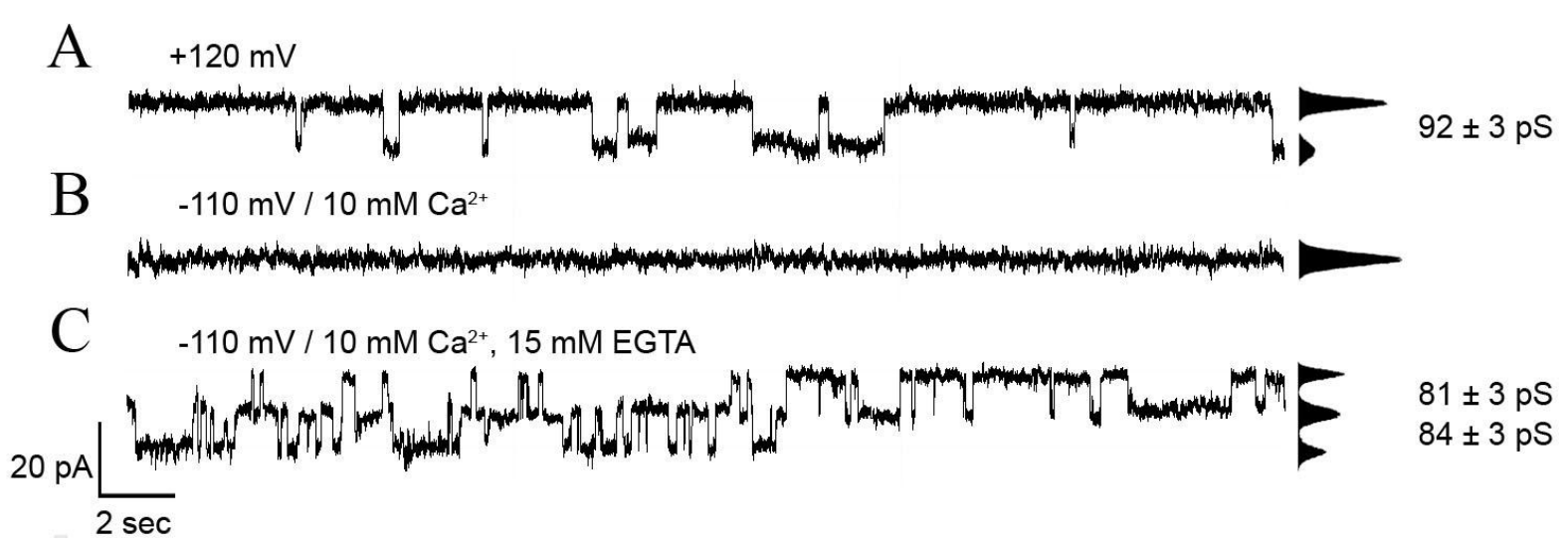

Abb. 4-27: Reversible Blockade des Cx26V84L in nano-BLMs mit Calcium auf Einzelkanalniveau. (A) Voltageclamp Messung einer nano-BLM mit rekonstituiertem Cx26V84L ( $V_{\mathrm{m}}=+120 \mathrm{mV}$, Puffer: $200 \mathrm{mM} \mathrm{KCl,} 10 \mathrm{mM}$ HEPES, $0.02 \mathrm{mM}$ EDTA, pH 7.4). Die stufenartigen Anstiege des Transmembranstromes sind auf einzelne Kanalöffnungen des funktionell integrierten Halbkanals zurückzuführen. Über ein Punktamplituden-Histogramm (rechts) lässt sich eine gemittelte Leitfähigkeit von $G=(92 \pm 3) \mathrm{pS}$ bestimmen. (B) Vollständige Blockade des Cx26V84L Halbkanals 1 min nach Zugabe von $10 \mathrm{mM} \mathrm{Ca}^{2+} . G=0 \mathrm{pS}$. (C) Aufhebung der Blockade durch Komplexierung der Calcium-Ionen 5 min nach Zugabe von 15 mM EGTA. Während dieser Messung sind zwei Halbkanäle aktiv. $G=(81 \pm 3) \mathrm{pS}$ bzw. $G=(84 \pm 3) \mathrm{pS}$.

Die bei einem $V_{\mathrm{m}}$ von $120 \mathrm{mV}$ nachgewiesenen einheitlichen Kanalöffnungen mit einer Leitfähigkeit von $(92 \pm 3) \mathrm{pS}$ (Abb. 4-27 A), verschwinden direkt nach Anheben der Calciumionenkonzentration auf $10 \mathrm{mM}$ im Messpuffer. Über einen Zeitraum von $10 \mathrm{~min}$ kann keine Kanalaktivität nachgewiesen werden (Abb. 4-27 B). Das Komplexieren der Calciumionen durch Zugabe von EGTA bis zu einer Endkonzentration von 15 mM im Puffer, führt direkt nach Zugabe zu einer erneut einsetzenden Aktivität des Kanals und belegt die Reversibilität der Blockade. Die Aktivität liegt anfangs mit $(66 \pm 2) \mathrm{pS}$ noch unter dem Ausgangswert von 92 pS, erreicht aber nach wenigen Minuten mit $(84 \pm 3) \mathrm{pS}$ annähernd das Ausgangsniveau (Abb. 4-27 C). Im Spezialfall dieser Messung war es möglich, die Aktivität 
zweier gleichzeitig aktiver Halbkanäle nachzuweisen. Die reversible Blockade des Kanals mit Calcium kann mehrfach reproduziert werden.

\subsubsection{Ergebnisse der Nanion Technologie GmbH}

Die Nanion Technologie GmbH mit Dr. Niels Fertig als Geschäftsführer war im Rahmen dieser Arbeit ein wichtiger Kooperationspartner. Die Zusammenarbeit konzentrierte sich hierbei auf den WT des Cx26 und die Mutante M34A. Dies eröffnete die Möglichkeit, die Ergebnisse der Integration von Connexonen in Lipidmembranen auf nanoporösen Oberflächen mit den Daten eines Systems zu vergleichen, welches auf einer anderen Rekonstitutionsstrategie basiert.

Die von Mohamed Kreir durchgeführten Experimente werden mit dem von Nanion entwickelten Port-a-Patch Setup durchgeführt (Abb. 4-28). Hierbei wird aufgereinigtes Cx26 zunächst in GUVs rekonstituiert. Die GUVs werden dann mit einem Unterdruck von -10 bis 40 mbar mit einer wenige Mikrometer messenden Apertur eines mikrostrukturierten Chips aus Glas angesaugt und zum Spreiten gebracht. Nach Ausbildung einer hochohmigen planaren Membran können die rekonstituierten Halbkanäle mittels voltage-clamp Technik hinsichtlich ihrer elektrophysiologischen Eigenschaften untersucht werden.

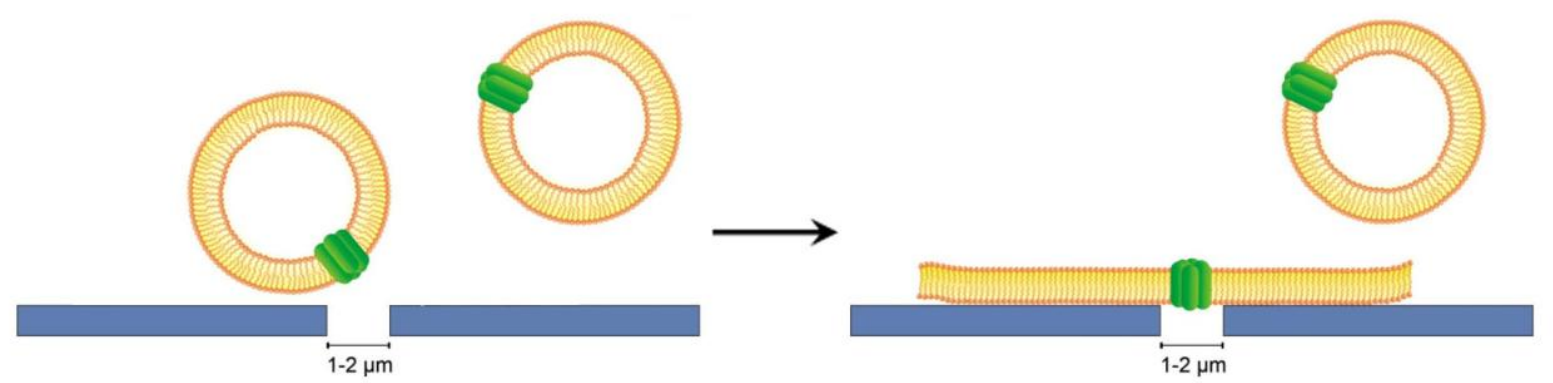

Abb. 4-28: Schematische Darstellung der Port-a-Patch Technik. Ausbildung einer planaren, lösungsmittelfreien, freitragenden Membran auf einem mikrostrukturierten Glasträger durch leichtes Ansaugen von Connexonen dotierten GUVs.

Die von Nanion etablierte Technik kommt vollständig ohne Lösungsmittel aus, wohingegen nano-BLMs in Teilbereichen stark lösungsmittelhaltig sein können. Weiterhin sind die Cx26 Halbkanäle bei der von Nanion verwendeten Technik bereits vor dem Spreiten in die Membran der GUVs integriert, wohingegen unter Verwendung von nano-BLMs die Halbkanäle mittels Detergenzien in eine bereits bestehenden porenüberspannende Membran rekonstituiert werden müssen. 


\subsubsection{WT}

Abb. 4-29 A zeigt eine charakteristische Einzelkanalmessung des Cx26-Oligomers in einer planaren porenüberspannenden Membran auf einem Glaschip. Anhand des PunktamplitudenHistogramms kann für dieses Beispiel eine Leitfähigkeit von $(42 \pm 7) \mathrm{pS}$ bestimmt werden. Diese Ereignisse können damit der Leitfähigkeitsstufe $G_{1, \text { WT }}$ in nano-BLMs zugewiesen werden. Die in Abb. 4-29 B dargestellte lineare Strom-Spannungs-Abhängigkeit bestätigt zudem das ohmsche Verhalten des Kanals. Anhand der Steigung lässt sich eine Leitfähigkeit von $(95 \pm 2) \mathrm{pS}$ ermitteln.

A

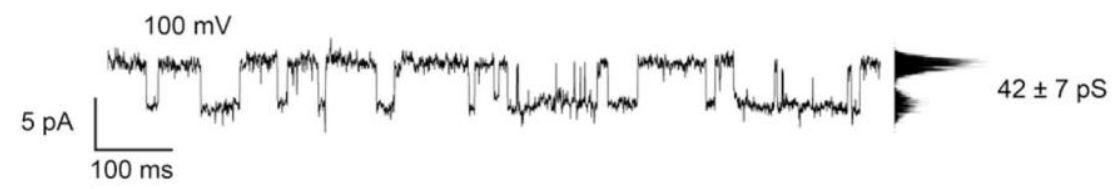

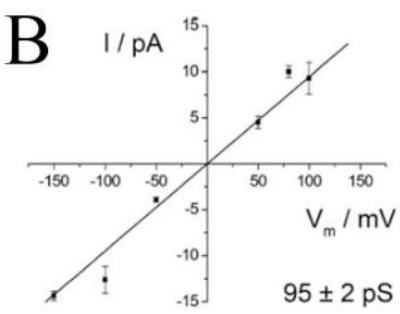

Abb. 4-29: Mittels Port-a-Patch Technik erhaltene Ergebnisse für Cx26WT [Gaßmann et al. 2009]. (A) Charakteristische Einzelkanalmessung bei einer Transmembranspannung von $+100 \mathrm{mV}$ in $200 \mathrm{mM} \mathrm{KCl,} 10 \mathrm{mM}$ HEPES, 2 mM EDTA, pH 7.0. Über ein Punktamplituden-Histogramm (rechts) lässt sich eine gemittelte Leitfähigkeit von $(42 \pm 7) \mathrm{pS}$ bestimmen. (B) Strom-Spannungs-Abhängigkeit. Die lineare $I-V$-Abhängigkeit lässt auf ein ohmsches Verhalten des Kanals schließen. Aus der Steigung kann nach $G=I / U$ eine Leitfähigkeit von $(95 \pm 2) \mathrm{pS}$ berechnet werden.

Insgesamt können mittels Port-a-Patch Technik wie auch in nano-BLMs drei voneinander unterscheidbare Hauptleitfähigkeiten bestimmt werden (siehe Tabelle 11).

Tabelle 11: Hauptleitfähigkeitsstufen von Cx26WT Connexonen in planaren, porenüberspannenden, artifiziellen Membransystemen.

\begin{tabular}{ccc}
\hline Leitfähigkeitsstufe & Port-a-Patch / $\mathbf{p S}$ & nano-BLM / pS \\
\hline$G_{1}$ & $38 \pm 10$ & $34 \pm 8$ \\
$G_{2}$ & $101 \pm 20$ & $70 \pm 8$ \\
$G_{3}$ & $156 \pm 20$ & $165 \pm 19$ \\
\hline
\end{tabular}

$G_{1, \text { WT }}$ und $G_{3, \text { WT }}$ sind für beide eingesetzten Techniken nahezu identisch. Lediglich $G_{2, \text { WT }}$ weicht bei dem von Nanion etablierten System etwas in einen Bereich höherer Leitfähigkeiten ab. Analog zu den Ergebnissen in nano-BLMs, dominieren unter Verwendung der Port- $a$ Patch Technik Ereignisse, welche der Leitfähigkeitsstufe $G_{1, \mathrm{wT}}$ zugeordnet werden können, wohingegen Vertreter von $G_{3, \text { wT }}$ nur selten zu detektieren sind. Dies gilt allerdings nur für Spannungen im Bereich zwischen $\pm 100 \mathrm{mV}$ und $\pm 150 \mathrm{mV}$. 


\subsubsection{M34A}

Neben dem WT wird auch Cx26M34A mit der in Abb. 4-28 vorgestellten Technik rekonstituiert in einer planaren, lösungsmittelfreien und porenüberspannenden Membran auf dem von Nanion verwendeten mikrostrukturierten Glasträger spannungsabhängig untersucht. Ein Teil dieser Ergebnisse ist nachstehender Abbildung zu entnehmen.

A
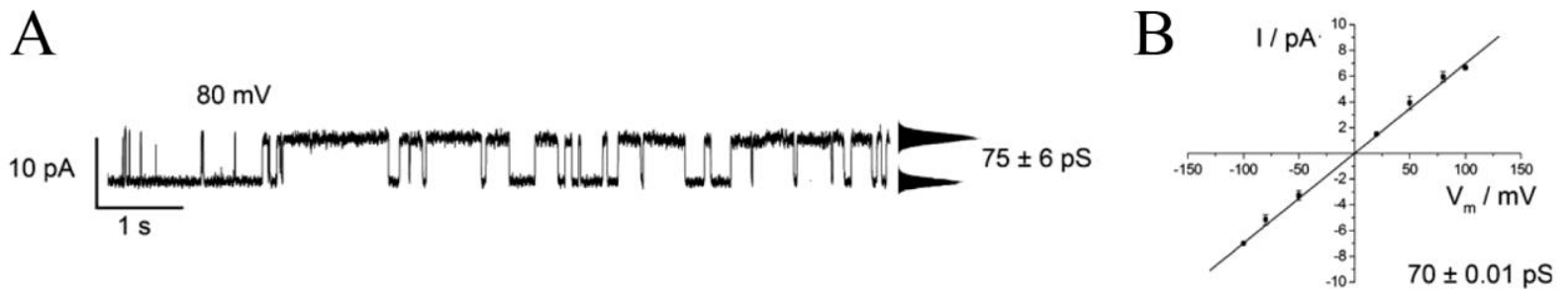

Abb. 4-30: Mittels Port-a-Patch Technik erhaltene Ergebnisse für Cx26M34A [Gaßmann et al. 2009]. (A) Charakteristische Einzelkanalmessung bei einer Transmembranspannung von $+80 \mathrm{mV}$ in $200 \mathrm{mM} \mathrm{KCl}, 10 \mathrm{mM}$ HEPES, 2 mM EDTA, pH 7.0. Über ein Punktamplituden-Histogramm (rechts) lässt sich eine gemittelte Leitfähigkeit von $(75 \pm 6) \mathrm{pS}$ bestimmen. (B) Strom-Spannungs-Abhängigkeit. Die lineare $I$ - $V$-Abhängigkeit lässt auf ein ohmsches Verhalten des Kanals schließen. Aus der Steigung kann nach $G=I / U$ eine Leitfähigkeit von $(70 \pm 0.01) \mathrm{pS}$ berechnet werden.

Die in Abb. 4-30 B dargestellte lineare Strom-Spannungs-Abhängigkeit belegt das ohmsche Verhalten des M34A Halbkanals. Die anhand der Steigung ermittelte Leitfähigkeit von (70 \pm 0.01) pS entspricht in etwa der Leitfähigkeit von $(75 \pm 6) \mathrm{pS}$, welche sich mittels eines Punktamplituden-Histogramms für die in Abb. 4-30 A dargestellte repräsentative Einzelkanalmessung von M34A bestimmen lässt. Diese Ereignisse können der in nano-BLMs gefundenen Leitfähigkeitsstufe $G_{2, \mathrm{M} 34 \mathrm{~A}}$ zugeordnet werden. Ebenfalls nachweisbar sind

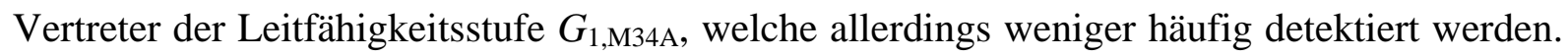
Nachstehende Tabelle fasst diese Ergebnisse zusammen.

Tabelle 12: Hauptleitfähigkeitsstufen von Cx26M34A Connexonen in planaren, porenüberspannenden, artifiziellen Membransystemen.

Leitfahigkeitsstufe

$G_{1}$

$G_{2}$
Port-a-Patch / pS

$\sim 30$

$\sim 70$
nano-BLM / pS

$44 \pm 6$

$69 \pm 10$

\subsubsection{Chemische Modulation der Leitfähigkeit}

Konnte die reversible Calcium-abhängige Blockade von Cx26 Halbkanälen bereits in nanoBLMs nachgewiesen werden, so liegt der Fokus der Untersuchungen mittels Port-a-Patch Technik auf der Blockade von Cx26 Halbkanälen mittels Azidifizierung und Lanthan. 
Zahlreiche Studien belegen die pH-abhängige Regulierung von Cx26 Halbkanälen [Bevans \& Harris 1999; Tao \& Harris 2004; Yu et al. 2007]. Hierbei kommen vor allem protonierte Sulfonsäuren wie Taurin und HEPES zum Einsatz. Mit diesen Substanzen ist es möglich, die Aktivität von Cx26WT auch im verwendeten artifiziellen Membransystem nachhaltig zu modulieren (Abb. 4-31).

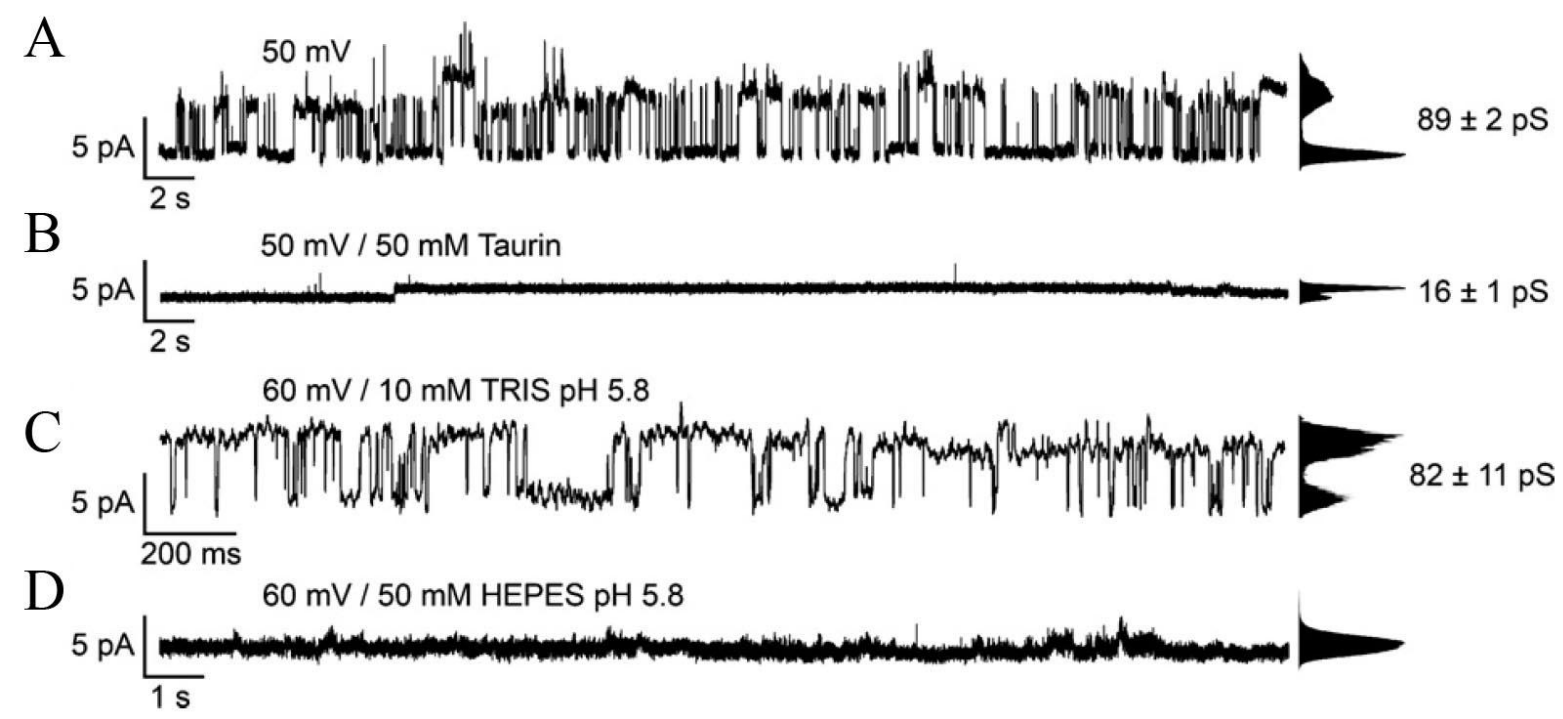

Abb. 4-31: Modulation der Kanalaktivität von Cx26WT mit Taurin und HEPES in planaren, porenüberspannenden Lipidmembranen auf mikrostrukturierten Glasträgern. (A) Einzelkanalmessung von Cx26WT bei einer Transmembranspannung von $+50 \mathrm{mV}$ in $200 \mathrm{mM} \mathrm{KCl}, 10 \mathrm{mM}$ HEPES, $2 \mathrm{mM}$ EDTA, pH 7.0. Über ein Punktamplituden-Histogramm (rechts) lässt sich eine gemittelte Leitfähigkeit von $(89 \pm 2) \mathrm{pS}$ bestimmen. (B) Kanalaktivität 1 min nach Zugabe von $50 \mathrm{mM}$ Taurin mit einer reduzierten Leitfähigkeit von $(16 \pm 1) \mathrm{pS}$. (C) Einzelkanalmessung von Cx26WT bei einer Transmembranspannung von $+60 \mathrm{mV}$ in $200 \mathrm{mM}$ $\mathrm{KCl}, 10 \mathrm{mM}$ TRIS/HCl, $2 \mathrm{mM}$ EDTA, pH 5.8 mit einer gemittelten Leitfähigkeit von $(82 \pm 11) \mathrm{pS}$. (D) Vollständige Blockade des Cx26WT Halbkanals 1 min nach Zugabe von 50 mM HEPES pH 5.8.

Abb. 4-31 A und B zeigen den Effekt von $50 \mathrm{mM}$ Taurin $\left(\mathrm{p} K_{\mathrm{S}}(\mathrm{Amin})=8.74\right)$ bei $\mathrm{pH} 7.0$ auf die Aktivität des Cx26WT. Etwa 1 min nach Zugabe dieser Aminosulfonsäure reduziert sich die Leitfähigkeit des Halbkanals von ursprünglich $(89 \pm 2) \mathrm{pS}$ auf $(16 \pm 1) \mathrm{pS}$. Wird der $10 \mathrm{mM}$ TRIS Puffer mit pH 5.8 während einer Einzelkanalmessung mit Puffer einer Konzentration von 50 mM HEPES und pH 5.8 ausgetauscht, geht dies direkt nach Zugabe mit einem vollständigen Aktivitätsverlust des Cx26 Halbkanals einher.

Entsprechende Ergebnisse können erzielt werden, wenn dem Messpuffer der aktiven Cx26 Mutante M34A Lanthan hinzugefügt wird (Abb. 4-32). Diese dreiwertigen Ionen können bereits in anderen Studien dazu verwendet werden, die Aktivität von Cx43 zu modulieren [Contreras et al. 2002; Kondo et al. 2000; Ye et al. 2003]. 


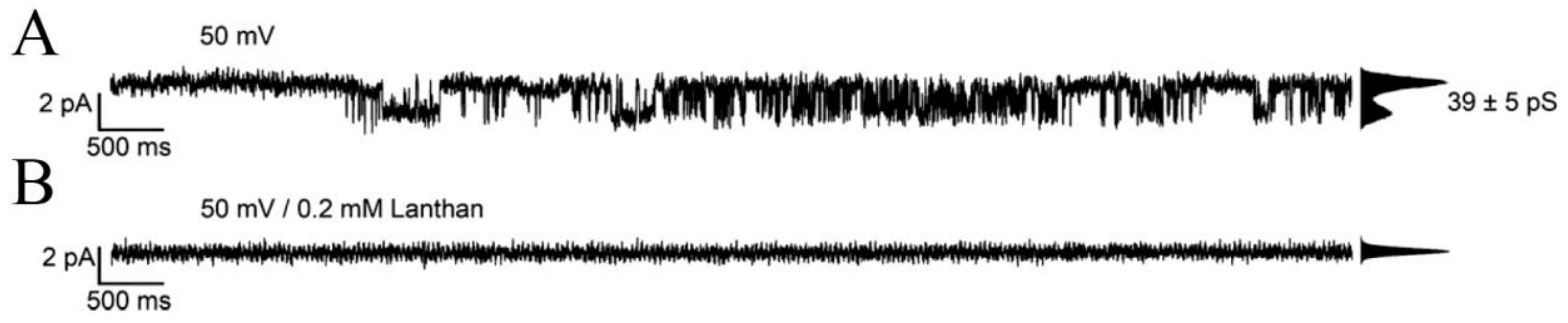

Abb. 4-32: Modulation der Kanalaktivität von Cx26M34A mit Lanthan in planaren porenüberspannenden Lipidmembranen auf mikrostrukturierten Glasträgern. (A) Einzelkanalmessung von Cx26M34A bei einer Transmembranspannung von $+50 \mathrm{mV}$ in $200 \mathrm{mM} \mathrm{KCl}, 10 \mathrm{mM}$ HEPES, $2 \mathrm{mM}$ EDTA, pH 7.0. Über ein Punktamplituden-Histogramm (rechts) lässt sich eine gemittelte Leitfähigkeit von $(39 \pm 5) \mathrm{pS}$ bestimmen. (B) Vollständige Blockade des Cx26M34A Halbkanals 1 min nach Zugabe von $0.2 \mathrm{mM}$ Lanthan.

Der Abbildung ist zu entnehmen, dass die Zugabe von $0.2 \mathrm{mM}$ Lanthan in einer vollständigen Blockade des Kanals direkt nach Zugabe resultiert.

Zusammen mit der calciumabhängigen Blockade von Cx26 in nano-BLMs bestätigen diese Ergebnisse, dass es sich bei der in den artifiziellen Membransystemen nachgewiesenen Ionenkanalaktivität eindeutig um funktionell rekonstituierte Cx26 Ionenkanäle handelt. 


\subsection{Integration von Connexonen in Lipidmembranen auf mikroporösen Oberflächen}

Neben dem elektrophysiologischen Nachweis der Rekonstitution einzelner Cx26 Halbkanäle in nano-BLMs sollte ein Ansatz verfolgt werden, der es ermöglicht, eine hohe Dichte von Connexonen in eine porenüberspannende Membran zu integrieren. Hierzu steht die Technik der konfokalen Laserrastermikroskopie (CLSM) zur Verfügung. Da die Auflösung eines solchen Mikroskops in der Praxis parallel zur optischen Achse auf etwa $300 \mathrm{~nm}$ begrenzt ist [ESA et al. 2000], müssen mikroporöse Substrate verwendet werden. Hierfür kommen so genannte Mikrosiebe zum Einsatz (fluXXion), welche in der Lebensmittelindustrie z.B. zur Sterilfiltration von Milch verwendet werden. Diese bestehen aus einer soliden Stützstruktur aus Silizium, deren Stege als Träger einer $1 \mu \mathrm{m}$ dicken porösen Schicht aus Siliziumnitrid dienen. Diese Mikrosiebe sind mit Porengrößen zwischen 0.4 und $8 \mu \mathrm{m}$ verfügbar. In dieser Arbeit wird mit $1.2 \mu \mathrm{m}$ Poren gearbeitet (Abb. 4-33).

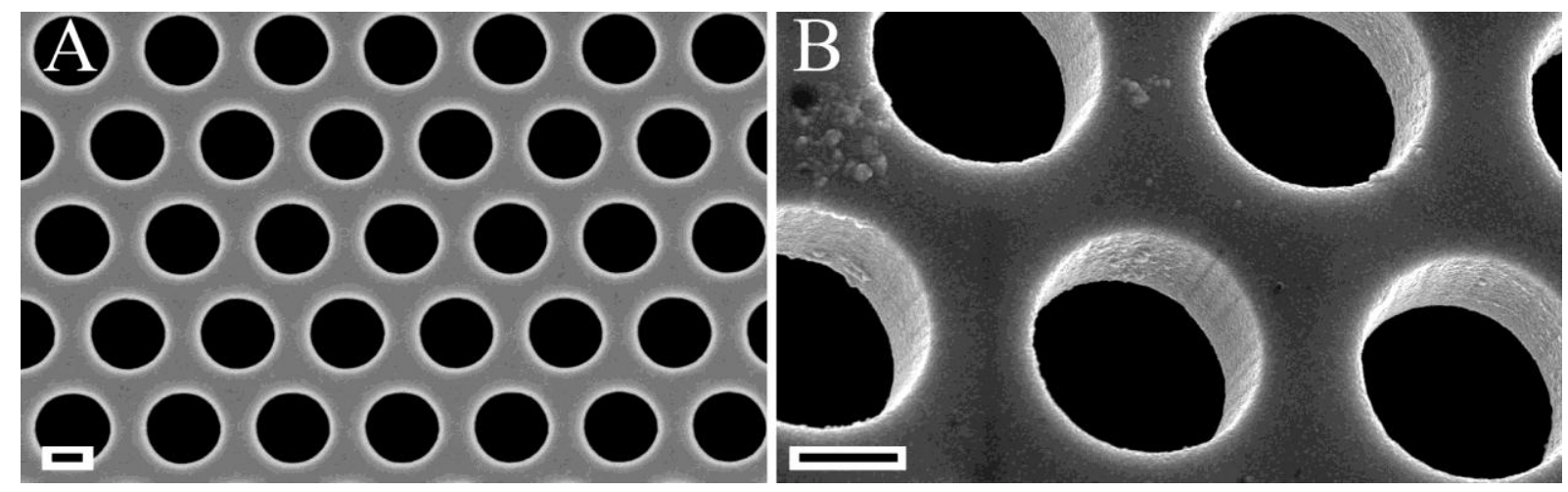

Abb. 4-33: Rasterelektronenmikroskopische Aufnahme von 1.2 $\mu \mathrm{m}$ Siliziumporen (fluXXion) in 21.000facher Vergrößerung (A) und 65.000facher Vergrößerung (B). Maßstab = $500 \mathrm{~nm}$.

Um den Nachweis einer Rekonstitution des Cx26 in der porenüberspannenden Membran zu erbringen, sollen auf den in Abb. 4-33 dargestellten Substraten Connexon-dotierte GUVs gespreitet werden. Hierfür ist es zunächst erforderlich, eine geeignete Methode zu finden, mit welcher eine nachweisbare Menge an Protein in die GUVs integriert werden kann.

\subsubsection{Rekonstitution von Cx26 in GUVs}

Für die Rekonstitution von Connexonen in GUVs werden zahlreiche Methoden beschrieben, deren Eignung für das angestrebte Ziel überprüft werden soll. 


\subsubsection{Detergenzbasierte Rekonstitution}

Ähnlich der Integration von Cx26 in nano-BLMs können Connexone mit geeigneten Detergenzien in GUVs rekonstituiert und elektrophysiologisch nachgewiesen werden [Gaßmann et al. 2009]. Diese Rekonstitutionsstrategie basiert auf der Integration des Kanals in detergenzgesättigte GUVs. Bei der Anwendung dieser Technik ergeben sich jedoch einige Schwierigkeiten (siehe Abb. 4-34).
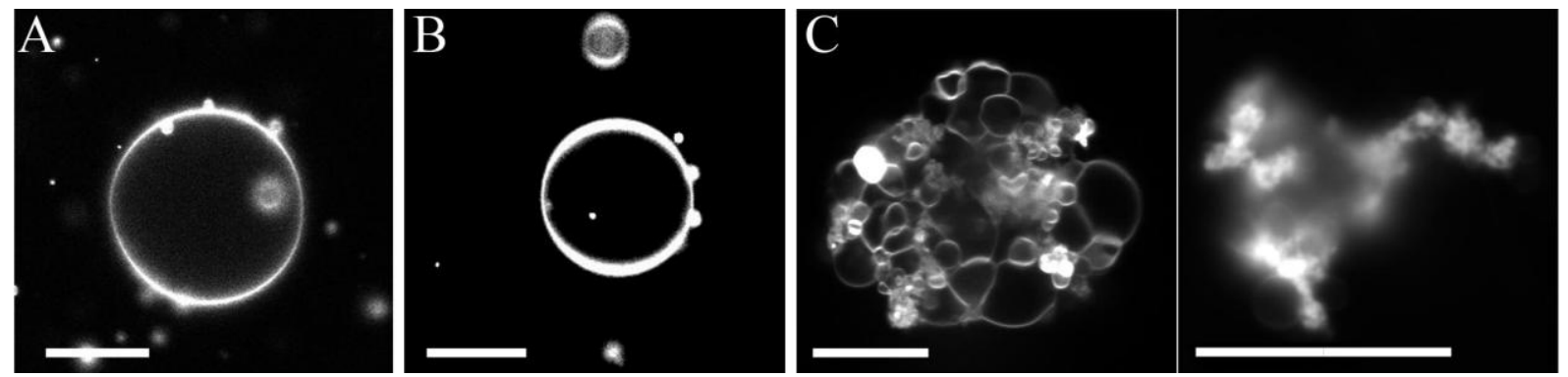

Abb. 4-34: Detergenzbasierte Rekonstitution von Cx26 in GUVs. Maßstab: $20 \mu \mathrm{m}$. Puffer: $100 \mathrm{mM} \mathrm{KCl,} 10 \mathrm{mM}$ TRIS, pH 7.4. (A) OG dotierter GUV (DPhPC, 0.4 mol\% OG-DHPE) vor Inkubation mit Detergenz und Protein. (B) OG dotierter GUV nach Inkubation mit Detergenz (0.01\% POE) und Puffer ohne Protein. (C) Beispiele für starkes Clustern Fluorophor dotierter GUVs nach Inkubation mit Detergenz und Puffer mit Protein $(0.01 \mathrm{mg} / \mathrm{ml})$.

Mittels Elektroformation werden GUVs ausreichender Anzahl und Größe hergestellt (Abb. 4-34 A). Anschließend erfolgt die Inkubation der GUVs mit $0.01 \%$ POE (CMC = $1 \%$ ) und Protein bis zu einer Konzentration von $0.01 \mathrm{mg} / \mathrm{ml}$ (Proteinstammlösung: $1 \mathrm{M} \mathrm{NaCl}, 300 \mathrm{mM}$ L-Histidin, $280 \mathrm{mM} \mathrm{NaOH}, 250 \mathrm{mM} \mathrm{HCl}, 10 \mathrm{mM}$ HEPES, $0.1 \%$ DoDM, $0.005 \% \mathrm{NaN}_{3}$,

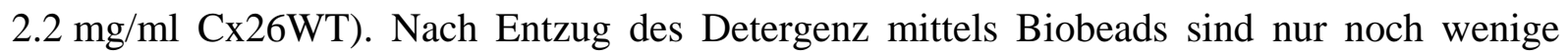
intakte GUVs zu beobachten. Der Ansatz wird durch vesikuläre Cluster (Abb. 4-34 C) dominiert, die in Form und Größe wesentlich von den Charakteristika der ursprünglichen GUVs abweichen. Werden die GUVs hingegen unter den gleichen Bedingungen mit Detergenz und Puffer ohne Protein inkubiert, tritt keine Veränderung des Erscheinungsbildes auf (Abb. 4-34 B).

Für die Integration großer Mengen an Protein in intakte und zahlreiche GUVs, welche für das Spreiten bzw. die Ausbildung großflächig porenüberspannender Membranen auf den mikroporösen Substraten erforderlich sind, kann diese Methode nicht adaptiert werden. Daher muss ein anderer Ansatz verfolgt werden, welcher sich an dem von Girard et al. [2004] etablierten Verfahren, der partiellen Dehydrierung von Proteoliposomen, orientiert.

\subsubsection{Rekonstitution mittels partieller Dehydratisierung}

Bei der Methode der partiellen Dehydratisierung werden zunächst Proteoliposomen nach dem in 3.6.5 beschriebenen Verfahren hergestellt. Die Proteoliposomen werden in Anwesenheit 
einer gesättigten NaCl-Lösung im Exsikkator auf den ITO-beschichteten Gläsern dehydratisiert. Durch die anschließende Elektroformation in Rehydratisierungspuffer (210 mM Sorbitol) entstehen GUVs.

Im Gegensatz zu der detergenzbasierten Methode können mit dieser Technik GUVs hergestellt werden, in denen von vornherein Cx26 integriert ist. Nachteil dieser Methode ist jedoch die extrem geringe Ausbeute an GUVs. Sowohl eine Variation der Rehydratisierungspuffer sowie der Lipidkomposition als auch die Verwendung verschiedener Lipid-Protein-Verhältnisse (40:1, 80:1, 160:1) ist nicht zielführend.

\subsubsection{Rekonstitution durch Fusion von Proteoliposomen}

Beide Methoden, die detergenzbasierte Rekonstitution von Cx26 in bestehende GUVs und die partielle Dehydratisierung von Proteoliposomen mit anschließender Elektroformation, liefern eine so geringe Ausbeute an GUVs, dass durch Spreiten dieser Vesikel keine größeren Flächen einer porenüberspannenden Membran ausgebildet werden können. Hierfür ist eine große Anzahl einheitlicher GUVs erforderlich. Letztlich kann diese Anforderung durch eine Erweiterung der Methode der Elektroformation erfüllt werden. Hierbei werden zunächst Cx26 Proteoliposomen hergestellt. Die ITO-beschichteten Objektträger werden mit dem gewünschten Lipidfilm beschichtet und getrocknet. Nach Zusammenbau der Elektroformationskammer wird diese durch Zugabe der Proteoliposomen und der Rehydratisierungslösung befüllt. Die Elektroformation erfolgt zu Standardbedingungen. Dabei fusionieren die beigefügten Proteoliposomen mit den sich bildenden oder schon bestehenden GUVs. Die erfolgte Rekonstitution von Cx26 in die GUVs kann indirekt mittels fluoreszenzmarkierter Lipide und direkt via fluoreszenzmarkiertem Antikörper nachgewiesen werden.

\section{Indirekter Nachweis der Rekonstitution durch Lipid-gekoppelte Fluoreszenz}

Bei der Herstellung der GUVs werden die auf den ITO-beschichteten Objektträgern aufgebrachten Lipidfilme unter Verwendung von TR-DPHE (Texas Red 1,2-dihexadecanoyl$s n$-glycero-3-phosphoethanolamine; $\lambda_{\mathrm{Ex}}: 595 \mathrm{~nm}, \lambda_{\mathrm{Em}}: 615 \mathrm{~nm}$ ) fluoreszenzmarkiert, damit die gebildeten Vesikel mittels CLSM nachweisbar sind. Die der Elektroformationskammer beigefügten Proteoliposomen sind ebenfalls mit einem Lipid-gekoppelten Fluorophor dotiert. Hier bietet sich ein Fluorophor an, dessen Anregungsspektrum nicht mit dem Anregungsspektrum von TR überlappt, also spektral in den Bereich kürzerer Wellenlängen verschoben ist. Dies ist bei PB-DMPE (Pacific Blue 1,2-dihexadecanoyl-sn-glycero-3phosphoethanolamine; $\lambda_{\mathrm{Ex}}: 411 \mathrm{~nm}, \lambda_{\mathrm{Em}}: 454 \mathrm{~nm}$ ) gegeben und Voraussetzung für den 
Nachweis der erfolgreichen Fusion der Proteoliposomen mit GUVs nach dem in Abb. 4-35 dargestellten Prinzip.

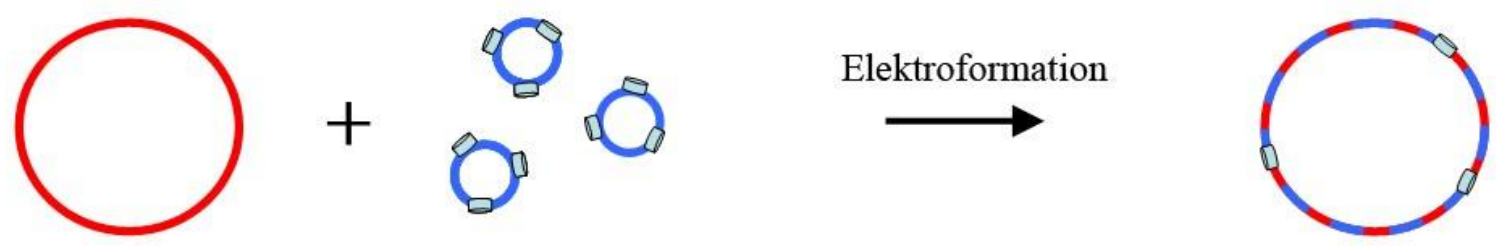

Abb. 4-35: Schematische Darstellung des indirekten Nachweises der Rekonstitution von Cx26 in TR-dotierte GUVs anhand der Fluoreszenz PB-dotierter Proteoliposomen.

Sollten bei dem Prozess der Elektroformation die PB-dotierten Cx26 Proteoliposomen mit den entstehenden oder bestehenden GUVs fusionieren, müsste neben TR auch die PB Fluoreszenz mittels CLSM in den GUVs nachgewiesen werden können. Nachstehende Abbildung zeigt die Ergebnisse, welche bei der Elektroformation reiner TR-dotierter Lipidfilme und bei der Elektroformation in Gegenwart von PB-dotierten Proteoliposomen erhalten werden.

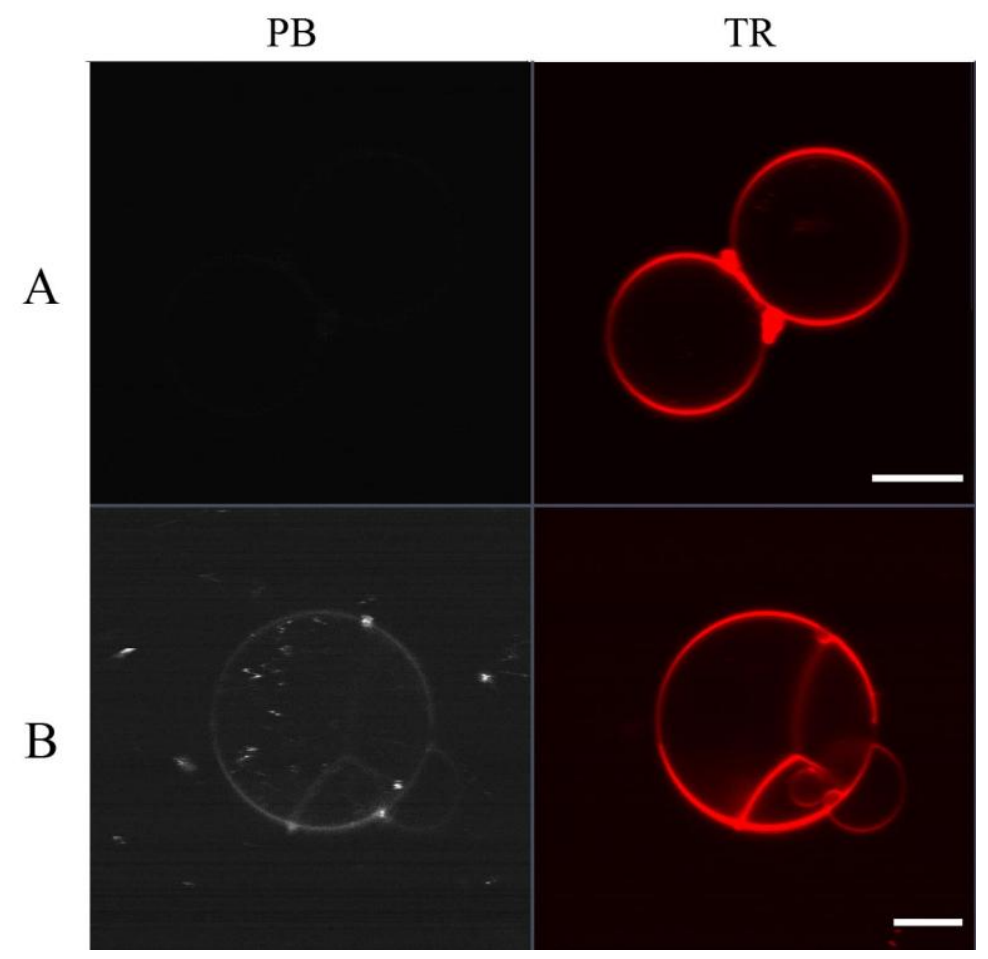

Abb. 4-36: Nachweis der PB-Fluoreszenz in TR-dotierten GUVs. Maßstab: $20 \mu \mathrm{m}$. Puffer: $200 \mathrm{mM} \mathrm{KCl}, 20 \mathrm{mM}$ HEPES, $0.02 \mathrm{mM}$ EDTA, pH 7.4. GUVs (POPC, $0.1 \mathrm{~mol} \%$ TR-DHPE) hergestellt in $200 \mathrm{mM}$ Sorbitol. Proteoliposomen (DPhPC:DOPC 6:4, 0.4 mol\% PB-DMPE, Lipid-Protein-Verhältnis 80:1) hergestellt in $200 \mathrm{mM}$ Sorbitol, $2 \mathrm{mM} \mathrm{KCl}, 1 \mathrm{mM}$ MOPS/TRIS, pH 7.4. Dargestellt sind die Fluoreszenzen von PB und TR. (A) Negativkontrolle. TR-dotierter GUV ohne fusionierte PB Proteoliposomen. Laserpower: $5 \%$, Digital Gain: 15, Master Gain: 600, Pinhole: 84, Digital offset: 0. (B) TR-dotierter GUV nach Elektroformation mit Proteoliposomen. Laserpower: 5 \%, Digital Gain: 15, Master Gain: 460, Pinhole: 84, Digital offset: 0. 
Reine TR-GUVs zeigen bei einer Anregungsfrequenz von $405 \mathrm{~nm}$ keine detektierbare Fluoreszenz im gewählten Emissionsbereich (445-470 nm) des Fluorophors PB (Abb. 4-36 A). Im Gegensatz dazu kann bei den in Anwesenheit von Proteoliposomen hergestellten TR-GUVs bei gleicher Anregungsfrequenz und identischem Filterbereich eindeutig eine PBFluoreszenz nachgewiesen werden (Abb. 4-36 B).

Der Nachweis der Lipid-gekoppelten Fluoreszenz der Proteoliposomen in den GUVs ist letztlich nur auf die erfolgreiche Fusion der PB-Proteoliposomen mit den TR-GUVs zurückzuführen. Für den direkten Nachweis der fusionsvermittelten Rekonstitution von Cx26 in die GUVs wird ein fluoreszenzmarkierter Antikörpers verwendet, welcher gegen den HisTag der Cx26 Untereinheit gerichtet ist.

\section{Direkter Nachweis der Rekonstitution durch FITC markierten Antikörper}

Die verwendeten Cx26 Proteine sind mit einem an der C-terminalen Domäne lokalisierten His $_{6}$-Tag versehen. Dieser dient in erster Linie der Aufreinigung des Proteins über NickelNTA-Agarose, kann letztlich aber auch als Target bzw. Antigen eines Anti-His-Antikörpers dienen. Um den direkten Nachweis der Rekonstitution des Cx26 in GUVs zu erbringen, werden Cx26 Proteoliposomen bei der Elektroformation mit ebenfalls nicht Fluorophordotierten GUVs fusioniert und anschließend $2 \mathrm{~h}$ bei RT mit einem Anti-His-Antikörper in einer Verdünnung von 1:250 inkubiert (Abb. 4-37). Der Antikörper ist mit dem Fluorophor FITC (Fluoresceinisothiocyanat; $\lambda_{\mathrm{Ex}}: 494 \mathrm{~nm}, \lambda_{\mathrm{Em}}: 518 \mathrm{~nm}$ ) markiert und damit mittels CLSM nachweisbar.

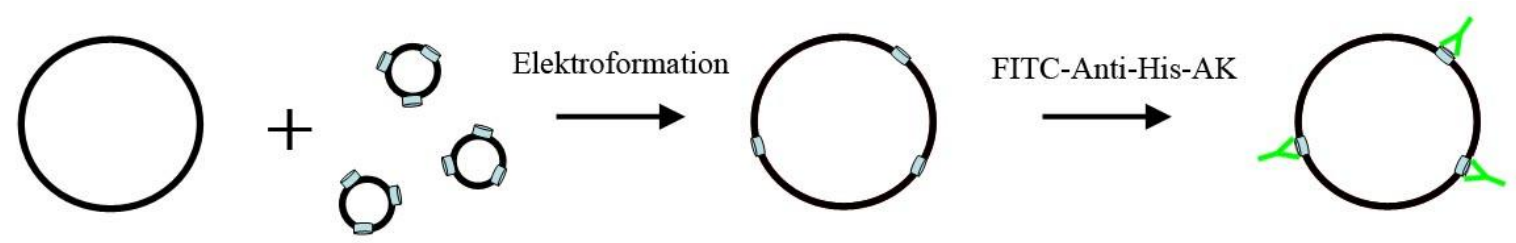

Abb. 4-37: Schematische Darstellung des direkten Nachweises der Rekonstitution von Cx26 in GUVs mittels FITC markiertem Anti-His-Antikörper.

Sollten bei der Fusion der Proteoliposomen mit GUVs ausreichende Mengen an Cx26 übertragen werden, müsste die FITC Fluoreszenz im Bereich der Membran nachweisbar sein. Die Ergebnisse dieser Analyse sind exemplarisch in Abb. 4-38 dargestellt. 

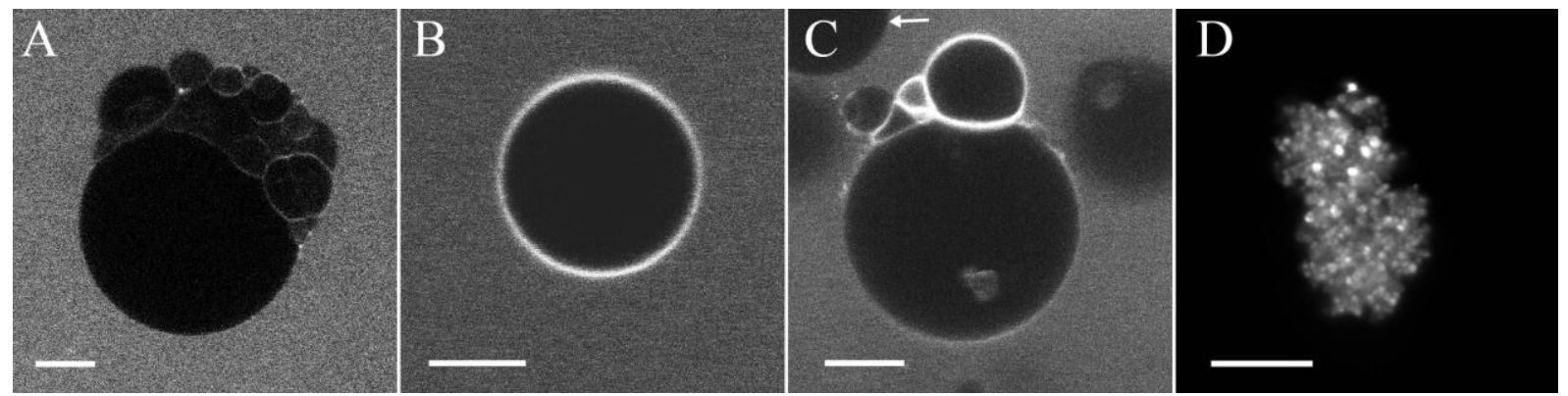

Abb. 4-38: Direkter Nachweis der Rekonstitution von Cx26 in GUVs mittels FITC markiertem Anti-HisAntikörper. Maßstab: $10 \mu \mathrm{m}$. Puffer: $136.9 \mathrm{mM} \mathrm{NaCl}, 2.7 \mathrm{mM} \mathrm{KCl}, 8.1 \mathrm{mM} \mathrm{Na} \mathrm{HPO}_{4}, 1.5 \mathrm{mM} \mathrm{KH}_{2} \mathrm{PO}_{4} \mathrm{mit}$ $4 \mu \mathrm{l} / \mathrm{ml}$ Anti-His-AK. Inkubation mit AK $2 \mathrm{~h}$ bei RT. Die Abbildungen zeigen die FITC-Fluoreszenz eines gegen den His-Tag des Cx26 gerichteten Antikörpers. (A) Reine POPC GUVs. (B) POPC GUVs mit rekonstituiertem Cx26. Herstellungsmethode: Elektroformation mit Cx26-Proteoliposomen (POPC, Lipid-Protein-Verhältnis 40:1). (C) Wie (B), dargestellt ist ein deutlich fluoreszierender GUV, der an einen gering fluoreszierenden GUV bindet und der Teilausschnitt eines nicht fluoreszierenden GUVs (Pfeil). (D) Aggregate von vermutlich Cx26Proteoliposomen (POPC, Lipid-Protein-Verhältnis 40:1).

Nach Inkubation mit dem Antikörper ist bei einer Anregungsfrequenz von $488 \mathrm{~nm}$ und einem Emissionsbereich von 490-600 nm eine sich klar von der Hintergrundfluoreszenz abhebende Fluoreszenz der GUV Membranen erkennbar (Abb. 4-38 B). Die Tatsache, dass auch weniger deutlich markierte (großer GUV in Abb. 4-38 C) und nicht markierte GUVs (Pfeil in C) in der Suspension zu beobachten sind, lässt vermuten, dass die fusionsvermittelte Cx26 Transferrate stark variiert. Weiterhin sind stark fluoreszierende größere Vesikelcluster erkennbar (Abb. 4-38 D), deren vesikuläre Untereinheiten in der Größenordnung der Proteoliposomen (200$400 \mathrm{~nm}$ ) liegen. Vergleichende Messungen mit reinen POPC GUVs zeigen keine unspezifische Bindung des Antikörpers (Abb. 4-38 A).

\subsubsection{Herstellung porenüberspannender Cx26 dotierter Lipidmembranen}

Die vorgestellten Ergebnisse belegen, dass durch die Fusion mit Proteoliposomen nachweisbare Mengen des Cx26 in den GUVs rekonstituiert werden können. Durch Spreiten dieser Vesikel auf den Mikrosieben mit einem Porendurchmesser von $1.2 \mu \mathrm{m}$ (Abb. 4-33) sollen großflächig porenüberspannende Membranen hergestellt werden. Die Substrate werden hierfür mit $2.5 \mathrm{~nm}$ Titan, $45 \mathrm{~nm}$ Gold und Tetradekanthiol (TDT) funktionalisiert. Für den indirekten Nachweis der Rekonstitution kann die Lipid-gekoppelte PB-Fluoreszenz in den porenüberspannenden Membranen nachgewiesen werden. Für den direkten Nachweis der Rekonstitution steht der FITC-gekoppelte Anti-His-Antikörper zur Verfügung. Zur besseren Charakterisierung des Systems soll in einem weiteren Schritt die laterale Mobilität der Lipide und der rekonstituierten Cx26 Halbkanäle analysiert werden. Hierfür kommt mit dem fluorescence recovery after photobleaching (FRAP) eine Methode zum Einsatz, mit welcher 
die laterale Mobilität von Lipiden oder Proteinen innerhalb einer Membran untersucht werden kann.

\subsubsection{Direkter Nachweis der Rekonstitution von Cx26 in porenüberspannenden Membranen durch FITC markierten Antikörper}

Die Cx26 Proteoliposomen werden zunächst bei der Elektroformation mit ebenfalls nicht fluoreszenzmarkierten POPC GUVs fusioniert. Diese werden durch Inkubation für $2 \mathrm{~h}$ bei $37^{\circ} \mathrm{C}$ auf den TDT funktionalisierten Substraten $(1.2 \mu \mathrm{m})$ gespreitet. Nach anschließender Inkubation ( $2 \mathrm{~h}$ bei RT) mit dem FITC markierten Anti-His-Antikörper in einer Verdünnung von 1:250 werden die Proben gespült und mit dem CLSM bei einer Anregungsfrequenz von $488 \mathrm{~nm}$ untersucht.
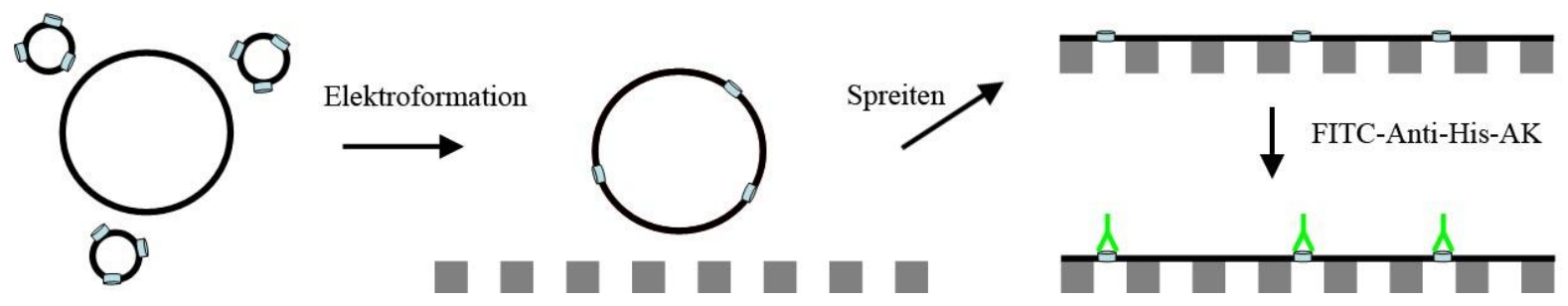

Abb. 4-39: Schematische Darstellung des direkten Nachweises der Rekonstitution von Cx26 in porenüberspannenden Membranen mittels FITC gekoppeltem Anti-His-Antikörper.

Nach dem in Abb. 4-39 schematisch dargestellten Prinzip können auf den mikroporösen Substraten auf großer Fläche porenüberspannende Membranen hergestellt werden. In diesen mikro-BLMs kann eine deutliche FITC Fluoreszenz innerhalb der Poren des Substrates detektiert werden (Abb. 4-40). Die Fluoreszenz der Stegbereiche ist aufgrund der goldinduzierten Fluoreszenzlöschung nicht detektierbar. Hierbei findet ein strahlungsloser Energietransfer des angeregten Fluorophors auf die Metalloberfläche statt, weshalb keine Photonen emittiert werden [Ritchie \& Burstein 1981]. FITC ist stark fotoinstabil, weshalb die Probe durch die Laser-induzierte fotochemische Zerstörung des Fluorophors leicht zu bleichen ist. Abb. 4-40 A zeigt einen Bereich vollständiger Membranbelegung. Die kaum fluoreszierende kreisrunde Fläche (siehe Pfeil) ist in ihrem Erscheinungsbild typisch für das Spreiten eines GUVs auf dem mikroporösen Substrat. Bereits in Abb. 4-38 C werden GUVs nachgewiesen, deren membranständige Fluoreszenz aufgrund der nur geringen Konzentrationen an rekonstituiertem Cx26 sehr schwach ist. Spreiten solche nur gering Cx26 dotierten Vesikel auf der funktionalisierten Substratoberfläche, ist nur bei vollständiger lateraler Immobilität der FITC Fluoreszenz des Antikörpers kein Intensitätsausgleich mit den umgebenden Poren zu erwarten. 


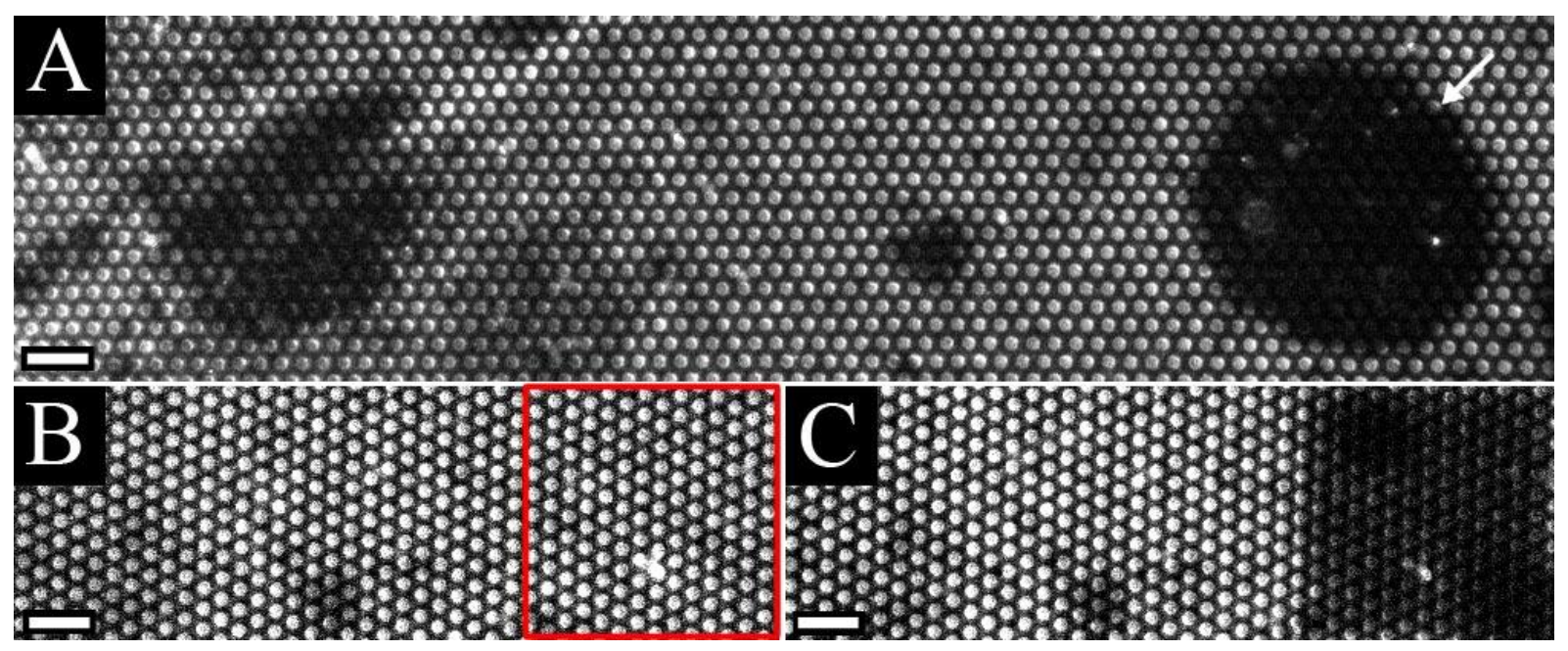

Abb. 4-40: Fluoreszenzmikroskopische Aufnahme der Fluoreszenz des FITC markiertem Anti-His-Antikörpers gebunden an eine Cx26 dotierte porenüberspannenden Membran auf fluXXion Mikrosieben (1.2 $\mu \mathrm{m}$ Porendurchmesser). Maßstab $=5 \mu \mathrm{m}$. Funktionalisierung: TDT. Zum Spreiten verwendete GUVs: POPC, hergestellt mittels Elektroformation in $210 \mathrm{mM}$ Sorbitol in Gegenwart von Cx26 Proteoliposomen (POPC, Lipid-Protein-Verhältnis 40:1, Puffer: $210 \mathrm{mM}$ Sorbitol). Spreitpuffer: $100 \mathrm{mM} \mathrm{KCl,} 10 \mathrm{mM}$ TRIS, pH 7.4. Spreiten: $2 \mathrm{~h}$ bei $37{ }^{\circ} \mathrm{C}$. Inkubation mit Antikörper: $2 \mathrm{~h}$ bei RT mit $4 \mu \mathrm{l} / \mathrm{ml}$. (A) Charakteristische Aufnahme der Cx26 dotierten Membran nach Inkubation mit FITC markiertem Antikörper. (B) Aufnahme der FITCFluoreszenz eines definierten Substratbereiches. Im rot eingegrenzten Bereich wird im Anschluss an diese Aufnahme ein FRAP-Experiment durchgeführt. (C) Gleicher Substratbereich wie in (B), 15 min nach Bleichen der Fluoreszenz durch das FRAP-Experiment.

Es können weitere Beobachtungen gemacht werden, welche auf eine laterale Immobilität des Antikörpers schließen lassen. Wird beispielsweise der in Abb. 4-40 B rot eingerahmte Substratausschnitt einer eingehenden Untersuchung durch ein FRAP-Experiment wie in Abb. 4-41 unterzogen, ist die Fluoreszenzintensität auch 15 min nach dem dadurch verursachten Bleichen nicht regeneriert (Abb. 4-40 C). Die beobachtete Immobilität des fluoreszenzmarkierten Antikörpers auf der Probe kann durch das gezielte Bleichen eines definierten Bereiches mit den durchgeführten FRAP-Experimenten bestätigt werden (Abb. 4-41).
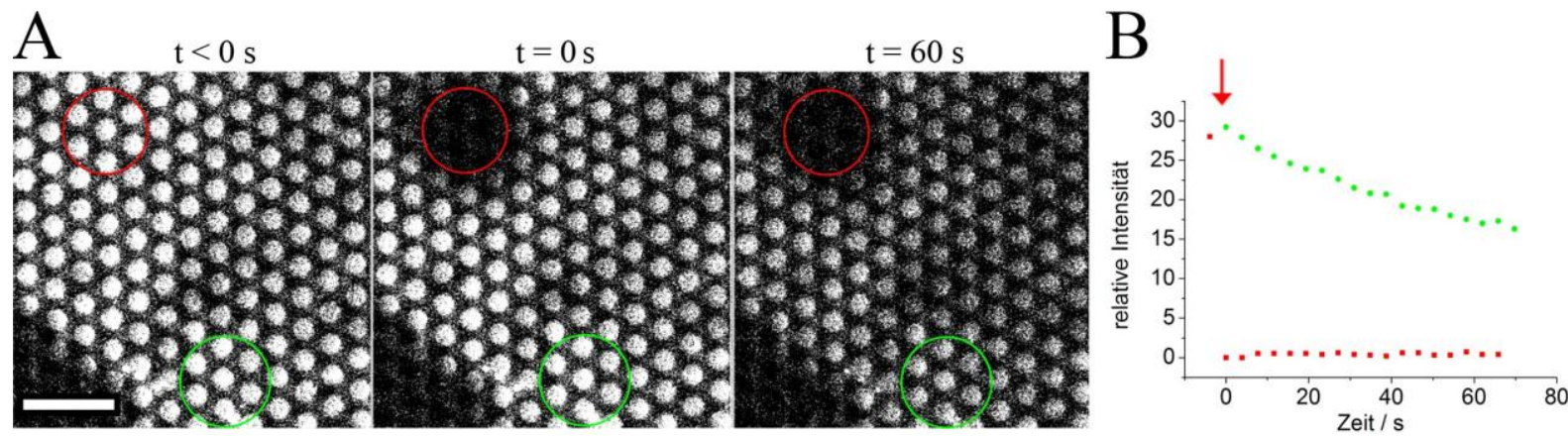

Abb. 4-41: FRAP-Studie zum Bestimmung der lateralen Mobilität von Cx26 in porenüberspannenden Membranen mittels FITC markiertem Anti-His-Antikörper. Maßstab $=5 \mu \mathrm{m}$. Substrat: fluXXion Mikrosieb, $1.2 \mu \mathrm{m}$ Porendurchmesser. Funktionalisierung: TDT. Zum Spreiten verwendete GUVs: POPC, hergestellt mittels Elektroformation in $210 \mathrm{mM}$ Sorbitol in Gegenwart von Cx26 Proteoliposomen (POPC, Lipid-ProteinVerhältnis 40:1, Puffer: 210 mM Sorbitol). Spreitpuffer: $100 \mathrm{mM} \mathrm{KCl,} 10 \mathrm{mM}$ TRIS, pH 7.4. Spreiten: 2 h bei $37{ }^{\circ} \mathrm{C}$. Inkubation mit Antikörper: $2 \mathrm{~h}$ bei RT mit $4 \mu \mathrm{l} / \mathrm{ml}$. (A) Zeitserie des FRAP-Experimentes. Roter Kreis: Bleichspot (ROI), grüner Kreis: Referenzbereich. (B) Relative Fluoreszenzintensität innerhalb des ROI ( $\mathbf{\square}$ ) und des Referenzbereiches $(\bullet)$. Der rote Pfeil markiert den Zeitpunkt des Bleichens $(\mathrm{t}=0 \mathrm{~s})$. 
Die Zeitserie in Abb. 4-41 A und die Auftragung der relativen Fluoreszenzintensität in Abb. 4-41 B zeigen, dass der Fluorophor FITC innerhalb der ROI (roter Kreis in A, a in B) durch einen Laserimpuls bei $\lambda_{\mathrm{Ex}}: 494 \mathrm{~nm}$ vollständig gebleicht werden kann, ohne dass ein Wiederanstieg der Fluoreszenzintensität im Beobachtungszeitraum zu erkennen ist. Die Fluoreszenz des Referenzbereiches (grüner Kreis in A, • in B) nimmt aufgrund der Fotoinstabilität des FITC im Verlauf der Messung kontinuierlich ab.

Diese Untersuchungen belegen, dass durch das Spreiten Cx26 dotierter GUVs eine so hohe Dichte an Connexonen in die porenüberspannende Membran integriert werden kann, dass diese mit einem Anti-His-Antikörper eindeutig nachgewiesen werden können. Die Ergebnisse zeigen aber auch die laterale Immobilität der mittels Antikörper fluoreszenzmarkierten Cx26 Halbkanäle auf den TDT funktionalisierten mikroporösen Substraten. Der Nachweis, dass die Connexone tatsächlich in eine kontinuierliche, porenüberspannende Membran integriert sind, kann nur erbracht werden, wenn bei den Lipiden in diesem System eine laterale Mobilität zu beobachten ist. Dies soll im nächsten Abschnitt überprüft werden.

\subsubsection{Laterale Mobilität der Lipid-gekoppelten Fluoreszenz}

In Abb. 4-36 kann der Lipid-gekoppelte Fluorophor PB-DMPE in den TR-dotierten GUVs detektiert werden. Dies ist ein Beleg für die erfolgte Fusion der Proteoliposomen mit den GUVs und ein indirekter Nachweis für den Transfer von Cx26. Die so präparierten GUVs sollen nach dem in Abb. 4-42 dargestellten Prinzip auf den funktionalisierten Mikrosieben gespreitet werden. Dies ermöglicht die Untersuchung der lateralen Mobilität der Lipide.
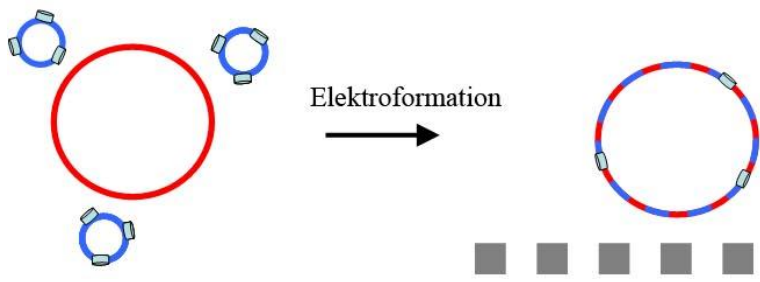

Spreiten

Abb. 4-42: Schematische Darstellung des indirekten Nachweises der Rekonstitution von Cx26 in porenüberspannenden Membranen anhand der Fluoreszenz PB-dotierter Proteoliposomen.

Nach erfolgreichem Spreiten dieser GUVs sind porenüberspannende Membranen zu erwarten, welche sowohl eine TR Fluoreszenz als auch eine PB Fluoreszenz aufweisen. Aufgrund einer hohen Fotostabilität sollte die TR Fluoreszenz nicht durch den starken Laserimpuls fotochemisch zerstört werden können, wohingegen mit dem weniger fotostabilen Fluorophor PB FRAP-Experimente zur Bestimmung der lateralen Mobilität durchführbar sein sollten. Die Bestätigung dieser Annahme ist Abb. 4-43 zu entnehmen. 

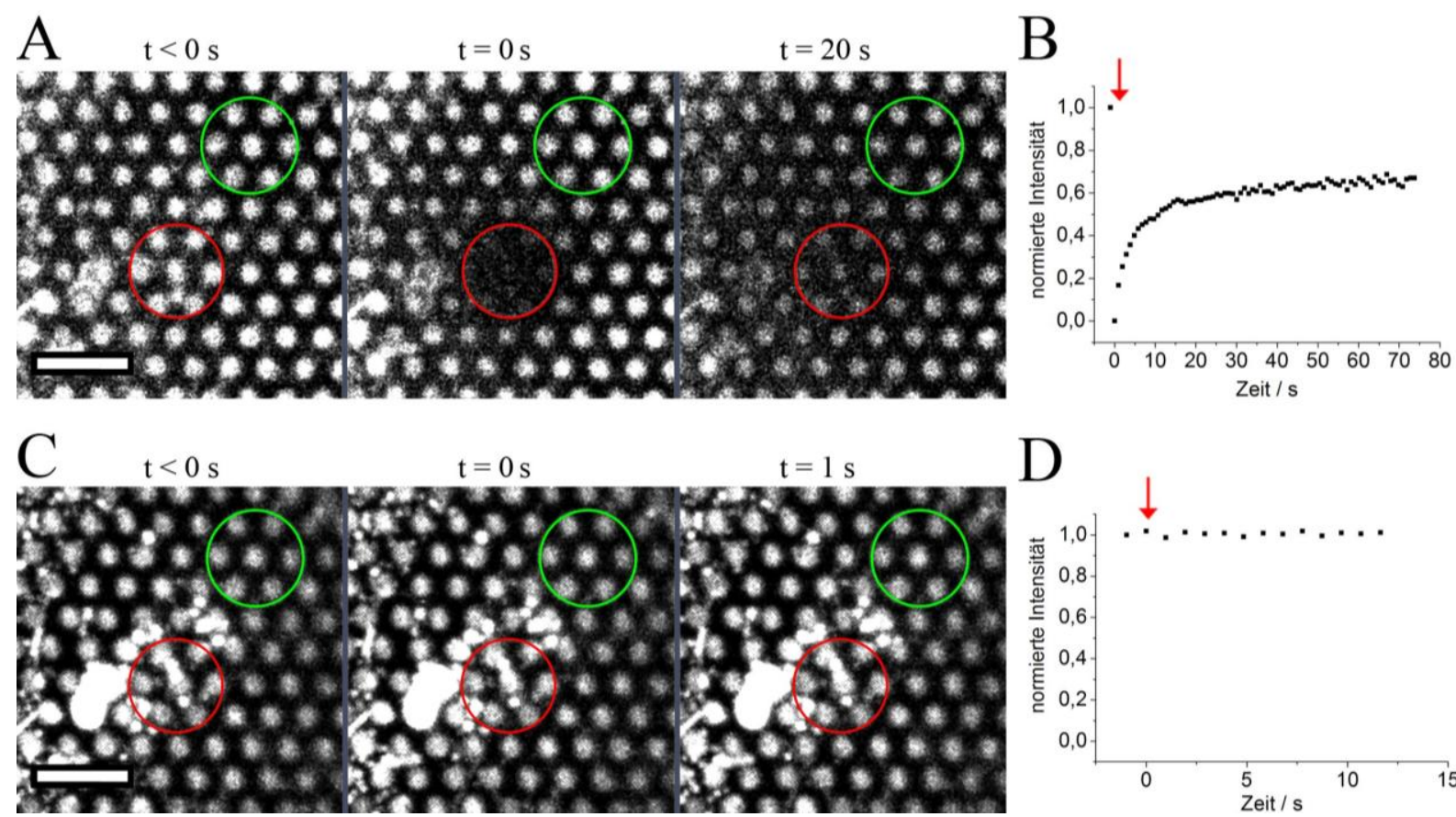

Abb. 4-43: FRAP-Studie zum indirekten Nachweis der Rekonstitution von Cx26 in porenüberspannenden Membranen und zur Bestimmung der lateralen Mobilität von Lipiden. Maßstab $=5 \mu \mathrm{m}$. Substrat: fluXXion Mikrosieb, $1.2 \mu \mathrm{m}$ Porendurchmesser. Funktionalisierung: TDT. Gespreitet wurden die in Abb. 4-36 B dargestellten TR-DHPE dotierten POPC GUVs mit fusionierten PB-DMPE dotierten Cx26-Proteoliposomen. Spreitpuffer: $100 \mathrm{mM} \mathrm{KCl,} 10 \mathrm{mM}$ TRIS, pH 7.4. Spreiten: $2 \mathrm{~h}$ bei $37^{\circ} \mathrm{C}$. (A) Zeitserie des FRAP-Experimentes mit PB Fluoreszenz. Roter Kreis: Bleichspot (ROI), grüner Kreis: Referenzbereich. (B) Normierte Fluoreszenzintensität innerhalb der ROI für das Bleichen der PB Fluoreszenz. Der rote Pfeil markiert den Zeitpunkt des Bleichens ( $\mathrm{t}=0 \mathrm{~s})$. (C) und (D) Wie (A) und (B) für die TR Fluoreszenz.

Abb. 4-43 zeigt ein FRAP-Experiment an einer porenüberspannenden Membran, welche nach dem in Abb. 4-42 beschriebenen Prinzip generiert wurde. A und C zeigen dieselbe Stelle des Substrates bei verschiedenen Anregungsfrequenzen und Emissionsfilterbereichen (A: $\left.\lambda_{\mathrm{Ex}}=405 \mathrm{~nm}, \quad \lambda_{\mathrm{Em}}=425-475 \mathrm{~nm} ; \quad \mathrm{B}: \lambda_{\mathrm{Ex}}=594 \mathrm{~nm}, \lambda_{\mathrm{Em}}=600-690 \mathrm{~nm}\right)$. Die jeweiligen Fluoreszenzen sind mit Ausnahme von an der Oberfläche adsorbierter Vesikel nur in den porenüberspannenden Bereichen detektierbar. In den Stegbereichen wird die Emission von Photonen des angeregten Lipid-gekoppelten Fluorophors durch den strahlungslosen Energietransfer auf die Goldoberfläche unterbunden (Fluoreszenzlöschung). Dieser Effekt dominiert allerdings nur in einem Bereich $<100 \AA$ über der funktionalisierten Substratoberfläche [Ritchie \& Burstein 1981], so dass adsorbierte Vesikel auch auf den Stegen des Substrates detektierbar bleiben. Abb. 4-43 C und D zeigen, dass die Fluoreszenzintensität des fotostabilen Fluorophors TR innerhalb einer definierten ROI (roter Kreis) durch einen starken Laserimpuls mit $\lambda_{\mathrm{Ex}}=594 \mathrm{~nm}$ nicht verringert werden kann. Im Gegensatz dazu wird die Fluoreszenz des Fluorophors PB innerhalb der ROI (roter Kreis, Abb. 4-43 A) durch einem Laserimpuls mit $\lambda_{\mathrm{Ex}}=405 \mathrm{~nm}$ vollständig gebleicht werden. Über einen Zeitraum von etwa $60 \mathrm{~s}$ nach dem Bleichen wird die Fluoreszenz, normiert auf die Hintergrundfluoreszenz des 
Referenzbereiches (grüner Kreis), beobachtet (Abb. 4-43 B). Nach der fotochemischen Zerstörung des PB Fluorophors bei $\mathrm{t}=0 \mathrm{~s}$ steigt die normierte Fluoreszenzintensität innerhalb von $20 \mathrm{~s}$ auf etwa $60 \%$ des Ausgangswertes. Bei dem Bleichen werden die Lipid-gekoppelten Fluorophore der oberen und der unteren Membranschicht zerstört. Aufgrund der Funktionalisierung der Porenstege mit einer Monolage TDT können nur die Lipide der oberen Membranhälfte über die Porenstege hinaus diffundieren und mit den Lipiden umgebender nicht gebleichter Regionen ausgetauscht werden. Lipide der unteren Membranschicht verbleiben innerhalb der gebleichten Pore. Aufgrund dessen erreicht die Fluoreszenzintensität nicht den Ausgangswert vor dem Bleichen und es verbleibt in dem gezeigten Beispiel ein immobiler Anteil von etwa $40 \%$. Der bei t $>20 \mathrm{~s}$ beobachtete langsame und kontinuierliche lineare Anstieg der normierten PB Fluoreszenzintensität ist auf das kontinuierliche Bleichen der Hintergrundfluoreszenz im Verlauf des FRAP-Experimentes zurückzuführen.

Mit der Regeneration der Fluoreszenzintensität innerhalb der ROI kann die laterale Mobilität der Lipide eindeutig nachgewiesen werden. Der Lipid-gekoppelte Fluorophor PB-DMPE eignet sich jedoch nicht für die Bestimmung der zweidimensionalen Diffusionsgeschwindigkeit $D_{\text {eff }}$ der Lipide auf dem mikroporösen Substrat. Bei $D_{\text {eff }}$ wird neben der Diffusionsgeschwindigkeit der Lipide innerhalb des porenüberspannenden Bereiches auch die reduzierte Diffusionsgeschwindigkeit auf den mit einer Monolage aus TDT funktionalisierten Porenstegen berücksichtigt. Aufgrund der starken Fotoinstabilität und dem damit verbundenen Bleichen der Hintergrundfluoreszenz würden mit dem Fluorophor PB zu kleine Werte für $D_{\text {eff }}$ ermittelt. Aufgrund dessen wird in weiteren FRAP-Experimenten mit dem fotostabilen Lipid-gekoppelten Fluorophor BODIPY-DHPE gearbeitet. Hiermit lassen sich auf TDT funktionalisierten Substraten Diffusionskoeffizienten von $3.4 \mu \mathrm{m}^{2} / \mathrm{s}$ bestimmen. Der immobile Anteil liegt bei $40 \%$ (Abb. 4-44).
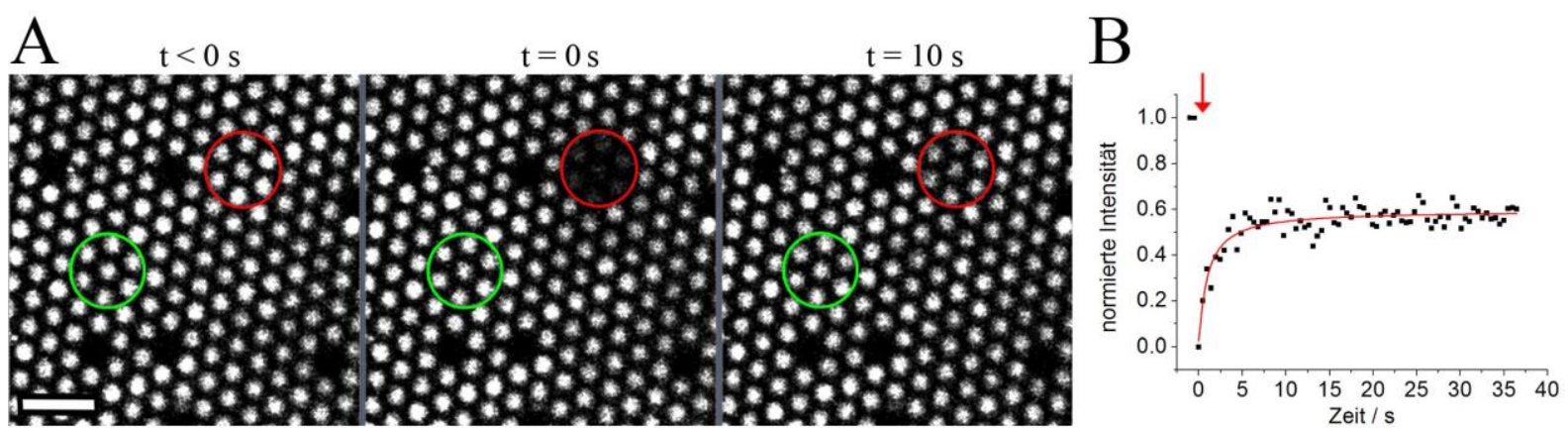

Abb. 4-44: FRAP-Studie zur Bestimmung des effektiven Diffusionskoeffizienten von Lipiden in mikro-BLMs. $\mathrm{Maßstab}=5 \mu \mathrm{m}$. Substrat: fluXXion Mikrosieb, $1.2 \mu \mathrm{m}$ Porendurchmesser. Funktionalisierung: TDT. Zum Spreiten verwendete GUVs: POPC mit 0.1 mol\% BODIPY-DHPE. Spreitpuffer: $100 \mathrm{mM} \mathrm{KCl,} 10 \mathrm{mM}$ TRIS, pH 7.4. Spreiten: 2 h bei $37^{\circ}$ C. (A) Zeitserie des FRAP-Experimentes. Roter Kreis: Bleichspot (ROI), grüner Kreis: Referenzbereich. (B) Normierte Fluoreszenzintensität innerhalb der ROI. Kurvenanpassung (一) nach Axelrod (Gleichung 3-10). Der rote Pfeil markiert den Zeitpunkt des Bleichens. Effektiver Diffusionskoeffizient $\mathrm{D}_{\text {eff }}=3.4 \mu \mathrm{m}^{2} / \mathrm{s}$, immobiler Anteil $\mathrm{IM}=40 \%$. 
Abb. 4-44 A zeigt die Zeitserie eines FRAP-Experimentes mit BODIPY-DHPE. Durch den Laserimpuls kann die Fluoreszenz innerhalb der ROI (roter Kreis) bei $\mathrm{t}=0 \mathrm{~s}$ nahezu vollständig gebleicht werden. Bereits $10 \mathrm{~s}$ nach dem Bleichen ist die Fluoreszenzintensität wieder auf etwa $60 \%$ der ursprünglichen Intensität angestiegen. Für dieses Beispiel lässt sich durch eine Datenanpassung der normierten Fluoreszenzintensitäten (Abb. 4-44 B) nach Axelrod et al. [1976] (Gleichung 3-10) ein effektiver Diffusionskoeffizient von $3.4 \mu \mathrm{m}^{2} / \mathrm{s}$ und ein immobiler Anteil von $40 \%$ bestimmen.

Durch den Nachweis der lateralen Mobilität der Lipide kann belegen werden, dass die Connexone rekonstituiert in einer kontinuierlichen, porenüberspannenden Membran vorliegen. 


\subsection{Nachweis der Proteinaktivität mittels GUV basierter Assays}

Kann via FITC-Anti-His-Antikörper die Integration von Connexonen in GUVs und porenüberspannenden Membranen nachgewiesen werden, so ist diese Methode nicht geeignet eine tatsächlich funktionelle Rekonstitution aktiver Cx26 Ionenkanäle zu verifizieren. Hier besteht die Möglichkeit, sich die grundlegendste Eigenschaft dieses nicht selektiven Ionenkanals zu Nutze zu machen, den passiven Transport von Molekülen bis zu einer Größenordnung von $1 \mathrm{kDa}$. Es wurde der Transport von Farbstoffmolekülen über die ansonsten nicht permeable Membran von GUVs mit Hilfe der konfokalen Laserrastermikroskopie (CLSM) untersucht. Hierfür werden zwei Ansätze verfolgt. Zum einen soll der Transport eines Farbstoffes durch die Halbkanäle untersucht werden, zum anderen ist geplant, den Farbstofftransfer zwischen GUVs sichtbar zu machen. Der damit erbrachte Nachweis eines funktionellen Gap Junction Kanals ist von entscheidender Bedeutung für die im Rahmen des BMBF Projektes angestrebte elektrische Kopplung von Zellen an porenüberspannende Connexonen-dotierte Lipidmembranen.

\subsubsection{Farbstofftransferassay}

Mit dem Cytochrom $c$ basierten Vesikelassay kann bereits die intravesikuläre Reduktion des Cytochrom $c$ nachgewiesen werden. Diese wird durch den passiven Transport des Ascorbats durch den funktionellen Cx26 Halbkanal vermittelt. Mittels bekannter Connexon-Blocker kann dieser transmembrane Molekültransfer unterbunden werden. Dem GUV basierten Farbstofftransferassay liegt ein ganz ähnliches Prinzip zu Grunde (Abb. 4-45). 


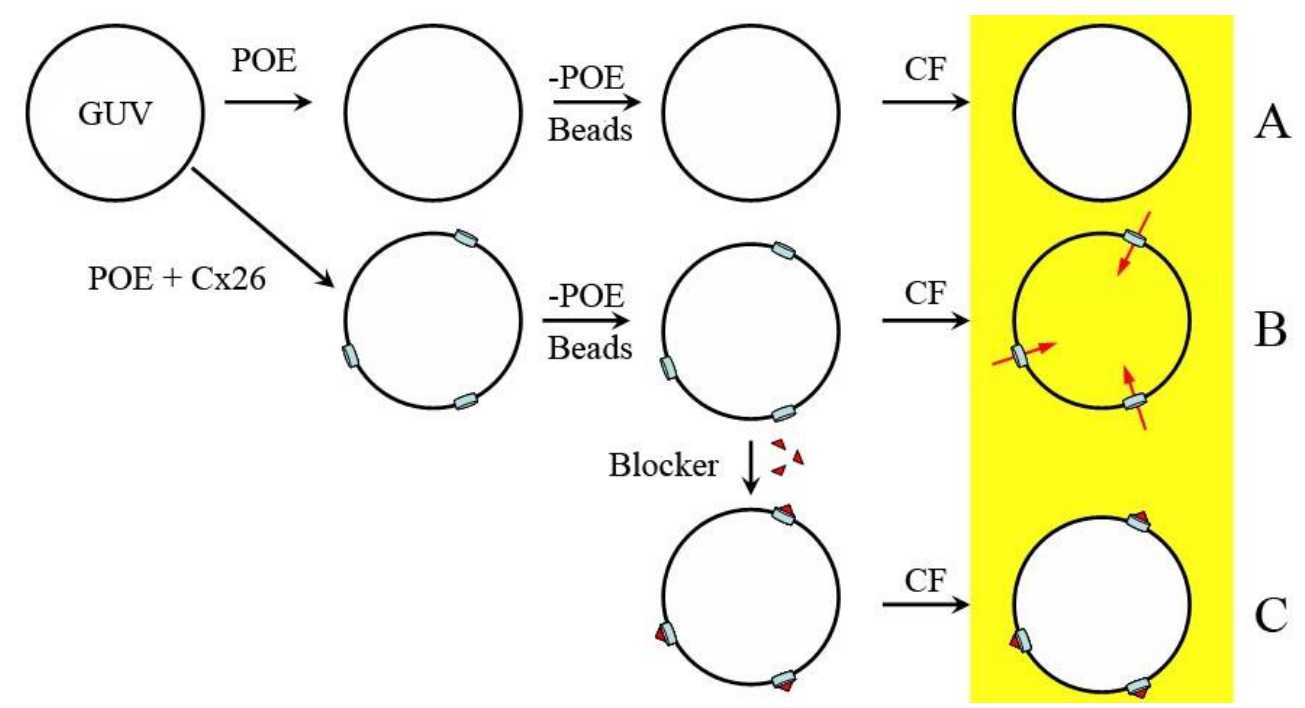

Abb. 4-45: Prinzip des GUV basierten Farbstofftransferassays. (A) Negativkontrolle. (B) Detergenzbasierte Rekonstitution von Cx26 in GUVs und Entzug des Detergenz mittels Biobeads. Bei funktioneller Integration der transmembranen Ionenkanäle sollte ein Farbstofftransfer in den Vesikel ermöglicht werden. (C) Die chemische Blockade funktionell rekonstituierter Cx26 Halbkanäle verhindert Farbstofftransfer.

Zunächst sollten durch Elektroformation Fluorophor dotierte GUVs hergestellt werden. Der Assay wurde zu einem Zeitpunkt konzipiert, als noch mit der detergenzbasierten Rekonstitution von Cx26 in GUVs gearbeitet wurde (siehe 4.3.1.1). Daher erfolgt die Integration der Connexone unter Zugabe von Detergenz und Protein. Das Detergenz wird mittels Biobeads entzogen und die verbleibenden intakten GUVs werden mit dem Fluorophor Carboxyfluorescein (CF) in einer Konzentration von $1 \mu \mathrm{M}$ inkubiert. Nach funktioneller Rekonstitution sollte daher ein Farbstofftransfer über die Cx26 Halbkanäle nachweisbar sein (Abb. 4-45 B). Nicht Connexondotierte GUVs (Abb. 4-45 A) oder mittels entsprechender Blocker inkubierte Cx26 dotierte GUVs (Abb. 4-45 C) sollten demnach keinen intravesikulären Farbstofftransfer ermöglichen.

Zunächst muss überprüft werden, ob der Eintritt von Farbstoff in GUVs zeitaufgelöst detektiert werden kann. Hierfür werden fluoreszenzmarkierte GUVs hergestellt, deren CFPermeabilität durch Detergenzzugabe initiiert wird (Abb. 4-46).
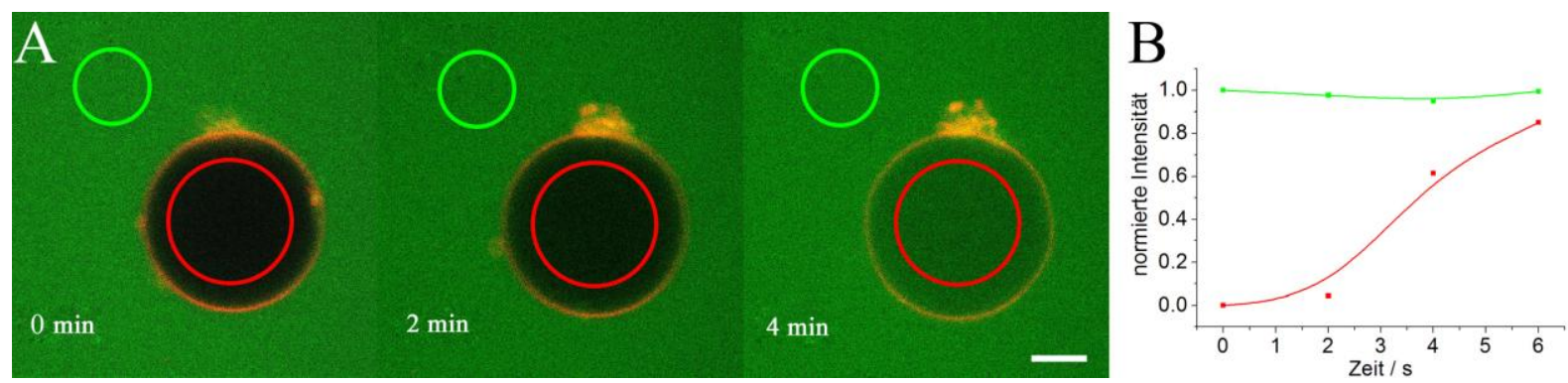

Abb. 4-46: Überprüfung des Messprinzips für die Umsetzung des GUV-Farbstofftransferassays. (A) Zeitserie eines TR-dotierten GUVs (DPhPC, 0.2 mol\% TR-DHPE) in $100 \mathrm{mM} \mathrm{KCl,} 10 \mathrm{mM}$ TRIS, $1 \mu \mathrm{M} \mathrm{CF}, \mathrm{pH} 7.4 \mathrm{mit}$ $0.02 \%$ POE. Roter Kreis = ROI, grüner Kreis = Hintergrundfluoreszenz (Referenzbereich). Maßstab $=10 \mu \mathrm{m}$. (B) Auftragung der normierten Fluoreszenzintensitäten innerhalb der ROI ( $\square$ ) und im Referenzbereich ( $\square$ ) in Abhängigkeit von der Zeit. 
Die CF-Permeabilität der zuvor nicht farbstoffgängigen GUVs kann durch Zugabe des Detergenz POE $(0.02 \%)$ soweit erhöht werden, dass der transmembrane Farbstofftransfer mittels CLSM zeitaufgelöst dargestellt werden kann. Binnen 6 min gleicht sich die intravesikuläre Fluoreszenzintensität ( $\square$ ) der extravesikulären Intensität ( $\square$ ) des CF an (Abb. 4-46 B).

Auf Grundlage dieser Ergebnisse werden zahlreiche Versuche unternommen, einen solchen Farbstofftransfer in den nach Proteinzugabe und Detergenzentzug verbliebenen Connexondotierten GUVs nachzuweisen. Zu keinen Zeitpunkt kann ein transmembraner Farbstofftransfer nachgewiesen werden, der im Vergleich zu den Kontrollmessungen ohne Protein auf die Funktionalität des Cx26 Halbkanals zurückzuführen wäre (Beispielmessung siehe Abb. 4-47).
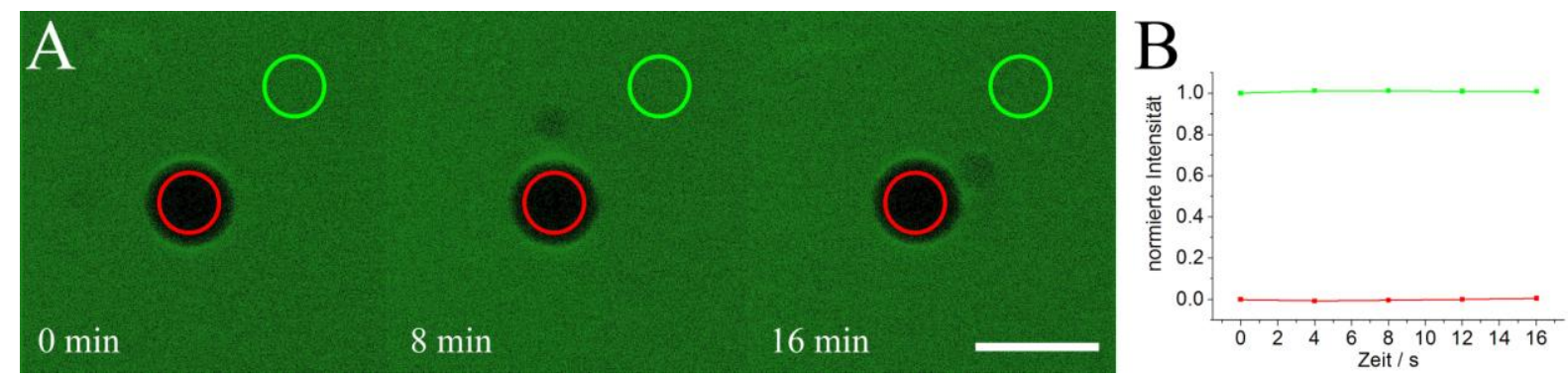

Abb. 4-47: (A) Zeitserie eines Cx26 dotierten GUVs (DPhPC, 0.2 mol\% TR-DHPE) in $100 \mathrm{mM} \mathrm{KCl,} 10 \mathrm{mM}$ TRIS, pH 7.4 nach Zugabe von $\mathrm{CF}$ bis zu einer Konzentration von $1 \mu \mathrm{M}$. Roter Kreis $=$ ROI, grüner Kreis $=$ Hintergrundfluoreszenz $\quad$ (Referenzbereich). Maßstab $=10 \mu \mathrm{m}$. (B) Auftragung der normierten Fluoreszenzintensitäten innerhalb der ROI ( $\square$ ) und im Referenzbereich ( $\square$ ) in Abhängigkeit von der Zeit.

Abb. 4-47 ist $\mathrm{zu}$ entnehmen, dass in diesem repräsentativen Beispiel über einen Beobachtungszeitraum von 16 min kein Farbstofftransfer beobachtet werden kann. Auch mit der später etablierten Rekonstitutionsmethode, welche auf der Fusion von Proteoliposomen während der Elektroformation beruht (siehe 4.3.1.3), kann letztlich kein Connexonspezifischer Nachweis erbracht werden.

\subsubsection{GUV Paarungsassay}

Nachdem Cx26 dotierte GUVs keine Connexon-spezifische Permeabilität für den Farbstoff CF aufweisen, sollte in Anlehnung an die von Kaneda et al. [2009] durchgeführten Experimente der Gap Junction vermittelte Farbstofftransfer zwischen zwei GUV Populationen nachgewiesen werden (Abb. 4-48). 


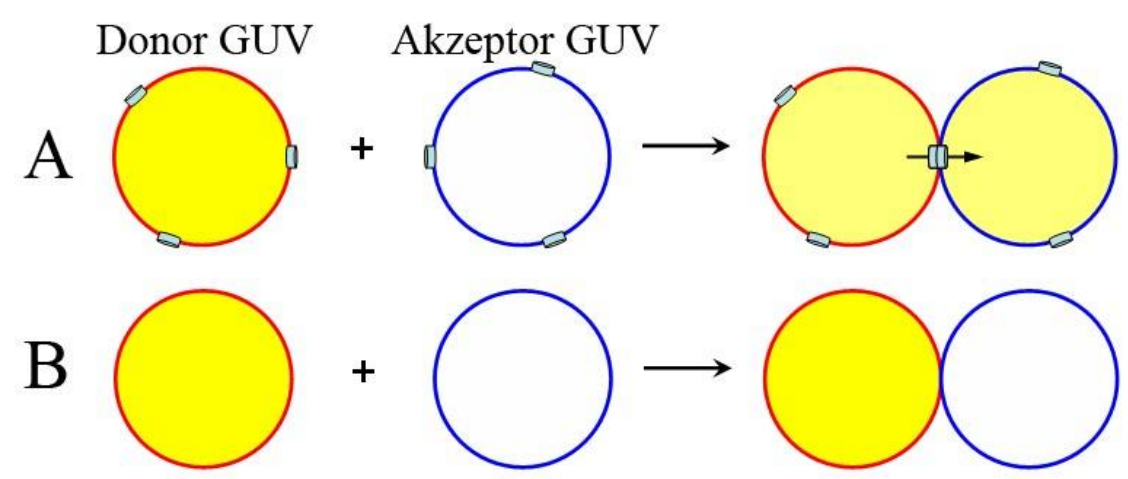

Abb. 4-48: Prinzip des GUV Paarungsassay zum Nachweis der Ausbildung von Gap Junctions. (A) Ausgehend von zwei unterschiedlich dotierten Populationen an Connexon dotierten GUVs soll ein Gap Junction vermittelter intervesikulärer Farbstofftransfer nachgewiesen werden. (B) Negativkontrolle ohne Protein und damit ohne Farbstofftransfer.

Die GUV Populationen sollten im CLSM deutlich voneinander unterscheidbar sein. Voraussetzung hierfür ist eine klare spektrale Trennung der Anregungs- und Emissionsbereiche. Daher wird anfangs mit dem Lipid-gekoppelten Fluorophor TR-DHPE $\left(\lambda_{\mathrm{Ex}}: 595 \mathrm{~nm}, \lambda_{\mathrm{Em}}: 615 \mathrm{~nm}\right)$ und dem nicht Lipid-gekoppelten Fluorophor Perylen $\left(\lambda_{\mathrm{Ex}}: 440\right.$, $\lambda_{\text {Em: }}$ 450) gearbeitet. In späteren Versuchen steht der Lipid-gekoppelte Fluorophor PB-DMPE ( $\lambda_{\mathrm{Ex}}: 411 \mathrm{~nm}, \lambda_{\mathrm{Em}}: 454 \mathrm{~nm}$ ) zur Verfügung. Das CF soll als wasserlöslicher Fluorophor dienen und wird, wie in Abb. 4-48 veranschaulicht, in den TR-GUVs eingeschlossen. Hierzu erfolgt die Elektroformation dieser GUVs in einem Rehydratisierungspuffer mit $1 \mu \mathrm{M} C F$. Werden diese GUVs bei der Durchführung der Experimente mit dem verwendeten Messpuffer 1:20 verdünnt, hebt sich die intravesikuläre CF Fluoreszenz deutlich von der Hintergrundfluoreszenz extravesikulären CF-Fluorophors ab (Abb. 4-49 A). Erste Versuche mit Kontrollvesikeln ohne rekonstituiertes Cx26 bestätigten, dass die verwendeten Fluorophore der beiden GUV Populationen getrennt voneinander detektiert werden können (Abb. 4-49). 

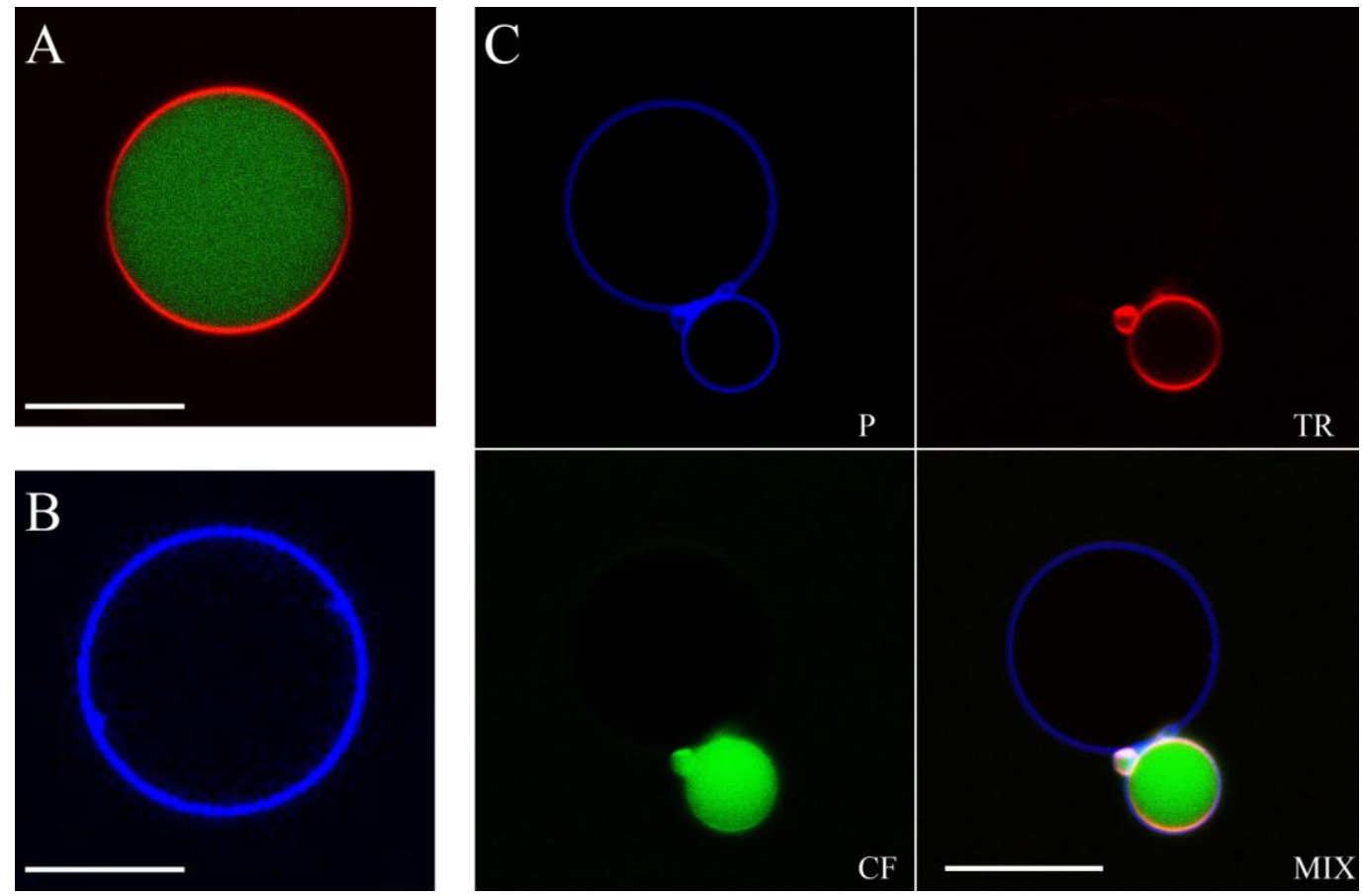

Abb. 4-49: Überprüfung der generellen Eignung der CLSM Technik für die Umsetzung des GUVPaarungsassays. Maßstab: $20 \mu \mathrm{m}$. Puffer: $100 \mathrm{mM} \mathrm{KCl,} 10 \mathrm{mM}$ TRIS, pH 7.4. (A) TR-dotierter GUV (DPhPC, $0.1 \mathrm{~mol} \%$ TR-DHPE) mit intravesikulärem CF $(1 \mu \mathrm{M})$. Dargestellt ist die Überlagerung der TR und der CF Fluoreszenz. (B) Perylen dotierter GUV (DPhPC, 0.4 mol\% Perylen). (C) Paarung eines TR dotierten GUVs mit eingeschlossenem CF und eines Perylen dotierten GUVs. Dargestellt sind die Perylen-Fluoreszenz P, die TRFluoreszenz TR, die CF-Fluoreszenz CF und die Überlagerung aller Fluoreszenzen MIX.

In den Kontrollvesikeln ohne Protein ist kein Transfer des CF zwischen den GUV zu beobachten. Die Verwendung des Fluorophors Perylen erweist sich hingegen als suboptimal. Dieser vollzieht bei Kontakt mit einem TR dotierten GUV einen Intermembranübergang und ist anschließend in beiden GUVs nachweisbar (Abb. 4-49 C). Zudem können unter Verwendung dieses Farbstoffes nur unzureichende Mengen an GUVs hergestellt werden, welche zudem häufig stark multilamellar sind (Abb. 4-50 B). Als weiterer Nachteil dieses Systems erweist sich die geringe Fotostabilität des CF (Abb. 4-50 A).
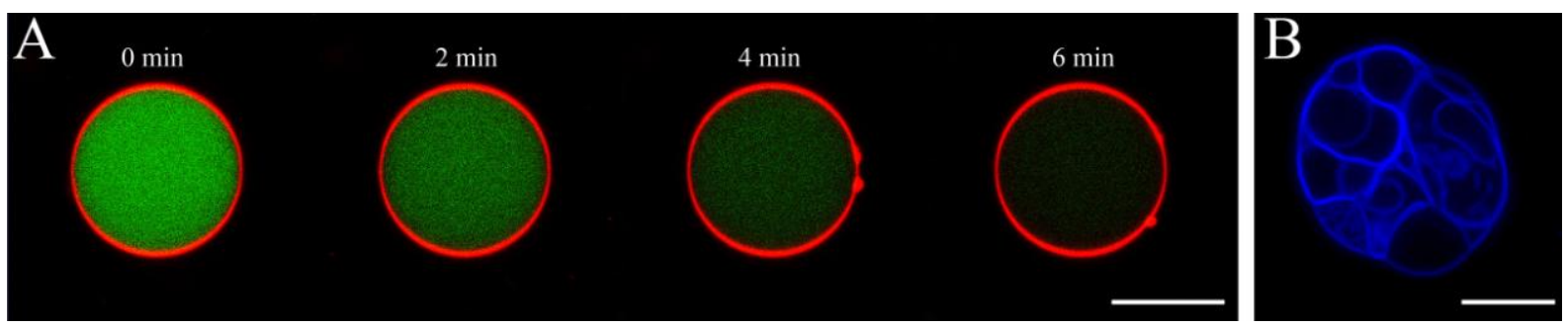

Abb. 4-50: Generelle Schwierigkeiten des GUV Paarungsassays. Messpuffer: $100 \mathrm{mM} \mathrm{KCl,} 10 \mathrm{mM}$ TRIS, $\mathrm{pH}$ 7.4. (A) Zeitserie eines TR-dotierter GUVs (DPhPC, $0.1 \mathrm{~mol} \%$ TR-DHPE, $1 \mu \mathrm{M} \mathrm{CF}$ ). Der intravesikuläre Farbstoff CF kann sehr leicht gebleicht werden. (B) Perylen-dotierter GUV (DPhPC, 0.4 mol\% Perylen). Stark deformierter, multilamellarer GUV.

Der verwendete nicht Lipid-gekoppelte Fluorophor Perylen wird aufgrund seiner nicht zu umgehenden Nachteile in späteren Versuchen durch PB-DMPE ersetzt. Mit dieser 
Konstellation an Fluorophoren kann der Farbstofftransferassay schließlich durchgeführt werden. Als Rekonstitutionsmethode wird die Fusion von Cx26 Proteoliposomen mit GUVs bei der Elektroformation verwendet (siehe 4.3.1.3). Von den hergestellten GUV Populationen werden anschließend jeweils $100 \mu \mathrm{zu} 2.8 \mathrm{ml}$ Puffer gegeben und über Nacht inkubiert. Der Nachweis einer erfolgreichen Paarung (Übertritt von Farbstoff) der Cx26 dotierter GUV Populationen kann direkt oder indirekt erfolgen.

\section{Indirekter Nachweis der Gap Junction Aktivität}

Der indirekte Nachweis eines Gap Junction vermittelten Farbstofftransfers beschränkt sich auf das Identifizieren von PB-GUVs (Akzeptor-GUVs), welche eine im Vergleich zum umgebenden Medium erhöhte intravesikuläre Konzentration an CF aufweisen. Diese ist im Idealfall das Resultat einer vorausgehenden Paarung mit einem TR-GUV (Donor-GUV) und erfolgtem CF Transfer. Im Verlauf der Experimente können mehrere CF gefüllte AkzeptorGUVs nachgewiesen werden (Abb. 4-51).

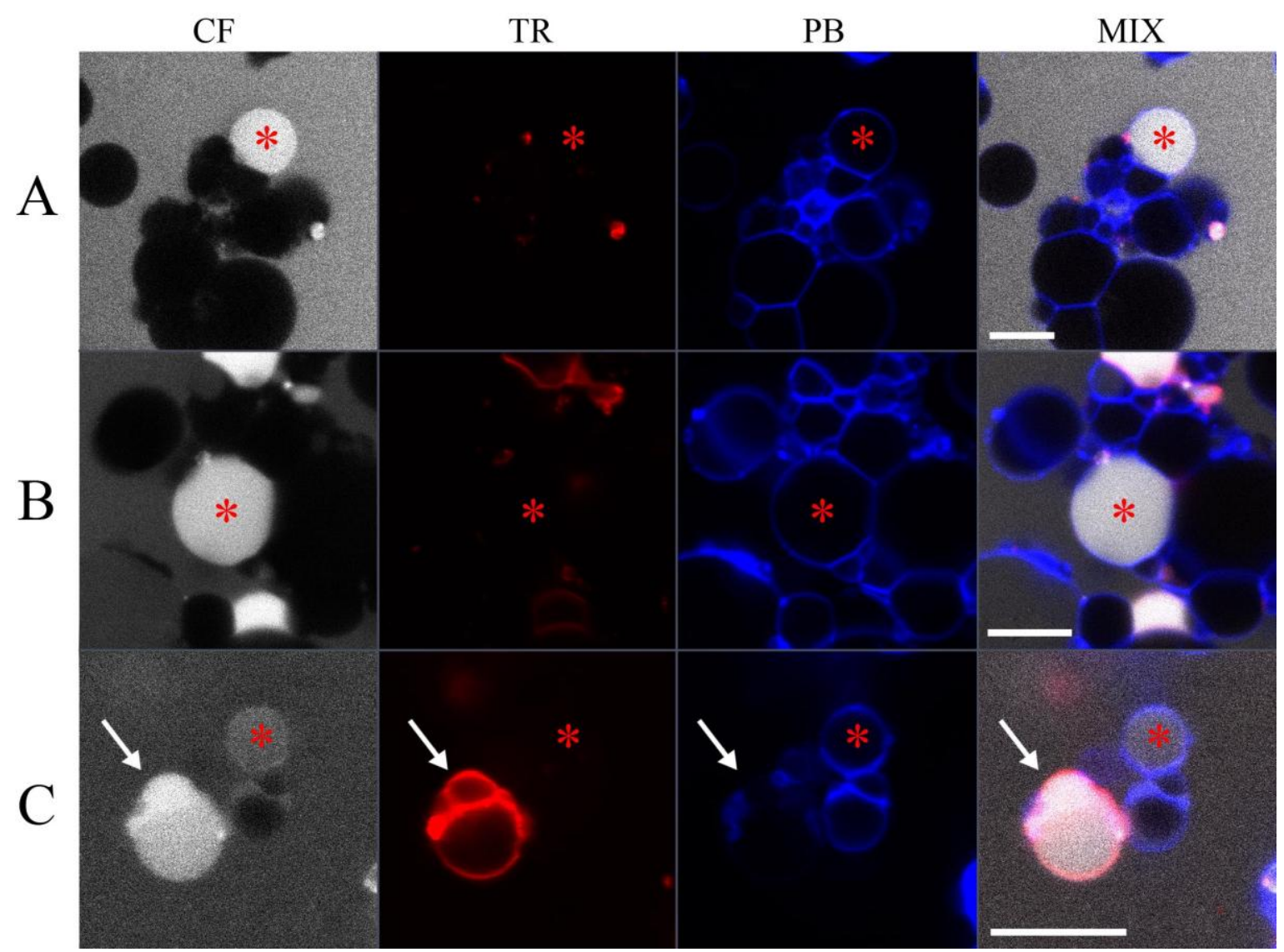

Abb. 4-51: Nachweis von PB markierten, Cx26 dotierten GUVs mit hoher intravesikulärer CF-Fluoreszenz (*) (Akzeptor-GUV). Der Pfeil markiert einen CF gefüllten TR markierten Donor-GUV. Maßstab: $10 \mu \mathrm{m}$. GUVs (POPC, $0.1 \mathrm{~mol} \%$ TR-DHPE mit $1 \mu \mathrm{M}$ CF / POPC, $0.5 \mathrm{~mol} \%$ PB-DMPE) hergestellt in $200 \mathrm{mM}$ Sorbitol in Anwesenheit von Cx26 Proteoliposomen (DPhPC:DOPC 6:4, 0.4 mol\% PB-DMPE, Lipid-Protein-Verhältnis 80:1, Puffer: $200 \mathrm{mM}$ Sorbitol). Messpuffer: $200 \mathrm{mM} \mathrm{KCl,} 20 \mathrm{mM}$ HEPES, $0.02 \mathrm{mM}$ EDTA, pH 7.4. Abgebildet sind jeweils die Fluoreszenzen von $\mathrm{CF}$, TR, PB und deren Überlagerung (MIX) für drei unterschiedliche GUVs (A bis C). 
Die in Abb. 4-51 A-C mit einem roten Stern (*) markierten PB-dotierten Akzeptor-GUVs weisen keinen bestehenden direkten Kontakt mit einem CF gefüllten TR-dotierten DonorGUV (siehe Pfeil Abb. 4-51 C) auf. Dennoch beträgt ihre auf die Hintergrundintensität normierte intravesikuläre CF Intensität $325 \%$ (in A), $161 \%$ (in B) und $138 \%$ (in C). Dies könnte ein indirekter Nachweis für einen zuvor erfolgten Farbstofftransfer sein. Die Akzeptor-GUVs treten meist in einem Verbund mit ungefüllten PB GUVs auf und werden selten isoliert detektiert.

\section{Direkter Nachweis der Gap Junction Aktivität}

Für den direkten Nachweis eines Gap Junction vermittelten CF Transfers werden die in Abb. 4-52 dargestellten Paarungstypen untersucht.
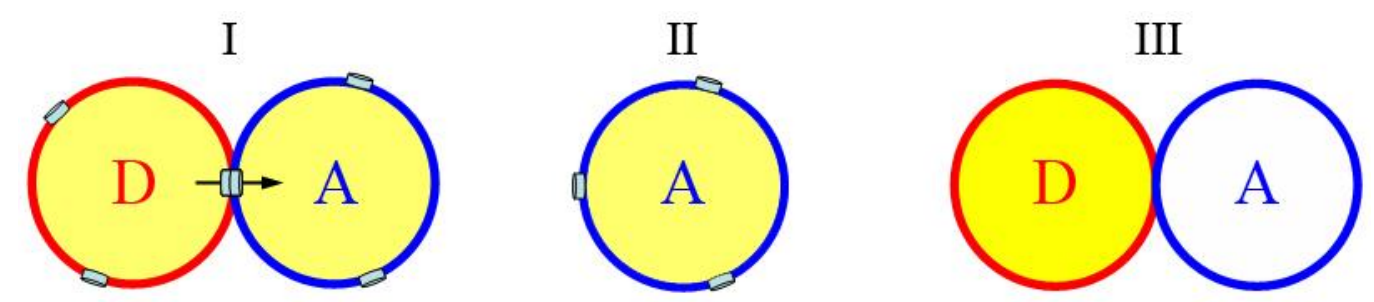

Abb. 4-52: Für den GUV-Paarungsassay relevante Ansätze. (I) Paarung von TR-dotiertem Donor-GUV (D) mit PB-dotiertem Akzeptor-GUV (A) und rekonstituiertem Cx26. (II) PB-dotierter Akzeptor-GUV mit rekonstituiertem Cx26. (III) Paarung eines TR-dotierten GUV mit einem PB-dotierten GUV ohne rekonstituiertes Cx26.

Bei dem Paarungstyp I handelt es sich um eine Paarung Cx26 dotierter TR-dotierter DonorGUVs und PB-dotierter Akzeptor-GUVs mit rekonstituiertem Cx26. Geht man davon aus, dass der Farbstofftransfer vom Donor-GUV in den Akzeptor-GUV bis zum Konzentrationsausgleich erfolgt, sollte in beiden Populationsvertretern eine identische und im Vergleich zum umgebenden Medium erhöhte CF Fluoreszenzintensität identifiziert werden können. Um auszuschließen, dass die intravesikuläre CF Intensität der Akzeptor-GUVs aufgrund von nicht Cx26 spezifischen Undichtigkeiten des Vesikels eingeschleust wird, soll diese mit einem ausreichend starken Laserimpuls vollständig gebleicht werden. Anschließend soll die Regenerierung der Intensität über einen Zeitraum von $10 \mathrm{~min}$ verfolgt werden. Bei bestehender Gap Junction vermittelter Verbindung beider GUVs sollte demnach ein Wiederanstieg der CF Intensität in den Akzeptor-GUVs nachweisbar sein.

Zur Überprüfung dieses Cx26 spezifischen Transfers zwischen den GUV-Populationen wird zudem der Paarungstyp II untersucht. Wie bereits in Abb. 4-51 gezeigt, können vereinzelt auch nicht mit einem Donor-GUV gepaarte Cx26 dotierte Akzeptor-GUVs nachgewiesen werden, welche eine erhöhte intravesikuläre CF Intensität aufweisen. Nach Bleichen dieser 
Akzeptor-GUVs dürfte demnach keine Regeneration der intravesikulären CF Intensität stattfinden. Die Untersuchung dieses Paarungstyps dient daher als Negativkontrolle zum Gap Junction spezifischen Transfer in Paarungstyp I.

Der Paarungstyp III dient ebenfalls als Negativkontrolle. Hierbei wird die Paarung nicht Connexon-dotierter Donor- und Akzeptor-GUVs untersucht. Ohne die Möglichkeit zur Ausbildung der intervesikulären Gap Junctions sollte bei Vertretern dieses Paarungstyps keine CF Intensität in den Akzeptor-GUVs nachgewiesen werden können.

Charakteristische Vertreter aller drei Paarungstypen sind in Abb. 4-53 dargstellt.

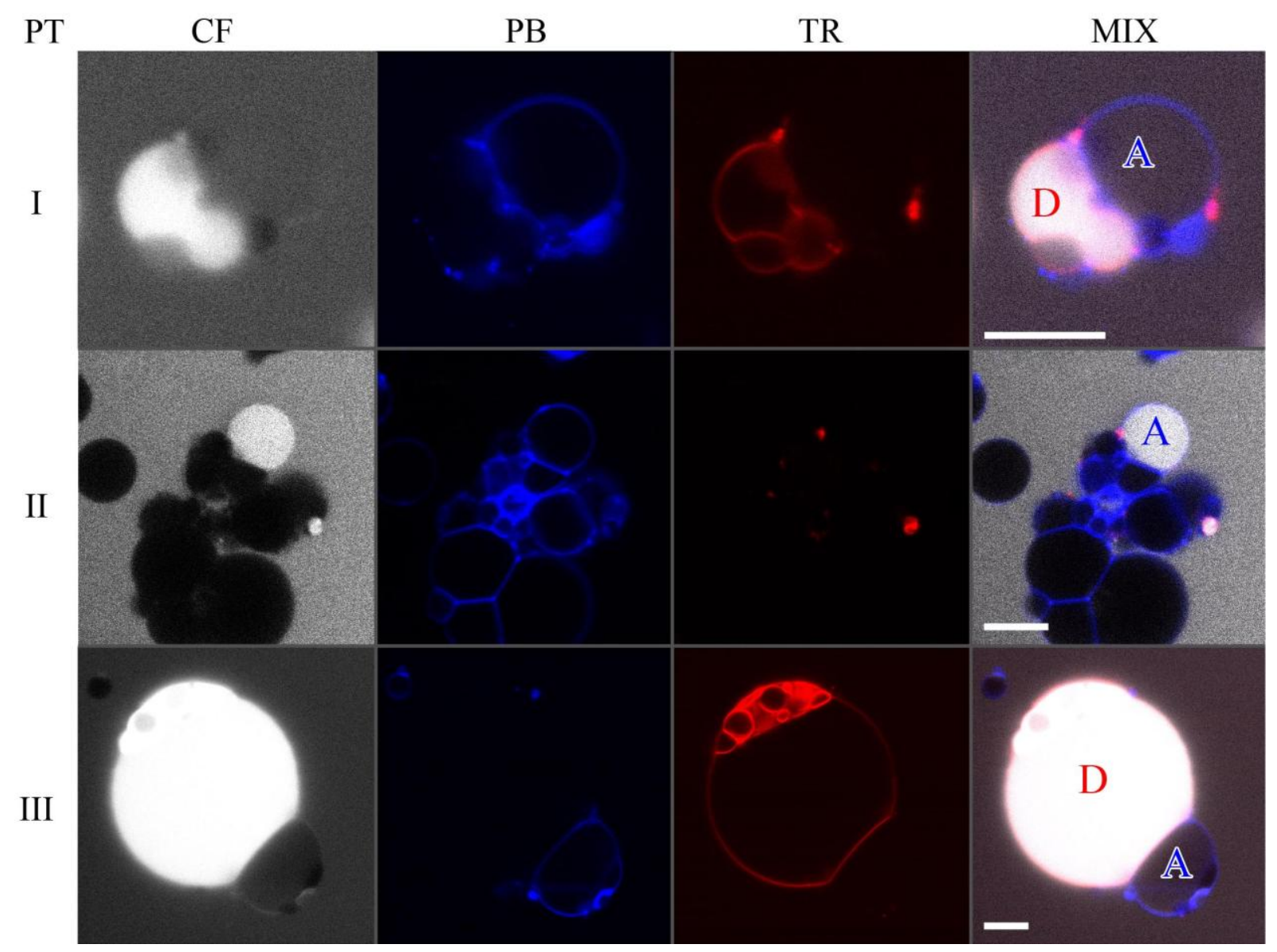

Abb. 4-53: Nachweis des Transfers von CF aus TR-dotierten Donor-GUVs (D) in PB-dotierte Akzeptor-GUVs (A) mit und ohne rekonstituiertem Cx26. Maßstab: $10 \mu \mathrm{m}$. GUVs (POPC, 0.1 mol\% TR-DHPE und $1 \mu \mathrm{M}$ CF / POPC, $0.5 \mathrm{~mol} \%$ PB-DMPE) hergestellt in $200 \mathrm{mM}$ Sorbitol in Anwesenheit von Cx26 Proteoliposomen (DPhPC:DOPC 6:4, 0.4 mol\% PB-DMPE, Lipid-Protein-Verhältnis 80:1, Puffer: 200 mM Sorbitol). Messpuffer: $200 \mathrm{mM} \mathrm{KCl}, 20 \mathrm{mM}$ HEPES, 0.02 mM EDTA, pH 7.4. Abgebildet sind jeweils die Fluoreszenzen von CF, TR, PB und deren Überlagerung (MIX) für die in Abb. 4-52 dargestellten Paarungstypen (PT) I, II und III.

Der Idealfall einer gleich hohen intravesikulären Intensität des Transferfarbstoffes CF in den Donor- und Akzeptor-GUVs von Paarungstyp I kann bei keinem der gefundenen Vertreter nachgewiesen werden. Die Fluoreszenzintensität des Akzeptor-GUVs liegt in den meisten Fällen im Bereich der Intensität des umgebenden Mediums, selten auffällig erhöht. Der 
intravesikulär detektierte Fluorophor CF könnte daher durch temporäre oder bestehende nicht Gap Junction Transfer spezifische Permeabilitätsschwankungen des GUVs eingeschleust werden. Zur Überprüfung dieser Annahme wird die intravesikuläre CF Intensität der PBdotierten Akzeptor-GUVs mit einen ausreichend starken Laserimpuls gebleicht. In etwa $90 \%$ der untersuchten Fälle kommt es im Anschluss an das Bleichen zu einem Wiederanstieg der intravesikulären CF Intensität der Akzeptor-GUVs. Der Anstieg liegt, normiert auf die extrazelluläre Fluoreszenzintensität, im Mittel bei $(15 \pm 7) \%$ über einen Zeitraum von $10 \mathrm{~min}$.

Im Gegensatz dazu kann nach Bleichen der intravesikulären CF Intensität der AkzeptorGUVs von Paarungstyp II ohne aggregierten Donor-GUV nur in etwa $10 \%$ der Fälle ein ähnlicher Wiederanstieg der CF Intensität detektiert werden. Alle anderen untersuchten Akzeptor-GUVs zeigen keinen Wiederanstieg.

Anders als erwartet, können auch beim Paarungstyp III Akzeptor-GUVs nachgewiesen werden, welche eine intravesikuläre CF Fluoreszenz erkennen lassen. Die Intensität liegt jedoch, anders als bei den Cx26 dotierten GUVs von Paarungstyp I und II, in allen Fällen deutlich unterhalb der Intensität des Hintergrunds und kann ausschließlich auf Undichtigkeiten der Lipidmembran zurückgeführt werden. Nach Bleichen dieser intravesikulären CF Intensität ist in keinem der untersuchten Fälle ein Wiederanstieg der Fluoreszenz erkennbar.

Die Ergebnisse der Regeneration der in den Akzeptor-GUVs detektierten CF Fluoreszenzintensität nach vorhergehendem Bleichen sind für alle Paarungstypen exemplarisch in Abb. 4-54 dargestellt. Die in Abhängigkeit von der Zeit aufgetragene Intensität $I$ wird nach:

$$
I=\frac{I_{\text {Intra }}-I_{\text {Intra(0) }}}{I_{\text {Exra }}} \cdot 100
$$

auf die extravesikuläre Fluoreszenzintensität des Hintergrundes $I_{\text {Extra }}$ normiert. $I_{\text {Intra }}$ ist die absolute, innerhalb der Akzeptor-GUVs bestimmte CF Intensität und $I_{\text {Intra( }(0)}$ deren Ausgangsintensität zu Beginn der Messung. 
A

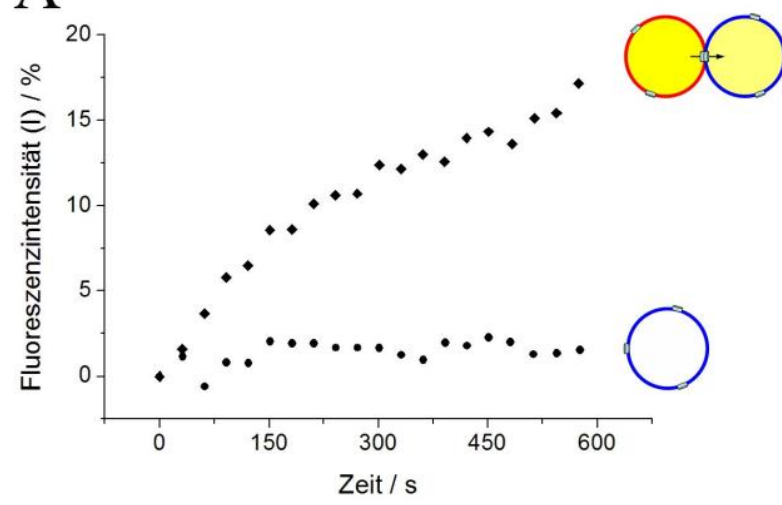

$\mathrm{B}$

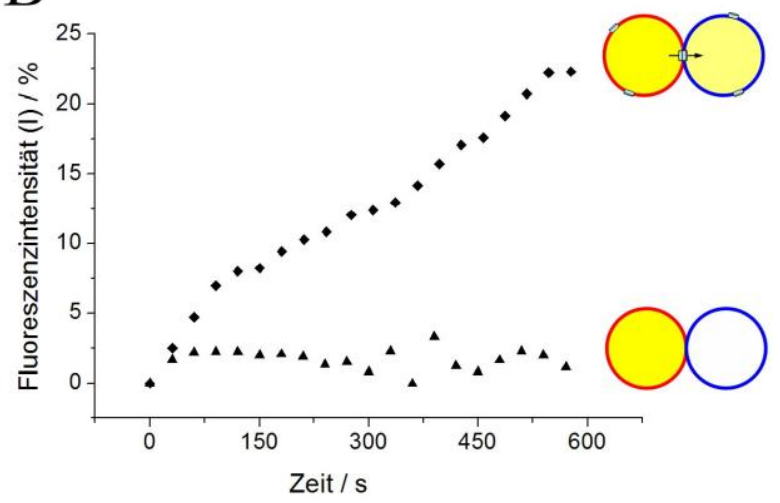

Abb. 4-54: Verlauf der intravesikulären CF Fluoreszenzintensität $I$ in Abhängigkeit von der Zeit nach Bleichen eines zuvor CF gefüllten PB-dotierten Akzeptor-GUVs bei verschiedenen Paarungstypen (siehe Abb. 4-52).

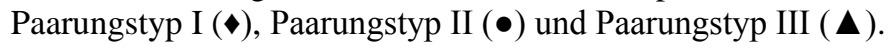

Die Ergebnisse deuten einen Cx26 spezifischen, intervesikulären Transfer des Farbstoffes CF aus den Donor- in die Akzeptor-GUVs an. Dieser könnte bei funktioneller Rekonstitution des Proteins auf die Ausbildung von Gap Junctions zurückzuführen sein. 


\section{Diskussion}

\subsection{Aktivitätsnachweis von Cx26 in Proteoliposomen}

In dieser Arbeit gelingt es mit dem Cytochrom $c$ Assay eine Nachweismethode zu etablieren mit der die funktionelle Rekonstitution von Cx26 in Lipidvesikel nachgewiesen werden kann. Neben dem Nachweis der Kanalaktivität in diesem einfachen artifiziellen Membransystem kann der Connexin-mediierte Transfer von Ascorbat mittels chemischer Blocker modulieren und damit verifiziert werden. Der Aktivitätsnachweis ist notwendig, um in einem nächsten Schritt die funktionelle Integration von Connexonen in Lipidmembranen auf porösen Oberflächen umzusetzen. Zudem ist der Assay in besonderer Weise für den Nachweis der Kanalaktivität von Panx2 geeignet [Ambrosi et al. 2010], dessen Funktionalität bislang weder in Zellstudien noch anderen Experimenten nachgewiesen werden konnte [Bruzzone et al. 2003/2005].

Für die Untersuchung der funktionellen Rekonstitution von kanalbildenden Proteinen wie Connexonen in einem artifiziellen Membransystem existieren zahlreiche Ansätze, in denen häufig mit Lipidvesikeln gearbeitet wird. Einige dieser Studien basieren auf dem kanalvermittelten Anschwellen von Proteoliposomen in isoosmotischen Sucrose Lösungen [Girsch \& Peracchia 1985], andere fokussieren sich auf das Absinken der Proteoliposomen in einem isoosmotischen Dichtegradienten [Rhee et al. 1996; Harris et al. 1992; Ahmad \& Evans 2002]. Der Cytochrom $c$ Assay basiert auf der intraliposomalen Reduktion dieses wasserlöslichen Proteins durch das Reduktionsmittel Ascorbat. Diese elektrochemische Zustandsänderung kann mittels UV/VIS-Spektroskopie sichtbar gemacht werden. Ursprünglich wurde der Assay von Gooden et al. [1985] entwickelt, um damit das major intrinsic protein 26 (MIP26), ein kanalbildendes Protein der menschlichen Augenlinse, hinsichtlich seiner Aktivität zu untersuchen und ist bis heute eine weit verbreitete Methode zur Untersuchung von Connexonen. So kann damit generell die Aktivität dieser Proteinklasse überprüft werden. Weiterhin bietet sich die Möglichkeit, den Kanal unabhängig von Wechselwirkungen mit anderen zellulären Komponenten hinsichtlich seiner Modulierbarkeit durch physikalische Parameter wie Temperatur [Diez et al. 1994] oder niederfrequente magnetische Felder [Ramundo-Orlando et al. 2005] zu untersuchen. Der Assay kann auch dazu genutzt werden, eine spezifische Blockade der rekonstituierten Connexone mittels chemischer Agenzien zu untersuchen. So nutzten Locke et al. [2004] den Cytochrom $c$ Assay zum Nachweis der Blockade des Cx26 mit $\alpha$-Cyclodextrin ( $\alpha$-CD). 


\subsubsection{Chemische Modulation der Kanalaktivität von $\mathbf{C x 2 6}$}

Für das Cx26 werden chemische Blocker verwendet, deren Wechselwirkungen mit diesem Connexin-Typ in der Literatur bereits eindeutig nachgewiesen werden konnten [Locke et al 2004; Ripps et al. 2004; Bruzzone et al. 2005]. Hierbei handelt es sich um das zyklische Oligosaccharid $\alpha$-Cyclodextrin $(\alpha-\mathrm{CD}), \mathrm{Ca}^{2+}$ und Carbenoxolon $(\mathrm{CBX})$, ein synthetisches Derivat der Glycyrrhitinsäure.

\subsubsection{Modulation der Kanalaktivität mit $\alpha-C D$}

Mittels Transport-spezifischer Fraktionierung (TSF, Abb. 5-1 B) konnten Locke et al. [2004] die Connexon-spezifische Blockade von Cx26 nachweisen. Das zyklische Oligosaccharid $\alpha$ Cyclodextrin ( $\alpha-\mathrm{CD}$, Abb. 5-1 A) besteht aus 6 Glucoseuntereinheiten und hat eine molekulare Masse von $0.973 \mathrm{kDa}$. Die leicht konische Struktur weist einen primären Durchmesser von $12.7 \AA$ und einen sekundären Durchmesser von $14 \AA$ auf. Dies entspricht in etwa den Dimensionen des Porendurchmessers eines Cx26 Hexamers. Die TSF Experimente zeigen, dass $\alpha$-Cyclodextrin im Konzentrationsbereich zwischen 0 und $10 \mathrm{mM}$ geeignet ist, in Liposomen rekonstituierte Cx26 Halbkanäle zu blockieren (Abb. 5-1 C). Dies wird auf eine rein physikalische Verschließung der Pore durch das konisch geformte zyklische Oligosaccharid zurückgeführt.

A

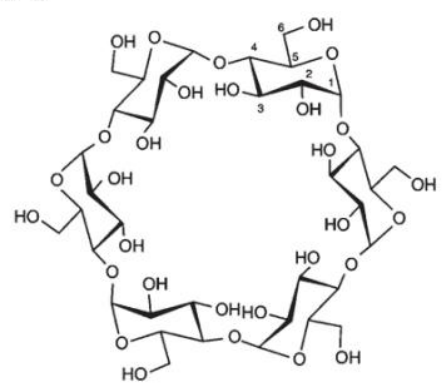

$\mathrm{B}$

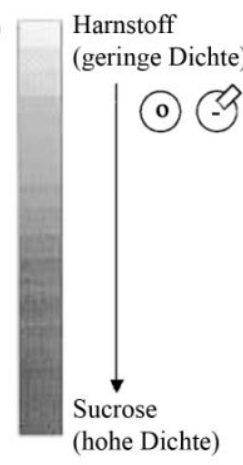

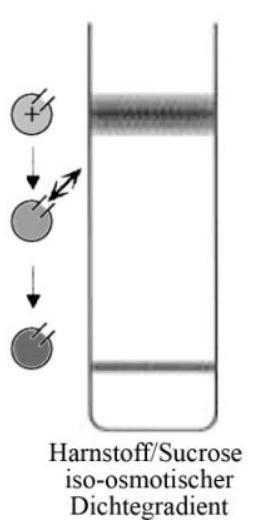

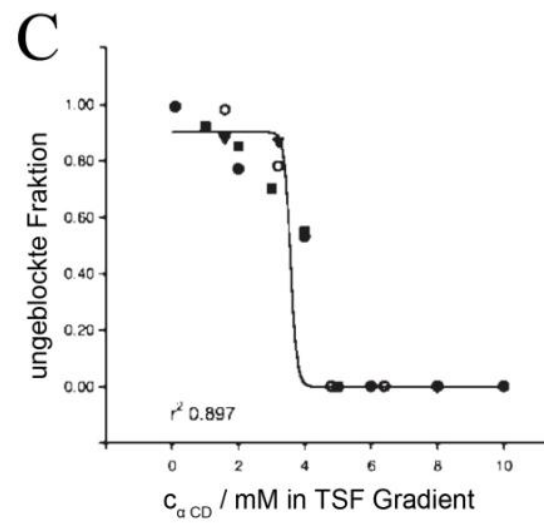

Abb. 5-1: Blockade von Connexonen mit $\alpha$-Cyclodextrin. (A) Struktur von $\alpha$-Cyclodextrin $(\alpha$-CD), einem zyklischen $\alpha[1 \rightarrow 4]_{6}$ Glucose Zucker. Masse $=0.973 \mathrm{kDa}, \varnothing \approx 14 \AA ̊$. (B) Grundprinzip der Transportspezifischen Liposom Fraktionierung (TSF). Sucrose-permeable Liposomen (+) mit rekonstituierten Connexonen (hier Cx32) sinken aufgrund ihres Dichtezuwachses in einem isoosmotischen Dichtegradienten aus Harnstoff und Sucrose im künstlichen Schwerefeld einer Zentrifugation ab und konzentrieren sich im Bereich der unteren Bande. Kontrollvesikel ohne Protein (o) und blockierte Proteoliposomen (-) sind für Sucrose impermeabel und konzentrieren sich im Bereich der oberen Bande. Nach [Rhee et al. 1996]. (C) Ergebnis einer TSF in Abhängigkeit von der Konzentration an eingesetztem Blocker $\alpha$-CD. In der Auftragung ist die Fraktion unblockierter Cx26 Proteoliposomen (untere Bande in Abb. B) als Funktion der $\alpha$-CD Konzentration im Gradienten aufgetragen. Die Daten sind normiert auf die Werte für eine TSF in Abwesenheit von CD. Nach [Locke et al. 2004]. 
Die Vesikel werden in einem harnstoffhaltigen Puffer hergestellt, welcher in seiner Dichte der oberen Bande im isoosmotischen Dichtegradient entspricht (siehe Abb. 5-1 B). Diese Proteoliposomen werden ebenfalls mit einer Methode hergestellt, bei welcher einem Ansatz aus ternären Mizellen (Protein, Lipid, Detergenz) das Detergenz mittels Biobeads entzogen wird. Das daraus resultierende artifizielle Membransystem sollte daher ähnlich den für den Cytochrom $c$ Assay verwendeten Proteoliposomen sein. Im Falle einer funktionellen Rekonstitution von Cx26 in die Vesikel, findet ein kanalvermittelter Austausch des intraliposomalen Puffers mit dem umgebenden Medium des Dichtegradienten statt. Über den aktiven Cx26 Halbkanal gelangt Sucrose im Austausch mit Harnstoff in die Vesikel, wodurch deren Gesamtmasse erhöht wird. Die Proteoliposomen sinken daher im Verlauf einer Ultrazentrifugation im Dichtegradienten ab und konzentrieren sich im Bereich der unteren Bande. Die Liposomen sind mit Fluoreszenz-markierten Lipiden dotiert, welche deren Nachweis und Quantifizierung ermöglichen. Kontrollvesikeln oder mittels $\alpha$-CD blockierte Proteoliposomen wird kein Austausch mit dem umgebenden Medium des Dichtegradienten ermöglicht, weshalb diese Vesikel nicht im Schwerefeld der Zentrifugation absinken und im Bereich der oberen Bande bleiben.

Das Grundprinzip dieses Assays ist in seinem Aufbau dem Cytochrom $c$ basierten Assay sehr ähnlich. Auch hier findet ein indirekter Nachweis der Proteinaktivität in einem vesikulären artifiziellen Membransystem durch den Transfer kleinerer Moleküle über die ansonsten permeabilitätsbeschränkte Membran statt.

Werden die Cytochrom $c$ gefüllten Proteoliposomen mit $\alpha$-CD inkubiert, kann bis zu einer Konzentration von $5 \mathrm{mM}$ nach Zugabe von Ascorbat eine reduzierte intraliposomale Reduktion von Cytochrom $c$ festgestellt werden. Dies könnte auf eine Blockade der Cx26 Halbkanäle mit dem zyklischen Oligosaccharid zurückzuführen sein. Bei Konzentrationen $>5 \mathrm{mM} \alpha$-CD kommt es hingegen zu einer starken Trübung der Suspension mit einem, den Boden bedeckenden Niederschlag. Hierbei handelt es sich vermutlich um das Ausfällen der im Puffer suspendierten Proteoliposomen mittels $\alpha$-CD. In der Literatur werden Studien beschrieben, in welchen $\alpha$-CD dazu verwendet wird, Lipoproteine mittels Flockulation aus dem Blutserum zu entfernen [Sharma et al. 1990]. Lipoproteine liegen mit Durchmessern im Bereich um $50 \mathrm{~nm}$ in der Größenordnung der für den Cytochrom $c$ Assay verwendeten Proteoliposomen $(\varnothing \approx 200 \mathrm{~nm}$ ). Diese mizellenähnlichen Vesikel bestehen ebenfalls aus Proteinen und Lipiden, haben allerdings einen unpolaren Kern, da sie beispielsweise im Blut dem Transport wasserunlöslicher Bestandteile wie Cholesterin dienen. Die zyklischen Oligosaccharide bilden über einer Koagulation CD-Lipoprotein-Präzipitate hoher Dichte, 
welche leicht aus dem Blutserum mittels Zentrifugation entfernt werden können. Eine effektive Fällung kann mit Konzentrationen > $10 \mathrm{mM} \alpha-\mathrm{CD}$ erzielt werden. Bei dem im Cytochrom $c$ Assay beobachteten Niederschlag handelt es sich daher höchstwahrscheinlich um nicht lösliche $\alpha$-CD-Proteoliposom-Präzipitate.

\subsubsection{Modulation der Kanalaktivität mit Calciumionen und CBX}

Vielfach werden in der Literatur zelluläre Studien beschrieben, in welchen die chemische Blockade von Connexin-Halbkanälen untersucht wird. So zeigten Ripps et al. [2004] anhand von Zwei-Elektroden voltage-clamp Messungen (Abb. 5-2 A), dass die transmembrane Leitfähigkeit Cx26 exprimierender Xenopus Oocyten mittels $\mathrm{Ca}^{2+}$ und Carbenoxolon (CBX) stark reduziert werden kann (Abb. 5-2 B und C).
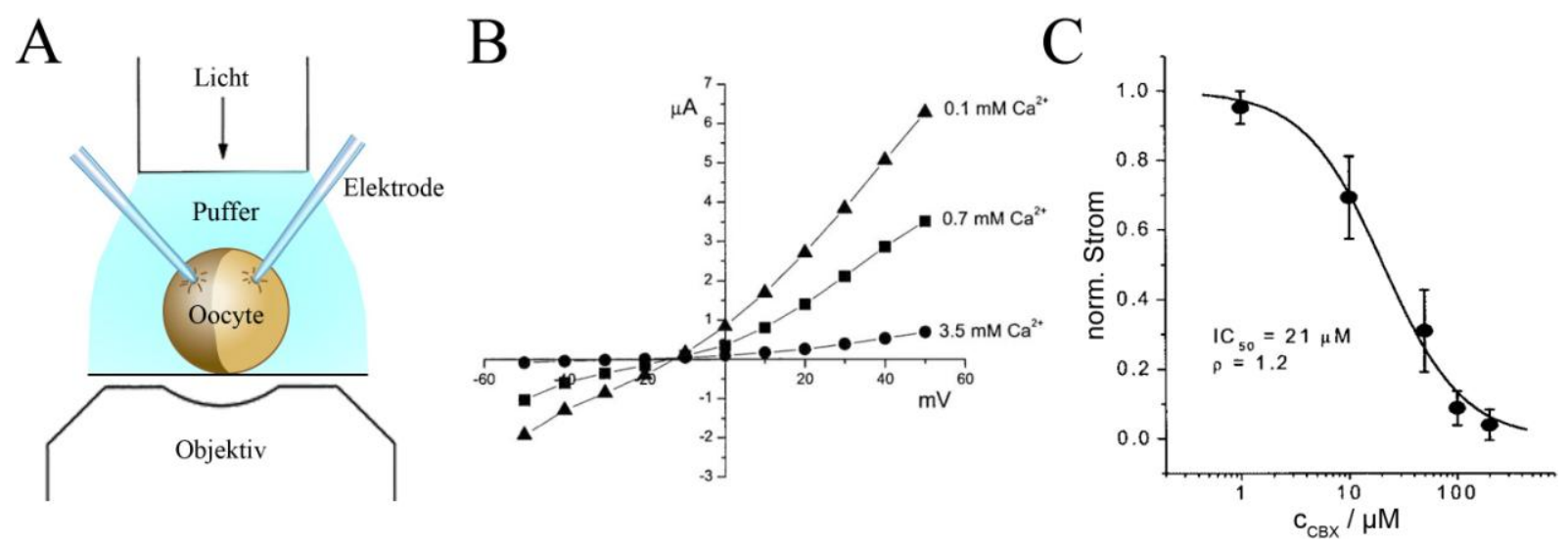

Abb. 5-2: Blockade von Connexonen mit Calcium und Carbenoxolon (CBX). (A) Grundprinzip einer ZweiElektroden voltage-clamp Messung zur elektrophysiologischen Untersuchung der makroskopischen Leitfähigkeit von Connexonen in Cx-exprimierenden Oocyten. Nach [Barbe et al. 2006]. (B) Strom-Spannungs-Abhängigkeit von Cx26 exprimierenden Oocyten in Abhängigkeit von der Calciumkonzentration im umgebenden Puffer. Eine steigende Calciumkonzentration führt zur nahezu vollständigen Blockade der Cx26 Halbkanäle. (C) Semilogarithmische Auftragung der normierten makroskopischen Leitfähigkeit von Cx26-exprimierenden Oocyten in Abhängigkeit von der Konzentration an CBX im umgebenden Medium. Den Daten ist eine Hill Funktion (siehe Formel 4-2) mit $I C_{50}=21 \mu \mathrm{M}$ und einem Hill Koeffizient von 1.2 angepasst. (B) und (C) nach [Ripps et al. 2004].

Zur Expression von Cx26 Halbkanälen in den Xenopus Oocyten muss diesen mittels einer Mikropipette etwa $50 \mathrm{ng}$ cRNA injiziert werden, welche für das Connexin26 kodiert. Damit in den Zellen nur Cx26 spezifische Ströme detektiert werden, muss zusätzlich die endogene Expression von Cx38 unterdrückt werden. Hierzu wird ein zur kodierenden Region von Cx38 komplementäres antisense Oligomer in die Zellen injiziert. Zur Detektion transmembraner Ströme werden zwei Elektroden in die Oocyte gestochen. Eine der Elektroden prägt dem System eine Spannung auf, mit der zweiten Elektrode können die Ströme über die Membran aufgezeichnet werden. Anhand dieses Prinzips kann die Leitfähigkeit von Cx26 Halbkanälen, exprimiert in der Plasmamembran von Xenopus Oocyten, konzentrationsabhängig mittels 
Connexon-Blockern moduliert werden. So kann eindeutig nachgewiesen werden, dass die makroskopische Leitfähigkeit bei einer Konzentration von $3.5 \mathrm{mM} \mathrm{Ca}^{2+}$ nahezu vollständig blockiert werden kann (Abb. 5-2 B), wohingegen nur $21 \mu \mathrm{M} \mathrm{CBX}$ ausreichen, um eine halbmaximale Blockade der Cx26 Halbkanäle zu erzielen. Diese Ergebnisse können mit dem Cytochrom $c$ basierten Assay in Cx26 dotierten Proteoliposomen verifiziert werden. So ist die intraliposomale Reduktion von Cytochrom $c$ mit einer Konzentration von $10 \mathrm{mM}$ Calcium nahezu vollständig unterbunden. Bei Verwendung des Connexon-spezifischen Blockers CBX werden Daten erhalten, an die in sehr guter Näherung eine Hill Funktion mit einem $I C_{50}$ von $21 \mu \mathrm{M}$ und einem Hill Koeffizient von 1.2 angepasst werden kann. Die gleiche Funktion wird von Ripps et al. [2004] verwendet, um die durch Zwei-Elektroden voltage-clamp erhaltene konzentrationsabhängige Blockade von Cx26 Halbkanälen zu beschreiben. Die mittels Cytochrom $c$ Assay erhaltenen Daten sind daher nahezu identisch zu den in Xenopus Oocyten ermittelten Ergebnissen und beweisen die funktionelle Rekonstitution von Cx26 in das artifizielle, vesikuläre Membransystem.

Aufgrund der Möglichkeit zur chemischen Blockade und der Übereinstimmung der Ergebnisse mit den Literaturdaten ist der Assay in besonderer Weise dazu geeignet, neben dem Cx26 auch Panx1 und Panx2 zu untersuchen. Dies ist zwar nicht von zentraler Bedeutung für die Umsetzung der Ziele dieser Arbeit, dennoch kann damit in Kooperation mit Gina E. Sosinsky (UCSD) eine aktuelle wissenschaftliche Fragestellung bearbeitet werden. 


\subsection{Nachweis der Kanalaktivität von Pannexin2}

Die Ergebnisse des Cytochrom $c$ Assays zeigen eindeutig, dass es sowohl in Panx1 als auch in Panx2 dotierten Vesikeln zu einer intraliposomalen Reduktion von Cytochrom $c$ kommt. Ähnlich den Experimenten mit Cx26 ist der dazu notwendige transmembrane Transfer von Ascorbat mittels CBX modulierbar. Mit einem $I C_{50}$ von $(14 \pm 4) \mu \mathrm{M}$ für Panx1 und einem $I C_{50}$ von $(15 \pm 4) \mu \mathrm{M}$ für Panx2 wird die halbmaximale Blockade der Ionenkanäle in einer Größenordnung erzielt, welche für Pannexin1 mit $5 \mu \mathrm{M}$ CBX bereits aus der Literatur bekannt ist [Bruzzone et al. 2005] (Abb. 5-3 D). Mit diesen, auf einem artifiziellen Membransystem basierenden Studien können damit zum einen die Ergebnisse aus den zellulären Studien für Panx1 bestätigt werden zum anderen wird erstmals der Nachweis einer Panx2 spezifischen Aktivität erbracht. Diese Ergebnisse stehen im Gegensatz zu elektrophysiologischen Studien von Bruzzone et al. [2003] (Abb. 5-3).
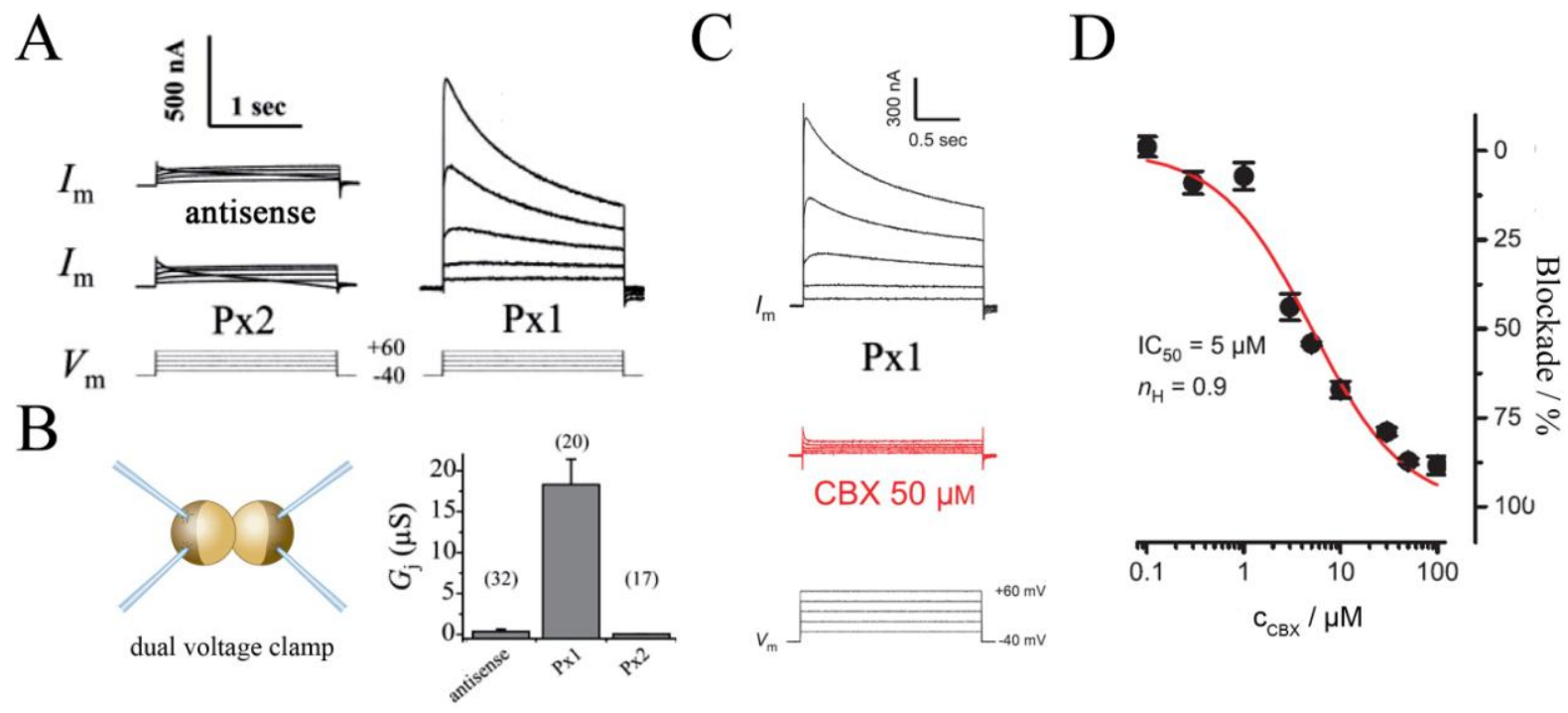

Abb. 5-3: Elektrophysiologische Studien zur Aktivitätsuntersuchung von Pannexin1 und Pannexin2 Halbkanälen sowie Gap Junctions. (A) Zwei-Elektroden voltage-clamp Messung von Pannexin-exprimierenden ungepaarten Oocyten. Pannexin2 exprimierende Zellen zeigen bei Depolarisierung im Vergleich zu Kontrollzellen (antisense) ohne spannungssensitive Ionenkanälen keinen Anstieg der makroskopischen Leitfähigkeit. Pannexin1 exprimierende Oocyten zeigen hingegen einen deutlichen Anstieg der makroskopischen Leitfähigkeit. Nach [Bruzzone et al. 2003]. (B) Vier-Elektroden dual-voltage-clamp Messungen gepaarter Oocyten (schematische Abb. nach [Barbe et al. 2006]) zur Untersuchung der funktionellen Ausbildung von Pannexin Gap Junctions. Bei Depolarisierung einer der beiden Zellen zeigen Panx1 exprimierende Zellen im Vergleich zur Kontrolle (antisense) hohe interzelluläre Leitfähigkeiten, wohingegen Panx2 exprimierende gepaarte Zellen keine detektierbare Leitfähigkeit aufweisen. Nach [Bruzzone et al. 2003]. (C) Mittels Zwei-Elektroden voltage-clamp ermittelte Blockade der makroskopischen Leitfähigkeit Pannexin1 exprimierender einzelnen Oocyten mit $50 \mu \mathrm{M}$ Carbenoxolon (CBX) bei verschiedenen Transmembranspannungen [Bruzzone et al. 2005]. (D) Semilogarithmische Auftragung zur Darstellung der CBX abhängigen Blockade von Pannexin1 Halbkanälen exprimiert in Oocyten [Bruzzone et al. 2005]. Den Datenpunkten ist eine Hill Funktion (siehe Formel 4-2) mit $I C_{50}=5 \mu \mathrm{M}$ und einem Hill Koeffizient von 0.9 angepasst. 
Mittels Zwei-Elektroden voltage-clamp Messungen an Xenopus Oocyten (Methode siehe Abb. 5-2 A) kann die Aktivität von Panx1 Halbkanälen jedoch nicht von Panx2 Halbkanälen nachgewiesen werden [Bruzzone et al. 2005]. Abb. 5-3 A zeigt die Ergebnisse der Messungen mit Pannexin-exprimierenden ungepaarten Oocyten und Kontrollzellen. In Letzteren ist die endogene Expression von Cx38 mittels antisense cRNA unterdrückt. Diese Zellen zeigen daher beim Anlegen einer transmembranen Potentialdifferenz keine Ionenkanal-spezifischen Ströme. Das gleiche Strom-Zeit-Profil wird bei der Depolarisierung Pannexin2 exprimierende Zellen erhalten. Hieraus kann geschlossen werden, dass in der Membran der Oocyten keine funktionellen Panx2 Halbkanäle integriert sind. Pannexin1 exprimierende Oocyten zeigen bei Depolarisation hingegen einen deutlichen Anstieg der makroskopischen Leitfähigkeit, was eindeutig auf eine Aktivität der Panx1-Halbkanäle hindeutet. Diese Leitfähigkeit kann durch die Verwendung des spezifischen Blockers CBX konzentrationsabhängig moduliert werden, so dass bei einer Konzentration von $50 \mu \mathrm{M}$ CBX die Panx1 Aktivität nahezu vollständig blockiert ist (Abb. 5-3 C und D).

Bei dem in Abb. 5-3 B dargestellten Ergebnissen handelt es sich um Vier-Elektroden dual voltage-clamp Messungen gepaarter Oocyten [Bruzzone et al. 2003]. Anhand dieser Messungen kann überprüft werden, ob es zwischen zwei gepaarten Pannexin exprimierenden Zellen zur Ausbildung funktioneller Gap Junction kommt. Bei Depolarisierung einer der beiden Zellen, zeigen Panx1 exprimierende Zellen im Vergleich zur Kontrolle (antisense) hohe interzelluläre Leitfähigkeiten, wohingegen Panx2 exprimierende gepaarte Zellen keine detektierbare Leitfähigkeit aufweisen.

Bei den in Abb. 5-3 dargestellten Ergebnissen werden jedoch einige relevante Parameter nicht berücksichtigt, welche die Inaktivität von Pannexin2 im Rahmen dieser Studien erklären können. Zum einen wird Pannexin2 hauptsächlich in intrazellulären Vesikeln nachgewiesen und scheint in der Zellmembran eine nur untergeordnete Rolle zu spielen, zum anderen wurde in Bruzzones zellulären Studien mit einer Panx2 Mutante gearbeitet, welche eine Deletion der ersten 10 Aminosäuren der N-terminalen Domäne aufweist [Sosinsky 2008]. In diesem Zusammenhang muss berücksichtigt werden, dass Pannexine eine den Connexonen nahezu identischen Membrantopologie aufweisen [Barbe et al. 2006]. Die N-terminale Domäne eines Connexins ist zudem vermutlich an der Funktionalität des Halbkanals beteiligt [Oshima et al. 2008]. 


\subsection{Integration von Connexonen in Lipidmembranen auf nanoporösen Oberflächen}

Mit dem Cytochrom $c$ Assay kann der Nachweis der Proteinaktivität nur indirekt über die intraliposomale Reduktion von Cytochrom $c$ erfolgen. Für den direkten Nachweis der Kanalaktivität werden in dieser Arbeit Einzelkanalmessungen in nano-BLMs durchgeführt. Bei der Einzelkanalmessung werden im Gegensatz zum Cytochrom $c$ basierten Assay einzelne Halbkanäle in eine porenüberspannende, artifizielle Membran integriert und mit der hochsensitiven voltage-clamp Technik untersucht. Mit dieser Methode war es nicht nur möglich den Nachweis der funktionellen Rekonstitution von Cx26 in porenüberspannende Membranen $\mathrm{zu}$ erbringen, vielmehr konnte eine vollständige elektrophysiologische Charakterisierung des Cx26 Halbkanals durchgeführt werden. Die Herstellung von langzeitstabilen und hochohmigen nano-BLMs wurde hierfür soweit optimiert, dass es möglich war neben dem WT des CX26 zusätzlich die Mutanten M34A und V84L vollständig zu Charakterisieren. Weiterhin bot sich mit diesem System die Möglichkeit die chemische Modulation der Kanalaktivität auf Einzelkanalniveau mittels $\mathrm{Ca}^{2+}$ zu untersuchen. Im Rahmen einer Kooperation mit der Nanion Technologie GmbH konnten die in nano-BLMs ermittelten Ergebnisse vollständig mittels Port-a-Patch Technik verifiziert werden.

\subsubsection{Einzelkanalaktivität von Cx26WT}

Die statistische Analyse der Daten ergibt für das Cx26 eine lineare Strom-SpannungsAbhängigkeit (Abb. 4-17). Dieses ohmsche Verhalten des Kanals wurde auch in zellbasierten Studien für Cx26 Gap Junctions gefunden werden [Suchyna et al. 1999; Oh et al. 1999] (Abb. 5-4 A und B). Weiterhin wird auch der charakteristische glockenförmige Verlauf der Öffnungswahrscheinlichkeit mittels zellulärer Studien bestätigt (Abb. 5-4 C). Diese ist zwar wie etwa bei Oh et al. [1999] als normierte Leitfähigkeit $G_{\mathrm{j}}$ dargestellt, entscheidend hierbei ist jedoch, dass die makroskopische Leitfähigkeit letztlich aus der Öffnungswahrscheinlichkeit beteiligter Halbkanäle bzw. Gap Junction resultiert. Dieser Zusammenhang macht daher durchaus einen direkten Vergleich zu den in dieser Arbeit gewonnenen Daten möglich, auch wenn sich diese aus einer anderen Methode ableiten. 

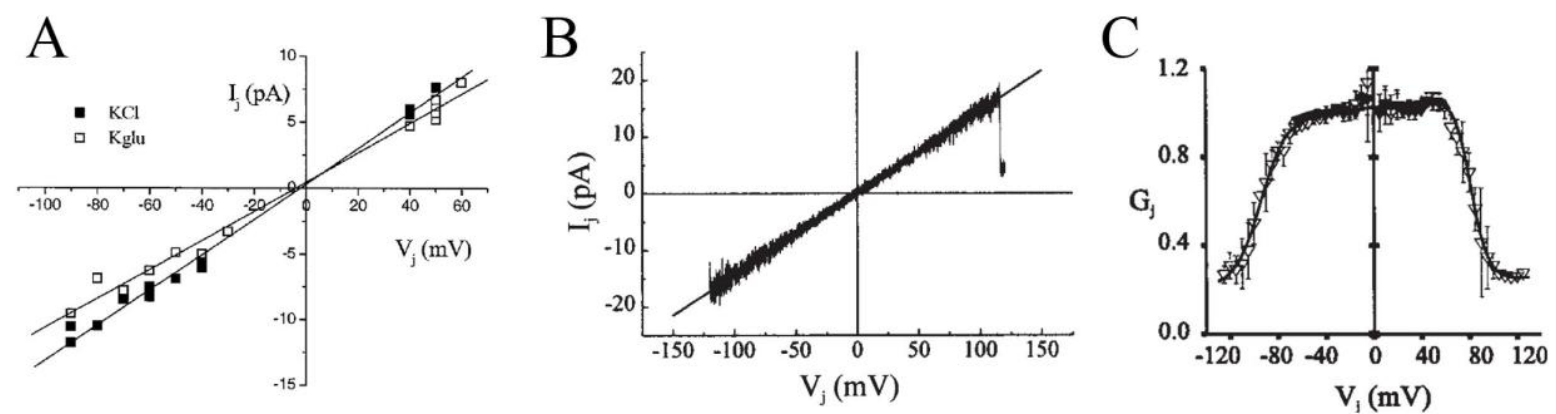

Abb. 5-4: (A) Strom-Spannungs-Abhängigkeit eines offenen Gap Junction Kanals in gepaarten Cx26 exprimierenden N2A Zellen in zwei unterschiedlichen Puffersystemen [Suchyna et al. 1999]. Grundlage dieser Darstellung ist die Auswertung einzelner Kanalereignisse bei verschiedenen Spannungen. (B) Strom-Spannungs -Abhängigkeit eines offenen Gap Junction Kanals in gepaarten Cx26 exprimierenden Neuro-2a Zellen [Oh et al. 1999]. Hierbei wurde eine $6 \mathrm{sec}$ Spannungsrampe in einem Bereich zwischen $\pm 120 \mathrm{mV}$ appliziert. (C) Abhängigkeit der normierten makroskopischen Leitfähigkeit $G \mathrm{j}$ von der Potentialdifferenz zwischen gepaarten Xenopus Oocyten [Oh et al. 1999].

Neben diesen Übereinstimmungen mit Literaturdaten gibt es bei den ermittelten Leitfähigkeiten jedoch entscheidende Unterschiede. Bei dem WT des Cx26 können in dieser Arbeit drei Leitfähigkeitsstufen $G_{1, \mathrm{WT}}=(34 \pm 8) \mathrm{pS}, G_{2, \mathrm{WT}}=(70 \pm 8) \mathrm{pS}$ und $G_{3, \mathrm{WT}}=(165 \pm$ 19) $\mathrm{pS}$ identifiziert werden (Abb. 4-16 A). In Zellpaar-Studien werden Leitfähigkeiten im Bereich zwischen 100 und $150 \mathrm{pS}$ ermittelt. Hierbei gilt es zu beachten, dass es sich bei diesen Werten um die Leitfähigkeit eines interzellulären Gap Junction Kanals handelt. Das unterschiedliche elektrische Verhalten von Gap Junctions und Connexonen wird in Abb. 5-5 schematisch gezeigt.

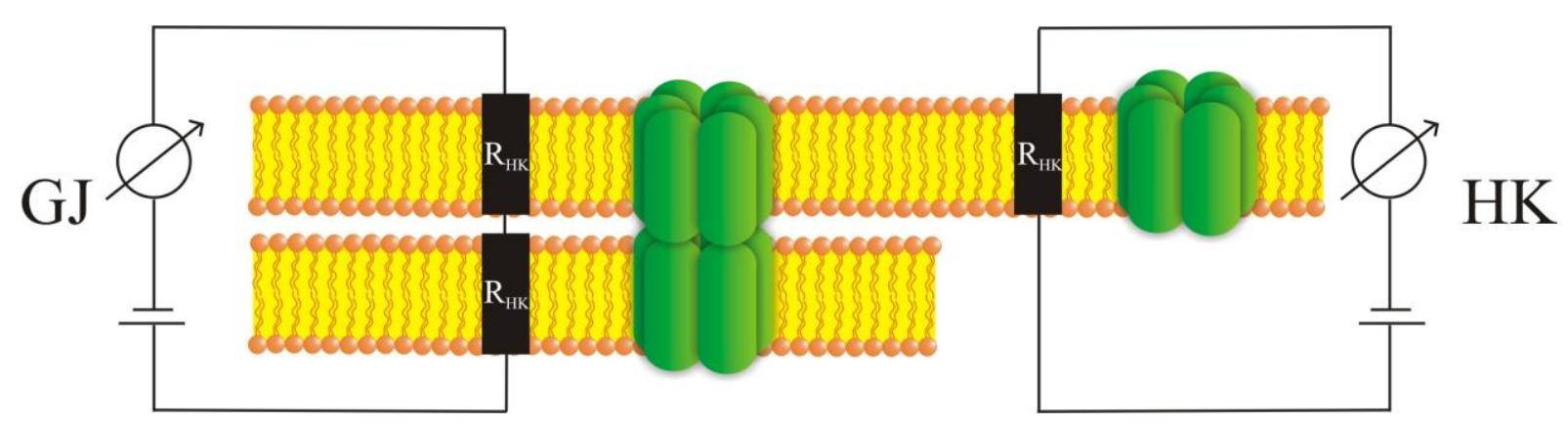

Abb. 5-5: Schematische Darstellung des elektrischen Verhaltens eines Gap Junction Kanals (GJ) und eines Halbkanals bzw. eines Connexons (HK).

Der Cx26 Halbkanal verhält sich wie ein ohmscher Widerstand. Daher ist die Leitfähigkeit eines Halbkanals gleich der doppelten Leitfähigkeit eines Gap Junction Kanals [Saez et al. 2005], wie Gleichung 5-1 zeigt:

$$
G_{\mathrm{GJ}}=\frac{1}{R_{\mathrm{ges}}}=\frac{1}{R_{\mathrm{HK}}+R_{\mathrm{HK}}}=\frac{1}{2 R_{\mathrm{HK}}}
$$


Daraus folgt:

$$
G_{\mathrm{HK}}=\frac{1}{R_{\mathrm{HK}}}=2 G_{\mathrm{GJ}}
$$

Hierbei ist $G_{\mathrm{GJ}}$ die Leitfähigkeit des Gap Junction Kanals, $R_{\text {ges }}$ der Gesamtwiderstand des Kanals, $R_{\mathrm{HK}}$ der Widerstand des Halbkanals und $G_{\mathrm{HK}}$ die Leitfähigkeit eines Halbkanals. Nach Gleichung 5-2 berechnet sich die Leitfähigkeit der Cx26 Halbkanäle aus den Zellpaarungsstudien zu 200 bis 300 pS und liegt damit weit über den in dieser Arbeit ermittelten Werten. Eine Übersicht der Literaturergebnisse ist Tabelle 13 zu entnehmen.

Tabelle 13: Leitfähigkeiten von Cx26 Gap Junctions $\left(G_{\mathrm{GJ}}\right)$ und Halbkanälen $\left(G_{\mathrm{HK}}\right)$ aus Zellpaar-Studien.

\begin{tabular}{ccc}
\hline Quelle & $\boldsymbol{G}_{\mathbf{G J}} / \mathbf{p S}$ & $\boldsymbol{G}_{\mathbf{H K}} / \mathbf{p S}$ \\
\hline$[$ Kwak et al. 1995] & $70 / 110 / 145$ & $140 / 220 / 290$ \\
{$[$ Mese et al. 2008] } & 100 & 200 \\
{$[$ [Beltramello et al. 2004] } & 105 & 210 \\
{$[$ [Bicego et al. 2006] } & 114 & 228 \\
{$[$ Gong \& Nicholsen 2001] } & 130 & 160 \\
\hline [Suchyna et al. 1999] & 135 & 170 \\
{$[$ Kojima et al. 1999] } & 150 & 300 \\
\hline
\end{tabular}

Vergleichbar hohe Leitfähigkeiten eines Connexons von etwa 300 pS [Kojima et al. 1999] konnten in einzelnen Cx26 exprimierenden Xenopus Oocyten mittels patch-clamp Experimenten in cell-attached Konfiguration bestätigt werden. So detektieren González et al. [2006] Kanalöffnungen im Bereich von (317 \pm 12$)$ pS.

Hierbei gilt es zu berücksichtigen, dass diese Studien an lebenden Zellen durchgeführt werden. Laterale Wechselwirkungen mit benachbarten Connexonen in formation plaques oder gap junctional plaques sowie Wechselwirkungen mit anderen zellulären Komponenten wie Lipiden oder Proteinen können einen wesentlichen Einfluss auf die Leitfähigkeit des Ionenkanals haben. Im Gegensatz dazu werden die Einzelkanalmessungen in dieser Arbeit an nano-BLMs durchgeführt, in denen Wechselwirkungen mit zellulären Bestandteilen ausgeschlossen sind. Ähnliche Messungen an artifiziellen Membransysteme werden von Buehler et al. [1995] und Falk et al. [1997] durchgeführt. Hier werden aufgereinigte bzw. zellfrei synthetisierte Halbkanäle zunächst in Vesikel rekonstituiert und anschließend mit einer artifiziellen Membran fusioniert, welche über die wenige Mikrometer große Öffnung einer patch-clamp Elektrode gespannt ist. In diesen Studien werden Einzelkanalereignisse in 
einem Leitfähigkeitsbereich $<110 \mathrm{pS}$ detektiert, die sich analog zu den Ergebnissen in dieser Arbeit in einem Bereich zwischen 20 und 60 pS konzentrieren. Im Gegensatz dazu zeigt die Öffnungswahrscheinlichkeit der Kanalereignisse in Abhängigkeit von der Potentialdifferenz bei Buehler et al. [1995] nicht den in nano-BLMs gefundenen glockenförmigen Zusammenhang und auch bei den ermittelten mittleren Öffnungsdauern gibt es deutliche Abweichungen (siehe Abb. 5-6).
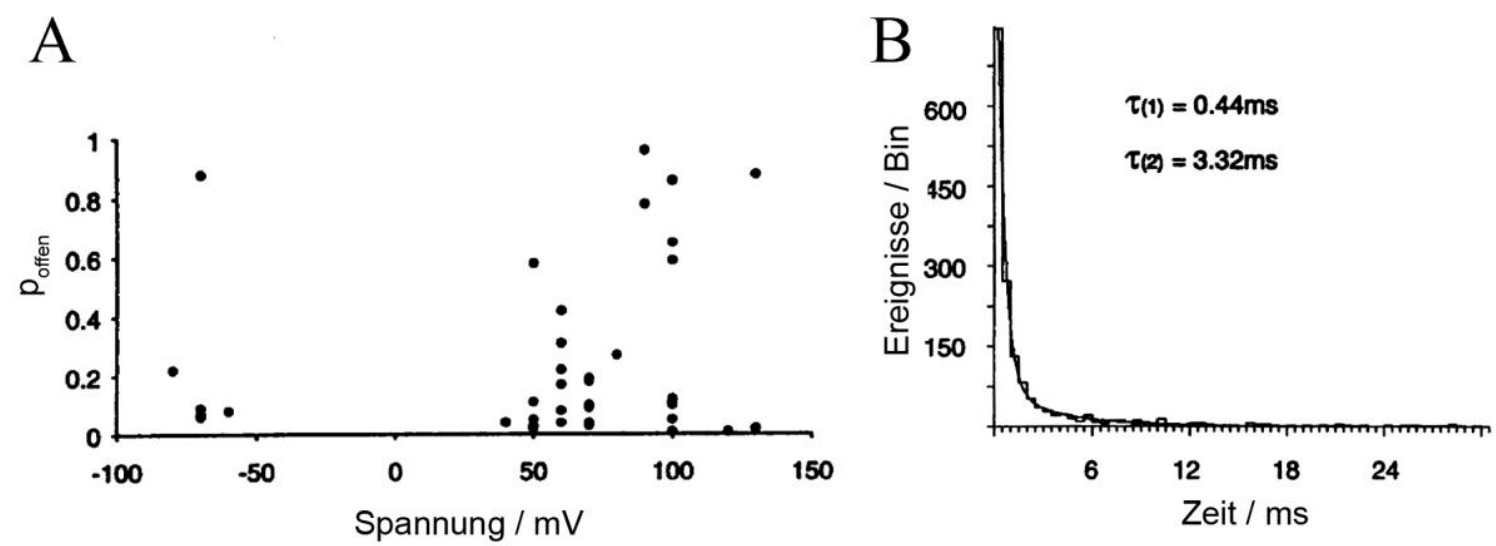

Abb. 5-6: Analyse von Cx26 Halbkanälen in einem artifiziellen Membransystem [Buehler et al. 1995]. (A) Öffnungswahrscheinlichkeit in Abhängigkeit vom Membranpotential. (B) Histogrammanalyse zur Bestimmung der mittleren Öffnungsdauer bei einem Membranpotential von $+50 \mathrm{mV}$. An die Daten ist eine Exponentialfunktion 2ter Ordnung angepasst.

Die mittleren Öffnungsdauern von $0.44 \mathrm{~ms}$ und $3.32 \mathrm{~ms}$ liegen weit unterhalb der in dieser Arbeit ermittelten Werte von $22 \mathrm{~ms}, 68 \mathrm{~ms}$ und $318 \mathrm{~ms}$ (siehe Tabelle 6). Dies ist allerdings systembedingt, da die mittels voltage-clamp detektierten Daten für die Auswertung mit einem $100 \mathrm{~Hz}$ Gauß Filter digital nachgefiltert werden mussten. Hierdurch werden alle Ereignisse die kleiner als $3.5 \mathrm{~ms}$ sind herausgefiltert (siehe 3.2.4).

\subsubsection{Einzelkanalaktivität von Cx26V84L}

Im Rahmen dieser Arbeit kann nachgewiesen werden, dass eine minimale Veränderung der Aminosäuresequenz einen enormen Einfluss auf das elektrophysiologische Verhalten des Cx26 Halbkanals haben kann. Die in nano-BLMs durchgeführten Studien belegen, dass sich V84L in nahezu allen untersuchten Parametern von den Eigenschaften des Cx26WT unterscheidet. Hierzu zählen u.a. deutlich erhöhte, uneinheitlichere und zahlreichere Hauptleitfähigkeitsstufen, verlängerte Öffnungsdauern sowie eine gegenläufige Spannungsabhängigkeit der Öffnungswahrscheinlichkeiten.

Bereits bei den exemplarisch dargestellten Einzelkanalmessungen (Abb. 4-15) deuten sich wesentliche Unterschiede des elektrischen Verhaltens an. So hat der WT stabile 
niederfrequente Öffnungen zu einem einheitlichen Stromplateau, wohingegen die Mutante V84L hochfrequente und stark uneinheitliche Kanalöffnungen $\mathrm{zu}$ unterschiedlichen Stromplateaus aufweist. Die Histogrammanalyse aller ermittelten Leitfähigkeiten (Abb. 4-16) zeigt für den WT drei definierte Hauptleitfähigkeitsstufen im Bereich $<200 \mathrm{pS}$. Die Leitfähigkeitsverteilung der Mutante V84L ist bei gleicher Intervallbreite deutlich inhomogener und verteilt sich mit sieben ermittelten Hauptleitfähigkeiten über einen Bereich von 0 bis $350 \mathrm{pS}$. Einige dieser stark überlagerten Verteilungen sind allerdings deckungsgleich mit denen des WT (siehe Tabelle 14).

Tabelle 14: Hauptleitfähigkeitsstufen des Cx26WT und der Mutante V84L

\begin{tabular}{|c|c|c|c|c|c|c|c|}
\hline \multirow{2}{*}{$\begin{array}{c}\text { Тур } \\
\text { WT }\end{array}$} & \multicolumn{7}{|c|}{ Hauptleitfähigkeitsstufen / pS } \\
\hline & & $34 \pm 8$ & $70 \pm 8$ & & $165 \pm 19$ & & \\
\hline V84L & $17 \pm 3$ & $41 \pm 4$ & $69 \pm 25$ & $127 \pm 12$ & $170 \pm 14$ & $242 \pm 31$ & $284 \pm 17$ \\
\hline
\end{tabular}

Weiterhin ergeben sich deutliche Unterschiede bei der Verteilung der Öffnungsdauern. Kanalöffnungen des V84L sind tendenziell länger als die des WT und häufen sich in einem Bereich um $200 \mathrm{~ms}$, wohingegen beim WT Öffnungsdauern in einem Bereich um $75 \mathrm{~ms}$ dominieren (siehe Abb. 4-21 B). Auch die Spannungsabhängigkeit der Öffnungsdauern unterscheidet sich wesentlich von der des WT (Abb. 4-25). Werden die in diesem Zusammenhang ermittelten mittleren Öffnungsdauern $\tau_{1}$ des WT bei steigender Transmembranspannung tendenziell kürzer, so ist beim V84L kein eindeutiger Trend erkennbar (siehe Tabelle 10). Am auffälligsten ist hingegen das spannungsabhängige Verhalten der Öffnungswahrscheinlichkeiten des V84L. Nimmt die Wahrscheinlichkeit einer Kanalöffnung beim WT mit steigender Potentialdifferenz ab, so ist beim V84L ein gegenläufiger Trend erkennbar (Abb. 4-26). Die einzige Übereinstimmung bei den im Rahmen dieser Arbeit ermittelten elektrophysiologischen Charakteristika ist das ohmsche Verhalten des V84L Halbkanals (Abb. 4-17).

Die Strukturanalyse des Cx26 zeigt, dass die Transmembranregion 2 (TM2) an der Stelle Prolin 87, dem Mittelpunkt dieses $\alpha$-helikalen Strukturelementes, geknickt ist [Maeda et al. 2009]. Mutationen innerhalb dieser Region wie L79P, S85P, P87L, L90P oder das V84L stehen nachweislich im Zusammenhang mit angeborener Taubheit [Suchyna et al. 1993; Laird 2006; Beltramello et al. 2005]. Das in nano-BLMs nachgewiesene stark vom WT des Cx26 abweichende Verhalten der Mutante V84L würde hierfür einen Erklärungsansatz liefern. Diese Ergebnisse können allerdings nicht von den Ergebnissen zellulärer Studien bestätigt 
werden. So kann die uneingeschränkte Aktivität von homotypischen V84L Gap Junctions sowohl in gepaarten Xenopus Oocyten als auch gepaarten HeLa Zellen nachgewiesen werden [Bruzzone et al. 2003; Beltramello et al. 2005] (Abb. 5-7).

A

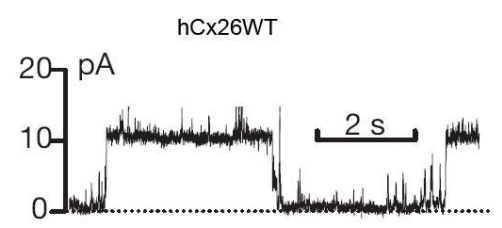

$\mathrm{C}$

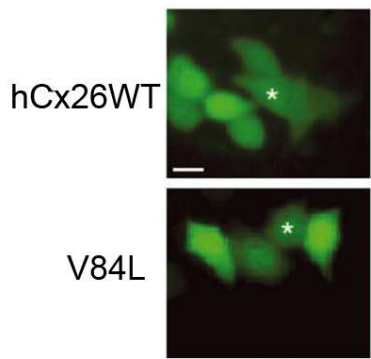

GFP

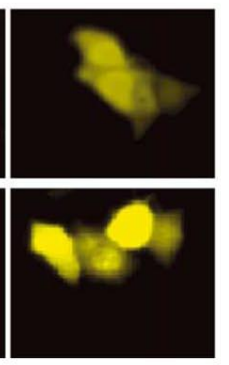

LY
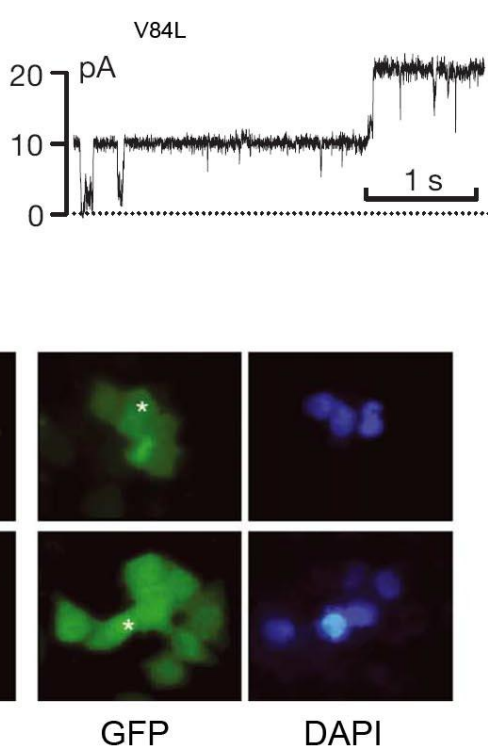

$\mathrm{B}$

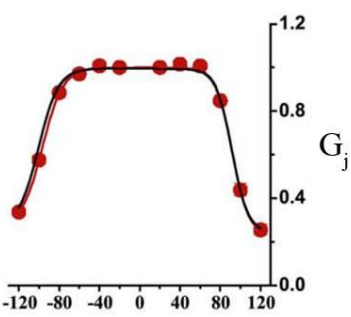

$\mathrm{V}_{\mathrm{j}} / \mathrm{mV}$

$\mathrm{D}$

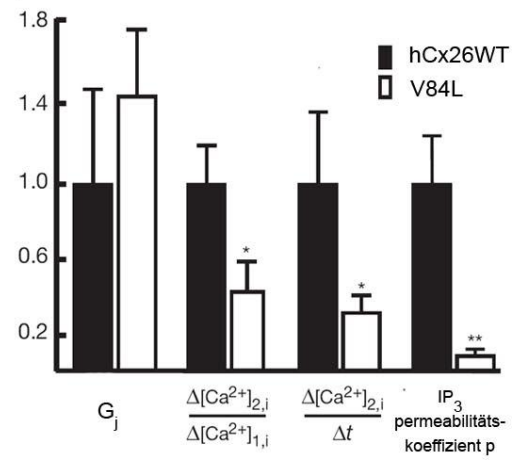

Abb. 5-7: Charakteristika der Cx26 Mutante V84L. (A) Charakteristische Einzelkanalmessung von Cx26WT und V84L Gap Junctions in HeLa-Zellpaaren. (B) Abhängigkeit der normierten makroskopischen Leitfähigkeit von der Potentialdifferenz zwischen gepaarten Xenopus Oocyten. Die rote Kurve (-) zeigt die an die Daten von V84L angepasste Boltzmann Verteilung, die schwarze Kurve (-) zeigt die Verteilung, welche für den WT des Cx26 erhalten wird. (C) Farbstofftransfer von LY und DAPI zwischen GFP exprimierenden HeLa Zellen, welche über hCx26WT oder V84L Gap junctions miteinander verbunden sind. Ein Stern markiert die Zelle, in welcher der Farbstoff injiziert wird. Maßstab $=10 \mu \mathrm{m}$. (D) Kritische Parameter in hC26WT und V84L transfizierten HeLa Zellpaaren: $G \mathrm{j}$ ist die normierte makroskopischen Leitfähigkeit zwischen benachbarten Zellen; $\Delta\left[\mathrm{Ca}^{2+}\right]_{2, \mathrm{i}} / \Delta\left[\mathrm{Ca}^{2+}\right]_{1, \mathrm{i}}$ ist die Änderung der $\mathrm{Ca}^{2+}$ Konzentration der Akzeptorzelle, relativ zur Donorzelle, nach Injektion von $\mathrm{IP}_{3}$ in die Donorzelle; $\Delta\left[\mathrm{Ca}^{2+}\right]_{2, \mathrm{i}} / \Delta \mathrm{t}$ ist die Anstiegsrate der $\mathrm{Ca}^{2+}$ Konzentration in der Akzeptorzelle; $p$ ist der Permeabilitätskoeffizient für $\mathrm{IP}_{3}$ zwischen benachbarten Zellen. (A) und (D) nach [Beltramello et al. 2005]. (B) und (C) nach [Bruzzone et al. 2003].

Abb. 5-7 A zeigt, dass die elektrophysiologischen Charakteristika der Cx26V84L Gap Junctions von denen des WT nicht zu unterscheiden sind. Gepaarte Cx26WT exprimierende HeLa Zellen sowie gepaarte V84L exprimierende HeLa Zellen zeigen eine einheitliche Gap Junction Leitfähigkeit von 115 bzw. 110 pS. Auch die spannungsabhängige makroskopische Leitfähigkeit zwischen gepaarten Xenopus Oocyten zeigt keine spezifischen Unterschiede (Abb. 5-7 B). Des Weiteren können in Farbstofftransferstudien zwischen benachbarten HeLa Zellen mit dem zweifach negativ geladenen Fluorophor LY (lucifer yellow, MW = $457 \mathrm{~g} / \mathrm{mol}$ ) und dem einfach positiv geladenen DAPI (4',6-Diamidin-2-phenylindol, MW = 350 g/mol) im Vergleich zum WT keine Unterschiede in der Permeabilität nachgewiesen werden (Abb. 5-7 C). Diese Ergebnisse können in weiteren Studien bestätigt werden [Wang et al. 2003; 
Zhang et al. 2005]. Der einzige relevante Unterschied des V84L scheint seine eingeschränkte Permeabilität für den sekundären Botenstoff Inositol-1,4,5-trisphosphat $\left(\mathrm{IP}_{3}\right.$, $\mathrm{MW}=420 \mathrm{~g} / \mathrm{mol}$ ) zu sein, welcher in den Stützzellen des Cortischen Organs (siehe 1.1.6.1) unter anderem für die Weiterleitung von $\mathrm{Ca}^{2+}$-Wellen essentiell ist. So ist zwar die makroskopische Leitfähigkeit zwischen V84L exprimierenden HeLa Zellen ähnlich hoch mit der von Cx26WT exprimierenden Zellen, doch ist die $\mathrm{IP}_{3}$ induzierte Weiterleitung von $\mathrm{Ca}^{2+}$ Wellen bei V84L transfizierten Zellen deutlich eingeschränkt (Abb. 5-7 D).

Bei den in Abb. 5-7 dargestellten Ergebnissen handelt es sich ausschließlich um in vivo Studien mit gepaarten Zellen, welche den Fokus auf die Charakterisierung des interzellulären Transfers legen. Im Rahmen dieser Arbeit wird mit einem artifiziellen Membransystem, den nano-BLMs, gearbeitet. Dieses System ist reduziert auf vier Komponenten, das mit einer Monoschicht aus TDT funktionalisierte nanoporöse Substrat, die artifizielle porenüberspannende Membran aus DPhPC, einen einzelnen rekonstituierten V84L Halbkanal und den umgebenden Puffer. Im Gegensatz dazu kann es bei der Verwendung zellulärer Systeme zu Wechselwirkungen mit lateral aggregierten Connexonen, anderen Membrankomponenten oder cytosolischen Bestandteilen kommen, welche das Verhalten von V84L modulieren bzw. beeinflussen können. Zum anderen werden in den nano-BLMs V84L Halbkanäle rekonstituiert und untersucht, wohingegen in Zellpaar-Studien Gap Junctions im Fokus der Betrachtung liegen. Mutationsbedingte, konformative Strukturänderungen der V84L Connexin Untereinheiten, haben bei ungepaarten Connexonen einen wesentlichen Einfluss auf die Funktionalität. Es ist nicht ausgeschlossen, dass diese Veränderung des spannungssensitiven Verhaltens nach Ausbildung eines interzellulären Gap Junction Kanals durch erneute Konformationsänderungen aufgehoben wird.

\subsubsection{Einzelkanalaktivität von Cx26M34A}

M34A ist keine human nachgewiesene Mutation. Die ursprünglich im Cx26 von Atsunori Oshima eingeführte Mutation M34A lieferte bei der Kultivierung in Sf9 Zellen höhere Ausbeuten als der WT, weshalb dieses Protein und nicht der WT als Grundlage für Kristallisationsstudien verwendet wurde [Oshima et al. 2007]. Im Rahmen dieser Arbeit wird diese Mutante erstmals eingehend elektrophysiologisch charakterisiert und mit den Eigenschaften des Cx26WT verglichen. Die umfassende statistische Analyse der Einzelkanalereignisse zeigt, dass diese Mutation im Gegensatz zu V84L keine grundlegenden Unterschiede im Vergleich zum WT erkennen lässt. So gleichen die ermittelten 
Hauptleitfähigkeitsstufen $G_{1, \mathrm{M} 34 \mathrm{~A}}$ und $G_{2, \mathrm{M} 34 \mathrm{~A}}$ denen des WT. Es können allerdings keine Vertreter im Bereich der Hauptleitfähigkeitsstufe $G_{3 \text {,wT }}$ gefunden werden (siehe Tabelle 15 und Abb. 4-16), die beim WT mit einem vergleichsweise geringen Anteil von $9 \%$ vertreten sind.

Tabelle 15: Hauptleitfähigkeitsstufen von Cx26 und M34A Connexonen in nano-BLMs.

\begin{tabular}{ccc}
\hline Leitfähigkeitsstufe & WT / pS & M34A / pS \\
\hline$G_{1}$ & $34 \pm 8$ & $44 \pm 6$ \\
$G_{2}$ & $70 \pm 8$ & $69 \pm 10$ \\
$G_{3}$ & $165 \pm 19$ & \\
\hline
\end{tabular}

Weiterhin verhält sich die Mutante M34A wie ein ohmscher Kanal (Abb. 4-17) und zeigt bei der spannungsabhängigen Öffnungswahrscheinlichkeit keinen Unterschied zum Verhalten des WT (Abb. 4-26). Die Verteilung der Öffnungsdauern sind ebenfalls identisch (Abb. 4-21 B) und auch die ermittelten mittleren Öffnungsdauern verhalten sich analog. Lediglich die genaue Analyse der Öffnungsdauer in Abhängigkeit von der Leitfähigkeit und der Transmembranspannung $V_{\mathrm{m}}$ lässt einen einzigen Unterschied zum Verhalten des WT erkennen. So weist zwar die Verteilung der Öffnungsdauern bei Vertretern der Hauptleitfähigkeitsstufen $G_{1, \mathrm{M} 34 \mathrm{~A}}$ und $G_{2, \mathrm{M} 34 \mathrm{~A}}$ keine merklichen Unterschiede zum WT auf (siehe hierzu Abb. 4-22 und Abb. 4-23), doch der Trend der mittleren Öffnungsdauer $\tau_{1}$ in Abhängigkeit von der Potentialdifferenz ist eindeutig gegenläufig (siehe Tabelle 10). Wird $\tau_{1}$ beim WT des Cx26 bei steigendem $V_{\mathrm{m}}$ kleiner, so steigt die mittlere Öffnungsdauer beim M34A in Folge einer größer werdenden Potentialdifferenz.

Im Gegensatz zum WT analogen Verhalten der elektrophysiologischen Charakteristika des M34A in nano-BLMs, zeigen die von Oshima et al. [2007; 2008] durchgeführten röntgenkristallographischen Studien bei dieser Mutante eine hohe Elektronendichte im Zentrum der Pore (Abb. 5-8 B). Untersuchungen der Deletionsmutante Cx26M34Adel2-7 bestätigen, dass es sich hierbei um Teile der N-terminalen Domäne handeln muss. Farbstofftransferstudien belegen zudem die eingeschränkte Permeabilität für den Fluorophor Sulforhodamin (Abb. 5-8 C). Demnach könnte die Mutation bei M34A wie beim M34T in einer irregulären Konformationsänderung resultieren, welche gegenüber dem WT abweichende elektrophysiologische Charakteristika erwarten ließe. So weicht die Leitfähigkeit von Cx26M34T Gap Junctions mit etwa 13 pS deutlich von der Leitfähigkeit des WT mit etwa 114 pS ab (Abb. 5-8 A). 

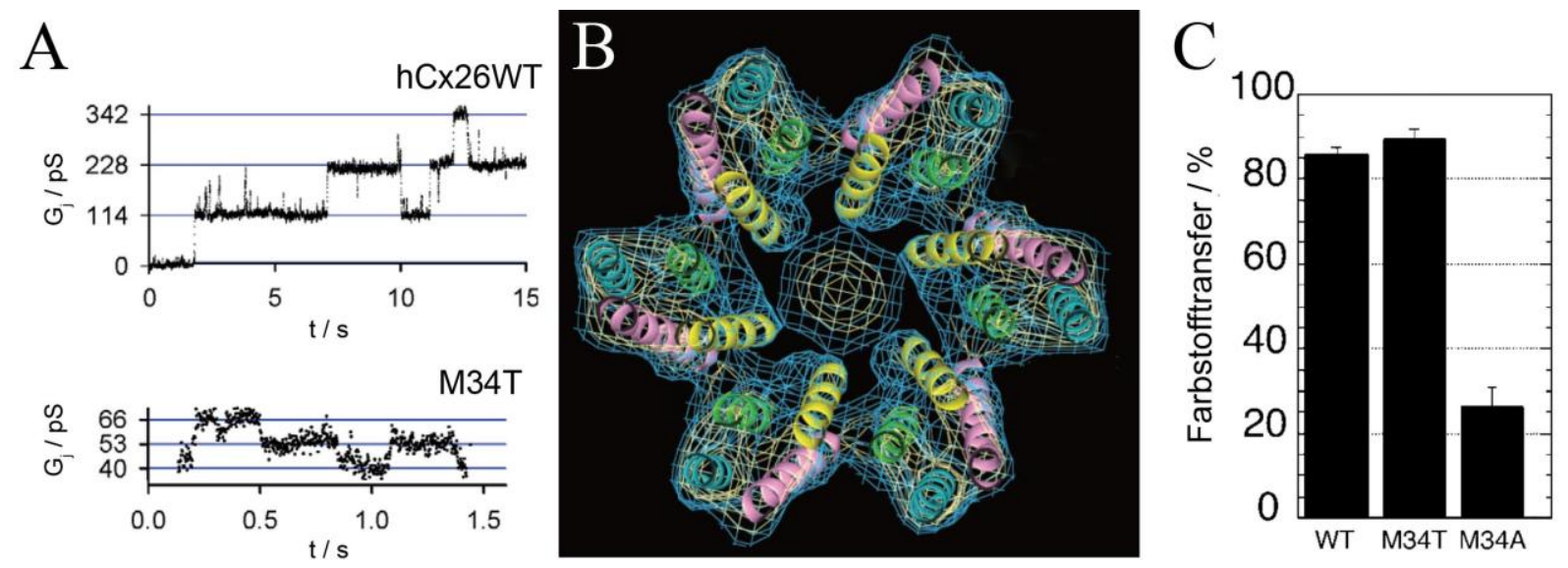

Abb. 5-8: Charakteristika der Cx26 Mutanten M34A und M34T. (A) Charakteristische Leitfähigkeitsstufen von Cx26WT und M34T Gap Junctions in gepaarten HeLa Zellen bei einer Potentialdifferenz von -100 mV [Bicego et al. 2006]. (B) Elektronendichteprojektion mit Strukturmerkmalen eines Cx26M34A Connexons mit einer Auflösung $<7 \AA$ [Oshima et al. 2007]. Die Abbildung zeigt einen Längsschnitt durch den hexameren Kanal parallel zur Membran mit einer deutlichen Elektronendichte im Zentrum der Pore. (C) Effizienz des Farbstofftransfers von Sulforhodamin zwischen gepaarten HeLa Zellen. Alle Connexin-Typen sind an der Cterminalen Domäne mit einem GFP fusioniert [Oshima et al. 2003].

Analog zu den Ergebnissen für V84L, ist die interzelluläre Weiterleitung mechanisch induzierter $\mathrm{Ca}^{2+}$-Wellen beim M34T nicht gewährleistet [Bicego et al. 2006]. Im Gegensatz dazu ist die Permeabilität des Fluorophors Sulforhodamin (MW =552 g/mol) zwischen benachbarten Zellen nicht beeinträchtigt (Abb. 5-8 C).

Die von Maeda et al. [2009] aufgeklärte Struktur des Cx26 liefert zwar einen Erklärungsansatz für die physiologische Fehlfunktion der Mutante M34T (siehe 1.1.6.2). Für die Mutation M34A kann jedoch kein so eindeutiger Zusammenhang gefunden werden. Die Substitution der unpolaren und hydrophoben Aminosäure Methionin durch die ebenfalls unpolare und hydrophobe Aminosäure Alanin:<smiles>CSCCC(N)C(=O)O</smiles><smiles>[CH]1C=C1</smiles><smiles>CC(N)C(=O)O</smiles>

muss nicht zwingend wie beim M34T zu einer gestörten bzw. verminderten Wechselwirkung mit dem W3 der benachbarten NTH führen (siehe hierzu Abb. 1-10), da lediglich eine molekulare Verkürzung des Aminosäurerestes vorliegt, nicht aber eine Änderung der chemischen Eigenschaften. Das vollständige Ablösen der an der Porenwandung fixierter NTHs würde wie beim M34T in einer Verkleinerung des Porendurchmessers und damit einer stark verminderten Leitfähigkeit des Kanals resultieren. Dies kann anhand der Einzelkanalmessungen in nano-BLMs nicht bestätigt werden. Das Fehlen von Einzelkanalereignissen mit Leitfähigkeiten im Bereich der Hauptleitfähigkeitsstufe $G_{3, \mathrm{WT}}$ 
würde allerdings für ein leichtes Ablösung der NTHs von der Porenwandung sprechen. Bei einer minimalen Verkleinerung des Porendurchmessers könnten größere Leitfähigkeiten im Bereich von $165 \mathrm{pS}$ unterbunden werden. Eine mutationsbedingte Konformationsänderung, die in einer vollständigen Blockade der Pore des Halbkanals resultiert kann allerdings vollständig ausgeschlossen werden. Hierbei gilt es $\mathrm{zu}$ beachten, dass die Kristallisationsbedingungen der Studien von Oshima et al. [2007; 2008] potentiell die Konformation eines geschlossenen Kanals erwarten lassen. Für die Kristallisation werden ein niedriger $\mathrm{pH}$ Wert von 5.8, eine CBX Konzentration von $100 \mu \mathrm{M}$ und eine Konzentration von $5 \mathrm{mM}$ Calcium eingesetzt. Insgesamt sind dies Bedingungen, welche nachweislich zu einer chemischen Blockade des Kanals führen (siehe 1.1.4.2). Demnach wäre die physikalische Blockade der Poren durch die sechs zentral angeordneten NTHs nicht mutationsbedingt und würde den von Oshima et al. postulierten plug-gating-Mechanismus stützen, welcher die zentrale Elektronendichte unabhängig von einer mutationsbedingten Strukturveränderung erklärt.

Da die elektrische Leitfähigkeit, also der Transport von Ionen über den Kanal, unabhängig von den Permeabilitätseigenschaften des Kanals für größere Moleküle wie etwa Farbstoffe oder sekundäre Botenstoffe betrachtet werden muss [Beltramello et al. 2005], schließt das zum WT gefundene analoge spannungsabhängige Verhalten von M34A nicht den nachgewiesenen reduzierten Transfer von Sulforhodamin [Oshima et al. 2003] aus. Angenommen diese Mutation würde in den Zellen des Cortischen Organs exprimiert, wäre eine funktionelle Fehlfunktion daher nicht auszuschließen. Trotz eines kaum vom WT unterscheidbaren elektrophysiologischen Verhaltens des M34A Halbkanals in nano-BLMs könnte der Transfer von sekundären Botenstoffen wie $\mathrm{IP}_{3}$ über den nur eingeschränkt funktionellen Gap Junction beeinträchtigt sein.

\subsubsection{Modulation der Leitfähigkeit mit Calciumionen}

Neben der spannungsabhängigen Regulierung von Connexin Halbkanälen können diese ebenfalls durch chemische Agenzien beeinflusst werden. Für den Nachweis des chemicalgating ist es erforderlich Wirkstoffe zu verwenden, deren Effekte auf die Leitfähigkeit des Kanals reversibel sind. Das irreversible und vollständige Schließen des Kanals könnte sonst nicht von einem Agens-unabhängigen Aktivitätsverlust des Kanals differenziert werden.

Die reversible chemische Blockade des Kanals kann am Beispiel der Mutante V84L eindeutig nachgewiesen werden (Abb. 4-27). Die vollständige und schnelle Blockade direkt nach 
Zugabe von $\mathrm{Ca}^{2+}$ in das cis-Kompartiment der Messkammer ermöglicht zudem eine Aussage über die Orientierung des Kanals in der porenüberspannenden Membran. So ist das chemicalgating durch $\mathrm{Ca}^{2+}$ gut untersucht [Pfahnl \& Dahl 1999; Gómez-Hernández et al. 2003] und wurde bereits in umfassenden Studien für das Cx26 beschrieben werden [Müller et al. 2002; Ripps et al. 2004]. Hierbei handelt es sich vermutlich um eine rein physikalische Verschließung des Kanals durch Wechselwirkung divalenter $\mathrm{Ca}^{2+}$-Ionen mit Asparaginsäureresten der extrazellulären Domänen E2. Für das Cx32 ist nachgewiesen, dass Asp 169 (D169) und Asp 178 (D178) für eine Blockade des Halbkanals mit $\mathrm{Ca}^{2+}$ essentiell sind. Die Mutanten D169N und D178N, in denen die Asparaginsäure durch die neutrale Aminosäure Asparagin substituiert ist, zeigen keine Calcium-abhängige Blockade des Kanals [Gómez-Hernández et al. 2003]. Diese extrazelluläre Calciumbindungsstelle mit millimolarer Affinität ist aber nicht unter allen Connexin Isoformen konserviert, so dass letztlich auch andere Bindungsmechanismen in Frage kommen. Sicher ist jedoch, dass es sich hierbei um eine direkte Wechselwirkung des $\mathrm{Ca}^{2+}$ mit dem Halbkanal handeln muss, da auch in zellfreien Systemen z.B. mittels Rasterkraftmikroskopie eine Calcium-induzierte Verschließung von Cx26 Halbkanälen nachgewiesen werden kann [Müller et al. 2002]. Unter Verwendung von EGTA konnte die Kanalaktivität des V84L direkt nach Zugabe nahezu vollständig wiederhergestellt werden. Die schnelle und vollständig reversible Blockade des Kanals mit $\mathrm{Ca}^{2+}$ kann nur dann ermöglicht werden, wenn die extrazellulären Domänen nach Rekonstitution des Kanals in die nano-BLM direkt von der cis-Seite der Messzelle aus zugänglich sind.

\subsubsection{Vergleich der verwendeten artifiziellen Membransysteme}

In dieser Arbeit können die in nano-BLMs ermittelten elektrophysiologischen Charakteristika eines Ionenkanals erstmals direkt mit den Ergebnissen eines anderen artifiziellen Membransystems, dem Port-a-Patch der Nanion Technologie GmbH, verglichen werden. Im Fokus der Untersuchungen standen hierbei der WT des Cx26 und die Mutante M34A. Die Eigenschaften beider Systeme sollen im Folgenden kurz aufgelistet werden.

Die nano-BLMs eignen sich aufgrund ihrer Hochohmigkeit und enormen Langzeitstabilität von einigen Tagen in besonderer Weise für die elektrische Charakterisierung von Ionenkanälen. Grundlage dieses Systems sind die porösen Aluminate mit einem Porendurchmesser von $60 \mathrm{~nm}$. Diese müssen zunächst in einem mehrstufigen elektrochemischen Verfahren hergestellt und anschließend mit Titan, Gold sowie TDT 
funktionalisiert werden. Aufgrund der Herstellung der porenüberspannenden Membran mittels painting-Technik, kann diese in Teilen lösungsmittelhaltig sein. Insgesamt wird bei diesem System, mit dem verwendeten Setup (verfügbare Substratoberfläche $3.14 \mathrm{~mm}^{2}$, Porosität $33 \%$ ) eine porenüberspannende Membranfläche von etwa $1 \mathrm{~mm}^{2}$ zur Verfügung gestellt. Die Integration von Connexonen erfolgt mittels Detergenzien (Abb. 4-14). Hierbei geht ein Großteil der in das System eingebrachten Proteine durch Aggregatbildung verloren und nur ein verschwindend geringer Bruchteil der Proteine kann funktionell rekonstituiert werden.

Das Port-a-Patch Setup kommt vollständig ohne Lösemittel aus. Hier werden zunächst Connexon-dotierte GUVs hergestellt, welche anschließend auf einem mikrostrukturierten Glaschip angesaugt und gespreitet werden (Abb. 4-28). Bei diesem System erfolgt die Ausbildung der Connexon-dotierten porenüberspannenden Membran in einem Schritt. Die mikroporösen Glaschips sind kommerziell verfügbar und müssen für die Anwendung nicht aufwendig funktionalisiert werden. Allerdings befindet sich in diesem Substrat nur eine einzelne Pore mit einem Durchmesser von etwa $2 \mu \mathrm{m}$, deren Langzeitstabilität im Vergleich zu den nano-BLMs stark eingeschränkt ist. Die zur Verfügung gestellte porenüberspannende Membranfläche beträgt etwa $1 * 10^{-5} \mathrm{~mm}^{2}$.

Festzuhalten bleibt, dass trotz einiger grundlegender Unterschiede beider Systeme die Ergebnisse der Einzelkanalmessungen in nano-BLMs vollständig mit den Messungen im Port-a-Patch Setup bestätigt werden konnten [Gaßmann et al. 2009]. Ein negativer Einfluss von Lösungsmittelresten in der porenüberspannenden Membran auf die elektrophysiologischen Charakteristika des Kanals kann somit ausgeschlossen werden. 


\subsection{Integration von Connexonen in Lipidmembranen auf mikroporösen Oberflächen}

Mit dem Cytochrom $c$ basierten Vesikelassay kann zunächst die Aktivität von Cx26 in einem einfachen artifiziellen Membransystem nachgewiesen werden. Mit den voltage-clamp in nano-BLMs wird gezeigt, dass einzelne Halbkanäle funktionell in porenüberspannende Membranen auf nanoporösen Substraten integriert werden können. Für das Ziel des Verbundprojektes, die elektrische Kopplung von Zellen an Connexon-dotierte porenüberspannende Lipidmembranen, ist die Integration der Halbkanäle in hoher Dichte erforderlich. Nur dann besteht die Möglichkeit einer elektrischen Kontaktierung der Zellen durch die Ausbildung von Gap Junction Plaques. Hierfür ist auch die Orientierung des Proteins innerhalb der Membran von zentraler Bedeutung. Weiterhin muss geklärt werden, welche Möglichkeiten zur Blockade falsch orientierter oder ungepaarter Connexone bestehen und welches Substrat für eine elektrische Kopplung der Zellen am geeignetsten ist.

\subsubsection{Herstellung von mikro-BLMs mit hoher Connexon- Oberflächenkonzentration}

Die Integration von Connexonen in hoher Dichte in eine porenüberspannende Membran kann in dieser Arbeit durch das Spreiten Cx26 dotierter GUVs auf funktionalisierten Mikrosieben erzielt werden.

\subsubsection{Rekonstitution von $\mathrm{Cx} 26$ in GUVs}

Die Integration von Connexonen in Proteoliposomen mit Durchmessern im Bereich von $200 \mathrm{~nm}$ ist ein viel genutztes und etabliertes Verfahren (siehe hierzu 5.1). Die Integration von Connexonen in größere Vesikel wie GUVs ist nur wenig untersucht und bislang nicht etabliert. Es wird lediglich ein Verfahren beschrieben, dass auf der in vitro Synthese von Cx43 in Liposomen beruht [Kaneda et al. 2009]. Die Liposomen entstehen bei der natürlichen Rehydratisierung dehydratisierter Lipidfilme und enthalten das Lysat zellkernfreier eukaryotischer Zellen (Retikulozyten, unreife rote Blutkörperchen) mit dem gesamten Transkriptions- und Translationsapparat. Das Gen für Cx43 wird hinzugegeben. Für die Integration aufgereinigter und in Puffer solubilisierter Connexone in GUVs existierten allerdings bislang keine Verfahren. In Kooperation mit der Nanion Technologie GmbH werden in dieser Arbeit zunächst zwei Ansätze verfolgt. 
Mit der detergenzbasierten Rekonstitution und der partiellen Dehydratisierung werden Methoden verwendet, welche generell für die funktionelle Rekonstitution von Cx26 in GUVs und den Nachweis der Kanalaktivität mittels Port-a-Patch Technik geeignet zu sein scheinen [Gaßmann et al. 2009]. Bei der partiellen Dehydratisierung werden GUVs hergestellt, in denen von vornherein Cx26 integriert ist. Hierfür werden zunächst ternäre Mizellen, bestehend aus Protein-, Detergenz- und Lipiduntereinheiten hergestellt. Über einen Detergenzentzug mit Bio-Beads SM2 entstehen unilamellare Proteoliposomen (Abb. 5-9).

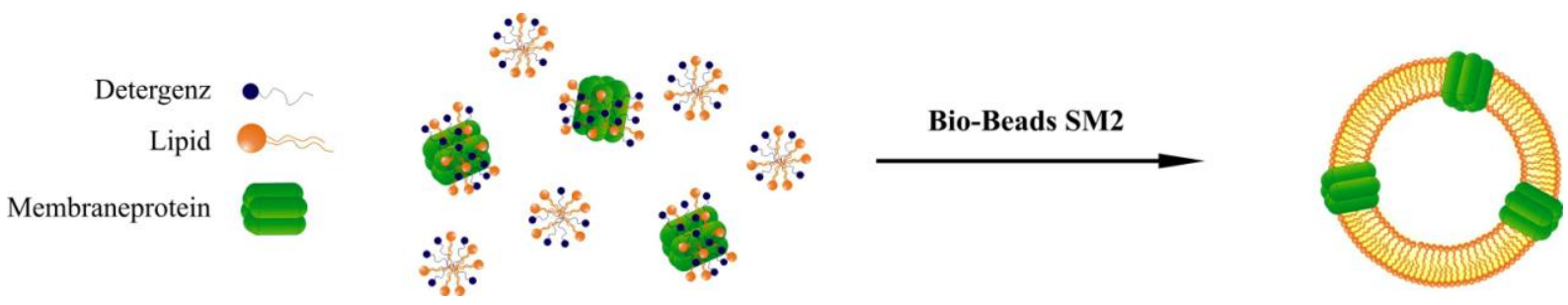

Abb. 5-9: Schematische Darstellung der Rekonstitution von Membranproteinen mittels Detergenzentzug ternärer Mizellen anhand von Bio-Beads SM2.

Die Elektroformation der GUVs erfolgt anschließend aus den zuvor teilweise dehydratisierten Proteoliposomen [Girard et al. 2004]. Bei der detergenzbasierten Rekonstitution werden zuerst GUVs mittels Elektroformation hergestellt. Ähnlich den Messungen in nano-BLMs werden diesem artifiziellen Membransystem in Detergenz solubilisierte Connexine hinzugegeben. Die Rekonstitution des Proteins erfolgt hierbei in detergenzdotierte GUVs (Abb. 5-10).
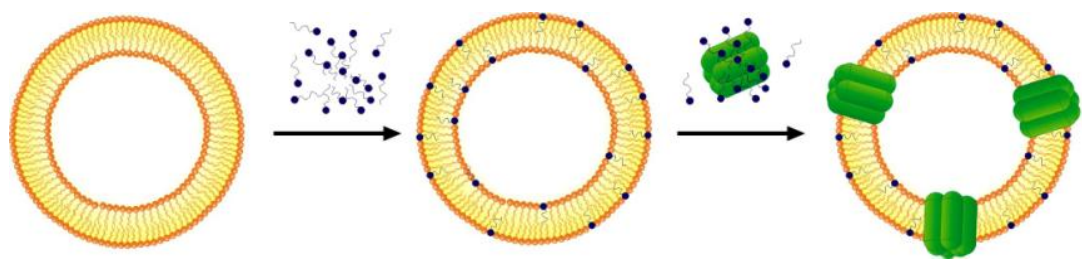

Bio-Beads SM2

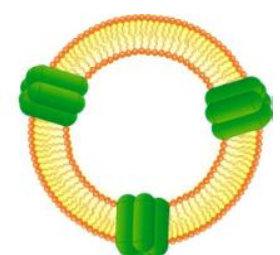

Abb. 5-10: Schematische Darstellung der Rekonstitution von Membranproteinen in detergenzgesättigte GUVs.

Diese Methode basiert auf einer von Rigaud et al. [1995/1997] beschriebenen Technik, welche die unidirektionale Integration von transmembranen Proteinen in Liposomen mit Detergenzkonzentrationen nahe der CMC vorsieht. Für die Herstellung in hoher Dichte Connexon-dotierter porenüberspannender Membranen sind beide Verfahren allerdings grundsätzlich ungeeignet. Zum einen werden damit nur Proteinmengen rekonstituiert, die einen hochsensitiven elektrischen Aktivitätsnachweis mittels Port-a-Patch auf Einzelkanalniveau ermöglichen. Zum anderen ist die Ausbeute intakter GUVs so gering, dass damit durch Spreiten der Vesikel keine größeren porenüberspannenden Flächen auf den mikroporösen Substraten hergestellt werden können. 
Mit der Fusion von Proteoliposomen mit GUVs wird in dieser Arbeit ein Verfahren entwickelt, mit welchem eine große Anzahl in hoher Dichte Connexon-dotierte GUVs herstellt werden können. Hierfür werden zunächst Proteoliposomen entsprechend der in Abb. 5-9 beschriebenen Methode hergestellt. Diese Proteoliposomen werden anschließend nicht dehydratisiert, sondern direkt verwendet und während der Elektroformation mit den entstehenden GUVs fusioniert. Die Fusion kann durch den Nachweis des Lipid-gekoppelten Fluorophors PB-DMPE in den GUVs bewiesen werden (Abb. 4-36). Dass bei diesem Fusionsprozess auch ausreichende Mengen an Cx26 transferiert werden, kann direkt mit einem FITC markierter Anti-His-Antikörper nachgewiesen werden (Abb. 4-38). Mit diesen GUVs ist es möglich, kontinuierliche, porenüberspannende Connexon-dotierte Membranen herzustellen.

\subsubsection{Spreiten von GUVs auf funktionalisierten mikroporösen Substraten}

Die Herstellung großflächig porenüberspannender Membranen durch Spreiten von GUVs ist schwierig. Häufig sind nach Inkubation der mit Gold und TDT funktionalisierten Mikrosiebe nur kleine Bereiche der Substratoberfläche durch das Spreiten einzelner GUVs mit einer Membran überspannt. Durch die Optimierung der Spreitbedingungen können in dieser Arbeit größere zusammenhängende Bereiche mit einer Connexon-dotierten Membran hergestellt werden. Die Proteindichte innerhalb der Membran ist so hoch, dass die integrierten Halbkanäle nach Inkubation mit einem FITC markierten Anti-His ${ }_{6}$-Antikörper bei einer Anregungsfrequenz von $\lambda_{\mathrm{Ex}}=494 \mathrm{~nm}$ nachgewiesen werden können (Abb. 4-40). Die FRAP-Experimente (Abb. 4-41) zeigen, dass die Cx26-Antikörper-Komplexe auf dem mikroporösen Substrat lateral immobil sind und kein Austausch mit den umgebenden Poren stattfindet. Demgegenüber ist nach Bleichen des Lipid-gekoppelten Fluorophors PB-DMPE eine eindeutige laterale Mobilität der Lipide nachweisbar (Abb. 4-43), bei der allerdings ein immobiler Anteil von etwa $40 \%$ festgestellt werden kann. Diese Beobachtungen können mit Abb. 5-11 erklärt werden.

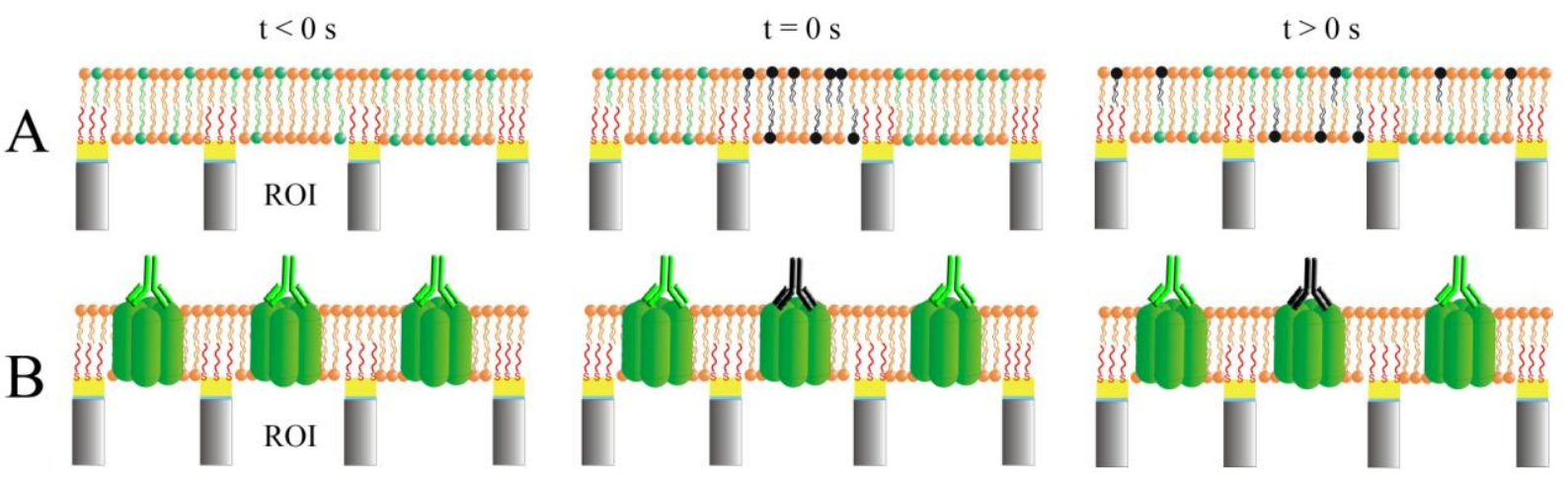

Abb. 5-11: Schematische Darstellung der Zeitserie eines FRAP-Experimentes mit (A) fluoreszenzmarkierten Lipiden und mit Connexonen die durch Bindung eines Fluorophor-gekoppelten Antikörpers fluoreszenzmarkiert sind (B). Die mittlere Pore ist jeweils die region of interest (ROI) in der die Fluorophore bei $\mathrm{t}=0 \mathrm{~s}$ gebleicht werden. 
Abb. 5-11 A zeigt die schematische Zeitserie eines FRAP-Experimentes mit fluoreszenzmarkierten Lipiden. Das poröse Substrat ist mit Titan, Gold und einer Monolage TDT funktionalisiert. Werden die fluoreszenzmarkierten Lipide der mittleren Pore (ROI) zum Zeitpunkt $\mathrm{t}=0 \mathrm{~s}$ gebleicht, können sie nach dem Bleichen $(\mathrm{t}>0 \mathrm{~s})$ innerhalb der oberen Membranhälfte über die Porenstege hinaus diffundieren. Fluoreszenzmarkierte Lipide umgebender Poren, deren Fluorophor nicht fotochemisch zerstört wurde, diffundieren nach, so dass die Fluoreszenzintensität innerhalb der ROI wieder ansteigt. Der Austausch gebleichter fluoreszenzmarkierter Lipide in der unteren Membranhälfte mit den umgebenden Poren ist durch die Monolage TDT nicht möglich. Da eine transversale Diffusion, also z.B. der Wechsel eines Lipids von der unteren Membranschicht in die obere Schicht um den Faktor $10^{9}$ langsamer ist als die laterale Diffusion innerhalb einer Membranschicht [Berg et al. 2003], sind die gebleichten fluoreszenzmarkierten Lipide der unteren Membranhälfte innerhalb der ROI für den hohen immobilen Anteil verantwortlich. Bei der Verwendung des fotostabilen Lipid-gekoppelten Fluorophors BODIPY-DHPE werden in dieser Arbeit auf den Mikrosieben $(1.2 \mu \mathrm{m}$ Porendurchmesser) mit effektiven Diffusionskoeffizienten von $3.4 \mu \mathrm{m}^{2} / \mathrm{s}$ und einem immobilen Anteil von $40 \%(\mathrm{n}=26)$ Werte erzielt, welche in der Größenordnung der von Weiskopf [2009] ermittelten Daten liegen. Da in dieser Arbeit lediglich der Nachweis einer lateralen Mobilität der Lipidkomponente ausschlaggebend ist, nicht aber die Höhe der Diffusionsgeschwindigkeit oder der Einfluss verschiedener Funktionalisierungen auf $D_{\text {eff }}$ und den immobilen Anteil, wird an dieser Stelle für eine detailliertere Betrachtung auf Weiskopf verwiesen.

Abb. 5-11 B zeigt die schematische Zeitserie eines FRAP-Experimentes mit Connexonen innerhalb einer porenüberspannenden Membran, die durch Bindung eines Fluorophorgekoppelten Antikörpers fluoreszenzmarkiert sind. Nach Bleichen des fluoreszenzmarkierten Antikörpers bei $\mathrm{t}=0 \mathrm{~s}$ findet für $\mathrm{t}>0 \mathrm{~s}$ kein Austausch mit nicht gebleichten ConnexonAntikörper-Komplexen statt. Entscheidend ist in diesem Zusammenhang der Sachverhalt, dass der Antikörper spezifisch an das Cx26, ein membrandurchspannendes, kanalbildendes Protein mit ausladenden extrazellulären und intrazellulären Domänen gebunden ist. Da die Porenstege mit einer Monolage immobiler TDT Moleküle funktionalisiert sind, ist lediglich die laterale Mobilität der Lipide der oberen Membranhälfte über die Stege hinaus gewährleistet (Abb. 5-11 A), wohingegen membrandurchspannende Komponenten wie etwa Connexone keinen Austausch mit umgebenden Poren erfahren. Ihre Mobilität ist auf die Fläche des porenüberspannenden Bereiches limitiert. Grundlegend muss noch berücksichtigt werden, dass die Dimensionierung eines Moleküls einen Einfluss auf die zweidimensionale 
Diffusion innerhalb der Membran hat. So ist die laterale Mobilität umgekehrt proportional zum Radius $R$ der zu untersuchenden Membrankomponente und beträgt beispielsweise für das Bacteriorhodopsin $(R=18 \AA$, $26.5 \mathrm{kDa})$ etwa $1.3 \mu \mathrm{m}^{2} / \mathrm{s}$ [Gambin et al. 2006]. Berücksichtigt man, dass sich das Cx26 mit ebenfalls $26 \mathrm{kDa}$ zu einem hexameren Halbkanal mit einem Radius von etwa $45 \AA$ zusammenlagert [Maeda et al. 2009], ist nach Gambin et al. [2006] etwa einen Diffusionskoeffizienten von $0.6 \mu \mathrm{m}^{2} / \mathrm{s}$ zu erwarten, der bei einer lateralen Mobilität von Cx26 auf dem mikroporösen Substrat nachweisbar sein sollte. Es müsste allerdings noch die eingeschränkte Mobilität auf den funktionalisierten Stegbereichen berïcksichtigt werden. Eine durch Antikörperbindung an die C-terminale Domäne des Cx26 erhöhte molekulare Masse hat demgegenüber kaum einen Einfluss auf die laterale Mobilität, was mit einer im Vergleich zur wässrigen Phase stark erhöhten Viskosität der Lipidmembran begründet werden kann [Reits \& Neefjes 2001]. In den durchgeführten FRAP-Experimenten kann eine solche laterale Mobilität allerdings nicht nachgewiesen werden.

\subsubsection{Proteinorientierung}

Mit dem FITC markierten Anti-His-Antikörper kann das Cx26 in den mikro-BLMs nachgewiesen werden. Zugleich liefert dieser Nachweis auch eine Information über die Orientierung des Proteins in der Membran. In Abb. 5-11 B wird suggeriert, dass die Cx26 Halbkanäle nach Spreiten der Connexon dotierten GUVs eine einheitliche Orientierung haben. Die Connexone wären in dieser Orientierung für eine Ausbildung von Gap Junctions nicht zugänglich. Für die geplante elektrische Kopplung der Zellen müssten auf der cis-Seite des Substrates die extrazellulären Domänen E1 und E2 zugänglich sein (siehe hierzu auch Abb. 5-17). Der Antikörper bindet allerdings an die mit einem His-Tag versehene C-terminale Domäne des Cx26, welche in vivo auf der cytoplasmatischen Seite lokalisiert ist (Abb. 5-12).

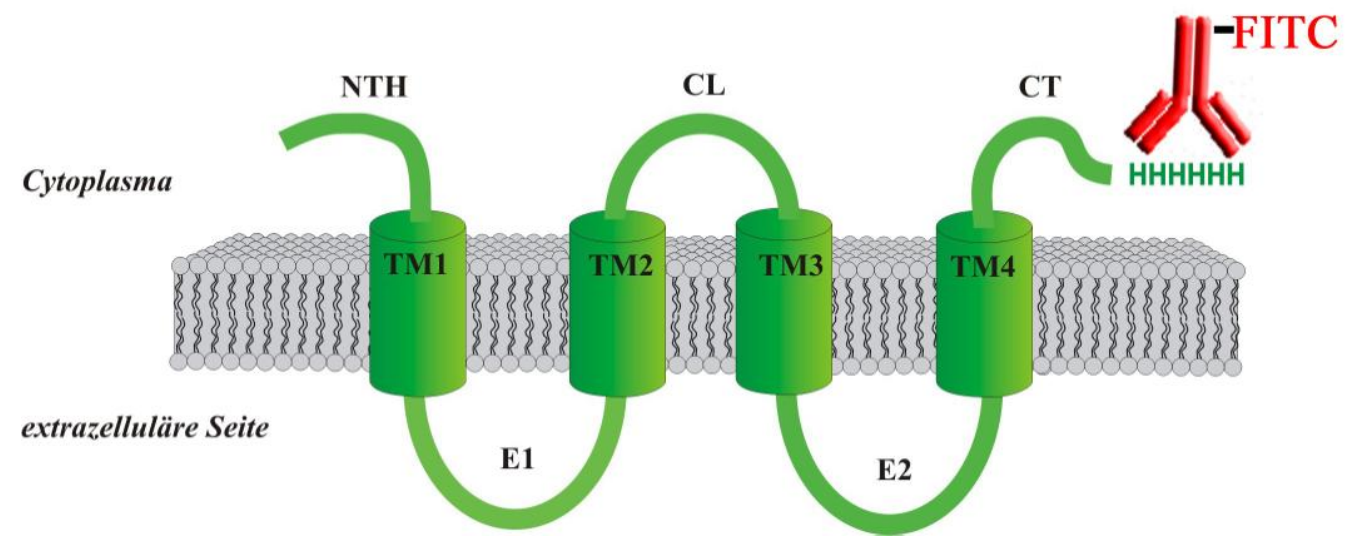

Abb. 5-12: Schematische Darstellung der Membrantopologie eines Cx26 Protomers mit einem His ${ }_{6}$-Tag an der C-terminalen Domäne (CT). In rot dargestellt ist ein FITC markierter Anti-His-Antikörper. 
Es ist davon auszugehen, dass die Orientierung der Proteine bei der Connexon-dotierten mikro-BLMs zufällig ist und bei $50 \%$ liegt. Dies kann mit der Herstellungstechnik der Proteoliposomen begründet werden. So entstehen diese durch Detergenzentzug mittels Biobeads aus ternären Mizellen (Cx26, Lipid, Detergenz). Hierbei wird das Protein mit einer zufälligen Orientierung in die Vesikel integriert (Abb. 5-13 A). Um eine Rekonstitution mit einer bevorzugten Orientierung des Proteins $\mathrm{zu}$ erhalten, müssten die transmembranen Proteine in vorgeformte und anschließend detergenzgesättigte Liposomen integriert werden (Abb. 5-13 B). Hiermit können z.B. für das Bacteriorhodopsin, eine bakterielle Protonenpumpe, hoch asymmetrische Orientierungen von $95 \%$ erzielt werden [Rigaud et al. 1995].

\section{A}
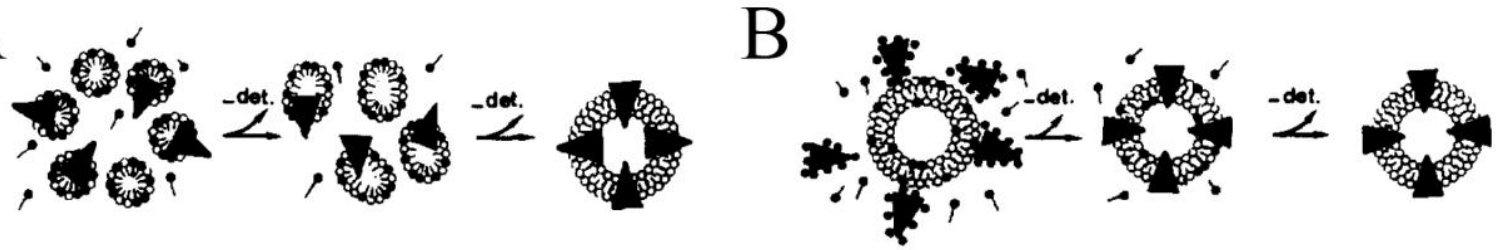

Abb. 5-13: Schematische Darstellung der Herstellung von Proteoliposomen aus (A) ternären Mizellen und (B) aus der Integration solubilisierten integraler Membranproteine in detergenzgesättigte Vesikel [Rigaud et al. 1995].

Die unidirektionale Integration der Proteine nach Abb. 5-13 B wird dadurch ermöglicht, dass die transmembranen Proteine vermutlich immer mit den hydrophobsten Domänen zuerst insertieren [Rigaud et al. 1995]. Die Hydrophobizitätsanalyse der Aminosäuresequenz des Cx26 nach Kyte \& Doolittle [ExPASy] ergibt, dass die intrazellulären Domänen NTH, CL und CT insgesamt hydrophiler sind als die extrazellulären Domänen E1 und E2 (Abb. 5-14).
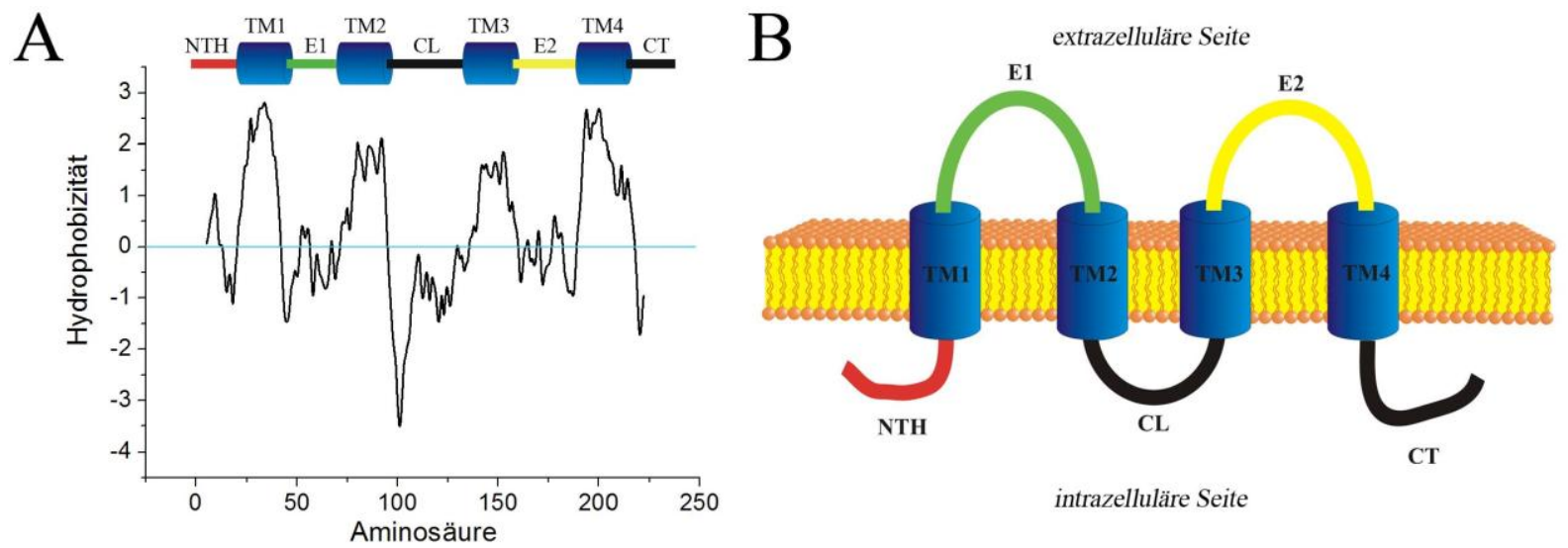

Abb. 5-14: (A) Hydrophobizitätsplot des Cx26 nach Kyte \& Doolittle. Erstellt mit Protscale des ExPASy Proteomic Servers. Den Daten ist eine schematische Abbildung der Domänen des Cx26 angepasst. Der Farbcode stimmt mit der in (B) dargestellten Membrantopologie des Cx26 überein. 
In der Theorie müsste sich das Cx26 demnach in detergenzgesättigte Vesikel so insertieren, dass anschließend die cytoplasmatischen Domänen von der extravesikulären Seite aus zugänglich sind. In der Literatur werden Connexone hauptsächlich in zellulären Systemen untersucht, weshalb keine Vorzugsorientierungen nach Integration in artifizielle Membransysteme bekannt sind. In dieser Arbeit kann durch die Versuche zur chemischen Blockade des V84L in nano-BLMs eine zur Theorie konträre Orientierung nach detergenzbasierter Rekonstitution abgeleitet werden. Werden die Proteine auf der cis-Seite der Messkammer pipettiert, kann der aktive Halbkanal nach Integration in die nano-BLM durch Zugabe von $\mathrm{Ca}^{2+}$ ohne Zeitverzögerung vollständig blockiert werden (4.2.3.7). Da die Calcium-sensitiven Bindungsstellen vermutlich in den extrazellulären Domänen E1 und E2 lokalisiert sind, würde dies für einen Mechanismus sprechen, bei welchem die cytoplasmatischen Domänen zuerst in die Membran insertieren. Diese Annahme kann mittels Port-a-Patch Messungen in mikro-BLMs auf Polycarbonatfolien [Kreir et al. 2010] gestützt werden. Auch hier werden die Cx26 Halbkanäle mittels Detergenzien in einer bestehenden porenüberspannenden Membran rekonstituiert, so dass anschließend die Ausbildung von Gap Junction ermöglicht wird [Kreir et al. 2010]. Geht man von einer unidirektionalen Insertion des Kanals mittels Detergenzien in die Membran aus, müssen auf der cis-Seite der Messeinheit die extrazellulären Domänen präsentiert werden, da sonst eine Ausbildung von Gap Junction mit Cx26 exprimierenden HeLa Zellen nicht möglich wäre.

Angenommen, die Connexonen werden in die detergenzgesättigten Proteoliposomen in einer Orientierung so insertiert, dass die extrazellulären Domänen auf der Oberfläche präsentiert werden, stellt sich die Frage, welche Orientierung die Halbkanäle nach Fusion mit den GUVs und letztlich nach Spreiten der GUVs auf der Oberfläche des mikrostrukturierten Substrates haben. Vorausgesetzt, die Fusion der Proteoliposomen erfolgt nach dem von Kozlov \& Markin [1983] postulierten Mechanismus (Abb. 5-15), bliebe die Orientierung der Connexone nach Fusion erhalten, so dass sich die extrazellulären Domänen auf der Oberfläche des GUVs befinden.

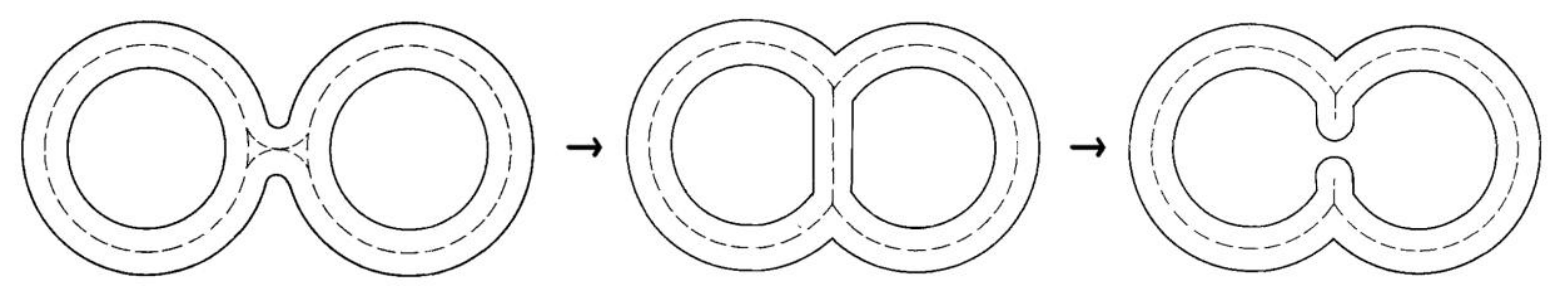

Abb. 5-15: Schematische Darstellung des stalk Mechanismus bei der Fusion zweier Vesikel [Kozlov \& Markin 1983] 
Die Vorhersage der Orientierung der Connexone nach Spreiten das GUV auf der Oberfläche eines mikroporösen Substrates ist schwierig. Bislang liegen nur Informationen für das Spreiten von Vesikeln oder GUVs auf planaren hydrophilen oder hydrophoben Substraten vor [Hamai et al. 2007; Jenkins et al. 2002].

A

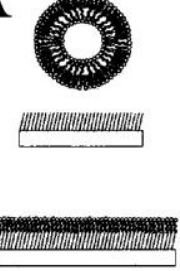

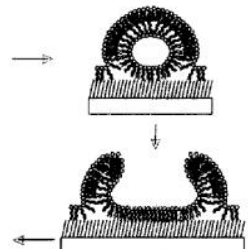

$\mathrm{B}$

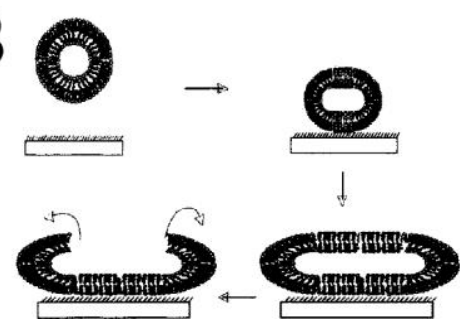

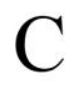

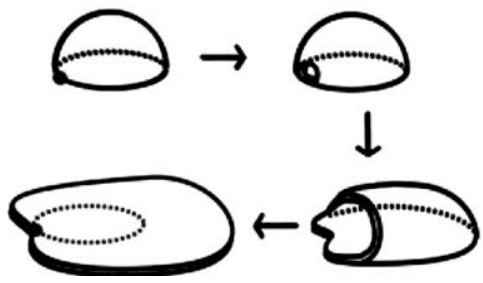

Abb. 5-16: Schematische Darstellung des Mechanismus der Adsorption von Vesikeln auf (A) hydrophoben und (B) hydrophilen Oberflächen [Jenkins et al. 2002]. (C) zeigt den Spreitmechanismus eines GUVs auf einer planaren Glasoberfläche [Hamai et al. 2007].

Nach Abb. 5-16 B und C spreiten Vesikel oder GUVs auf hydrophilen Oberflächen so, dass die äußere Membranschicht auf der Unterseite der ausgebildeten Lipiddoppelschicht lokalisiert ist, wohingegen beim Spreiten von Vesikeln auf hydrophoben SAMs (self assembled monolayer) beide Membranhälften die obere Lipidmonolage bilden (Abb. 5-16 A).

Die Verhältnisse nach Spreiten auf einem hydrophoben oder hydrophilen mikroporösen Substrat gilt es daher zu prüfen. Hier könnten zwei fluoreszenzmarkierte Antikörper zum Einsatz kommen, welche gegen eine cytosolische und eine extrazelluläre Domäne des Cx26 gerichtet sind. Anhand der relativen Fluoreszenzintensitäten könnte damit die Orientierung der Connexone abgeschätzt werden.

\subsubsection{Blockade falsch orientierter und ungepaarter Connexone}

In falscher Orientierung integrierte Connexonen können letztlich nicht ausgeschlossen werden, da eine $100 \%$ ige unidirektionale Rekonstitution der Proteine nicht möglich sein wird. Aufgrund dessen müssen Mittel oder Methoden gefunden werden, falsch orientierte und auch ungepaarte Halbkanäle zu blockieren (Abb. 5-17). Anderenfalls würden bei der elektrischen Kopplung von Zellen an die Connexon-dotierte porenüberspannende Membran elektrische Leckströme auftreten, welche eine elektrische Untersuchung der in den Zellen exprimierten Target Rezeptoren verhindern oder überlagern. Falsch orientierte Connexone könnten beispielsweise durch Zugabe von $\alpha$-Cyclodextrin $(\alpha-C D)$ auf der cis-Seite der Messeinheit blockiert werden. Nach Locke et al. [2004] hat die konische Molekülstruktur des $\alpha-C D$ eine zur Pore des Cx26 Halbkanals identische Dimension, so dass damit eine rein 
physikalische Blockade des Halbkanals möglich ist. Hierfür muss der insertierte Halbkanal von cytoplasmatischer Seite aus zugänglich sein. In Anlehnung an die von Gooden et al. [1985] durchgeführten Experimente besteht weiterhin die Möglichkeit, falsch orientierte Kanäle mit Antikörpern zu blockieren, welche gegen eine cytoplasmatische Domäne (z.B. NTH) des Cx26 gerichtet sind.

Die Blockade richtig orientierter Connexone, welche allerdings ungepaart vorliegen und keine Gap Junctions mit der Connexonen exprimierenden Zelle ausbilden, könnte ebenfalls mit einem Antikörper erzielt werden. Das Target müsste so ausgewählt werden, dass es auf der extrazellulären Seite, also in den Domänen E1 oder E2, lokalisiert ist und zugleich nicht die Paarung bereits ausgebildeter Gap Junctions beeinflusst.

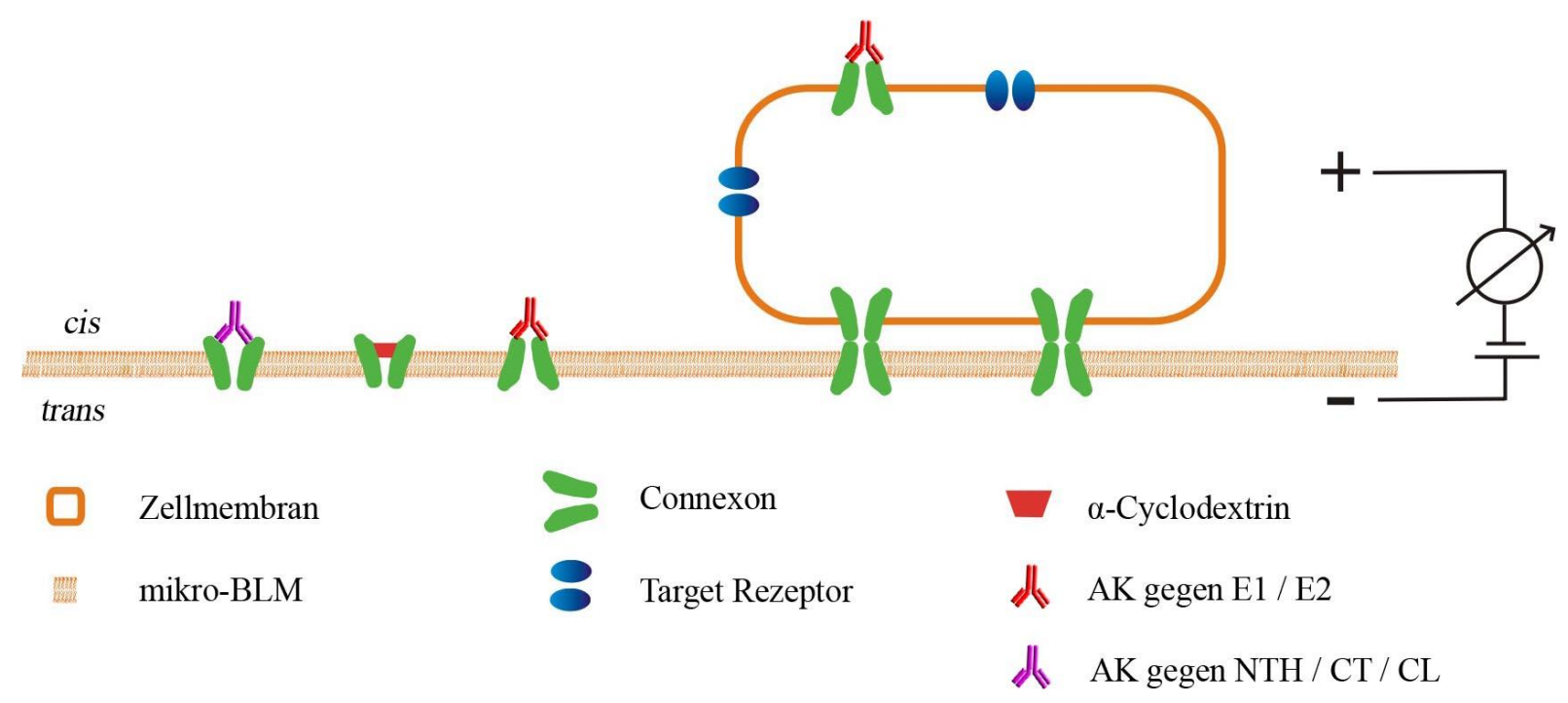

Abb. 5-17: Schematische Darstellung zur Blockade falsch orientierter und ungepaarter Connexonen bei der elektrischen Kopplung von Zellen an porenüberspannende Connexon-dotierte Lipidmembranen.

Sollte die Blockade mit Antikörpern aufgrund ihrer Dimensionierungen nicht effizient genug sein, könnten Antigen-bindende Fragmente der Antikörper, die so genannten Fab-Fragmente (fragment antigen binding) zum Einsatz kommen. Damit könnte die Effektivität einer Blockade aufgrund der erhöhten Zugänglichkeit verbessert werden [Hudson \& Souriau 2003]. Chemische Blocker, welche spezifisch nur ungepaarte Halbkanäle und nicht Gap Junctions blockieren, sind bislang nicht bekannt.

\subsubsection{Auswahl des Substrates und Herstellung der mikro-BLM}

Ein weiterer wichtiger Aspekt für die Umsetzung der elektrischen Kopplung von Zellen, mit dem Ziel der Herstellung eines Biochips, ist die Auswahl eines geeigneten porösen Substrates. 
Hierbei muss berücksichtigt werden, dass in vivo der interzelluläre Transfer über den Gap Junction Kanal nur in Form von Gap Junction Plaques mit mindesten 300 aggregierten Kanälen erfolgt. Die für die Herstellung von nano-BLMs verwendeten porösen Aluminate haben einen Porenradius von etwa $300 \AA$. Geht man von einer kreisrunden Pore aus, steht für die Integration von Connexonen eine maximale Fläche $A$ von etwa $280000 \AA^{2}$ zur Verfügung. Bei einer hexagonal dichtesten Packung der Connexone mit einem Radius von etwa $45 \AA$ und damit einem Flächenbedarf von etwa $6360 \AA^{2}$ können nach $\left(A_{\text {Pore }} \cdot 0.74\right) / A_{\mathrm{Cx}}$ nur etwa 30 Kanäle in einer Pore lateral aggregiert werden. Für eine $1.2 \mu \mathrm{m}$ Pore der in dieser Arbeit verwendeten Mikrosiebe berechnet sich eine Anzahl von etwa 13000 Connexonen. Auf mikrostrukturierten Substraten mit hoher Porendichte ist die Herstellung einer hochohmigen porenüberspannenden Membran durch Spreiten von GUVs allerdings sehr schwierig. Das Spreiten Connexon-dotierter GUVs ist aber vermutlich die beste Technik, mikro-BLMs mit einer hohen Oberflächenkonzentration herzustellen. Es könnten die von Kreir et al. [2010] beschriebenen mikrostrukturierten Glaschips mit begrenzter Anzahl an Poren verwendet werden. Die 9 Poren $(\varnothing=1 \mu \mathrm{m})$ dieser Substrate bieten genügend Fläche für die Ausbildung von Gap Junctions und zusätzlich ist die Ausbildung eines elektrischen Widerstands im G $\Omega$ Bereich durch Ansaugen und Spreiten von GUVs technisch realisierbar. Es stellt sich aber die Frage, ob ein solches Substrat mit einer Porosität von etwa $1 \%$ und einer insgesamt kleinen Gesamtoberfläche geeignet ist, das geplante Ziel der Herstellung eines Biochips umzusetzen. Es könnten maximal 9 Zellen direkt elektrisch über die $1 \mu \mathrm{m}$ Aperturen kontaktiert werden. Die elektrische Kontaktierung der verbliebenen Zellen müsste dann durch Ausbildung von Gap Junction Plaques untereinander erfolgen. Die alternative Nutzung von mikroporösen Polycarbonatfolien mit einer Porendichte von $10^{5}$ bis $6 \cdot 10^{8} 1 \mu \mathrm{m}$-Poren/ $/ \mathrm{cm}^{2}$ ist daher $\mathrm{zu}$ favorisieren. Für die Ausbildung einer hochohmigen Membran auf diesen Substraten mit einer Porosität von etwa 5 bis $20 \%$ muss allerdings bislang die Lösungsmittel-basierte paintingTechnik verwendet werden. Die Insertion von Connexonen in die bestehende porenüberspannende Membran erfolgt typischerweise mittels Detergenzien. Mit dieser Methode kann eine für die Ausbildung von Gap Junction Plaques mit tausenden Zellen notwendige hohe Connexonendichte nicht realisiert werden, da nur ein verschwindend geringer Bruchteil der eingesetzten Connexonen insertieren würde.

Eventuell könnte bei Substraten mit hoher Porendichte und Porosität die Integration großer Mengen an Protein in die bestehende mikro-BLM durch Fusion mit Proteoliposomen oder Connexon-dotierten GUVs erfolgen. Mit einem solchen Verfahren könnte zum einen die Hochohmigkeit der Membran und zum anderen die Connexonendichte erzielt werden, welche 
für die geplante Anwendung notwendig ist. Hier gilt es zu prüfen, in wieweit Lösungsmittelreste in der Membran die Vitalität der Zellen beeinflussen und ob es möglich ist, über die Ausbildung von Gap Junction Plaques eine ausreichende elektrische Kopplung der Zellen zu erzielen. Im Hinblick auf dieses Ziel sollte in dieser Arbeit die Ausbildung von Gap Junctions mit dem GUV Paarungsassay zunächst in einem einfachen artifiziellen Membransystem untersucht werden. 


\subsection{Ausbildung von Gap Junctions}

Mit dem FITC markierten Anti-His-Antikörper kann gezeigt werden, dass es möglich ist, durch die Fusion mit Proteoliposomen in hoher Dichte Connexon-dotierte GUV herzustellen (4.3.1.3). Aufgrund der Herstellungsmethode der Proteoliposomen ist davon auszugehen, dass die Orientierung der Cx26 Connexone innerhalb der Membran zufällig ist (5.4.2). Bei der Paarung von GUVs sollten daher etwa 50 \% der Connexone für eine Ausbildung von Gap Junctions zur Verfügung stehen. Experimente mit einzelnen Connexon-dotierten GUVs zeigen zunächst, dass der rekonstituierte Halbkanal für den wasserlöslichen Fluorophor Carboxyfluorescein (CF) nicht permeabel ist (4.4.1). Für den Nachweis eines Gap Junction vermittelten intervesikulären Transfers eines wasserlöslichen Fluorophors werden CF gefüllte TR-DHPE markierte Donor-GUVs und PB-DMPE markierte Akzeptor-GUVs hergestellt, die durch die Fusion mit Proteoliposomen Cx26 dotiert sind. Die Ergebnisse dieses GUV Paarungsassays haben eine klare Tendenz, die auf einen Cx26 spezifischen intervesikulären Farbstofftransfer hindeutet (4.4.2).

In Experimenten von Kaneda et al. [2009] werden ähnliche Beobachtungen gemacht. Hier werden Cx43 dotierte GUVs verwendet, die mit Calcein gefüllt sind (Abb. 5-18 B). Der Fluorophor liegt mit $0.623 \mathrm{kDa}$ in der Größenordnung des in dieser Arbeit verwendeten CF. Calcein gefüllte GUVs zeigen im Vergleich zu Kontrollvesikeln ohne Protein über einen Beobachtungszeitraum von $4 \mathrm{~h}$ keine erhöhte Permeabilität für den intravesikulären Farbstoff (Abb. 5-18 A).
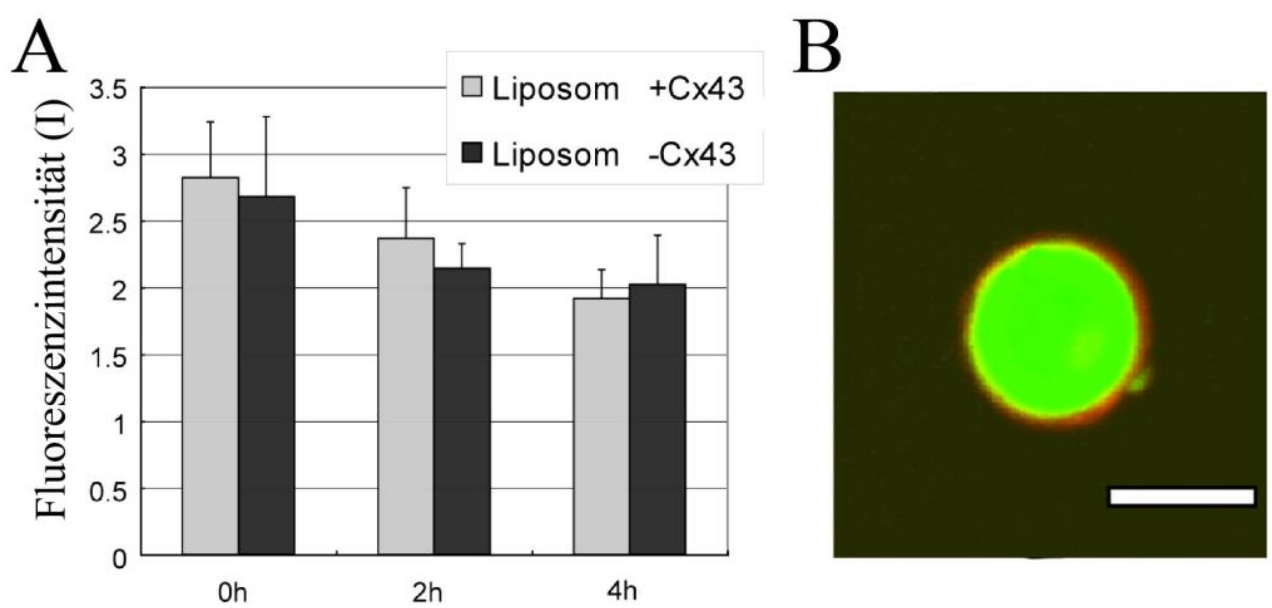

Abb. 5-18: Permeabilität von Cx43 dotierten GUVs für Calcein [Kaneda et al. 2009]. (A) Intraliposomale Farbstoffintensität von Cx43 dotierten GUVs und Kontrollvesikeln ohne Cx43 in Abhängigkeit von der Zeit. (B) Calcein gefüllter Cx43 dotierter GUV. Maßstab $=5 \mu \mathrm{m}$. 
Trotz der Impermeabilität des Cx43 Halbkanals für Calcein kann in diesen Experimenten der Gap Junction vermittelte Farbstofftransfer zwischen Cx43 dotierten GUVs und Cx43 exprimierenden U2OS Zellen (Abb. 5-19) nachgewiesen werden.
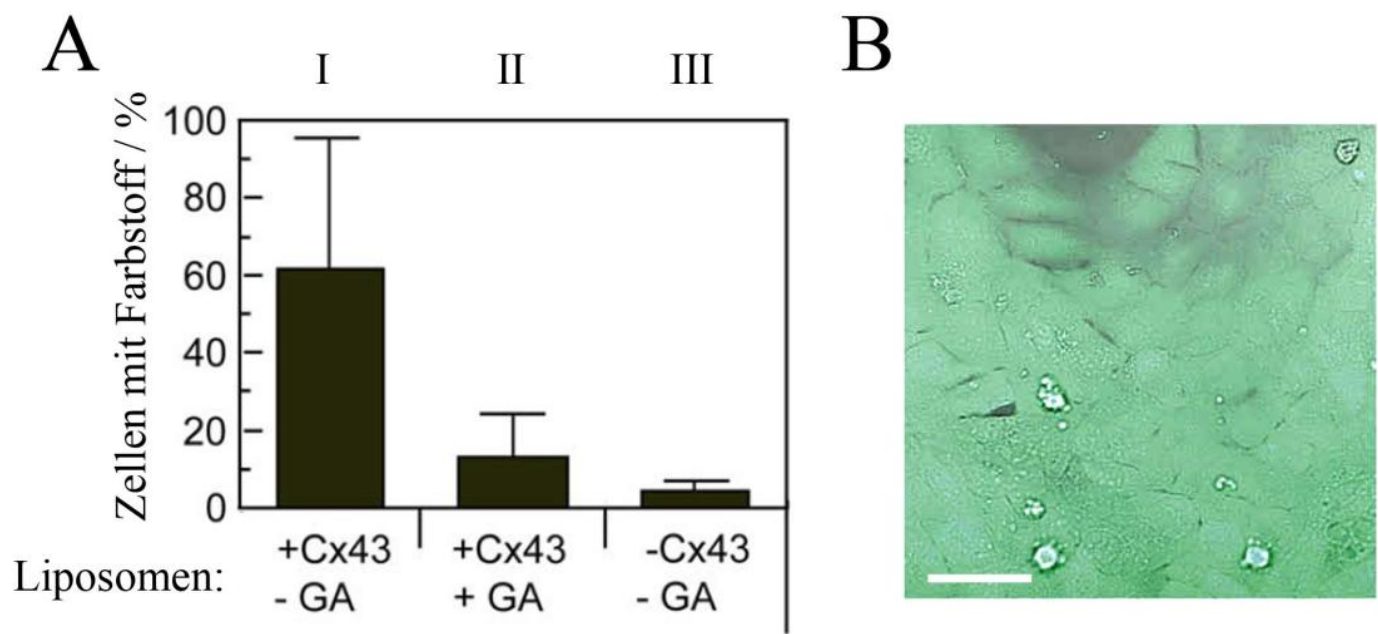

Abb. 5-19: Farbstofftransferassay nach Kaneda et al. [2009]. (A) Farbstofftransfer aus Cx43 dotierten Proteoliposomen (I und II) und Kontrollliposomen ohne Cx43 (III) in Cx43 exprimierende U2OS Zellen. Verwendung von $18 \beta$-Glycyrrhetinsäure $(10 \mathrm{mM})$ zur Blockade des Gap Junction vermittelten Farbstofftransfers (II). (B) Calcein gefüllte U2OS Zellen nach Inkubation mit Calcein gefüllten Proteoliposomen. $\mathrm{Maßstab}=50 \mu \mathrm{m}$.

Abb. 5-19 B zeigt eine fluoreszenzmikroskopische Aufnahme von Cx43 exprimierenden U2OS Zellen nach Inkubation mit Calcein gefüllten Cx43 Proteoliposomen. In etwa $60 \%$ der Zellen ist nach Inkubation eine intrazelluläre Fluoreszenzintensität nachweisbar (Abb. 5-19 A). Der Transfer des Fluorophors zwischen dem artifiziellen Membransystem und den Zellen kann durch den Connexon-spezifischen Blocker 18$\beta$-Glycyrrhetinsäure unterbunden werden. Da zudem bei Kontrollliposomen kein Transfer beobachtet werden kann, ist davon auszugehen, dass der beobachtete Farbstofftransfer Gap Junction vermittelt ist.

Mit den Ergebnissen des GUV Transferassays kann ein weiteres wichtiges Zwischenziel erreicht werden, das für die im Rahmen des Verbundprojektes geplante elektrische Kopplung von Zellen an Connexon-dotierte porenüberspannende Membranen essentiell ist. Es ergeben sich allerdings auch Fragen bezüglich der Permeabilität des Halbkanals bzw. des Gap Junction Kanals, die beantwortet werden müssen. 


\subsection{Permeabilität von Gap Junctions und Connexonen}

Gap Junctions werden häufig als unselektive Poren zwischen benachbarten Zellen beschrieben, die den interzellulären Transfer von Molekülen bis etwa $1 \mathrm{kDa}$ ermöglichen [Harris 2001]. Die Einzelkanalmessungen in nano-BLMs und der Aktivitätsnachweis von Connexonen in Cytochrom $c$ gefüllten Vesikeln belegen, dass der Cx26 Halbkanal für Ionen und Ascorbat permeabel ist. Demgegenüber zeigen Cx26 dotierte GUVs keine Permeabilität für den Fluorophor Carboxyfluorescein (CF). Ein Transfer kann nur nach Paarung mit einem zweiten GUV beobachtet werden, was auf die Ausbildung von Gap Junction zurückgeführt wird. Grundsätzlich sollte der Transfer von CF mit einem Molekulargewicht von $376.32 \mathrm{~g} / \mathrm{mol}$ durch den Cx26 Halbkanal möglich sein, da die molekularen Durchmesser mit $12.6 \times 12.7 \times 8.5 \AA$ [Brink \& Ramanan 1985] kleiner als der für Cx26 ermittelte minimalen Porendurchmesser von $14 \AA$ sind [Maeda et al. 2009]. Der Halbkanal scheint demzufolge eine gewisse selektive Permeabilität aufzuweisen, die mit einer unspezifischen Diffusion bis zu Molekülgrößen von $1 \mathrm{kDa}$ nicht erklärt werden kann. In den folgenden Abschnitten werden die aktuellen Erkenntnisse bzgl. dieser Fragestellung zusammengefasst.

\subsubsection{Gap Junctions}

Veenstra et al. [1995/1996] machten erstmals deutlich, dass hinsichtlich der unspezifischen Permeabilität ein Umdenken erforderlich ist. Die Experimente zeigten für das Cx45 eine eindeutige Präferenz für Kationen, wohingegen Cx32 Gap Junctions eine Präferenz für Anionen aufwiesen. Bei einem unspezifischen Transfer würde zudem die Permeabilität der Ionen mit ihrer Mobilität in wässriger Lösung korrelieren. Dieser Zusammenhang konnte eindeutig widerlegt werden [Beblo \& Veenstra 1997]. Vermutlich sind Ladungen am cytoplasmatischen und am extrazellulären Ende des Halbkanals für die spezifische Ionenselektivität verantwortlich [Musa et al. 2004; Trexler et al. 2000]. Grundsätzlich muss zwischen der Permeabilität für Ionen und größeren Molekülen wie Fluorophoren oder sekundären Botenstoffen unterschieden werden. Studien mit Cx26 Mutanten zeigten in diesem Zusammenhang, dass die elektrische Leitfähigkeit von Cx26V84L Gap Junctions nicht von der Leitfähigkeit des Cx26WT unterschieden werden kann, wohingegen die Transferrate für den sekundären Botenstoff $\mathrm{IP}_{3}$ deutlich eingeschränkt ist [Beltramello et al. 2005] (siehe Abb. 5-7). In einer weiteren Studie mit der Cx26 Mutante M34T wird gezeigt, dass zwar die Leitfähigkeit des Gap Junction Kanals im Vergleich zum WT um etwa $90 \%$ reduziert ist [Bicego et al. 2006], die Farbstofftransferrate des Fluorophors Sulforhodamin mit 
einer Masse von etwa $0.5 \mathrm{kDa}$ jedoch nicht eingeschränkt ist [Oshima et al. 2003] (siehe Abb. 5-8). Diese Ergebnisse beweisen, dass der Permeabilität von Ionen und größeren Molekülen zwei grundsätzlich verschiedene gating-Mechanismen zu Grunde liegen, welche bislang nur unzureichend verstanden sind. Die Permeabilität für größere Moleküle ist hierbei von mehreren Faktoren abhängig. So zeigen Farbstofftransferstudien mit dem anionischen Fluorophor lucifer yellow (LY, MW = 457 g/mol) und dem kationischen Fluorophor 4',6Diamidin-2-phenylindol (DAPI, $\quad \mathrm{WW}=350 \mathrm{~g} / \mathrm{mol}$ ) eine eindeutige Abhängigkeit der Transferrate von der Ladung des Fluorophors [Cao et al. 1998]. In Experimenten mit anionischen Fluorophoren unterschiedlicher molekularer Masse kann gezeigt werden, dass neben der Ladung auch die Molekülgröße von entscheidender Bedeutung ist [Weber et al. 2004] (Abb. 5-20).

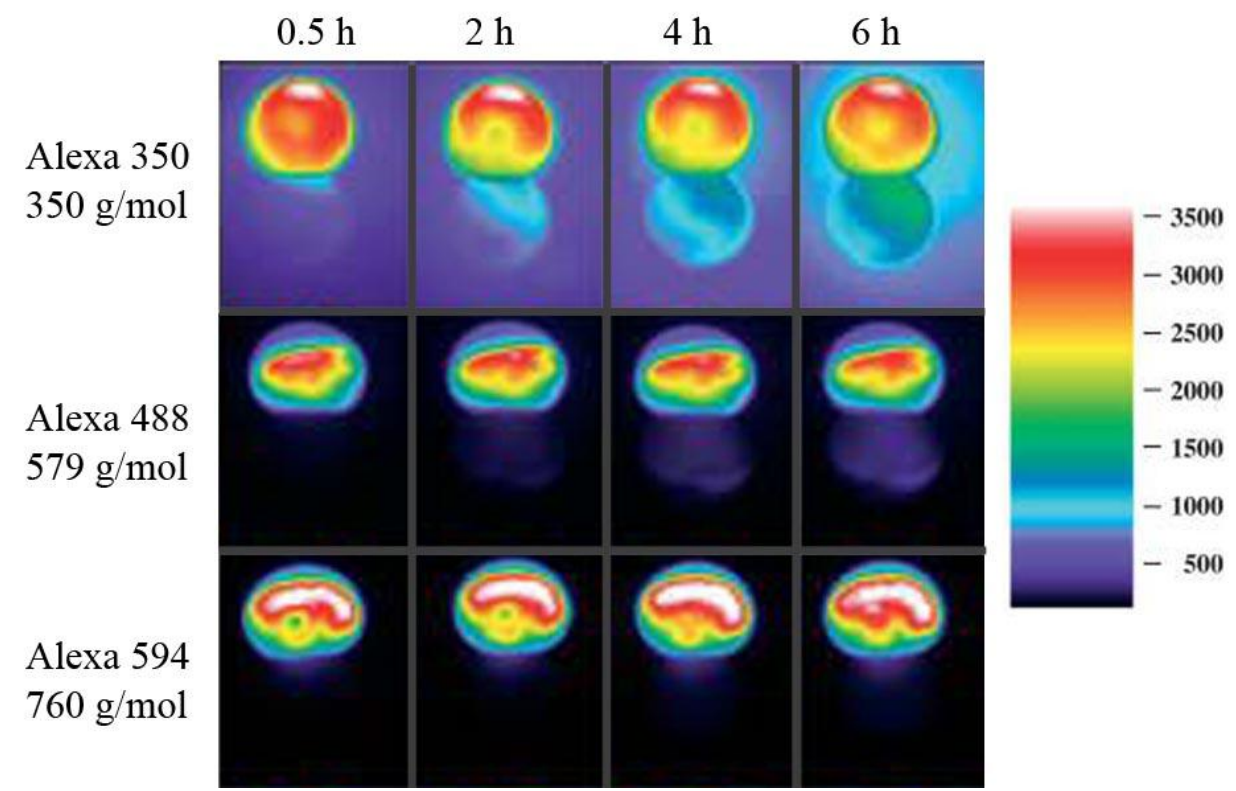

Abb. 5-20: Transfer verschiedener Fluorophore zwischen Cx26 exprimierenden gepaarten Xenopus Oocyten in Abhängigkeit von der Zeit [Weber et al. 2004]. Den jeweils oberen Zellen wurde 16-24 h vor der Paarung der Fluorophor injiziert. Die Konzentration des Fluorophors ist proportional zur Fluoreszenzintensität und entsprechend der Farbskala (rechts) wiedergegeben.

Abb. 5-20 zeigt den zeitlicher Verlauf des interzellularen Transfers der Fluorophore Alexa $350(\mathrm{MW}=350 \mathrm{~g} / \mathrm{mol})$, Alexa $488(\mathrm{MW}=350 \mathrm{~g} / \mathrm{mol})$ und Alexa $594(\mathrm{MW}=350 \mathrm{~g} / \mathrm{mol})$ zwischen gepaarten Cx26 exprimierenden Xenopus Oocyten. Ist die Transferrate von Alexa 350 und 488 in etwa identisch, so kann mit dem größten Fluorophor Alexa 594 eine deutliche Reduzierung der interzellulären Permeabilität beobachtet werden. Eine größenabhängige Ausschlussgrenze kann auch mit neutralen Transfermolekülen beobachtet werden [Bevans et al. 1998; Gong \& Nicholson 2001]. Solche Studien sind sehr aufschlussreich. Das eigentliche Interesse gilt allerdings der Selektivität von Gap Junctions für natürliche Moleküle 
wie sekundäre Botenstoffe oder Metabolite. So konnten Goldberg et al. [1999/2002] zeigen, dass die Permeabilität von Cx43 und Cx32 Gap Junctions für den anionischen Fluorophor Calcein gleich groß ist, sich für ATP aber um den Faktor 100 unterscheidet. Weiterhin zeigen theoretische Modelle, dass die beobachteten Permeabilitäten für Fluorophore etwa 1-2 Größenordnungen über der anhand reiner Diffusion möglichen Transferrate liegen [Nitsche et al. 2004; Weber et al. 2004]. Dies wird damit begründet, dass es vermutlich schwache Affinitäten der Moleküle mit der Porenwand gibt, wodurch die Aufenthaltswahrscheinlichkeit innerhalb der Pore erhöht wird. Dies hätte einen wesentlichen Einfluss auf den effektiven Konzentrationsgradienten und die Transferrate.

\subsubsection{Connexone}

Ist die selektive Permeabilität von Gap Junction heute eindeutig nachgewiesen, so besteht weiterhin eine grundsätzliche Debatte über die Aktivität und Permeabilität ungepaarter Halbkanäle. Weit verbreitet ist die Annahme, dass Connexone im zellulären System nur aggregiert in Form von Gap Junction Plaques aktiv sind, mit der Begründung, dass eine Permeabilität der Halbkanäle für Ionen und größere Moleküle den Zelltod einleiten würde. Tatsächlich ist die Mehrheit der membranständigen Connexone lateral in Form von formation plaques mit anderen Connexonen aggregiert und an der Ausbildung von gap junction plaques beteiligt [Harris 2001]. Es gibt allerdings Studien, welche eindeutig das Vorkommen ungepaarter Connexone innerhalb der Zellmembran belegen [Paul et al. 1991; Musil \& Goodenough 1991]. Die Öffnungswahrscheinlichkeit dieser Halbkanäle ist unter physiologischen Bedingungen (Zell-spezifisches Ruhepotential, $\mathrm{Ca}^{2+}$-Konzentration) zwar sehr gering, aktuellere Studien belegen aber eine Beteiligung solcher extra-junctional Connexone an einer Vielzahl biologischer Prozesse, wie etwa der interzellulären Kommunikation. Einen guten Überblick verschaffen hier Goodenough \& Paul [2003]. Experimente mit Membran-patches von Cx46 exprimierenden Xenopus Oocyten zeigen, dass die Halbkanäle für ungeladene Moleküle in der Größenordnung von 180 bis $666 \mathrm{Da}$ zugänglich sind [Qu \& Dahl 2004]. In ungepaarten HeLa, Zellen welche Cx43-EGFP exprimieren, korreliert die Aufnahme des Farbstoffes Ethidiumbromid aus dem extrazellulären Medium direkt mit dem Expressionslevel des Fusionsproteins [Contreras et al. 2003]. Durch den spezifischen Connexon Blocker $\beta$-Glycyrrhitinsäure kann diese Permeabilität reduziert werden. 



\section{Ausblick}

Nachdem die Aktivität der Cx26 Halbkanäle in Vesikeln (Cytochrom $c$ Assay) und in porenüberspannenden Membranen (Einzelkanalmessungen in nano-BLMs) bewiesen werden konnte, lieferte der GUV Paarungsassay mit dem Transfer eines wasserlöslichen Fluorophors zwischen zwei Connexon-dotierten GUV Populationen einen ersten Hinweis auf die Ausbildung von Gap Junctions. Um diesen Transfer weiter zu spezifizieren bietet es sich an, mit Gap Junction Blockern wie $\beta$-Glycyrrhitinsäure oder Carbenoxolon zu arbeiten. Hiermit sollte im Falle eines Gap Junction vermittelten intervesikulären Transfers ein Wiederanstieg der Fluoreszenz nach Bleichen des Akzeptor-GUVs unterbunden werden können. In einem nächsten Schritt sollte zunächst in Anlehnung an die von Kaneda et al. [2009] durchgeführten Experimente ein Transfer von Farbstoff zwischen GUVs und Cx26 exprimierenden Zellen nachgewiesen werden. Gelingt dies, können die Experimente mit den porösen Substraten fortgesetzt werden. In dieser Arbeit gelang es durch Spreiten von GUVs mikro-BLMs mit einer hohen Cx26 Oberflächenbelegung herzustellen. Für die geplante elektrische Kopplung von Zellen müsste zunächst die Orientierung der Connexone geklärt werden. Hier könnten beispielsweise fluoreszenzmikroskopische Methoden zur Anwendung kommen, in welchen mit fluoreszenzmarkierten Antikörpern gegen extra- und intrazelluläre Domänen des Cx26 gearbeitet wird. Weiterhin könnten durch Ansaugen und Spreiten von Connexon-dotierten GUVs auf mikroporösen Glaschips (Nanion) hochohmige mikro-BLMs hergestellt werden. Durch impedanzspektroskopische Analysen könnte durch Blocker wie $\mathrm{Ca}^{2+}$ oder $\alpha$ Cyclodextrin ( $\alpha$-CD) auf die Orientierung der Halbkanäle geschlossen werden. Für die Blockade mit $\alpha$-CD muss der Kanal von cytoplasmatischer Seite aus zugänglich sein. Die Calciumbindungsstellen sind vermutlich auf der extrazellulären Seite lokalisiert. Sind in der porenüberspannenden Membran aktive Halbkanäle integriert, resultiert die Zugabe von Blocker in einer Erhöhung des Membranwiderstandes. Würde man etwa $\alpha$-CD erst auf der cis-Seite und dann auf der trans-Seite der Messzelle hinzugeben, könnte aus dem Gesamtanstieg des Membranwiderstandes auf die Anzahl aktiver Kanäle geschlossen werden. Aus den jeweiligen Anstiegen nach Zugabe auf cis und trans-Seite wäre eine Aussage über die Orientierung möglich (Abb. 6-1). 


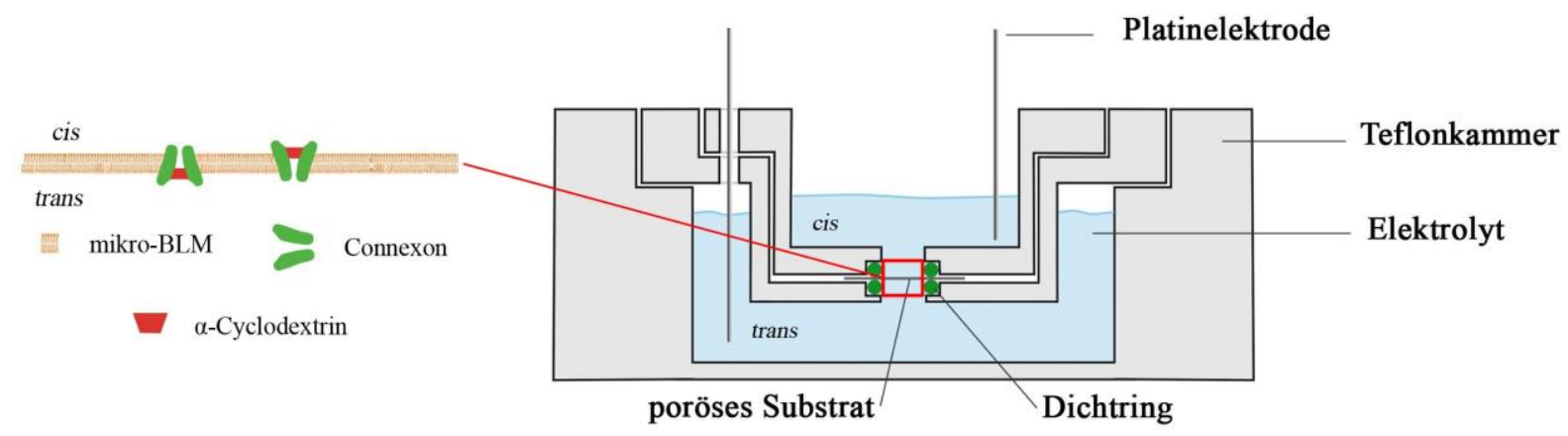

Abb. 6-1: Messzelle für den impedanzspektroskopischen Nachweis der Orientierung von Connexonen in mikroBLMs durch die Blockade der Halbkanäle mit z.B. $\alpha$-Cyclodextrin.

Für das in Abb. 6-1 schematisch dargestellte Prinzip eignen sich neben $\alpha-\mathrm{CD}$ und $\mathrm{Ca}^{2+}$ auch Antikörper oder deren Fab-Fragmente. Die Ergebnisse dieser Untersuchungen könnten auch dafür verwendet werden, Strategien zu entwickeln, ungepaarte oder falsch orientierte Kanäle zu blockieren. Sind diese grundlegenden Fragestellungen beantwortet, sollte anschließend überprüft werden, in wieweit etwa Lösungsmittelreste in der mikro-BLM (bei der Herstellung über painting-Technik) einen Einfluss auf die Vitalität an der Oberfläche gebundener Zellen haben und ob die Stabilität und Hochohmigkeit der Membran auch nach Zugabe der Zellen gewährleistet ist. Im Anschluss muss die Ausbildung von Gap Junctions nachgewiesen werden. Dies kann direkt mit einer elektrischen Kopplung der Zellen erfolgen. In Vorversuchen mittels Port-a-Patch Technik (Nanion Technologie GmbH) konnten hierfür schon erste Ergebnisse erhalten werden [Kreir et al. 2010]. Hierfür wurde zunächst mittels painting-Technik eine lösungsmittelhaltige mikro-BLM auf einer mikroporösen Polycarbonatfolie hergestellt. Anschließend wurden aufgereinigte Cx26 Halbkanäle mit einer detergenzbasierten Methode rekonstituiert. Die funktionelle Integration wurde mittels voltageclamp Messungen überprüft. Unter Kenntnis der Leitfähigkeit eines Cx26 Halbkanals konnte die Anzahl aktiver Connexone in der mikro-BLM bestimmt werden, welche sich im Schnitt auf etwa 100 bis 1000 aktive Kanäle belief. Die elektrischen Messungen 15 bis 25 min nach Zugabe von Cx26 exprimierenden HeLa Zellen deuten auf eine Ausbildung von Gap Junctions zwischen der Connexonen dotierten artifiziellen mikro-BLM und den Zellen hin. Es sind auch Methoden denkbar, in denen ein Farbstofftransfer aus dem trans-Kompartiment der Messeinheit über die ausgebildeten Gap Junctions in die Zellen erfolgt. Dies könnte mit dem CLSM überprüft werden.

Kann die Herstellung der Connexon-dotierten porenüberspannenden Membran und die elektrische Kopplung der Zellen abschließend in einem weitestgehend automatisierten System reproduzierbar realisiert werden, könnte dies die Basis eines high-throughput-fähigen Biochips für die pharmazeutische Forschung sein. 



\section{$7 \quad$ Zusammenfassung}

In dieser Arbeit wurden Methoden entwickelt, welche die funktionelle Integration von Connexonen in Lipidmembranen auf porösen Oberflächen ermöglichen. Dies ist ein wichtiger Meilenstein für die Umsetzung des BMBF geförderten Verbundprojektes, der elektrischen Kopplung von Zellen an porenüberspannende Connexon-dotierte Lipidmembranen.

In Phase I der Arbeit (Abb. 7-1 I) wurde eine funktionelle Rekonstitution des Connexin26 (Cx26) in einem einfachen artifiziellen Membransystem untersucht. Mit dem etablierten Vesikelassay konnte die funktionelle Rekonstitution der Ionenkanäle indirekt durch die intraliposomale Reduktion von Cytochrom $c$ mittels UV/VIS-Spektroskopie nachgewiesen werden. Der hierfür erforderliche transmembrane, Cx26 vermittelte Transfer des Reduktionsmittels Ascorbat konnte durch Connexon-spezifische Blocker wie Carbenoxolon, $\alpha$-Cyclodextrin und $\mathrm{Ca}^{2+}$ moduliert werden. Dieser Assay machte es weiterhin möglich, in einem Teilprojekt die Kanalaktivität von Pannexin2 zu beweisen.

In Phase II wurde das formulierte Ziel der Integration von Connexonen in porenüberspannende Lipidmembranen umgesetzt. $\mathrm{Zu}$ diesem Zweck wurden zwei grundsätzlich verschiedene Substrate und Nachweistechniken angewendet. Zum einen gelang mit Hilfe von Einzelkanalmessungen (Abb. 7-1 IIb) die umfassende elektrophysiologische Charakterisierung einzelner Cx26 Halbkanäle in nano-BLMs. Es wurden funktionalisierte poröse Aluminate mit einem Porendurchmesser von $60 \mathrm{~nm}$ verwendet, auf denen mittels painting-Technik hochohmige, langzeitstabile, porenüberspannende Membranen (nanoBLMs) hergestellt werden konnten. Mit diesem Membransystem konnten neben dem Wildtyp des Cx26 zusätzlich die Mutanten M34A und V84L untersucht werden. Die elektrophysiologischen Charakteristika des M34A waren sehr ähnlich zu denen des Wildtyps, wohingegen die Mutante V84L ein deutlich verändertes Verhalten aufwies. Zum anderen wurden funktionalisierte Mikrosiebe mit einem Porendurchmesser von $1.2 \mu \mathrm{m}$ und die konfokale Laserrastermikroskopie dazu verwendet, den Nachweis einer Integration von Cx26 Halbkanälen in hoher Dichte in porenüberspannende Membranen zu erbringen (Abb. 7-1 IIa). Hierfür wurden zunächst durch die Fusion mit Cx26 Proteoliposomen Connexon-dotierte riesige unilamellare Vesikel (GUVs) hergestellt. Nach Spreiten dieser Vesikel auf den Siliziumporen konnte die Integration der Connexone spezifisch mit einem fluoreszenzmarkiertem Antikörper nachgewiesen werden.

In Phase III gelang es mit dem GUV Paarungsassay (Abb. 7-1 III) einen ersten Hinweis auf die Ausbildung funktioneller Cx26 Gap Junctions zu erlangen, welche für eine elektrische 
Kopplung von Zellen an porenüberspannende Connexon-dotierte Lipidmembranen (Abb. 7-1 IV) notwendig ist.

I
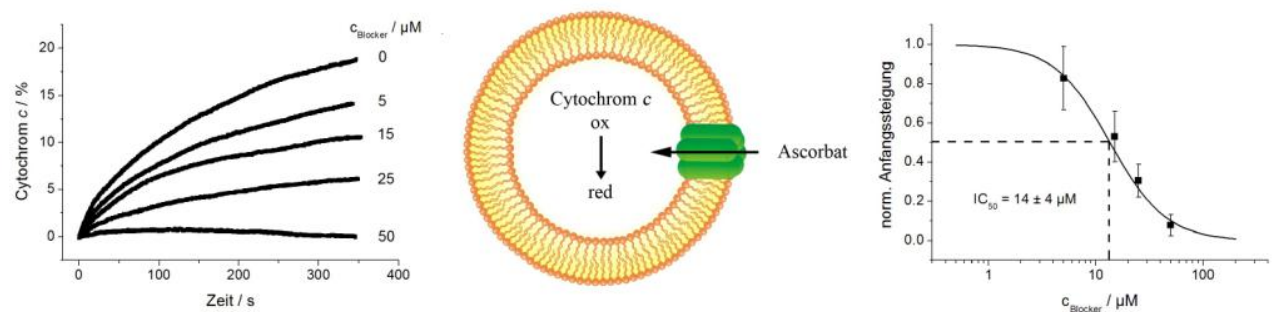

Nachweis der Connexonen-Aktivität mittels Cytochrom c Vesikel Assay

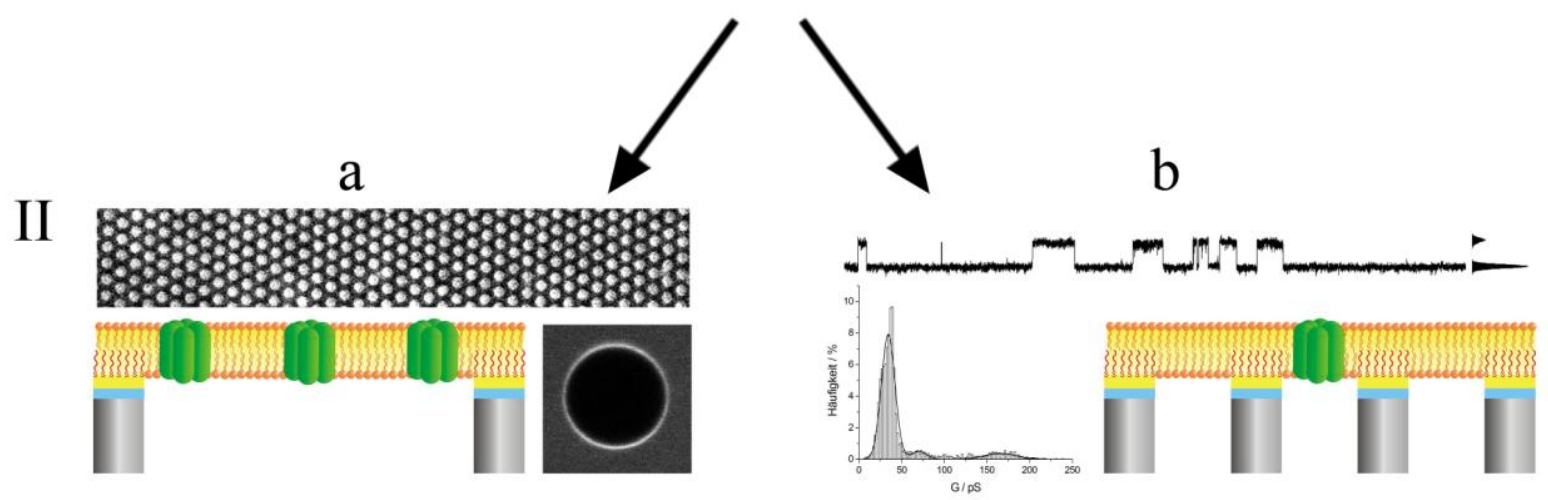

Visueller Nachweis in mikro-BLMs

Elektrophysiologische Charakterisierung in nano-BLMs
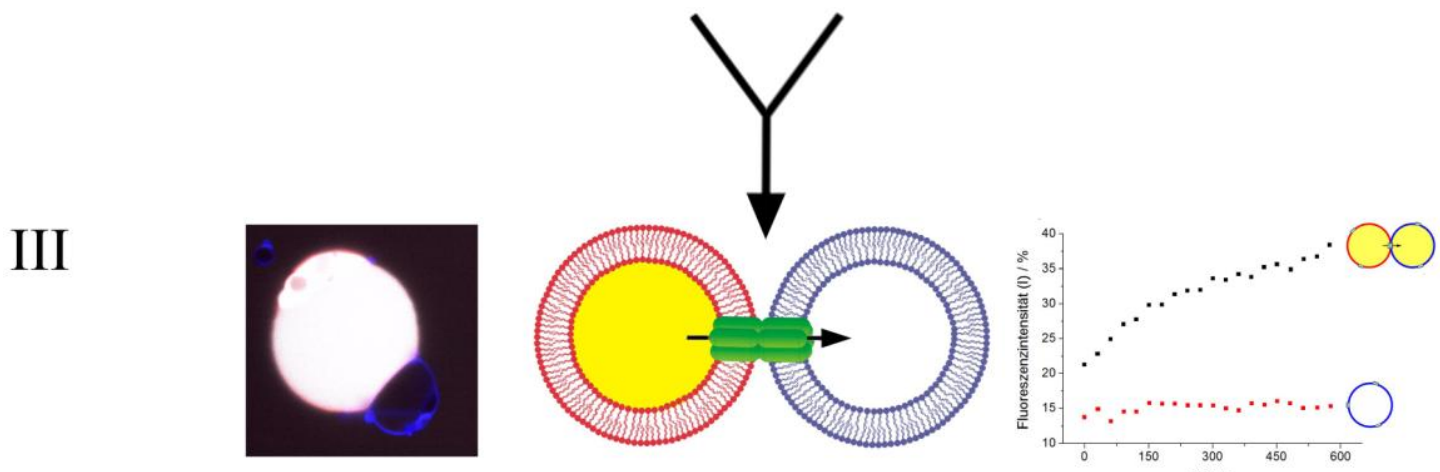

Nachweis der Gap Junction Aktivität mittels GUV Paarungsassay ${ }^{\text {zei }}$

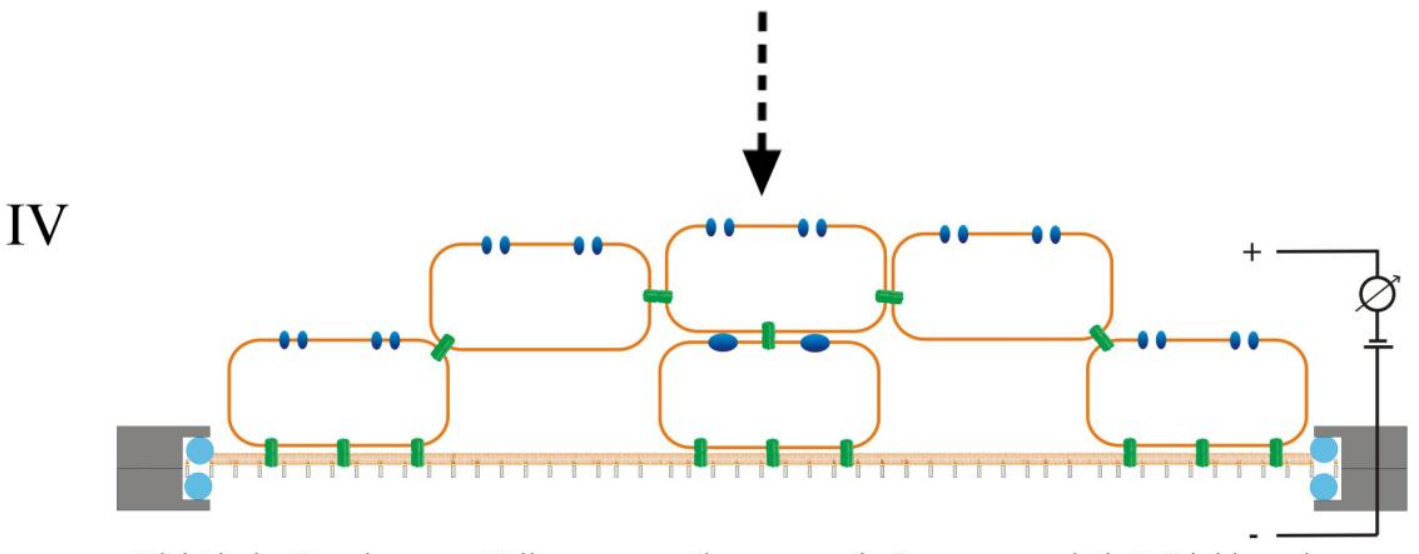

Elektrische Kopplung von Zellen an porenüberspannende Connexonen-dotierte Lipidmembranen

Abb. 7-1: Übersicht der in dieser Arbeit erreichten Ziele (Phase I bis III) als wichtige Meilensteine für die im Rahmen eines Verbundprojektes geplante elektrischen Kopplung von Zellen an porenüberspannende Connexonen-dotierte Lipidmembranen (IV). 



\section{$8 \quad$ Literaturverzeichnis}

Ahmad, S., Chen, S., Sun, J., Lin, X., 2003. Connexins 26 and 30 are co-assembled to form gap junctions in the cochlea of mice. Biochem Biophys Res Commun 307, 362-368.

Alberts, B., A. Johnson, J. Lewis, M. Raff, K. Roberts, and P. Walter. 2004. Molekularbiologie der Zelle. Wiley-VCH Verlag GmbH\&Co. KGaA, Weinheim.

Ambrosi, C., Gaßmann, O., Pranskevich, J. N., Boassa, D., Smock, A., Wang, J., Dahl, G., Steinem, C., Sosinsky, G. E., 2010. Pannexin1 and pannexin2 channels show quaternary similarities to connexin hemichannels, but different oligomerization numbers from each other. J Biomol Chem., eingereicht und akzeptiert.

Angelova M. I., Dimitrov, D. S., 1986. Liposome electroformation. Faraday Discuss Chem Soc $81,303-311$.

Angelova, M. I., Soléau, S., Méléard, P., Faucon, J. F., Bothorel, P., 1992. Preparation of giant vesicles by external ac electric fields; kinetics and applications. Progr Colloid Polym Sci 89, 127.

Angelova, M. I., Soléau, S., Méléard, P., Faucon, J. F., Bothorel, P., 1992. Preparation of giant vesicles by external ac electric fields; kinetics and applications. Progr Colloid Polym Sci 89, 127.

Atkins, W. B., 2001. Physikalische Chemie. Volume 3, Wiley-VCH-Verlag, Weinheim.

Axelrod, D., Koppel, D. E., Schlessinger, J., Elson, E., Webb, W. W., 1976. Mobility measurement by analysis of fluorescence photobleaching recovery kinetics. Biophys $\mathbf{J}$ $16,1055-1069$.

Bacia, K., Schwille, P., Kurzchalia, T., 2005. Sterol structure determines the separation of phases and the curvature of the liquid-ordered phase in model membranes. Proc Natl Acad Sci U S A 102, 3272-3277. 
Baranova, A., Ivanov, D., Petrash, N., Pestova, A., Skoblov, M., Kelmanson, I., Shagin, D., Nazarenko, S., Geraymovych, E., Litvin, O., Tiunova, A., Born, T. L., Usman, N., Staroverov, D., Lukyanov, S., Panchin, Y., 2004. The mammalian pannexin family is homologous to the invertebrate innexin gap junction proteins. Genomics 83, 706-716.

Barbe, M. T., Monyer, H., Bruzzone, R., 2006. Cell-cell communication beyond connexins: the pannexin channels. Physiology (Bethesda) 21, 103-114.

Beblo, D. A., Veenstra, R. D., 1997. Monovalent cation permeation through the connexin40 gap junction channel. $\mathrm{Cs}, \mathrm{Rb}, \mathrm{K}, \mathrm{Na}, \mathrm{Li}$, TEA, TMA, TBA, and effects of anions $\mathrm{Br}$, Cl, F, acetate, aspartate, glutamate, and NO3. J Gen Physiol 109, 509-522.

Beer, A., 1852. Bestimmung der Absorption des rothen Lichts in farbigen Flüssigkeiten. Annalen der Physik 86, 78-87.

Beltramello, M., Bicego, M., Piazza, V., Ciubotaru, C. D., Mammano, F., D'Andrea, P., 2003. Permeability and gating properties of human connexins 26 and 30 expressed in HeLa cells. Biochem Biophys Res Commun 305, 1024-1033.

Beltramello, M., Piazza, V., Bukauskas, F. F., Pozzan, T., Mammano, F., 2005. Impaired permeability to Ins(1,4,5)P3 in a mutant connexin underlies recessive hereditary deafness. Nat Cell Biol 7, 63-69.

Bengough, G. B., Stuart, J. M., 1923. The Article as The Anode in A Bath of Aqueous Solution of 3\% Chromic Acid. Britisches Patent Nr. 223993.

Berg, J. M., Tymoczko, J. L., Stryer, L., 2003. Biochemie. 5 ed.; Spektrum Akademischer Verlag: Heidelberg-Berlin.

Bevans, C. G., Harris, A. L., 1999. Regulation of connexin channels by pH. Direct action of the protonated form of taurine and other aminosulfonates. J Biol Chem 274, 37113719. 
Bevans, C. G., Kordel, M., Rhee, S. K., Harris, A. L., 1998. Isoform composition of connexin channels determines selectivity among second messengers and uncharged molecules. $\mathrm{J}$ Biol Chem 273, 2808-2816.

Bicego, M., Beltramello, M., Melchionda, S., Carella, M., Piazza, V., Zelante, L., Bukauskas, F. F., Arslan, E., Cama, E., Pantano, S., Bruzzone, R., D'Andrea, P., Mammano, F., 2006. Pathogenetic role of the deafness-related M34T mutation of Cx26. Hum Mol Genet 15, 2569-2587.

Blodgett, K., 1935. Films Built by Depositing Successive Monomolecular Layers on a Solid Surface. J. Am. Chem. Soc. 57, 1007-22.

BLT (Biophysics Laboratory Techniques): http://www.moleculardevices.com/pdfs/ Axon_Guide.pdf

Boettger, T., Hubner, C. A., Maier, H., Rust, M. B., Beck, F. X., Jentsch, T. J., 2002. Deafness and renal tubular acidosis in mice lacking the $\mathrm{K}-\mathrm{Cl}$ co-transporter $\mathrm{Kcc} 4$. Nature 416, 874-878.

Boger, D. L., Patterson, J. E., Guan, X., Cravatt, B. F., Lerner, R. A., Gilula, N. B., 1998. Chemical requirements for inhibition of gap junction communication by the biologically active lipid oleamide. Proc Natl Acad Sci U S A 95, 4810-4815.

Bouguer, B., 1729. Essai d'Optique sur la gradation de la Lumiere. Claude Jombert. Paris, $164 \mathrm{ff}$.

Brink, P. R., Ramanan, S. V., 1985. A model for the diffusion of fluorescent probes in the septate giant axon of earthworm. Axoplasmic diffusion and junctional membrane permeability. Biophys J 48, 299-309.

Brozell, A. M., Muha, M. A., Sanii, B., Parikh, A. N., 2006. A class of supported membranes: formation of fluid phospholipid bilayers on photonic band gap colloidal crystals. J Am Chem Soc 128, 62-63. 
Bruzzone, R., Hormuzdi, S. G., Barbe, M. T., Herb, A., Monyer, H., 2003. Pannexins, a family of gap junction proteins expressed in brain. Proc Natl Acad Sci U S A 100, 13644-13649.

Bruzzone, R., Veronesi, V., Gomes, D., Bicego, M., Duval, N., Marlin, S., Petit, C., D'Andrea, P., White, T. W., 2003. Loss-of-function and residual channel activity of connexin26 mutations associated with non-syndromic deafness. FEBS Lett 533, 7988 .

Buehler, L. K., Stauffer, K. A., Gilula, N. B., Kumar, N. M., 1995. Single channel behavior of recombinant beta 2 gap junction connexons reconstituted into planar lipid bilayers. Biophys J 68, 1767-1775.

Bukauskas, F. F., Verselis, V. K., 2004. Gap junction channel gating. Biochim Biophys Acta $1662,42-60$.

Cao, F., Eckert, R., Elfgang, C., Nitsche, J. M., Snyder, S. A., DF, H. u., Willecke, K., Nicholson, B. J., 1998. A quantitative analysis of connexin-specific permeability differences of gap junctions expressed in HeLa transfectants and Xenopus oocytes. $\mathrm{J}$ Cell Sci 111 (Pt 1), 31-43.

Chang, E. H., Van Camp, G., Smith, R. J., 2003. Ear: Hear 24, 314-323.

Clarke, A. R., Archenhold, G., Davidson, N. C., 1995. A novel technique for determining the 3D spatial distribution of glass fibres in polymer composites. Composites Science and Technology 55, 75-91.

Cole, K. S., 1949. Dynamic electrical characteristics oh the squid axon membrane. Arch Sci Physiol 3, 253-258.

Cole, K. S., Cole, R. H., 1941. Dispersion and Absorption in Dielectrics I. Alternating current characteristics. J. Chem. Phys. 9:341-351. 
Contreras, J. E., Saez, J. C., Bukauskas, F. F., Bennett, M. V., 2003. Gating and regulation of connexin 43 (Cx43) hemichannels. Proc Natl Acad Sci U S A 100, 11388-11393.

Contreras, J. E., Sanchez, H. A., Eugenin, E. A., Speidel, D., Theis, M., Willecke, K., Bukauskas, F. F., Bennett, M. V., Saez, J. C., 2002. Metabolic inhibition induces opening of unapposed connexin 43 gap junction hemichannels and reduces gap junctional communication in cortical astrocytes in culture. Proc Natl Acad Sci U S A 99, 495-500.

Cotrina, M. L., Lin, J. H., Alves-Rodrigues, A., Liu, S., Li, J., Azmi-Ghadimi, H., Kang, J., Naus, C. C., Nedergaard, M., 1998. Connexins regulate calcium signaling by controlling ATP release. Proc Natl Acad Sci U S A 95, 15735-15740.

Cremer, P. S., Boxer, S. G., 1999. Formation and spreading of lipid bilayers on planar glass supports. J. Phys. Chem. B 103, 2554-2559.

Dahl, G., Werner, R., Levine, E., Rabadan-Diehl, C., 1992. Mutational analysis of gap junction formation. Biophys J 62, 172-180.

Danh, 2006. Prinzip eines konfokalen Punktsensors. http://upload.wikimedia.org/ wikipedia/commons/9/9b/Konfokal_microskop_prinzip.svg

Davidson, J. S., Baumgarten, I. M., 1988. Glycyrrhetinic acid derivatives: a novel class of inhibitors of gap-junctional intercellular communication. Structure-activity relationships. J Pharmacol Exp Ther 246, 1104-1107.

Délèze, J., Hervé, J. C., 1983. Effect of several uncouplers of cell-to-cell communication on gap junction morphology in mammalian heart. J Membr Biol 74, 203-215.

Dertinger, T., von der Hocht, I., Benda, A., Hof, M., Enderlein, J., 2006. Surface sticking and lateral diffusion of lipids in supported bilayers. Langmuir 22, 9339-9344.

Despic, A., Parkhutik, V. P., 1989. Electrochemistry of Aluminium in Aqueous Solutions and Physics of its Anodic Oxide. Modern Aspects of Electrochemistry 20, 401-503. 
D'Hondt, C., Ponsaerts, R., De Smedt, H., Bultynck, G., Himpens, B., 2009. Pannexins, distant relatives of the connexin family with specific cellular functions? Bioessays 31 , 953-974.

Dick, B.; Yersin, H., Skript zum Physikalischen Praktikum II, Versuch2, Absorption und Emission organischer Moleküle - Fluoreszenz, Phosphoreszenz, Energieübertragung. Uni Regensburg.

Díez, J. A., Villalobo, A., 1996. Reconstitution of gap junction channels: Liposomes as tools to assay the activity of channel-forming proteins. Handbook of Nonmedical Applications of Liposomes, eds Barenholz Y \& Lasic DD (CRC Press, Boca Raton, Florida,), Vol 2, pp 261-270.

Diggle, J. W., Downie, T. C., and Goulding, C. W. (1968). Anodic oxide films on aluminium. pp. 365-405: Newcastle upon Tyne.

Doeven, M. K., Folgering, J. H., Krasnikov, V., Geertsma, E. R., van den Bogaart, G., Poolman, B., 2005. Distribution, lateral mobility and function of membrane proteins incorporated into giant unilamellar vesicles. Biophys J 88, 1134-1142.

Düzgünes, N., Nir, S., Wilschut, J., Bentz, J., Newton, C., Portis, A., Papahadjopoulos, D., 1981. Calcium- and magnesium-induced fusion of mixed phosphatidylserine/ phosphatidylcholine vesicles: effect of ion binding. J Membr Biol 59, 115-125.

Ebihara, L., 2003. New roles for connexons. News Physiol Sci 18, 100-103.

Ebihara, L., Berthoud, V. M., Beyer, E. C., 1995. Distinct behavior of connexin56 and connexin46 gap junctional channels can be predicted from the behavior of their hemigap-junctional channels. Biophys J 68, 1796-1803.

Eiberger, J., Degen, J., Romualdi, A., Deutsch, U., Willecke, K., Sohl, G., 2001. Connexin genes in the mouse and human genome. Cell Commun Adhes 8, 163-165. 
Engel, A., Fujiyoshi, Y., Gonen, T., Walz, T., 2008. Junction-forming aquaporins. Curr Opin Struct Biol 18, 229-235.

Esa, A., Edelmann, P., Kreth, G., Trakhtenbrot, L., Amariglio, N., Rechavi, G., Hausmann, M., Cremer, C., 2000. Three-dimensional spectral precision distance microscopy of chromatin nanostructures after triple-colour DNA labelling: a study of the BCR region on chromosome 22 and the Philadelphia chromosome. J Microsc 199, 96-105.

Evans, W. H., Martin, P. E., 2002. Gap junctions: structure and function (Review). Mol Membr Biol 19, 121-136.

ExPASy. http://expasy.org/cgi-bin/protscale.pl

Falk, M. M., Buehler, L. K., Kumar, N. M., Gilula, N. B., 1997. Cell-free synthesis and assembly of connexins into functional gap junction membrane channels. Embo J 16, 2703-2716.

Favero, G., Campanella, L., Cavallo, S., D'Annibale, A., Perrella, M., Mattei, E., Ferri, T., 2005. Glutamate receptor incorporated in a mixed hybrid bilayer lipid membrane array, as a sensing element of a biosensor working under flowing conditions. J Am Chem Soc 127, 8103-8111.

Flegler, S. L., Heckman, J. W., Klomparens K. L., 1995. Elektronenmikroskopie Grundlagen, Methoden, Anwendungen. Spektrum Akademischer Verlag, Heidelberg.

Florin, E. L., Gaub, H. E., 1993. Painted supported lipid membranes. Biophys. J. 64, 375-383.

Forge, A., Becker, D., Casalotti, S., Edwards, J., Marziano, N., Nevill, G., 2003. Gap junctions in the inner ear: comparison of distribution patterns in different vertebrates and assessement of connexin composition in mammals. J Comp Neurol 467, 207-231.

Franklin, R. W., 1957. Structure of Non-Porous Anodic Films on Aluminium. Nature 100, 1566. 
Frese, D., 2009. Rekonstitution von Bacteriorhodopsin in porenüberspannenden Membranen und dessen Einfluss auf die laterale Mobilität der Matrixlipide. Diplomarbeit am Institut für Organische und Biomolekulare Chemie, Universität Göttingen.

Gabriel, O., 2007. Vibronische Übergänge zur Veranschaulichung des Franck-CondonPrinzips. http://de.wikipedia.org/wiki/Datei:Franck-Condon-Prinzip.svg

Gambin, Y., Lopez-Esparza, R., Reffay, M., Sierecki, E., Gov, N. S., Genest, M., Hodges, R. S., Urbach, W., 2006. Lateral mobility of proteins in liquid membranes revisited. Proc Natl Acad Sci U S A 103, 2098-2102.

Gassmann, O., Kreir, M., Ambrosi, C., Pranskevich, J., Oshima, A., Roling, C., Sosinsky, G., Fertig, N., Steinem, C., 2009. The M34A mutant of Connexin26 reveals active conductance states in pore-suspending membranes. J Struct Biol 168, 168-176.

GE Healthcare 2007. Handbook: Gel Filtration/Principles and Methods. 18-1022-18

Girard, P., Pecreaux, J., Lenoir, G., Falson, P., Rigaud, J. L., Bassereau, P., 2004. A new method for the reconstitution of membrane proteins into giant unilamellar vesicles. Biophys J 87, 419-429.

Girsch, S. J., Peracchia, C., 1985. Lens cell-to-cell channel protein: I. Self-assembly into liposomes and permeability regulation by calmodulin. J Membr Biol 83, 217-225.

Goldberg, G. S., Lampe, P. D., Nicholson, B. J., 1999. Selective transfer of endogenous metabolites through gap junctions composed of different connexins. Nat Cell Biol 1, 457-459.

Goldberg, G. S., Moreno, A. P., Lampe, P. D., 2002. Gap junctions between cells expressing connexin 43 or 32 show inverse permselectivity to adenosine and ATP. J Biol Chem $277,36725-36730$. 
Gómez-Hernandez, J. M., de Miguel, M., Larrosa, B., Gonzalez, D., Barrio, L. C., 2003. Molecular basis of calcium regulation in connexin-32 hemichannels. Proc Natl Acad Sci U S A 100, 16030-16035.

Gong, X. Q., Nicholson, B. J., 2001. Size selectivity between gap junction channels composed of different connexins. Cell Commun Adhes 8, 187-192.

Gonzalez, D., Gomez-Hernandez, J. M., Barrio, L. C., 2006. Species specificity of mammalian connexin-26 to form open voltage-gated hemichannels. Faseb J 20, 23292338.

Gooden, M., Rintoul, D., Takehana, M., Takemoto, L., 1985. Major intrinsic polypeptide (MIP26K) from lens membrane: reconstitution into vesicles and inhibition of channel forming activity by peptide antiserum. Biochem Biophys Res Commun 128, 993-999.

Goodenough, D. A., Paul, D. L., 2003. Beyond the gap: functions of unpaired connexon channels. Nat Rev Mol Cell Biol 4, 285-294.

Gower, C. H. R., Stafford, O. \& Partners Ltd, 1927. Electrolyte Containing Sulphuric Acid. Britisches Patent Nr. 290901.

Hamai, C., Cremer, P. S., Musser, S. M., 2007. Single giant vesicle rupture events reveal multiple mechanisms of glass-supported bilayer formation. Biophys J 92, 1988-1999.

Harris, A. L., 2001. Emerging issues of connexin channels: biophysics fills the gap. Q Rev Biophys 34, 325-472.

Harris, A. L., Spray, D. C., Bennett, M. V., 1981. Kinetic properties of a voltage-dependent junctional conductance. J Gen Physiol 77, 95-117.

Hassel, A. W., Lohrengel, M. M., Rüße, S., Schulze J. W., 1994. On The Mechanism of Ion Transport in Thin (1-100 Nm) Oxide Films on Aluminium and Tantalum Bulletin of the Chemists and Technologists of Macedonia 13, 49-54. 
Herrig, A., Janke, M., Austermann, J., Gerke, V., Janshoff, A., Steinem, C., 2006. Cooperative adsorption of ezrin on PIP2-containing membranes. Biochemistry 45, 13025-13034.

Hesse, M.; Meier, H.; Zeeh, B., Spektroskopische Methoden in der organischen Chemie. Georg Thieme Verlag: Stuttgart, 1995.

Heyse, S., Ernst, O. P., Dienes, Z., Hofmann, K. P., Vogel, H., 1998. Incorporation of rhodopsin in laterally structured supported membranes: observation of transducin activation with spatially and time-resolved surface plasmon resonance. Biochemistry $37,507-522$.

Hollemann Wiberg Lehrbuch der Anorganischen Chemie 102, 2007.

Horn, C., 2005. Aktivität lichtaktivierter Proteine adsorbiert an funktionalisierten nanoporösen Aluminaten. Dissertation zur Erlangung des Doktorgrades der Naturwissenschaften (Dr. rer. nat.) der Naturwissenschaftlichen Fakultät IV - Chemie und Pharmazie -der Universität Regensburg.

Huang, Y., Grinspan, J. B., Abrams, C. K., Scherer, S. S., 2007. Pannexin1 is expressed by neurons and glia but does not form functional gap junctions. Glia 55, 46-56.

Hudson, P. J., Souriau, C., 2003. Engineered antibodies. Nat Med 9, 129-134.

Jass, J., Tjarnhage, T., Puu, G., 2000. From Liposomes to Supported, Planar Bilayer Structures on Hydrophilic and Hydrophobic Surfaces: An Atomic Force Microscopy Study. Biophys. J. 79, 3153-63.

Jenkins, A. T. A., Bushby, R. J., Evans, S. D., Knoll, W., Offenhäusser, A., Ogiier, S. D., 2002. Lipid Vesicle fusion on $\mu$ CP Patterned Self-Assembled Monolayers: Effect of Pattern Geometry on Bilayer Formation. Langmuir18, 3176-3180.

Jentsch, T. J., 2000. Neuronal KCNQ potassium channels: physiology and role in disease. Nat Rev Neurosci 1, 21-30. 
Jessensky, O., 1997. Untersuchungen zum Porenwachstum in 6H-Siliziumkarbid und anodischem Aluminiumoxid. Dissertation an der Martin-Luther-Universität HalleWittenberg.

Jessensky, O., Müller, F., Gösele, U., 1998. Self-organized formation of hexagonal pore structures in anodic alumina. J. Electrochem. Soc. 145, 3735-3740.

Jovic, V. D., 2003. Determination of the correct value of Cdl from the impedance results fitted by the commercially available software. Research Solutions and Resources.

Kaneda, M., Nomura, S. M., Ichinose, S., Kondo, S., Nakahama, K., Akiyoshi, K., Morita, I., 2009. Direct formation of proteo-liposomes by in vitro synthesis and cellular cytosolic delivery with connexin-expressing liposomes. Biomaterials 30, 3971-3977.

Keller, C. A., Glasmästar, K., Zhdanov, V. P., Kasemo, B., 2000. Formation of supported membranes from vesicles. Phys. Rev. Lett. 84, 5443-5446.

Keller, F. Hunter, M. S., Robinson, D. L., 1953. Structural Features of Oxide Coatings On Aluminium. Journal of the Electrochemical Society 100, 411-419.

Kelsell, D. P., Di, W. L., Houseman, M. J., 2001. Connexin mutations in skin disease and hearing loss. Am J Hum Genet 68, 559-568.

Kelsell, D. P., Dunlop, J., Stevens, H. P., Lench, N. J., Liang, J. N., Parry, G., Mueller, R. F., Leigh, I. M., 1997. Connexin 26 mutations in hereditary non-syndromic sensorineural deafness. Nature 387, 80-83.

Kikuchi, T., Kimura, R. S., Paul, D. L., Adams, J. C., 1995. Gap junctions in the rat cochlea: immunohistochemical and ultrastructural analysis. Anat Embryol (Berl) 191, 101-118.

Knol, J., Sjollema, K., Poolman, B., 1998. Detergent-mediated reconstitution of membrane proteins. Biochemistry 37, 16410-16415. 
Kojima, T., Srinivas, M., Fort, A., Hopperstad, M., Urban, M., Hertzberg, E. L., Mochizuki, Y., Spray, D. C., 1999. TPA induced expression and function of human connexin 26 by post-translational mechanisms in stably transfected neuroblastoma cells. Cell Struct Funct 24, 435-441.

Kondo, R. P., Wang, S. Y., John, S. A., Weiss, J. N., Goldhaber, J. I., 2000. Metabolic inhibition activates a non-selective current through connexin hemichannels in isolated ventricular myocytes. J Mol Cell Cardiol 32, 1859-1872.

Köper, I., Schiller, S. M., Giess, F., Naumann, R., Knoll, W., 2006. Functional tethered biomolecular lipid membranes (tBLMs). Advances in Planar Lipid Bilayers and Liposomes 3, 37-53.

Korlach, J., Schwille, P., Webb, W. W., Feigenson, G. W., 1999. Characterization of lipid bilayer phases by confocal microscopy and fluorescence correlation spectroscopy. Proc Natl Acad Sci U S A 96, 8461-8466.

Kozlov, M. M., Markin, V. S., 1983. [Possible mechanism of membrane fusion]. Biofizika 28, 242-247.

Kreir, M., Farre, C., Beckler, M., George, M., Fertig, N., 2008. Rapid screening of membrane protein activity: electrophysiological analysis of $\mathrm{OmpF}$ reconstituted in proteoliposomes. Lab Chip 8, 587-595.

Kreir, M., Methfessel, C., Habig, M., Carnarius, C., Steinem, C., Fertig, N., 2010. Bridging the gap between artificial bilayers and cell membranes: electrical access for patch clamp recordings via gap junction formation. Unveröffentlichte Ergebnisse.

Krishna, G., Schulte, J., Cornell, B. A., Pace, R. J., Osman, P. D., 2001. Thethered Bilayer Membranes Containing Ionic Reservoirs: The Interfacial Capacitance. Langmuir 17, 4858-66.

Krumreich, F., Properties of Electrons, their Interactions with Matter and Applications in Electron Microscopy: www.microscopy.ethz.ch. 
Kumar, N. M., Gilula, N. B., 1996. The gap junction communication channel. Cell 84, 381388.

Kwak, B. R., Hermans, M. M., De Jonge, H. R., Lohmann, S. M., Jongsma, H. J., Chanson, M., 1995. Differential regulation of distinct types of gap junction channels by similar phosphorylating conditions. Mol Biol Cell 6, 1707-1719.

Ladha, S., Mackie, A. R., Harvey, L. J., Clark, D. C., Lea, E. J., Brullemans, M., Duclohier, H., 1996. Lateral diffusion in planar lipid bilayers: a fluorescence recovery after photobleaching investigation of its modulation by lipid composition, cholesterol, or alamethicin content and divalent cations. Biophys J 71, 1364-1373.

Lagostena, L., Cicuttin, A., Inda, J., Kachar, B., Mammano, F., 2001. Frequency dependence of electrical coupling in Deiters' cells of the guinea pig cochlea. Cell Commun Adhes 8, 393-399.

Laird, D. W., 2006. Life cycle of connexins in health and disease. Biochem J 394, 527-543.

Lang, H., Duchl, C., Vogel, H., 1994. A New Class of Thiolipids for the Attachmentof Lipid Bilayers on Gold Surfaces. Langmuir 10, 197-210.

Langmuir, I., Schäfer, V., 1938. Activities of urease and pepsin monolayers. J. Am. Chem. Soc. $60,1351-1360$.

Lautermann, J., Frank, H. G., Jahnke, K., Traub, O., Winterhager, E., 1999. Developmental expression patterns of connexin26 and -30 in the rat cochlea. Dev Genet 25, 306-311.

Lavado, E., Sanchez-Abarca, L. I., Tabernero, A., Bolanos, J. P., Medina, J. M., 1997. Oleic acid inhibits gap junction permeability and increases glucose uptake in cultured rat astrocytes. J Neurochem 69, 721-728.

Lehninger, A. L., Nelson, D. L., Cox, M. M., 2009. Lehninger Biochemie. 3., vollständig überarbeitete und erweiterte Auflage. Springer-Verlag, Berlin. 
Li, A. P., Müller, F., Birner, A., Nielsch, K., and Gösele, U., 1999. Polycrystalline nanopore arrays with hexagonal ordering on aluminium. J. Vac. Sci. Technol. A 17, 1428-1431.

Li, A. P., Müller, F., Birner, A., Nielsch, K., Gösele, U., 1998. Hexagonal pore arrays with a 50-420 nm interpore distance formed by self-organization in anodic alumina. J. Appl. Physics 84, 6023-6026.

Li, A. P., Müller, F., Birner, A., Nielsch, K., Gösele, U., 1999. Fabrication and microstructuring of hexagonally ordered two-dimensional nanopore arrays in anodic alumina. Adv. Mater. 11, 483-487.

Locke, D., Koreen, I. V., Liu, J. Y., Harris, A. L., 2004. Reversible pore block of connexin channels by cyclodextrins. J Biol Chem 279, 22883-22892.

Locovei, S., Bao, L., Dahl, G., 2006. Pannexin 1 in erythrocytes: function without a gap. Proc Natl Acad Sci U S A 103, 7655-7659.

Lopez, A., Dupou, L., Altibelli, A., Trotard, J., Tocanne, J. F., 1988. Fluorescence recovery after photobleaching (FRAP) experiments under conditions of uniform disk illumination. Critical comparison of analytical solutions, and a new mathematical method for calculation of diffusion coefficient D. Biophys J 53, 963-970.

MacDonald, R. C. et al., Small-Volume Extrusion Apparatus for Preparation of Large, Unlilamellar Vesikels. Biochim. Biophys. Acta 1991, 1061, 297-303.

Maeda, S., Nakagawa, S., Suga, M., Yamashita, E., Oshima, A., Fujiyoshi, Y., Tsukihara, T., 2009. Structure of the connexin 26 gap junction channel at 3.5 A resolution. Nature 458, 597-602.

Mally, M., Majhenc, J., Svetina, S., Zeks, B., 2007. The response of giant phospholipid vesicles to pore-forming peptide melittin. Biochim Biophys Acta 1768, 1179-1189.

Masuda, H., Fukuda, K., 1998. Ordered metal nanohole arrays made by a two-step replication of honeycomb structures of anodic alumina. Science 268, 1466-1468. 
Mese, G., Valiunas, V., Brink, P. R., White, T. W., 2008. Connexin26 deafness associated mutations show altered permeability to large cationic molecules. Am J Physiol Cell Physiol 295, C966-974.

Mey, I., Stephan, M., Schmitt, E. K., Muller, M. M., Ben Amar, M., Steinem, C., Janshoff, A., 2009. Local membrane mechanics of pore-spanning bilayers. J Am Chem Soc 131, 7031-7039.

Meyer, F., 2008. Methoden der Chemie III. Göttingen.

Montal, M., Mueller, P., 1972. Formation of bimolecular membranes from lipid monolayers and a study of their electrical properties. Proc. Natl. Acad. Sci. U. S. A. 69, 35613566.

Moreno, A. P., Chanson, M., Elenes, S., Anumonwo, J., Scerri, I., Gu, H., Taffet, S. M., Delmar, M., 2002. Role of the carboxyl terminal of connexin43 in transjunctional fast voltage gating. Circ Res 90, 450-457.

Mühlpfordt, H., 2006. Schema eines Fluoreszenzmikroskops. http://upload.wikimedia.org/ wikipedia/commons/d/d4/FluorescenceFilters.svg

Müller, D. J., Hand, G. M., Engel, A., Sosinsky, G. E., 2002. Conformational changes in surface structures of isolated connexin 26 gap junctions. Embo J 21, 3598-3607.

Müller, P., Rudin, H. T., Tien, H. T., Wescott, W. C., 1963. Methods for the formation of single bimolecular lipid membranes in aqueous solution. J. Phys. Chem. 67, 534-535.

Musa, H., Fenn, E., Crye, M., Gemel, J., Beyer, E. C., Veenstra, R. D., 2004. Amino terminal glutamate residues confer spermine sensitivity and affect voltage gating and channel conductance of rat connexin40 gap junctions. J Physiol 557, 863-878.

Musil, L. S., Goodenough, D. A., 1991. Biochemical analysis of connexin43 intracellular transport, phosphorylation, and assembly into gap junctional plaques. J Cell Biol 115, $1357-1374$. 
Neufeld, P., Southall, D., 1975. Electrodep. and Surf. Treatment 3, 159.

Nielsch, K., 2002. Hochgeordnete ferromagnetische nano-Stabensembles, Elektrochemische Herstellung und magnetische Charakterisierung. Dissertation zur Erlangung des akademischen Grades doctor rerum naturalium (Dr. rer. nat.) vorgelegt der Mathematisch-Naturwissenschaftlich-Technischen Fakultät (mathematischnaturwissenschaftlicher Bereich) der Martin-Luther-Universität Halle-Wittenberg.

Nitsche, J. M., Chang, H. C., Weber, P. A., Nicholson, B. J., 2004. A transient diffusion model yields unitary gap junctional permeabilities from images of cell-to-cell fluorescent dye transfer between Xenopus oocytes. Biophys J 86, 2058-2077.

O'Sullivan, T., Wood, G. C., 1970. The Morphology and The Mechanism of Formation of Porous Anodic Films on Aluminium. Proceedings of the Royal Scientific Society A 317, 511-543.

Oh, S., Abrams, C. K., Verselis, V. K., Bargiello, T. A., 2000. Stoichiometry of transjunctional voltage-gating polarity reversal by a negative charge substitution in the amino terminus of a connexin32 chimera. J Gen Physiol 116, 13-31.

Oh, S., Rubin, J. B., Bennett, M. V., Verselis, V. K., Bargiello, T. A., 1999. Molecular determinants of electrical rectification of single channel conductance in gap junctions formed by connexins 26 and 32. J Gen Physiol 114, 339-364.

Oshima, A., Tani, K., Hiroaki, Y., Fujiyoshi, Y., Sosinsky, G. E., 2007. Three-dimensional structure of a human connexin26 gap junction channel reveals a plug in the vestibule. Proc Natl Acad Sci U S A 104, 10034-10039.

Oshima, A., Tani, K., Hiroaki, Y., Fujiyoshi, Y., Sosinsky, G. E., 2008. Projection structure of a N-terminal deletion mutant of connexin 26 channel with decreased central pore density. Cell Commun Adhes 15, 85-93.

Panchin, Y., Kelmanson, I., Matz, M., Lukyanov, K., Usman, N., Lukyanov, S., 2000. A ubiquitous family of putative gap junction molecules. Curr Biol 10, R473-474. 
Parkhutik, V. P., Shershulsky, V. I., 1992. Theoretical Modelling of Porous Oxide Growth on Aluminium. Journal of Applied Physics 25, 1258.

Paul, D. L., Ebihara, L., Takemoto, L. J., Swenson, K. I., Goodenough, D. A., 1991. Connexin46, a novel lens gap junction protein, induces voltage-gated currents in nonjunctional plasma membrane of Xenopus oocytes. J Cell Biol 115, 1077-1089.

Penuela, S., Bhalla, R., Nag, K., Laird, D. W., 2009. Glycosylation regulates pannexin intermixing and cellular localization. Mol Biol Cell 20, 4313-4323.

Perkins, G., Goodenough, D., Sosinsky, G., 1997. Three-dimensional structure of the gap junction connexon. Biophys J 72, 533-544.

Pfahnl, A., Dahl, G., 1998. Localization of a voltage gate in connexin46 gap junction hemichannels. Biophys J 75, 2323-2331.

Pfahnl, A., Dahl, G., 1999. Gating of cx46 gap junction hemichannels by calcium and voltage. Pflugers Arch 437, 345-353.

Pilz, C., 2007. Modulation der Helix-Bündel-Bildung eines Bipyridin-funktionalisierten peptidischen Ionenkanals durch Komplexierung von Ni(II). Dissertation zur Erlangung des Doktorgrades der Naturwissenschaften (Dr. rer. nat.) der Naturwissenschaftlichen Fakultät IV - Chemie und Pharmazie - der Universität Regensburg.

Plant, A. L., 1993. Self-assembled phospholipid/alkanethiol biomimetic bilayers on gold. Langmuir 9, 2764-2767.

Purnick, P. E., Benjamin, D. C., Verselis, V. K., Bargiello, T. A., Dowd, T. L., 2000. Structure of the amino terminus of a gap junction protein. Arch Biochem Biophys 381, 181-190. 
PyMOL. Freies 3D-Grafikprogramm zur Darstellung von Biomolekülen. DeLano, D. W., ThePyMOLMolecularGraphicsSystem, 2002. (www.pymol.org). Datei zur Darstellung des Cx26 Halbkanals: PDB2zw3.

Qu, Y., Dahl, G., 2004. Accessibility of cx46 hemichannels for uncharged molecules and its modulation by voltage. Biophys J 86, 1502-1509.

Raguse, B., Braach-Maksvytis, V., Cornell, B. A., King, L. G., Osman, P. D. J. Ron, J., 1998. Tethered Lipid Bilayer Membranes: Formation and Ionic Reservoir Characterization. Langmuir 14, 648-59.

Ramundo-Orlando, A., Serafino, A., Schiavo, R., Liberti, M., d'Inzeo, G., 2005. Permeability changes of connexin32 hemi channels reconstituted in liposomes induced by extremely low frequency, low amplitude magnetic fields. Biochim Biophys Acta $1668,33-40$.

Reimer, L., Pfefferkorn, G., 1999. Raster - Elektronenmikroskopie. 2. erw. Aufl., Springer Verlag, Berlin.

Reits, E. A., Neefjes, J. J., 2001. From fixed to FRAP: measuring protein mobility and activity in living cells. Nat Cell Biol 3, E145-147.

Revilla, A., Castro, C., Barrio, L. C., 1999. Molecular dissection of transjunctional voltage dependence in the connexin-32 and connexin-43 junctions. Biophys J 77, 1374-1383.

Rhee, S. K., Bevans, C. G., Harris, A. L., 1996. Channel-forming activity of immunoaffinitypurified connexin32 in single phospholipid membranes. Biochemistry 35, 9212-9223.

Riedel, E., Janiak, C., 2007. Anorganische Chemie. 5. Auflage, Gruyter-Verlag, Berlin.

Rigaud, J. L., Mosser, G., Lacapere, J. J., Olofsson, A., Levy, D., Ranck, J. L., 1997. BioBeads: an efficient strategy for two-dimensional crystallization of membrane proteins. J Struct Biol 118, 226-235. 
Rigaud, J. L., Pitard, B., Levy, D., 1995. Reconstitution of membrane proteins into liposomes: application to energy-transducing membrane proteins. Biochim Biophys Acta 1231, 223-246.

Ritchie, G., Burstein, E., 1981. Luminescence of dye molecules adsorbedat a Ag surface. Phys. Rev. B 24, 4843-4846.

Ripps, H., Qian, H., Zakevicius, J., 2004. Properties of connexin26 hemichannels expressed in Xenopus oocytes. Cell Mol Neurobiol 24, 647-665.

Roberts, G.G., 1990. Langmuir-Blodgett-films. Plenum Press, New York.

Roderfeld, M., Matern, S., Roeb, E., 2003. [Confocal laser scanning microscopy: a deep look into the cell]. Dtsch Med Wochenschr 128, 2539-2542.

Römer, W., Steinem, C., 2004. Impedance analysis and single-channel recordings on nanoblack lipid membranes based on porous alumina. Biophys J 86, 955-965.

Saez, J. C., Retamal, M. A., Basilio, D., Bukauskas, F. F., Bennett, M. V., 2005. Connexinbased gap junction hemichannels: gating mechanisms. Biochim Biophys Acta 1711, 215-224.

Schmitt, E. K., Nurnabi, M., Bushby, R. J., Steinem, C., 2008. Electrically insulating poresuspending membranes on highly ordered porous alumina obtained from vesicle spreading. Soft Matter 4, 250-253.

Schmitt, E. K., Weichbrodt, C., Steinem, C., 2009. Impedance analysis of gramicidin D in pore-suspending membranes. Soft Matter 5, 3347-3353.

SDU (University of Southern Denmark): http://scienceinyoureyes.memphys.sdu.dk/ SEM_en.gif

Sharma, A., Anderson, K., Baker, J. W., 1990. Flocculation of serum lipoproteins with cyclodextrins: application to assay of hyperlipidemic serum. Clin Chem 36, 529-532. 
Sigworth, F. J., Sine, S. M., 1987. Data transformations for improved display and fitting of single-channel dwell time histograms. Biophys J 52, 1047-1054.

Söhl, G., Willecke, K., 2004. Gap junctions and the connexin protein family. Cardiovasc Res $62,228-232$.

Sonnleitner, A., Schutz, G. J., Schmidt, T., 1999. Free brownian motion of individual lipid molecules in biomembranes. Biophys J 77, 2638-2642.

Sosinsky, G. E., 2008. Persönliche Korrespondenz mit Gina E. Sosinsky bzgl. der Funktionalität von Pannexin2.

Spinke, J., Yang, J., Wolf, H., Liley, M., Knoll, W., 1992. Polymer-supported bilayer on a solid substrate. Biophys J 63, 1667-1671.

Spray, D. C., Burt, J. M., 1990. Structure-activity relations of the cardiac gap junction channel. Am J Physiol 258, C195-205.

Steinem, C., Janshoff, A., 2008. Modellmambranen auf Oberflächen. Chem. Unserer Zeit 42, 116-117.

Steinem, C., Janshoff, A., Ulrich, W. P., Sieber, M., Galla, H. J., 1996. Impedance analysis of supported lipid bilayer membranes: a scrutiny of different preparation techniques. Biochim Biophys Acta 1279, 169-180.

Steinem, C., Spektroskopische Methoden der Bioanalytik / Biochemie, Skript zur Vorlesung an der Uni Regensburg.

Stout, C. E., Costantin, J. L., Naus, C. C., Charles, A. C., 2002. Intercellular calcium signaling in astrocytes via ATP release through connexin hemichannels. J Biol Chem 277, 10482-10488. 
Suchyna, T. M., Nitsche, J. M., Chilton, M., Harris, A. L., Veenstra, R. D., Nicholson, B. J., 1999. Different ionic selectivities for connexins 26 and 32 produce rectifying gap junction channels. Biophys J 77, 2968-2987.

Suchyna, T. M., Xu, L. X., Gao, F., Fourtner, C. R., Nicholson, B. J., 1993. Identification of a proline residue as a transduction element involved in voltage gating of gap junctions. Nature 365, 847-849.

Szilluweit, R., Boll, A., Lukowski, S., Gerlach, H., Fackler, O. T., Geyer, M., Steinem, C., 2009. HIV-1 Nef perturbs artificial membranes: investigation of the contribution of the myristoyl anchor. Biophys J 96, 3242-3250.

Takens-Kwak, B. R., Jongsma, H. J., Rook, M. B., Van Ginneken, A. C., 1992. Mechanism of heptanol-induced uncoupling of cardiac gap junctions: a perforated patch-clamp study. Am J Physiol 262, C1531-1538.

Tanaka, M., Sackmann, E., 2005. Polymer-supported membranes as models of the cell surface. Nature 437, 656-663.

Tao, L., Harris, A. L., 2004. Biochemical requirements for inhibition of Connexin26containing channels by natural and synthetic taurine analogs. J Biol Chem 279, 3854438554.

Thompson, G. E., Xu, Y., Skeldon, P., Shimizu, K., Han, S. H., Wood, G. C., 1987. Anodic Oxidation of Aluminium. Philosophical Magazine 55, 651.

Trexler, E. B., Bukauskas, F. F., Bennett, M. V., Bargiello, T. A., Verselis, V. K., 1999. Rapid and direct effects of $\mathrm{pH}$ on connexins revealed by the connexin 46 hemichannel preparation. J Gen Physiol 113, 721-742.

Trexler, E. B., Bukauskas, F. F., Kronengold, J., Bargiello, T. A., Verselis, V. K., 2000. The first extracellular loop domain is a major determinant of charge selectivity in connexin46 channels. Biophys J 79, 3036-3051. 
Ulman, A. 1996. Formation and structure of self-assembled monolayers. Chem. Rev. 96, 1533-1554.

Ulrich, A. S., 2002. Biophysical aspects of using liposomes as delivery vehicles. Biosci Rep 22, 129-150.

Unger, V. M., Kumar, N. M., Gilula, N. B., Yeager, M., 1999. Three-dimensional structure of a recombinant gap junction membrane channel. Science 283, 1176-1180.

Unwin, P. N., Ennis, P. D., 1984. Two configurations of a channel-forming membrane protein. Nature 307, 609-613.

Unwin, P. N., Zampighi, G., 1980. Structure of the junction between communicating cells. Nature 283, 545-549.

VanSlyke, J. K., Deschenes, S. M., Musil, L. S., 2000. Intracellular transport, assembly, and degradation of wild-type and disease-linked mutant gap junction proteins. Mol Biol Cell 11, 1933-1946.

Varnier, A., Kermarrec, F., Blesneac, I., Moreau, C., Liguori, L., Lenormand, J. L., PicolletD'hahan, N., 2010. A Simple Method for the Reconstitution of Membrane Proteins into Giant Unilamellar Vesicles. J Membr Biol. 233, 85-92.

Veenstra, R. D., 1996. Size and selectivity of gap junction channels formed from different connexins. J Bioenerg Biomembr 28, 327-337.

Veenstra, R. D., Wang, H. Z., Beblo, D. A., Chilton, M. G., Harris, A. L., Beyer, E. C., Brink, P. R., 1995. Selectivity of connexin-specific gap junctions does not correlate with channel conductance. Circ Res 77, 1156-1165.

Verselis, V. K., Ginter, C. S., Bargiello, T. A., 1994. Opposite voltage gating polarities of two closely related connexins. Nature $368,348-351$. 
Verselis, V. K., Trexler, E. B., Bukauskas, F. F., 2000. Connexin hemichannels and cell-cell channels: comparison of properties. Braz J Med Biol Res 33, 379-389.

Walter, P. L., 2004. Shock and Blast Measurement - Rise Time Capability of Measurement Systems? Technical Note TN-11, PBC Piezotronics Inc.

Wang, H. L., Chang, W. T., Li, A. H., Yeh, T. H., Wu, C. Y., Chen, M. S., Huang, P. C., 2003. Functional analysis of connexin-26 mutants associated with hereditary recessive deafness. J Neurochem 84, 735-742.

Weber, P. A., Chang, H. C., Spaeth, K. E., Nitsche, J. M., Nicholson, B. J., 2004. The permeability of gap junction channels to probes of different size is dependent on connexin composition and permeant-pore affinities. Biophys J 87, 958-973.

Weiskopf, D., Schmitt, E. K., Kluhr, M. H., Dertinger, S. K., Steinem, C., 2007. Micro-BLMs on highly ordered porous silicon substrates: rupture process and lateral mobility. Langmuir 23, 9134-9139.

Weiskopf, D. V., 2009. Stabilität und laterale Mobilität von porenüberspannenden Membranen auf porösen Siliziumsubstraten. Dissertation zur Erlangung des Doktorgrades der Mathematisch-Naturwissenschaftlichen Fakultäten der GeorgAugust-Universität zu Göttingen.

White, T. W., Srinivas, M., Ripps, H., Trovato-Salinaro, A., Condorelli, D. F., Bruzzone, R., 2002. Virtual cloning, functional expression, and gating analysis of human connexin31.9. Am J Physiol Cell Physiol 283, C960-970.

Williams, L. M., Evans, S. D., Flynn, T. M.,Marsh, A., Knowles, P. F., Bushby, R. J., Boden, N., 1997. Kinetics of the unrolling of small unilamellar phospholipid vesicles onto a self-assembled monolayer. Langmuir 13, 751-757.

Windschiegl, B., Orth, A., Römer, W., Berland, L., Stechmann, B., Bassereau, P., Johannes, L., Steinem, C., 2009. Lipid reorganization induced by Shiga toxin clustering on planar membranes. PLoS One 4, e6238. 
Ye, Z. C., Wyeth, M. S., Baltan-Tekkok, S., Ransom, B. R., 2003. Functional hemichannels in astrocytes: a novel mechanism of glutamate release. J Neurosci 23, 3588-3596.

Yu, J., Bippes, C. A., Hand, G. M., Muller, D. J., Sosinsky, G. E., 2007. Aminosulfonate modulated $\mathrm{pH}$-induced conformational changes in connexin26 hemichannels. J Biol Chem 282, 8895-8904.

Zaidan, Hojin, Rikagaku, Kenkyujo, 1924. Process of Electrolytically Depositing an Insulating Coating or Skin Using Aqueous Solution of Oxalic Acid and Oxalates. Britisches Patent Nr. 226536.

Zhang, Y., Tang, W., Ahmad, S., Sipp, J. A., Chen, P., Lin, X., 2005. Gap junction-mediated intercellular biochemical coupling in cochlear supporting cells is required for normal cochlear functions. Proc Natl Acad Sci U S A 102, 15201-15206. 


\section{$9 \quad$ Anhang}

\subsection{Abkürzungsverzeichnis}

A/D

AFM

BLM

BSE

CD

$\mathrm{CF}$

CL

CLSM

$\mathrm{CMC}$

CPE

CT

$\mathrm{Cx}$

DAPI

DC

DHPE

DMPE

$\mathrm{DPhPC}$

DNA

DoDM

DOPC

$\mathrm{DPhPC}$

$\mathrm{E}$

EDTA

EGTE

EZM

FITC

FRAP

GFP

GJ

GUV
Analog/Digital

Raszerkraftmikroskopie (atomic force microscope)

schwarze Membran (black lipid membrane)

Rückstreuelektronen (backscattered electrons)

Cyclodextrin

Carboxyfluoreszein

Cytoplasmatischer Loop

Konfokales Laserrastermikroskop (confocal laser scanning microscope)

kritische mizellare Konzentration (critical micellar concentration)

constant phase element

C-terminale Domäne

Connexin

4',6-Diamidin-2-phenylindol

Gleichstrom (direct current)

1,2-Dihexadecanoyl-sn-Glycero-3-Phosphoethanolamin

1,2-Dihexadecanoyl-sn-Glycero-3-Phosphoethanolamin

1,2-Diphytanoyl-sn-glycero-3-phospholcholin

Desoxiribonukleinsäure (desoxyribonucleic acide)

Dodecylmaltosid

1,2-Dioleoyl-sn-Glycero-3-Phosphocholin

1,2-Diphytanoyl-sn-Glycero-3-Phosphocholin

extrezelluläre Domäne

Ethylendiamintetraacetat

Ethylenglykol-bis(aminoethylether)-N,N'-tetraessigsäure

Extrazellularmatrix

Fluoresceinisothiocyanat

fluorescence recovery after photobleaching

grün fluoreszierendes Protein (green fluorescent protein)

Gap Junction

riesige unilamellare Vesikel (giant unilamellar vesicles) 


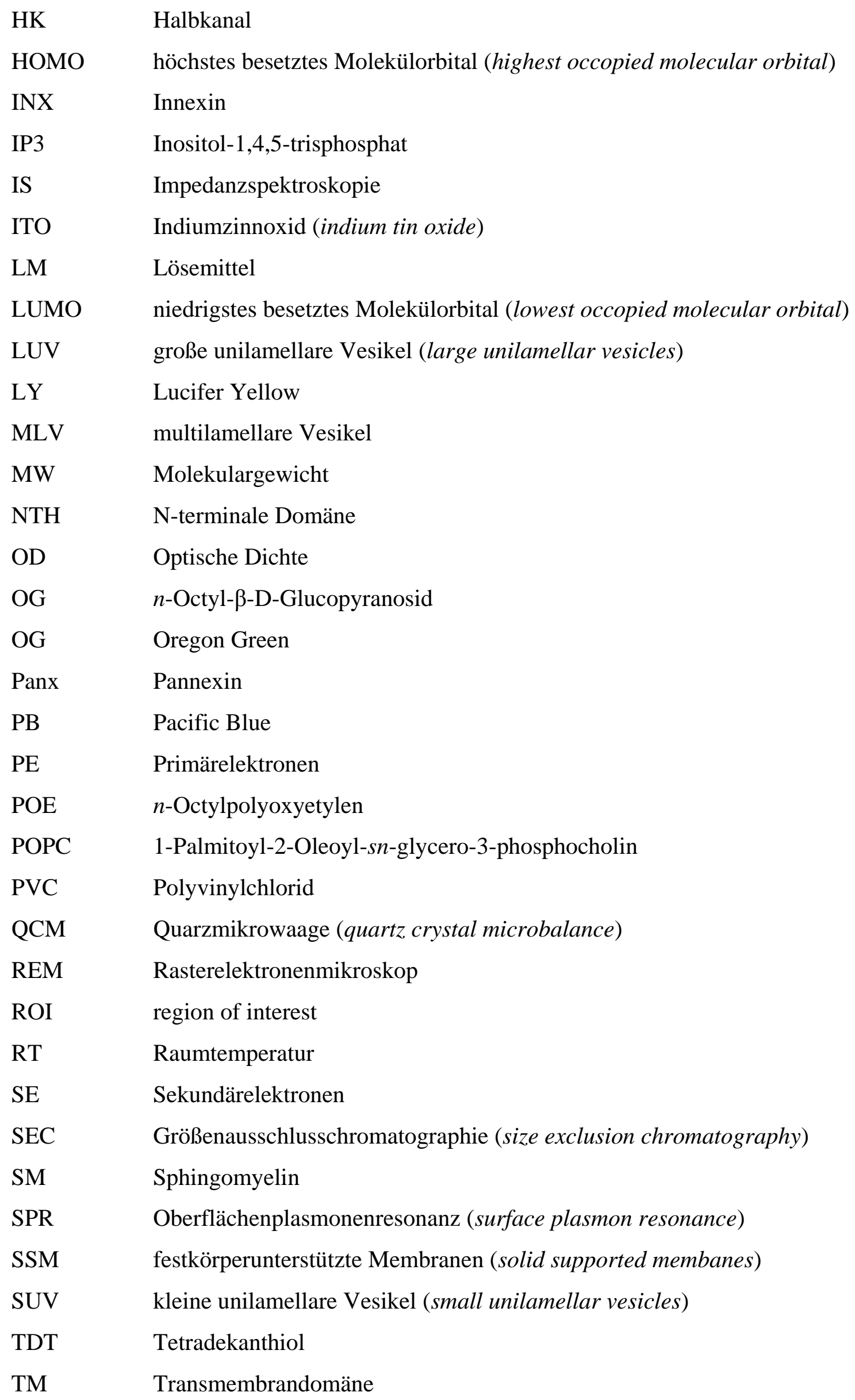


TR

Texas Red

TSF Transportspezifische Fraktionierung

UCSD University of California, San Diego

UV Ultraviolett

VIS sichtbar (visible)

WT Wildtyp

WW Wechselwirkung

\subsection{Symbolverzeichnis}

A

C

$c$

$d$

E

$f$

G

$h$

$I$

$I C_{50}$

$m$

$n$

$p$

$R$

$U$

Z

$\varepsilon$

$\lambda$

$\tau$

$\varphi$

$\omega$
Amplitude / CPE-Parameter

Kapazität

Lichtgeschwindigkeit / Konzentration

Durchmesser

Energie / Extinktion

Frequenz

Leitfähigkeit

Planksches Wirkungsquantum

Stromstärke / Intensität

Hill Parameter

Steigung

Ordnungszahl

Öffnungswahrscheinlichkeit

Widerstand

Spannung

Impedanz

Absorptionskoeffizient

Wellenlänge

mittlere Öffnungsdauer

Phasenverschiebung zwischen Strom und Spannung

Kreisfrequenz 


\subsection{Chemikalien}

5(6)-Carboxyfluorescien

Calciumchlorid Dihydrat

Carbenoxolone Natriumsalz

Chrom-(VI)-Oxid

DOPC

$\mathrm{DPhPC}$

EDTA

EGTA

Ethanol

HEPES

Kaliumchlorid

MOPS

Natriumascorbat

Natriumchlorid

n-Dekan

n-Oktan

OG-DHPE

ortho-Phosphorsäure

Oxalsäure-Dihydrat

PB-DMPE

POE

POPC

Quecksilber(II)-Chlorid

Schwefelsäure, 95-97 \%

TR-DHPE

TRIS

Triton-X 100

$\alpha$-Cyclodextrin
Sigma-Aldrich (Taufkirchen)

Merck (Darmstadt)

Sigma-Aldrich (Taufkirchen)

Merck (Darmstadt)

Avanti Polar Lipids (Alabaster, USA)

Avanti Polar Lipids (Alabaster, USA)

Sigma-Aldrich (Taufkirchen)

Carl Roth GmbH (Karlsruhe)

Merck (Darmstadt)

Carl Roth GmbH (Karlsruhe)

Merck (Darmstadt)

Carl Roth GmbH (Karlsruhe)

Sigma-Aldrich (Taufkirchen)

Merck (Darmstadt)

Sigma-Aldrich (Taufkirchen)

Sigma-Aldrich (Taufkirchen)

Invitrogen (Eugen, USA)

Merck (Darmstadt)

Applichem (Darmstadt)

Invitrogen (Eugen, USA)

Bachem (Bubendorf)

Avanti Polar Lipids (Alabaster, USA)

Merck (Darmstadt)

Merck (Darmstadt)

Sigma-Aldrich (Taufkirchen)

Carl Roth GmbH (Karlsruhe)

Merck (Darmstadt)

Sigma-Aldrich (Taufkirchen) 


\subsection{Materialien}

Aluminium (99.999 \%)

Goodfellow (Huntington, UK)

Braungläschen

OCHS GmbH (Göttingen)

Eppendorf-Cups

Eppendorf (Hamburg)

Eppendorfpipetten

Eppendorf (Hamburg)

Gold-Target

Elektronen Optik Service GmbH (Dortmund)

Hämatokritmasse

Brand GmbH (Wertheim)

ITO-Gläser

Präzisions Glas \& Optik GmbH (Iserlohn)

Kalrez ${ }^{\circledR}$ O-Ringe

Dupont Dow Elast (Newark, USA)

Klemmen

ALCO (Arnsberg)

Kupferband

Präzisions Glas \& Optik GmbH (Iserlohn)

Parafilm

Pechiney Plastik Packaging (Chicago, USA)

Petrischalen

Sarstedt (Nümbrecht)

Pipettenspitzen

Eppendorf (Hamburg)

Platindraht

Goodfellow (Huntington, UK)

$1.2 \mu \mathrm{m}$-Poren

fluXXion (Eindhofen, Niederlande)

Schleifpapier P100

AEG (Frankfurt/Main)

Schwingquarz-Kristall

Elektronen Optik Service GmbH (Dortmund)

Silberdraht

Goodfellow (Huntington, UK)

Silizium-Mykrometerporen

Fluxxion (Eindhoven, Niederlande)

Teflonkammern

Werkstadt, IOBC Uni Göttingen

Titan-Target

Elektronen Optik Service GmbH (Dortmund)

\subsection{Geräte}

\section{Ätzapperatur}

2400 Source Meter

Temperaturregler

Keithley Instr. (Cleveland, USA)

Greisinger Elektronik GmbH (Regenstauf)

\section{Einzelkanalmessung}

Axopatch 200B Amplifier

Axon Instr. (Union City, USA)

DIGIDATA 1322A

Axon Instr. (Union City, USA) 


\section{Impedanzspektrometer}

Dielectric Interface SI 1296

Impedance Gain-Phase Analyser SI 1260

\section{Kathodenzerstäuber}

Sputter Coater 108 auto

Thickness Controller mtm 20

\section{Konfokales Laserrastermikroskop}

LSM 710 Examiner

Rasterelektronenmikroskop

Supra $^{\text {TM }}$ 55VP

\section{UV/VIS-Spektrometer}

V-650

\section{Plasmacleaner}

Plasma Cleaner PDC 32 G-2

\section{Sonstige Geräte}

Feinwaage

Frequenzgenerator Agilent 33220A

Magnetrührer MR $3001 \mathrm{~K}$

$\mathrm{pH}-$ Meter

Reinstwasseranlage MilliQ Gradient A 10

Schenker CAT ST5

Spannungsquelle DC Power Suplly PS 280

Ultraschallbad Sonorex RK 255 H

Umluftofen N30/65HA

Vakuumtrockenschrank VD 23

Wasserbad E38
Solartron Instr. (Farnborough, UK)

Solartron Instr. (Farnborough, UK)

Cressington (Watfort, USA)

Cressington (Watfort, USA)

Carl Zeiss AG (Jena)

Carl Zeiss AG (Jena)

Jasco GmbH (Gross-Umstadt)

Harrick Plasma (Ithaca, USA)

Avesin (Ottawa, Kanada)

Agilent Technologies (Santa Clara, USA)

Heidolph (Schwabach)

Knick (Berlin)

Millipore (Schwalbach)

Zipperer GmbH (Staufen)

Textronics (Beaverton, USA)

Bandelin (Berlin)

Nabertherm GmbH (Lilienthal/Bremen)

Binder GmbH (Tuttlingen)

Dinkelberg Labortechnik (Neu-Ulm) 


\subsection{Software}

Clampfit 9.2

Igor Pro 6.0.3

Origin 6.0

pClamp 9.1

Spectra Manager

ZEN 2008 Light Edition

ZPlot

ZView 2
Axon Instr. (Union City, CA, USA)

WaveMetrics, Inc. (Lake Oswego, USA)

Microcal Software, Inc. (Northhampton, USA)

Axon Instr. (Union City, CA, USA)

Jasco GmbH (Gross-Umstadt)

Carl Zeiss AG (Jena)

Scribner Associates, Inc. (Southern Pines, USA)

Scribner Associates, Inc. (Southern Pines, USA)

\subsection{SI-Einheiten}

\begin{tabular}{ll} 
A & Ampere \\
$\%$ & Prozent \\
$\circ$ & Grad \\
$\AA$ & Angström \\
$\mathrm{cm}$ & Zentimeter \\
$\mathrm{Da}$ & Dalton \\
$\mathrm{eV}$ & Elektronenvolt \\
$\mathrm{g}$ & Gramm \\
$\mathrm{h}$ & Stunden \\
$\mathrm{Hz}$ & Hertz \\
$\mathrm{l}$ & Liter \\
$\mathrm{m}$ & Meter \\
$\mathrm{M}$ & Mol \\
$\mathrm{min}$ & Minuten \\
$\mathrm{s}$ & Sekunden \\
$\mathrm{S}$ & Siemens \\
$\mathrm{V}$ & Volt \\
$\Omega$ & Ohm \\
\hline
\end{tabular}




\subsection{Präfixe}

$\begin{array}{ll}\text { G } & \text { Giga }\left(10^{9}\right) \\ M & \operatorname{Mega}\left(10^{6}\right) \\ \mathrm{k} & \operatorname{kilo}\left(10^{3}\right) \\ \mathrm{m} & \operatorname{milli}\left(10^{-3}\right) \\ \mu & \operatorname{mikro}\left(10^{-6}\right) \\ \mathrm{n} & \text { nano }\left(10^{-9}\right) \\ \mathrm{p} & \text { pico }\left(10^{-12}\right)\end{array}$




\section{Danksagung}

Mein Dank gilt...

...an erster Stelle Frau Prof. Dr. Claudia Steinem für die Bereitstellung eines interessanten und vielseitigen Themas und die sehr gute wissenschaftliche Begleitung. In einem exzellenten wissenschaftlichen Umfeld war es mir so möglich, selbstständig Schwerpunkte zu setzen und die Arbeit entsprechend meiner Fähigkeit und Interessen zu gestalten.

...Herrn Prof. Dr. Christian Griesinger für die Übernahme des Korreferates.

...Prof. Dr. Gina E. Sosinsky und Cinzia Ambrosi von der University of California, San Diego, für die Bereitstellung von aufgereinigtem Cx26 als essentielle Grundlage meiner Arbeit und die gute Kooperation.

...Dr. Niels Fertig und Mohammed Kreir von der Nanion Technologie GmbH für die ausgezeichnete Zusammenarbeit.

...unser aller Jutta für ihre zuverlässige und gewissenhafte Arbeit und die neuesten News vom Formationstanz. Ich danke dir auch dafür, dass du es mir ermöglicht hast, einmal in meinem Leben Nick Nolte kennen zu lernen, den man ja sonst nur aus dem Fernsehen kennt!

...Gretel, Christian, Ines, Ingo und Thomas für das schnelle und gründliche Korrekturlesen von Teilen der Arbeit.

...Anja, Barbara, Eva und Ruth für die freundliche Aufnahme in der Arbeitsgruppe und die gute Einarbeitung zu Beginn meiner Doktorarbeit. Ihr habt mir den Einstieg in die Welt der Membranen und Membranproteine leicht gemacht. Danke auch für die vielen bayrischen Leckereien und die Erweiterung meines Wortschatzes, so dass ich mich nun auch südlich des Weißwurstäquators verständigen kann.

...dem Aui dafür, dass er mir in seiner Zeit in der Arbeitsgruppe ein guter Freund war und mich in die Gepflogenheiten und Räumlichkeiten des Nordcampus eingewiesen hat. Danke für die leckere Paella und die sonntäglichen Spiele der Göttingen Generals.

...meinen Oberassistenten-Kolleginnen Gretel und Sabine für die sehr gute Zusammenarbeit bei der Betreuung des Medizinerpraktikums. Mit euch hat mir dieser Job auch noch in der 6ten Runde viel Spaß gemacht. 
...meinen netten Damen aus dem Sekretariat: Frau Gastrock und Marianne. Ihr habt mir so manchen Tag versüßt und hattet immer ein offenes Ohr, Ratschläge und Süßigkeiten für mich. So musste ich meine morgendliche Banane auch häufig nicht alleine essen und wurde gleich zu Beginn des Tages mit den neuesten News versorgt. Es war sehr schön und lustig bei euch!

...meinem fleißigen Diplomanden Christian Röling und meinem fleißigen Bachelor Benjamin Gerdes, die mit ihrer sehr guten und selbstständigen Arbeit einen wesentlichen Beitrag zu dieser Arbeit geleistet haben.

...dem gesamten Arbeitskreis für die vielen schönen Momente und die lustigen Kaffeepausen, aber auch für die gute wissenschaftliche Zusammenarbeit, die gegenseitige Hilfe und Unterstützung.

...dem Team der Mensa Nord dafür, dass es mir täglich bereits um 11.30 Uhr eine warme Mahlzeit zur Verfügung gestellt hat, die fast immer genießbar, allerdings häufig ein wenig knoblauchlastig war.

...den Hausmeistern Peters und Matthies für ihre schnelle Hilfe bei klemmenden Rollos, verschlossenen Türen, kaputten Fenstern oder Lampen und natürlich für den Lieferdienst der zahlreichen Amazon-Sendungen.

...dem Team der Mechanik Werkstatt für ihre sehr gute Arbeit bei der Anfertigung und Reparatur von Geräten und Messkammern.

...in besonderer Weise meinem Freund und Arbeitskollegen Christian Carnarius. Er hat mich durch seinen Ideenreichtum immer wieder neu motiviert und war bei allen wissenschaftlichen und privaten Fragestellungen ein sehr guter Gesprächspartner. Er hat mich Fit gehalten, indem er mich alle $10 \mathrm{~min}$ zu sich bestellt hat, um mir die Vorzüge seines neuen Handys zu zeigen oder um mit mir die Eröffnung des Flughafens auf seiner virtuellen Insel zu feiern. Danke für deine nicht selbstverständliche Hilfe in allen Belangen und deine Freundschaft.

...meinen Eltern für ihre Unterstützung über all die Jahre. Es war sicherlich nicht ganz leicht ein wenig loszulassen. Aber ihr werdet ja bald Oma und Opa und auch räumlich werden wir wieder etwas näher zusammenrücken. Danke für alles!

...abschließend der wichtigsten Person in meinem Leben, meiner Frau Maike. Du bist die Quelle all meiner Energie und gibst meinem Leben einen ganz besonderen Sinn. Ich danke dir dafür, dass du immer für mich da bist, mich zum Lachen bringst, mir aber auch manchmal den Weg weist. Du hast mich durch die Höhen und Tiefen des Studiums und der Doktorarbeit begleitet und ich freue mich auf eine gemeinsame Zukunft mit dir an meiner Seite. 


\section{Lebenslauf}

Helmut Albin Oliver Gaßmann

Geboren am 24.11.1980 in Sondershausen

deutsch

Schulausbildung

$\begin{array}{ll}1987-1991 & \text { Grundschule Adolf Diesterweg (Ebeleben) } \\ 1991-1992 & \text { Orientierungsstufe am Eikel (Salzgitter-Bad) } \\ 1992-1993 & \text { Orientierungsstufe Christoph-Kolumbus (Gifhorn) } \\ 1993-2000 & \text { Otto-Hahn-Gymnasium (Gifhorn) }\end{array}$

Wehrdienst

2000 - $2001 \quad$ 2. Panzergrenadierlehrbatallion 92 (Hindenburg-Kaserne/Munster)

Studium

10/2001 Beginn des Studiums der Biotechnologie an der

Technischen Universität Braunschweig

09/2003 Vordiplom (Note: 1.68)

09/2005 - 11/2005 Studienarbeit am Institut für Partikeltechnik (TU-Braunschweig)

Thema: Enzymatische Trennung von Kohlenhydratgemischen mittels

Flüssigmembrantechnik

06/2006 - 12/2006 Diplomarbeit am Institut für Siedlungswasserwirtschaft

(TU-Braunschweig)

Thema: Biologische Phosphorrückgewinnung aus Überschussschlamm

01/2007 Diplom (Gesamtnote: „Sehr Gut“)

Dissertation

$04 / 2007$

Beginn der Dissertation am Institut für Organische und Biomolekulare Chemie an der Georg-August-Universität Göttingen

Thema: Integration von Connexonen in Lipidmembranen auf porösen Oberflächen 
$06 / 2007$

$04 / 2008$

$07 / 2008$

$03 / 2009$
Göttinger Fakultätstag der Chemie

Vortrag: Integration von connexonen in Lipidmembranen auf porösen Oberflächen

Biophysical Workshop Gomadingen

Poster: Channel activity of CX26 monitored in nano-BLMs

Göttinger Chemie Forum

Poster: Characterisierung von Cx26 anhand von Einzelkanalmessungen in nano-BLMs

Deutsches Peptidsymposium (Göttingen)

Poster: Channel activity of connexin Cx26 mutant M34A in nano-BLMs

Publikationen

Gassmann, O., Kreir, M., Ambrosi, C., Pranskevich, J., Oshima, A., Roling, C., Sosinsky, G., Fertig, N., Steinem, C., 2009. The M34A mutant of Connexin26 reveals active conductance states in pore-suspending membranes. J Struct Biol 168, 168-176.

Ambrosi, C., Gaßmann, O., Pranskevich, J. N., Boassa, D., Smock, A., Wang, J., Dahl, G.,

Steinem, C., Sosinsky, G. E., 2010. Pannexin1 and pannexin2 channels show quaternary similarities to connexin hemichannels, but different oligomerization numbers from each other. J Biomol Chem., eingereicht und akzeptiert. 

